\title{
Mechanism Study of Shale Gas Conversion via Chemical Looping and Heterocatalytic Processes
}

Lei Bai

West Virginia University, lebai@mix.wvu.edu

Follow this and additional works at: https://researchrepository.wvu.edu/etd

Part of the Catalysis and Reaction Engineering Commons

\section{Recommended Citation}

Bai, Lei, "Mechanism Study of Shale Gas Conversion via Chemical Looping and Heterocatalytic Processes" (2019). Graduate Theses, Dissertations, and Problem Reports. 3866.

https://researchrepository.wvu.edu/etd/3866

This Dissertation is protected by copyright and/or related rights. It has been brought to you by the The Research Repository @ WVU with permission from the rights-holder(s). You are free to use this Dissertation in any way that is permitted by the copyright and related rights legislation that applies to your use. For other uses you must obtain permission from the rights-holder(s) directly, unless additional rights are indicated by a Creative Commons license in the record and/ or on the work itself. This Dissertation has been accepted for inclusion in WVU Graduate Theses, Dissertations, and Problem Reports collection by an authorized administrator of The Research Repository @ WVU.

For more information, please contact researchrepository@mail.wvu.edu. 


\title{
Mechanism Study of Shale Gas Conversion via Chemical Looping and Heterocatalytic Processes
}

\author{
Lei Bai \\ Dissertation submitted to \\ the Benjamin M. Statler College of Engineering and Mineral Resources \\ at West Virginia University \\ in partial fulfillment of the requirements for the degree of \\ Doctor of Philosophy in the \\ Chemical and Biomedical Engineering
}

Hanjing Tian, Ph.D. Committee Chairperson

Jianli Hu, Ph.D.

John W. Zondlo, Ph.D.

Xingbo Liu, Ph.D.

Zili Wu, Ph.D.
Department of Chemical and Biomedical Engineering
Morgantown, West Virginia
2019

Keywords: Shale Gas, Chemical Looping Combustion, Oxidative Coupling of Methane, Dehydro-aromatization of Ethane.

Copyright 2019 Lei Bai 


\section{ABSTRACT \\ Mechanism Study of Shale Gas Conversion via Chemical Looping and Heterocatalytic Processes}

\section{Lei Bai}

The shale gas revolution has significantly changed the energy landscape in US. The technical-feasible, energy-effective schemes for shale gas combustion and utilization, especially from remote resources, have attracted increasing interest due to expensive transportation/distribution cost. In this research, for the first time, chemical looping combustion (CLC) of methane with inherent $\mathrm{CO}_{2}$ capture, oxidative coupling of methane (OCM) and dehydroaromatization (DHA) of ethane are systematically studied as promising alternatives at $\mathrm{O}_{2}$-rich, $\mathrm{O}_{2}$ lean and non-oxidative conditions, respectively.

Chemical looping combustion is bridging clean fuel combustion in energy production with inherent $\mathrm{CO}_{2}$ capture. CLC utilized an oxygen carrier (OC) to transfer oxygen to the fuel source in $\mathrm{O}_{2}$-rich conditions. However, the fundamental kinetics of surface structure with oxygen transfer on OC, as well as the reduction activity and coupled selectivity have yet been established. OCM directly converts methane to produce $\mathrm{C}_{2}$ hydrocarbons $\left(\mathrm{C}_{2} \mathrm{H}_{6}\right.$ and $\left.\mathrm{C}_{2} \mathrm{H}_{4}\right)$ in $\mathrm{O}_{2}$-lean condition. Perovskite catalysts have shown promising activity and selectivity to $\mathrm{C}_{2}$, but the role of surface acidity of perovskite-type catalyst on OCM kinetics has not been revealed. Non-oxidative ethane DHA provides an economical and environmentally friendly alternative for aromatics and $\mathrm{H}_{2}$ production. Pillared ZSM-5 with hierarchical pores could amplify the mass/heat transfer, which is a promising catalyst for DHA reaction. However, very few studies have been reported to directly associate the thickness of lamellar layers with reactant diffusion, Si/Al ratios, surface acidities as well as catalytic reactivity of ethane-DHA reaction.

The research objective is to provide fundamental insights of surface structure-performance relationship of model catalysts for catalytic $\mathrm{C} 2 / \mathrm{C} 3$ conversion in three aspects: 1) the oxygen transfer mechanisms in CLC by using surface calcium-doped (1,2 and $4 \mathrm{wt} \%$ ) copper oxides based $\mathrm{OC} ; 2$ ) the effect of surface compositions of perovskites on the OCM by using $\mathrm{SrTiO}_{3}$ as a model catalyst is investigated; and 3) a regenerable $\mathrm{MoO}_{\mathrm{x}} /$ lamellar ZSM-5 based on the strategy of optimizing micro/mesopores structure of zeolite framework, targeting high ethane conversion and aromatic selectivity by optimizing $\mathrm{Si} / \mathrm{Al}$ ratio, surface acidity and diffusion path. The work offers several economic-viable and technical-feasible solutions for shale gas utilization to value-added products. 


\section{Dedication}

To my family, friends, and colleagues who have given their selfless support throughout my doctoral education. 


\section{Acknowledgements}

I would like to express my sincere gratitude to my advisor Dr. Hanjing Tian for giving me the opportunity to join his research group and for his guidance throughout my endeavor at West Virginia University. His profound knowledge and expertise about chemical looping and catalysis research field were inspirational and broaden my scientific horizon.

I would like to thank my co-advisor Dr. Zili Wu in Oak Ridge National Laboratory for providing an extensive background in scientific research and problem solving. His profound knowledge about the catalysis throughout his active experience in academia helps and encourages me during my graduate research.

I am honored to have Dr. Jianli Hu, Dr. John W. Zondlo, and Dr. Xingbo Liu as my committee. I would like to thank my committee members for their time and contribution to my doctoral education.

I wish to thank Department of Chemical and Biomedical Engineering in West Virginia University, Oak Ridge National Laboratory and National Science Foundation for sponsoring my doctoral education and research activities. I have had the great opportunity to get trained at Argonne National Laboratory and Oak Ridge National Laboratory for the neutron and synchrotron experiments.

I would like to thank Dr. Jarrett Riley, Dr. William J. Benincosa III, Dr. Felipe Polo-Garzon and Dr. Zhenghong Bao for their support and suggestions on my Ph.D. research.

I would like to express my deepest gratitude to my loving parents, Mr. Liming Bai and Mrs. Caiping Liu for their love, encouragement and support. I would like to thank girlfriend Dr. $\mathrm{Xiao} \mathrm{Hu}$ for her constant motivation throughout this process. 


\section{Table of Contents}

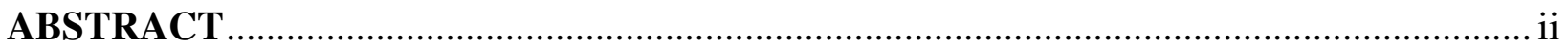

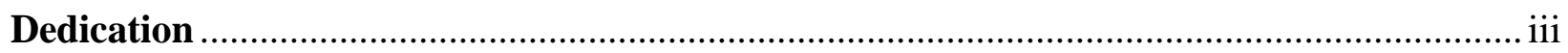

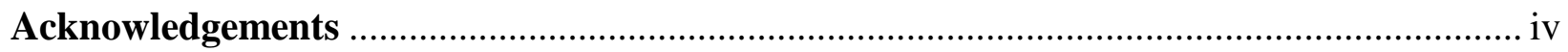

Table of Contents .................................................................................................................

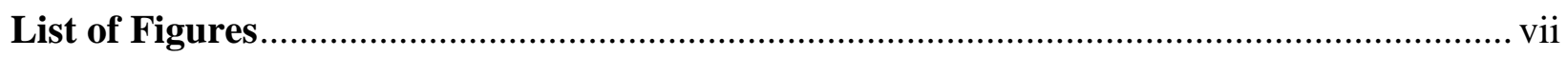

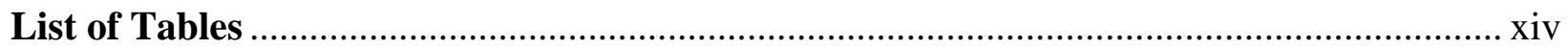

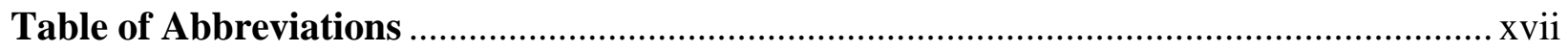

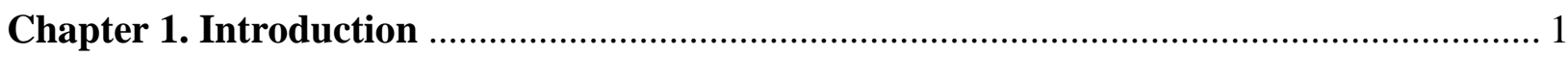

Chapter 2. Mechanism Study of Methane/char Chemical Looping Reduction Process over Calcium-doped Copper Oxide as Oxygen Carrier ............................................................... 5

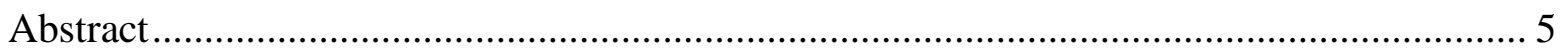

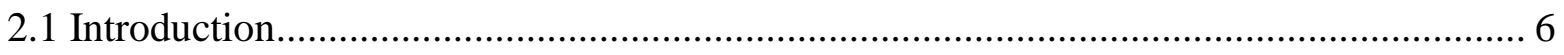

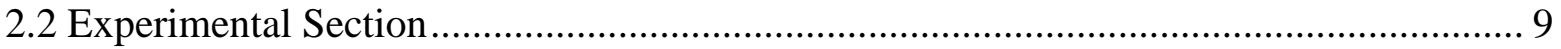

2.2.1 Materials and Oxygen Carrier Synthesis ......................................................... 9

2.2.2 Oxygen Carriers Characterization ..................................................................... 10

2.2.3 Temperature-programmed Reduction Analysis of OCs ..................................... 11

2.2.4 Reaction Performance and OCs Decomposition Characterization....................... 11

2.2.5 Raman Spectroscopy of OCs Decomposition .................................................... 12

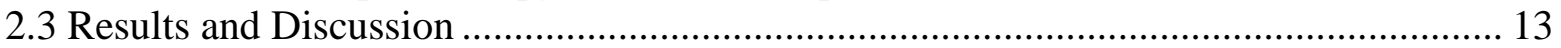

2.3.1 Characterization of Oxygen Carriers............................................................... 13

2.3.2 Temperature-Programmed Reduction Analysis ............................................... 16

2.3.3 Effect of Calcium on CLOU ………………………...................................... 18

2.3.4 Raman Spectra as Function of Temperature during OCs Decomposition .......... 20

2.3.5 Effect of Surface-doped Calcium on $\mathrm{CuO}$ on Char-CLC Performance .............. 22

2.3.6 Effect of Surfaced-doped Calcium on $\mathrm{CuO}$ on $\mathrm{CH}_{4}$-CLC performance ............. 24

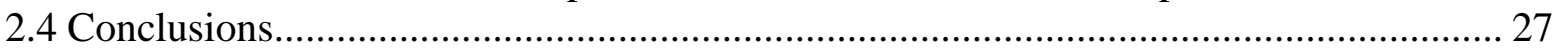

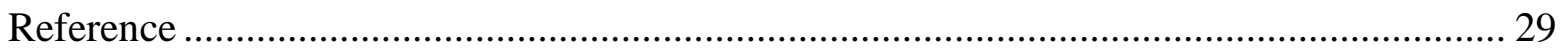

Chapter 3. Impact of Surface Composition of $\mathrm{SrTiO}_{3}$ Catalysts for Oxidative Coupling of

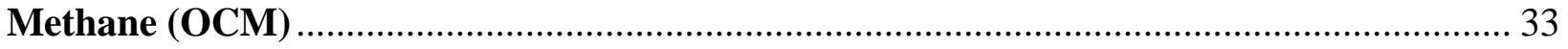

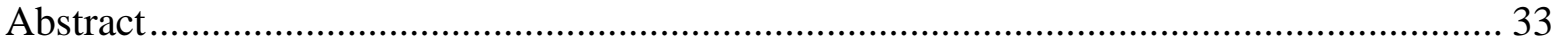

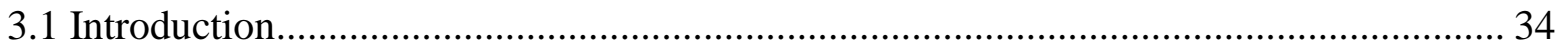

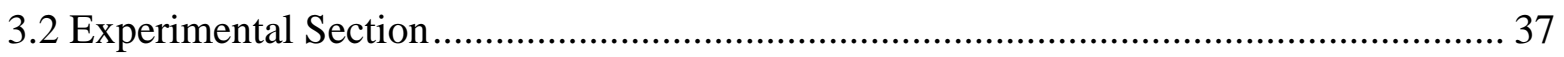

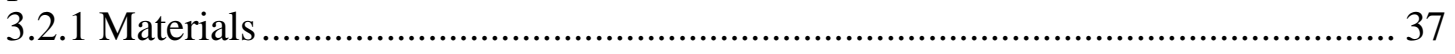

3.2.2 Sample Preparation..................................................................................... 37

3.2.3 Low Energy Ion Scattering (LEIS) Analysis ..................................................... 39 
3.2.4 Raman Spectroscopy

3.2.5 Temperature Programmed Desorption of Ammonia ( $\left.\mathrm{NH}_{3}-\mathrm{TPD}\right)$ and Carbon

Dioxide $\left(\mathrm{CO}_{2}\right.$-TPD) ................................................................................... 40

3.2.6 Temperature Programmed Reduction with Hydrogen $\left(\mathrm{H}_{2}-\mathrm{TPR}\right) \ldots \ldots \ldots \ldots \ldots \ldots \ldots \ldots . . . . .41$

3.2.7 Steady-State Kinetic Measurement .................................................................. 41

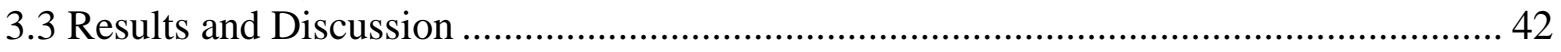

3.3.1 Surface Composition ................................................................................. 42

3.3.2 Raman Spectra as Function of Laser Excitations and Surface Composition ..... 44

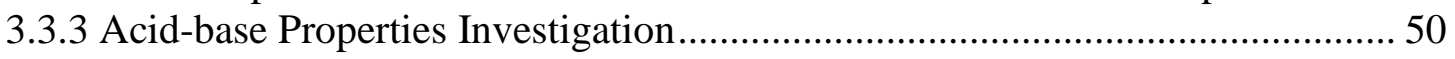

3.3.4 $\mathrm{H}_{2}$-TPR Analysis ………………………………………………….... 53

3.3.5 Catalytic Performance ...................................................................................... 54

3.3.6 Kinetics Analysis of STO Samples in OCM ……………………………….... 65

3.3.7 Methane and Oxygen Consumption Rates over STO Catalysts Based on Different

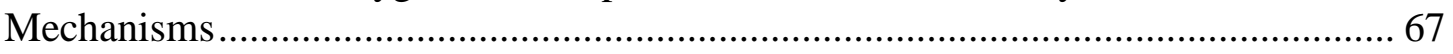

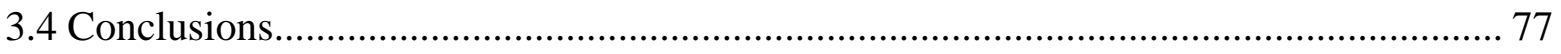

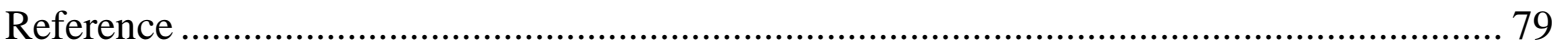

Chapter 4. Fabrication of Pillared ZSM-5 Framework for Shape Selectivity of Ethane

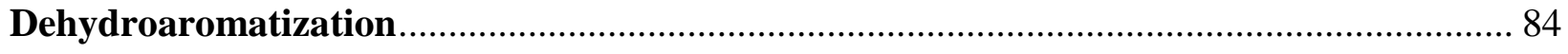

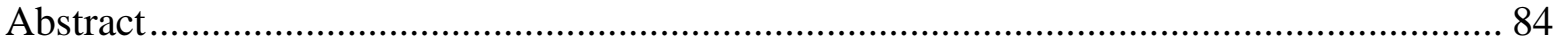

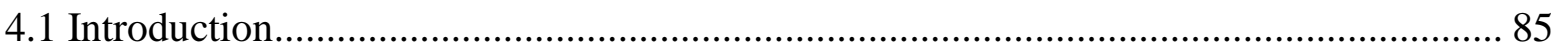

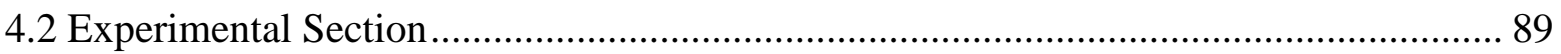

4.2.1 Catalyst Preparation ...................................................................................... 89

4.2.2 Catalyst Evaluation....................................................................................... 91

4.2.3 Catalytic Characterization ………….......................................................... 92

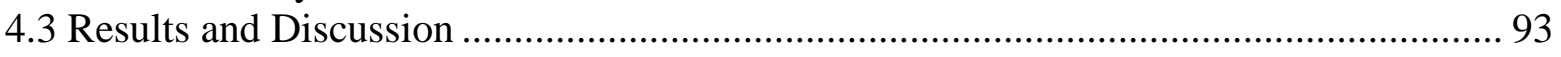

4.3.1 Bulk Structures and Morphology of the Zeolites ................................................. 93

4.3.2 Temperature-Programmed Reduction Analysis ................................................ 98

4.3.3 $\mathrm{NH}_{3}$-TPD Analysis .................................................................................... 101

4.3.4 Ethane Dehydro-aromatization on Mo/MFI Catalysts with Different Layer

Thickness ................................................................................................... 102

4.3.5 Ethane Dehydro-aromatization on Mo/MFI Catalysts with Different Si/Al Ratios 105

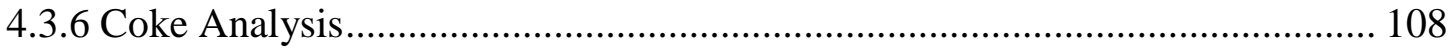

4.3.7 Oxidative Regenerations and Ethane Aromatization Reaction ........................ 110

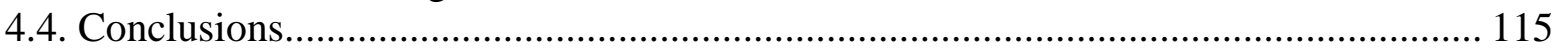

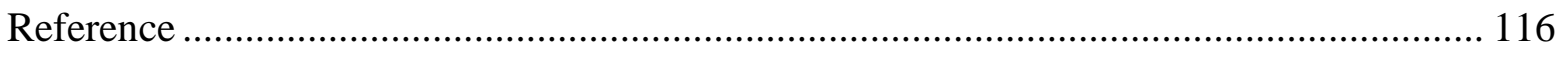

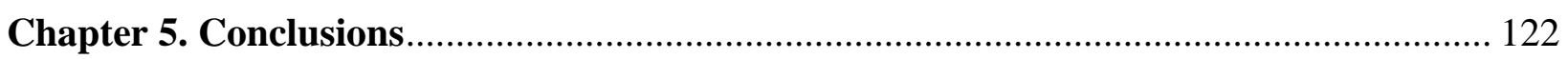




\section{List of Figures}

\section{Chapter 1. Introduction}

Figure. 1: U.S. dry natural gas production over the past and prediction.

\section{Chapter 2. Mechanism study of methane/char chemical looping reduction process over calcium-doped copper oxide as oxygen carrier}

Figure 1: Powder XRD patterns of $\mathrm{CaO}-\mathrm{CuO}$ oxygen carriers calcined at $550{ }^{\circ} \mathrm{C}$.

Figure 2: Detailed O1s XPS scan for OC samples with different amount of doping calcium.

Figure 3: $\mathrm{H}_{2}$ temperature-programmed reduction profiles for three $\mathrm{CaO}-\mathrm{CuO}$ OCs and pure $\mathrm{CuO}$.

(a) plot of TCD signal/Temperature vs. Time during whole reduction process; (b) plot of TCD signal vs. Temperature in $300-900{ }^{\circ} \mathrm{C}$ range.

Figure 4: $\mathrm{O}_{2}$ concentration in product gas during the temperature ramp for decomposition of $\mathrm{CaO}$ $\mathrm{CuO}$ oxygen carries and pure $\mathrm{CuO}$.

Figure 5: Raman spectra $(532 \mathrm{~nm})$ of (a)pure $\mathrm{CuO}$ collected at different temperatures and (b)comparison between pure $\mathrm{CuO}$ and $\mathrm{CaO}-\mathrm{CuO}$ oxygen carries at $900^{\circ} \mathrm{C}$.

Figure 6: Proposed reduction pathway scheme schematic for calcium-undoped/doped $\mathrm{CuO}$ based on decomposition reactivity and Raman spectra. 
Figure 7: $\mathrm{CO}_{2}$ (a) and $\mathrm{CO}$ (b) concentration in product gas during the temperature ramp as a function of time from reaction performance of char/OCs mixtures.

Figure 8: (a) $\mathrm{CO}_{2}$ and (b) $\mathrm{CO}$ concentration in product gas during the temperature ramp as a function of time from reaction performance of oxygen carriers and methane.

Figure 9: $\mathrm{H}_{2}$ concentration in product gas as a function of time during the temperature ramp of the reaction between oxygen carriers and methane. The curves in the small window represent the original curves for four oxygen carriers. Deconvolution peaks (r1, r2, r3, r4) of $\mathrm{H}_{2}$ concentration profiles are shown in the main window.

Figure 10: Scheme schematic of the contributing reactions in the $\mathrm{CH}_{4} /$ oxygen carrier system. 


\section{Chapter 3. Impact of Surface Composition of $\mathrm{SrTiO}_{3}$ catalysts for Oxidative Coupling of Methane (OCM)}

Figure 1: Process Sequences for the preparation of STO catalysts.

Figure 2: Sr-compositions $(\mathrm{Sr} /(\mathrm{Sr}+\mathrm{Ti}))$ of outermost surface layer and ratio of base/acid site of STO samples.

Figure 3: (a) Raman spectra of commercial STO excited at 325 and $442 \mathrm{~nm}$. (b) 325-nm excited Raman spectra of STO samples with surface reconstruction. (c) Ratio of $\mathrm{I}_{\mathrm{A} 4} / \mathrm{I}_{\mathrm{A} 7}$ values for different STO samples.

Figure 4: UV-vis diffuse reflectance spectrum of the commercial STO sample.

Figure 5: Raman spectra of all STO samples with excitation at $442 \mathrm{~nm}$.

Figure 6: Spectral deconvolution of the Raman spectrum of the commercial STO sample.

Figure 7: Raman spectra for commercial STO sample under OCM conditions at different temperatures and reaction time.

Figure 8: (a) $\mathrm{NH}_{3}$-TPD profiles and (b) $\mathrm{CO}_{2}$-TPD profiles of STO samples.

Figure 9: Correlation of base-site density with acid-site density on STO samples.

Figure 10: $\mathrm{H}_{2}$-TPR profiles of STO samples.

Figure 11: Regenerability test of commercial STO sample for OCM reaction. 
Figure 12: (a) $\mathrm{CH}_{4}$ conversion, (b) $\mathrm{CO}_{2}$ yield, (c) $\mathrm{CO}$ yield, (d) $\mathrm{C}_{2} \mathrm{H}_{6}$ yield and (e) $\mathrm{C}_{2} \mathrm{H}_{4}$ yield with respect to the composition of the top surface of various STO samples at different catalyst bed temperatures $\left(600,650,700,750,800^{\circ} \mathrm{C}\right)$ for OCM reaction with conditions in present work.

Figure 13: Rate of $\mathrm{CH}_{4}$ conversion versus composition of outermost atomic layer of various STO samples at different temperatures for methane combustion.

Figure 14: (a) Ratio of $\mathrm{C}_{2} / \mathrm{CO}_{\mathrm{x}}$ yield and (b) ratio of ethylene/ethane yield as function of top surface composition at different catalyst bed temperatures over various STO samples.

Figure 15: (a) Arrhenius plots for the $\mathrm{CH}_{4}$ consumption rate. (b) Apparent activation energies (Ea) measured under differential conditions, for $\mathrm{CH}_{4}$ consumption rate over STO catalysts under study with different surface Sr concentration. Experimental conditions: $5 \mathrm{mg}$ catalyst, $1.0 \mathrm{~atm}$, feed consists of $25 \mathrm{~mL} / \mathrm{min}$ of $10 \% \mathrm{CH}_{4} / \mathrm{Ar}, 10 \mathrm{~mL} / \mathrm{min}$ of $5 \% \mathrm{O}_{2} / \mathrm{He}$, and $15 \mathrm{~mL} / \mathrm{min}$ of $\mathrm{He}$ as balance gas.

Figure 16: The Arrhenius plots for $\mathrm{CO}, \mathrm{CO}_{2}$ and $\mathrm{C}_{2}$ formation during OCM over various STO catalysts.

Figure 17: $\mathrm{CH}_{4}$ conversion as the function of the surface base site density and the acid site density for OCM reaction over various STO samples.

Figure 18: $\mathrm{CH}_{4}$ conversion rate with respect to Base/(Base+Acid) ratio at different temperatures over various STO samples.

Figure 19: $\mathrm{CH}_{4}$ conversion rate with respect to temperatures over various STO samples (with different Base/(Base+Acid) ratios). 
Figure 20: Methane consumption rate as a function of (a) $\mathrm{CH}_{4}$ pressure at $\mathrm{P}\left(\mathrm{O}_{2}\right)=0.01$ atm and of (b) $\mathrm{O}_{2}$ pressure at $\mathrm{P}\left(\mathrm{CH}_{4}\right)=0.04$ atm, respectively, over various $\mathrm{STO}$ samples. (Reaction conditions: $650{ }^{\circ} \mathrm{C}$ for bed temperature, total flow rate $=50 \mathrm{~mL} / \mathrm{min}, \mathrm{He}+\mathrm{Ar}$ as balance gas.)

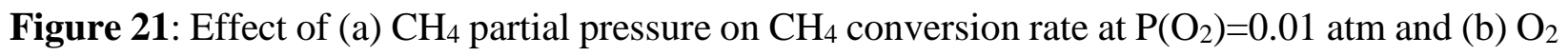
partial pressure on $\mathrm{CH}_{4}$ conversion rate at $\mathrm{P}\left(\mathrm{CH}_{4}\right)=0.04$ atm at $650^{\circ} \mathrm{C}$.

Figure 22: (a) Plots of $\frac{P_{O_{2}}^{0.5}}{r_{C_{4}}}$ against $\frac{1}{P_{C_{4}}}$ at $\mathrm{P}\left(\mathrm{O}_{2}\right)=0.01$ atm and (b)plots of $\frac{P_{C_{4}}}{r_{C_{4}}}$ against $\frac{1}{P_{O_{2}}^{0.5}}$ at $\mathrm{P}\left(\mathrm{CH}_{4}\right)=0.04 \mathrm{~atm}$ at $650{ }^{\circ} \mathrm{C}$.

Figure 23: Linearized correlations of (a) $\frac{P_{C_{4}}}{r_{C_{4}}}$ versus $P_{C_{4}}$ and (b) $\frac{P_{O_{2}}}{r_{C_{4}}}$ versus $P_{O_{2}}$. The inset in (b) shows an enlarged image of $\mathrm{Sr} / \mathrm{STO}\left(\mathrm{HNO}_{3}\right)-2$, STO, Sr/STO-1, Sr/STO-2 samples.

Figure 24: Linearized correlations of (a) $\frac{P_{C_{4}}}{r_{C_{4}}}$ versus $\frac{1}{P_{O_{2}}}$, and (b) $\frac{P_{O_{2}}}{r_{C_{4}}}$ versus $\frac{1}{P_{C_{4}}}$. The inset in (a) shows an enlarged image of Sr/STO(HNO 3$)-2$, STO, Sr/STO-1, Sr/STO-2 samples. 


\section{Chapter 4. Fabrication of Pillared ZSM-5 Framework for Shape Selectivity of Ethane Dehydroaromatization}

Figure 1: XRD patterns of lamellar MFI-50(T0), MFI-50(T2), MFI-50(T8), MFI-25(T8), MFI100(T8) and commercial MFI.

Figure 2: SEM images of a) MFI-50(T0); b) MFI-50(T2); c) MFI-50(T8); d) MFI-25(T8); e) MFI100(T8); f) commercial MFI.

Figure 3: a) $\mathrm{N}_{2}$ adsorption-desorption isotherms and b) pore size distributions as derived from $\mathrm{N}_{2}$ sorption of the zeolites. The pore size distribution were calculated by using Barrett-Joyner-Halenda (BJH) algorithm from the adsorption branch.

Figure 4: $\mathrm{H}_{2}$-TPR profiles for fresh Mo/MFI-50(T0), Mo/MFI-50(T2), Mo/MFI-50(T8), Mo/MFI25(T8), Mo/MFI-100(T8) catalysts.

Figure 5: $\mathrm{NH}_{3}$-TPD profiles of MFI-50(T0), MFI-50(T2), MFI-50(T8), MFI-25(T8) and MFI100(T8).

Figure 6: Mo/MFI-50(T0), Mo/MFI-50(T2), Mo/MFI-50(T8) and Mo/Commercial MFI catalysts in ethane aromatization reaction with the TOS of a) ethane conversion, b) $\mathrm{H}_{2}$ flow rate, c) $\mathrm{C}_{2} \mathrm{H}_{4}$ flow rate, d) aromatic yield, e) aromatic selectivity.

Figure 7: Mo/MFI-25(T8), Mo/MFI-50(T8), Mo/MFI-100(T8) catalysts in ethane aromatization reaction with the TOS of a) ethane conversion, b) $\mathrm{H}_{2}$ flow rate, c) $\mathrm{C}_{2} \mathrm{H}_{4}$ flow rate, d) aromatic yield, e) aromatic selectivity. 
Figure 8: TPO profiles for spent Mo/MFI-50(T0), Mo/MFI-50(T2), Mo/MFI-50(T8), Mo/MFI25(T8), Mo/MFI-100(T8) catalysts after ethane dehydro-aromatization reactions.

Figure 9:Ethane dehydro-aromatization reaction-regeneration cyclic operation. a), b) plots of ethane conversion and aromatic yield achieved on Mo/Commercial MFI catalyst in each reaction cycle; c), d) plots of ethane conversion and aromatic yield achieved on Mo/MFI-50(T8) in each reaction cycle.

Figure 10: TPO profiles for fresh Mo/Commercial MFI and Mo/MFI-50(T8) catalyst after the fourth dehydro-aromatization reactions-regeneration cycles. The curves in the small window represent the original curves between two used catalysts. Deconvolution peaks of TPO profiles in the main window: a) back solid line and red solid line stand for carbide associated with Mo species over Mo/Commercial MFI and Mo/MFI-50(T8), respectively; b) black and red dash-dot-dash lines are assigned to coke combined with Brønsted acid sites over Mo/Commercial MFI and Mo/MFI50(T8), respectively. 


\section{List of Tables}

Chapter 2. Mechanism study of methane/char chemical looping reduction process over calcium-doped copper oxide as oxygen carrier

Table 1: Proximate and ultimate analysis of Wyodak coal sample.

Table 2: $\mathrm{Ca}$ and $\mathrm{Cu}$ Concentrations of 1, 2, 4wt $\% \mathrm{CaO}-\mathrm{CuO}$ samples (Excluding oxygen) (\%).

Table 3: Peak areas for $\mathrm{H}_{2}$-TPR peaks.

Chapter 3. Impact of Surface Composition of $\mathrm{SrTiO}_{3}$ catalysts for Oxidative Coupling of Methane (OCM)

Table 1. Surface composition from LEIS analysis with in situ heat treatment in $\mathrm{O}_{2}$ atmosphere at $500^{\circ} \mathrm{C}$ for $30 \mathrm{~min}$.

Table 2: Raman peak assignments for STO samples.

Table 3: Acid and base site density of catalyst.

Table 4: $\mathrm{H}_{2}$ consumption of STO samples during $\mathrm{H}_{2}$-TPR.

Table 5: Fitted B values according to Eq3.3-3.

Table 6: Apparent Activation Energies for $\mathrm{CH}_{4}$ consumption and $\mathrm{CO}, \mathrm{CO}_{2}, \mathrm{C}_{2}$ formation.

Table 7. Slopes of trendlines for Base/(Base+Acid)- $\mathrm{CH}_{4}$ consumption relationship. 
Table 8: The OCM reaction scheme proposed by Takanabe and Iglesia.

Table 9: Results of reactant orders and rate constants for STO samples analyzed by power law model.

Table 10: The Mars-Van Krevelen mechanism for OCM reaction.

Table 11: Kinetic parameters for STO samples analyzed by Mars-Van Krevelen model.

Table 12: The Double site Langmuir-Hinshelwood mechanism for OCM reaction.

Table 13: Kinetic parameters for STO samples analyzed by Double site Langmuir-Hinshelwood model.

Table 14: The Eley-Rideal mechanism for OCM reaction.

Table 15: Kinetic parameters for STO samples analyzed by Eley-Rideal model. 


\section{Chapter 4. Fabrication of Pillared ZSM-5 Framework for Shape Selectivity of Ethane Dehydroaromatization}

Table 1: Key crystalline parameters of various zeolites from XRD result.

Table 2: Textural property of zeolites measured by $\mathrm{N}_{2}$ Adsorption-Desorption.

Table 3: Numerical results of TPR experiments on Mo loaded catalysts.

Table 4: $\mathrm{NH}_{3}$-TPD data of synthesized ZSM-5.

Table 5: The Si/Al and Al/Mo ratio for samples.

Table 6: Numerical results of TPO experiments on used Mo/MFI-T0, Mo/MFI-T2, Mo/MFIT8(Mo/MFI-50), Mo/MFI-25, Mo/MFI-100 catalysts.

Table 7: Ethane conversion ratio and aromatics yield ratio between reactions after cyclic regeneration and reaction with fresh sample at 150 and 900 s TOS. 


\section{Table of Abbreviations}

\begin{tabular}{|c|c|}
\hline$C L C$ & Chemical Looping Combustion \\
\hline CLOU & Chemical Looping with Oxygen Uncoupling \\
\hline$O C$ & Oxygen Carrier \\
\hline$M e_{x} O_{y}$ & Metal Oxide \\
\hline$M e_{x} O_{y-1}$ & Regenerated Metal Oxides \\
\hline$M e$ & Regenerated Metal Species \\
\hline$T G A$ & Thermogravimetric Analysis \\
\hline$X R D$ & X-Ray Diffraction \\
\hline$X P S$ & X-Ray Photoelectron Spectroscopy \\
\hline$T P R$ & Temperature Programmed Reduction \\
\hline$T C D$ & Thermal Conductivity Detector \\
\hline$\overline{U H P}$ & Ultra-High Purity \\
\hline$U V$-vis & Ultraviolet-visible Spectroscopy \\
\hline$C D M$ & Catalytic Decomposition of Methane \\
\hline$O C M$ & Oxidative Coupling of Methane \\
\hline STO & $\mathrm{SrTiO}_{3}$ \\
\hline LEIS & Low Energy Ion Scattering \\
\hline UV-Raman & Ultraviolet-Raman \\
\hline$T P D$ & Temperature Programmed Desorption \\
\hline$M T O$ & Methanol-to-Olefins \\
\hline$F T$ & Fischer-Tropsch \\
\hline
\end{tabular}




\begin{tabular}{|c|c|}
\hline NSR & $\mathrm{NO}_{\mathrm{x}}$ Storage and Reduction \\
\hline$I W I$ & Incipient Wetness Impregnation \\
\hline$B E T$ & Brunauer-Emmett-Teller \\
\hline$A M I$ & Altamira Instruments System \\
\hline$G C$ & Gas Chromatograph \\
\hline$R D S$ & Rate-Determining Step \\
\hline$E a$ & Apparent Activation Energies \\
\hline$B T X$ & Benzene, Toluene and Xylene \\
\hline DHA & Dehydroaromatization \\
\hline$S D A$ & Structure Directing Agent \\
\hline TPAOH & Tetrapropylammonium Hydroxide \\
\hline$C T A B$ & Cetyltrimethylammonium Bromide \\
\hline DI water & Deionized water \\
\hline SEM & Scanning Electron Microscopy \\
\hline$T P O$ & Temperature-Programmed Oxidation \\
\hline$M S$ & Mass Spectrometry \\
\hline$B J H$ & Barrett-Joyner-Halenda \\
\hline$M A S$ & Magic-Angle Spinning \\
\hline NMR & Nuclear Magnetic Resonance \\
\hline$\overline{D F T}$ & Density Functional Theory \\
\hline TOS & Time-on-Stream \\
\hline TOF & Turn-over-Frequency \\
\hline
\end{tabular}




\section{Chapter 1. Introduction}

Due to the innovative technological advances in horizontal drilling and hydraulic fracturing, a boom in shale gas (mainly $\mathrm{CH}_{4}$ ) production has emerged in the U.S during last decade.[1] According to an Energy Information Administration report[2], shale gas production rose by over $670 \%$ from 1.77 trillion cubic feet in 2000 to 13.64 trillion cubic feet by 2015.(See Fig. 1) The U.S. government also projects that the annual domestic shale gas production will account for $68 \%$ of United States gas supply by 2040. Recoverable deposits of shale gas are distributed worldwide, with major deposits in the countries in Asia, Europe, Latin America and many other regions.[3] The impact of the shale gas revolution has been notable in many areas of applications, including electricity/power generation, automobiles and transportation, residential heat supply, industrial and commercial applications.[4]

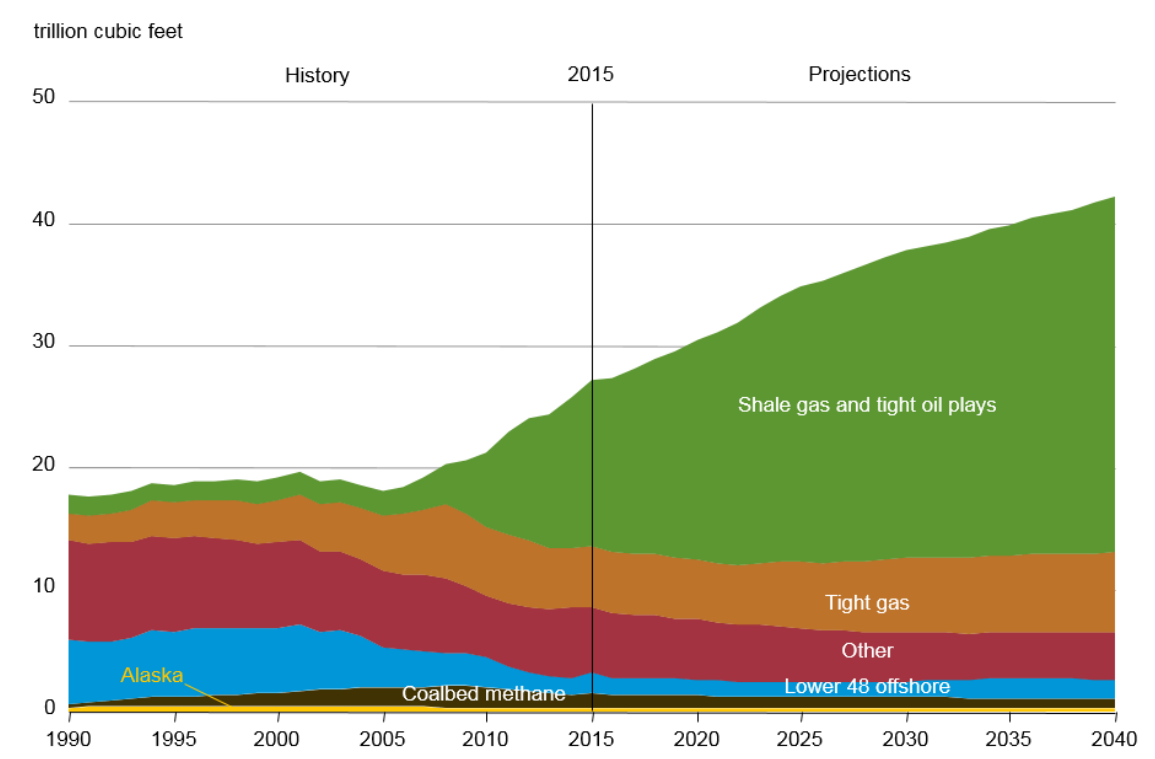

Figure. 1 U.S. dry natural gas production over the past and prediction.

Source: U.S. Energy Information Administration, Annual Energy Outlook 2018.

Note: "Tight oil" is light crude oil contained in petroleum-bearing formations of low permeability, often shale or tight sandstone, known as shale oil. "Tight gas" is natural gas produced from reservoir rocks with such low permeability that massive hydraulic fracturing is necessary to produce the well at economic rates. and "Coalbed methane" refers to is a form of natural gas extracted from coal beds. 
Shale gas exists as the fossil natural gas trapped within shale formations. Shale is sedimentary rock composed of clay and other minerals, especially quartz and calcite. Over time, decaying biomass became trapped in these sedimentary layers and was converted into methane via anaerobic biological and chemical processes. Some of methane formed from the deposited biomass became encapsulated within the sedimentary rock layers, while portions of the methane escaped to more superficial rock layers, ultimately yielding what is now known as conventional natural gas resources. However, a considerable amount of methane remained trapped in the low permeability shale layers, and it is only with recent advances in drilling technology that it has become economical to recover methane from these shale gas deposits.[5, 6] The composition of shale gas varies on the location of the shale reservoirs. The gas contains methane (70-90\%), as the major component, along with other hydrocarbons, such as ethane, propane, butane (0-20\%) and gases such as carbon dioxide and nitrogen (0-5\%). Especially, ethane is the second main component in some shale reservoirs. For example, the ethane component of the gas from Marcellus and Barnett shales are 16.1 and $11.8 \%$, respectively[7, 8]. Moreover, in some regions of the United States, the price of ethane is actually lower than natural gas[9].

On one hand, natural gas is now the largest source of U.S. electric power generation, helping reduce U.S. greenhouse gas emissions to mid-1990 levels.[10] Natural gas combustion emits about half as much $\mathrm{CO}_{2}$ as coal and $30 \%$ less than oil, and far fewer pollutants, per unit of energy delivered. To fully realize the potential climate benefits of natural gas, technologies and policies must be put in place to capture carbon emissions.

Despite the positive advances with methane production, costs for shale gas shipment from production wells to potential end users is still high. A promising alternative to these high gas 
shipping costs is to convert shale gas (methane and ethane) into a higher energy density liquid chemicals and fuels, which are more readily shipped via pipeline[11].

Dramatically increased supply of shale gas has led to a significant drop in natural gas prices. Therefore, there is potential to boost chemical and synthetic liquid fuel productions, providing methane from shale gas at low cost. However, the efficient conversion of shale gas to chemicals, liquid fuels, and electricity remains a major unsolved scientific problem. Therefore, there is a critical need to provide new and reliable approaches for further utilization of shale gas. Some promising alternatives are proposed in this project including methane combustion with inherent $\mathrm{CO}_{2}$ capture, oxidative coupling of methane and ethane dehydroaromatization. Details of these techniques will be discussed in the following chapters. 


\section{Reference}

[1] S. Luo, L. Zeng, D. Xu, M. Kathe, E. Chung, N. Deshpande, L. Qin, A. Majumder, T.-L. Hsieh, A. Tong, Z. Sun, L.-S. Fan, Shale gas-to-syngas chemical looping process for stable shale gas conversion to high purity syngas with a $\mathrm{H}_{2}: \mathrm{CO}$ ratio of $2: 1$, Energy \& Environmental Science, 7 (2014) 4104-4117.

[2] EIA - Annual Energy Outlook 2018. https://www.eia.gov/outlooks/archive/aeo18/, in, 2018.

[3] A. Galadima, O. Muraza, Revisiting the oxidative coupling of methane to ethylene in the golden period of shale gas: A review, Journal of Industrial and Engineering Chemistry, 37 (2016) $1-13$.

[4] S. Clark, Shale Gas Market by End User (Industrial, Power generation, Residential, Commercial, Transportation) - Global Opportunity Analysis and Industry Forecast, 2014 - 2022, in, 2016.

[5] E.I. Administration, What is Shale Gas? https://geology.com/energy/shale-gas, in, 2010.

[6]Wikipedia,Shalegas.https://en.wikipedia.org/w/index.php?title=Shale_gas\&oldid=859786243.

[7] A. Sharma, S. Namsani, J.K. Singh, Molecular simulation of shale gas adsorption and diffusion in inorganic nanopores, Molecular Simulation, 41 (2015) 414-422.

[8] K.A. Bulba, and Peter E. Krouskop, Compositional variety complicates processing plans for US shale gas, Oil \& Gas Journal, 107 (2009) 50-55.

[9] H. Chen, L. Li, J. Hu, Upgrading of stranded gas via non-oxidative conversion processes, Catalysis Today, 310 (2018) 94-97.

[10] Nature Gas, At-a-glance. https://www.c2es.org/content/natural-gas/, in.

[11] F. Polo-Garzon, Optimization of pyrochlore catalysts for the dry refoming of methane, in: Chemical Engineering, Clemson University, 2015. 


\title{
Chapter 2. Mechanism Study of Methane/char Chemical Looping Reduction Process over Calcium-doped Copper Oxide as Oxygen Carrier
}

\begin{abstract}
Chemical looping with oxygen uncoupling (CLOU) is a novel $\mathrm{CO}_{2}$ capture technology which uses metal oxides to release gaseous $\mathrm{O}_{2}$. Compared to regular chemical looping combustion (CLC), the advantage of CLOU is the instant oxygen releasing/transfer from the bulk or surface of oxygen carriers, so that the thermodynamic limits of the slow gasification step will be overcome. However, the fundamental kinetics of surface structure with oxygen transfer, as well as the reduction activity and coupled selectivity has not yet been established. In this study, calcium-doped (1, 2 or $4 \mathrm{wt} \%)$ copper oxide based oxygen carriers were prepared by the impregnation method and employed in CLC with Wyodak char and methane as fuels at $900^{\circ} \mathrm{C}$. Utilizing a combination of XRD and XPS analysis, calcium was confirmed to be dispersed on the surface of $\mathrm{CuO}$. It is found that doping $\mathrm{Ca}$ improves $\mathrm{CuO}$ oxygen uncoupling characteristics. By comparing the chemical looping reduction process of $\mathrm{Ca}$-doped $\mathrm{CuO}$ and un-doped $\mathrm{CuO}, \mathrm{Ca}$ surface-doping increases the lattice oxygen transfer and surface $\mathrm{O}_{2}$ formation under CLOU conditions. Meanwhile the comparison of thermal decomposition reactivity under an inert environment and in-situ Raman spectra of doped and undoped $\mathrm{CuO}$ suggested the change of reduction pathway from a sequential $\left(\mathrm{CuO} \rightarrow \mathrm{Cu}_{2} \mathrm{O} \rightarrow \mathrm{Cu}\right)$ to a direct transition $(\mathrm{CuO} \rightarrow \mathrm{Cu})$ during oxygen carrier decomposition. Different mechanisms were revealed for the calcium-doped copper(II) oxide oxygen carriers when reacted with different fuel types (solid: char, gaseous: methane). For the char CLC reduction
\end{abstract}


process, more $\mathrm{CO}_{2}$ was generated at a faster rate with $\mathrm{CaO}$-doped $\mathrm{CuO}$ than with pure $\mathrm{CuO}$. For methane CLC reduction, the calcium dopant not only accelerated the reaction rate, but also acted as an in situ adsorption site, which induced the methane reforming reaction.

\subsection{Introduction}

$\mathrm{CO}_{2}$ emission from fossil fuels combustion has been regarded as a major factor attributing to global warming in past decades[1-3]. $\mathrm{CO}_{2}$ capture and storage technologies are required to reduce the emission of this greenhouse gas. $\mathrm{CO}_{2}$ post combustion separation and capture after coalfired power plants are traditional technologies, which can carry a significant energy penalty. In contrast, the concept of chemical looping combustion (CLC) has been proposed as a promising low-cost $\mathrm{CO}_{2}$ capture technology to produce energy with inherent $\mathrm{CO}_{2}$ separation [4-6].

CLC is realized by the oxygen transfer from solid oxide materials to fuels. These solid oxide materials, called oxygen carriers (OCs), travel to and from between an air reactor and fuel reactor. In the fuel reactor, the oxygen carriers are reduced by the reaction with fuel, as shown below:

$$
(2 n+m) M e_{x} O_{y}+C_{n} H_{2 m} \rightarrow(2 n+m) \mathrm{Me}_{x} \mathrm{O}_{y-1}+n \mathrm{CO}_{2}+m \mathrm{H}_{2} \mathrm{O}
$$

where $M e_{x} O_{y}$ denotes a metal oxide and $M e_{x} O_{y-1}$ is reduced compound. The reduced oxygen carriers are transferred to the air reactor and oxidized by air. The regeneration of metal oxides is as follows:

$$
M e_{x} O_{y-1}+\frac{1}{2} O_{2} \rightarrow M e_{x} O_{y}
$$


Subsequently, the regenerated metal oxides travel back to the fuel reactor to initiate the next cycle. The oxygen transferred from air to fuels through metal oxides avoids direct contact between air and fuel. Consequently, $\mathrm{CO}_{2}$ and $\mathrm{H}_{2} \mathrm{O}$ can be obtained in a pure form without the need for energy-consuming separation. After simple condensation of steam, pure $\mathrm{CO}_{2}$ can be easily captured and stored.

The development of oxygen carriers is a key aspect in CLC technology. A large number of oxygen carriers have been proposed and tested by numerous researchers[7-12]. Several transition metal oxides of $\mathrm{Cu}, \mathrm{Fe}, \mathrm{Ni}, \mathrm{Co}$, and $\mathrm{Mn}$ have served as conventional oxygen carriers in CLC[13, 14]. Among these suitable metal complexes, $\mathrm{CuO}$ has been singled out for its high reactivity and oxygen transport capacity[15]. Oxygen carriers are always supported by inert materials such as $\mathrm{Al}_{2} \mathrm{O}_{3}, \mathrm{ZrO}_{2}, \mathrm{TiO}_{2}$, or $\mathrm{MgO}$ to enhance their redox reactivity as well as the recyclability[15-17]. Recently researchers demonstrated that the significant modification of the metal crystal phase can be achieved via addition of secondary metals, including alkali metal ions (e.g. $\mathrm{Li}^{+}, \mathrm{Na}^{+}$or $\mathrm{K}^{+}$), transition metals, and rare earth metals. For example, Zheng et al.[18] synthesized $\mathrm{LaFeO}_{3}$ supported $\mathrm{CeO}_{2}$ oxygen carriers for chemical looping reforming of methane, and claimed that $10 \%$ $\mathrm{CeO}_{2} / \mathrm{LaFeO}_{3}$ produced higher yields of syngas and pure hydrogen than those of pure $\mathrm{LaFeO}_{3}$. Galinsky et al.[19] reported that $\mathrm{CaMnO}_{3}$ doped with $25 \% \mathrm{Sr}$ exhibited a stabilized perovskite structure and noticeable oxygen release at significantly lower temperature than that observed for pure $\mathrm{CaMnO}_{3}$, which can shift the initial reduction temperature by approximately $200{ }^{\circ} \mathrm{C}$. Cheng et al.[20] modified the $\mathrm{Fe}_{2} \mathrm{O}_{3}$-based oxygen carriers by different potassium salts (i.e. $\mathrm{KNO}_{3}$, $\mathrm{K}_{3} \mathrm{PO}_{4}, \mathrm{KOH}, \mathrm{K}_{2} \mathrm{CO}_{3}$ ), and pointed out that the $10 \% \mathrm{KNO}_{3} / \mathrm{Fe}_{2} \mathrm{O}_{3}$ was proven to be favorable oxygen carrier for CLC with methane due to its improved activity and redox characteristics and stability. However, the metal oxide crystal phases and structure of oxygen carriers, can be altered 
due to the introduction of high concentration of dopants[16]. In addition, the oxygen carrying capacity can be degraded when a large quantity of dopant is added that does not contribute to the oxygen carrying capacity[16, 21]. Doping low concentrations of metal cations on the surface of oxygen carriers offers the possibility to improve reactivity and the oxygen releasing yield without changing the bulk phase structures. This approach is a challenging requirement for the oxygen carrier development field.

When solid fuels are used in CLC, the gasification of fuels occurs and generates products like $\mathrm{CO}$ and $\mathrm{H}_{2}$. The reaction between gasification products with oxygen carriers (metal oxide particles) happens simultaneously along with the slow fuel gasification. In contrast, chemical looping with oxygen uncoupling (CLOU) is utilized as an alternative to burn the solid fuels, where the gaseous oxygen is released/transferred from the bulk or surface of oxygen carriers. Therefore, the solid fuels are combusted in gas-phase oxygen in CLOU, so that the thermodynamic limits for combustion reaction in regular CLC will be overcome by avoiding the slow gasification step. However, the fundamental kinetics of surface structure with oxygen transfer, as well as the reduction activity/selectivity has not yet been established.

This study is designed to probe the mechanism of surface oxygen transfer of the oxygen carriers during the chemical looping reaction by using $\mathrm{CuO}$, with a $\mathrm{CaO}$ dopant well dispersed on the material surface. $\mathrm{CaO}$ is added as active dopant from 1-4 wt\% to avoid modifying the $\mathrm{CuO}$ crystalline phase. A series of experiments was conducted to understand the reduction characteristics of the $\mathrm{CaO}$ doped $\mathrm{CuO}$ materials, including, gas-fueled reduction, uncoupling potential and solid-fueled oxygen transfer. To examine oxygen transfer in these scenarios, the surface modified $\mathrm{CuO}$ was reacted with Wyodak char (solid fueled), methane and hydrogen (gas 
fueled) in the chemical looping process. In addition oxygen uncoupling potential was also explored. The reaction pathway of oxygen release/transfer on the $\mathrm{CaO}-\mathrm{CuO}$ surface and the surface-doping effects were determined through the present study.

\subsection{Experimental Section}

\subsubsection{Materials and Oxygen Carrier Synthesis}

The concept of CLC with solid fuels such as coal or char has been investigated extensively in the past $[13,14,22-24]$, and progress of the CLC technology for solid fuel combustion has been presented in various review articles[25-27]. Therefor we would like to firstly investigate the effect of surface modification of oxygen carriers on CLC performance when reacting with solid fuels, i.e. char. Wyodak coal samples in present work were obtained from the Penn State Coal Sample Bank (sample number: DECS-26). The composition of coal is listed in Table 1. Coal samples were crushed and ground, then pyrolyzed to remove volatiles and produce the chars. The coal samples were heated up to $900{ }^{\circ} \mathrm{C}$ at a ramp rate of $10{ }^{\circ} \mathrm{C} / \mathrm{min}$ in a vertical quartz tube furnace under atmospheric flow of $100 \mathrm{~mL} / \mathrm{min}$ pure helium and held isothermally for 30 min upon reaching the target temperature. Chars prepared from pyrolysis were subsequently ground and sieved to obtain particles below $106 \mu \mathrm{m}$. Although the ash is existing in the char, it is reported that the ash in the solid fuel does not affect the reactivity of the oxygen carriers in the CLC[28, 29].

Table 1. Proximate and ultimate analysis of Wyodak coal sample.

\begin{tabular}{ccccccccc}
\hline \multicolumn{3}{c}{ Proximate analysis (wt.\%) } & \multicolumn{4}{c}{ Ultimate analysis (wt.\%) } \\
\hline $\mathrm{M}_{\mathrm{ad}}$ & $\mathrm{V}_{\mathrm{d}}$ & $\mathrm{A}_{\mathrm{d}}$ & $\mathrm{FC}_{\mathrm{d}}$ & $\mathrm{C}_{\mathrm{daf}}$ & $\mathrm{H}_{\mathrm{daf}}$ & $\mathrm{N}_{\mathrm{daf}}$ & $\mathrm{S}_{\mathrm{daf}}$ & $\mathrm{O}_{\mathrm{daf}}$ \\
26.23 & 44.86 & 7.57 & 47.57 & 75.48 & 6.11 & 1.02 & 0.47 & 16.92 \\
\hline Note: ad-air dry basis; d-dry basis; daf-dry and ash free basis & & & &
\end{tabular}


$\mathrm{CaO}-\mathrm{CuO}$-based oxygen carriers were synthesized by an impregnation method using calcium hydroxide and copper(II) oxide as metal oxide precursors. The calcium hydroxide and copper(II) oxide were purchased from ACROS ORGANICS in the purity of $98 \%$ and $99+\%$, respectively. A prescribed amount of calcium hydroxide was dissolved in deionized water to give a solution. The solution was added to dry copper(II) oxide at a volume equal to its pore volume to form a wet paste. A muffle furnace was then used to calcine the paste at a temperature of $550{ }^{\circ} \mathrm{C}$ for $10 \mathrm{~min}$ at a ramp rate of $5^{\circ} \mathrm{C} / \mathrm{min}$ to decompose the hydrate to the desired calcium oxides covering the surface of copper oxide. Samples with different $\mathrm{CaO}$ weight percentages are designated as $1 \mathrm{wt} \%-\mathrm{CaO}-\mathrm{CuO}, 2 \mathrm{wt} \%-\mathrm{CaO}-\mathrm{CuO}$ and $4 \mathrm{wt} \%-\mathrm{CaO}-\mathrm{CuO}$, referring to the number of successive impregnations. Pure copper oxide is also used as a baseline oxygen carrier for comparison. Sample size range for all oxygen carriers was less than $106 \mu \mathrm{m}$.

\subsubsection{Oxygen Carriers Characterization}

The prepared oxygen carriers were characterized by X-ray diffraction (XRD) and X-ray photoelectron spectroscopy (XPS) to probe whether the calcium dopant exists on the copper oxide surface.

The XRD analysis was carried out using on a Panalytical X'Pert Pro XRD system in the range of $20^{\circ}$ to $80^{\circ}$ for $2 \theta$. $\mathrm{Cu}-\mathrm{K} \alpha 18047.2 \mathrm{eV}$ source and a maximum $\mathrm{X}$-Ray power of $45 \mathrm{kV}$ and $40 \mathrm{~mA}$ were used.

X-ray photoelectron spectra (XPS) were obtained with a Physical Electronics PHI 5000 VersaProbe XPS system. A monochromated $25 \mathrm{~W}, 15 \mathrm{kV}$ Al-Ka X-ray source (photon energy of $1486.6 \mathrm{eV}$ ) and a hemispherical analyzer were used. The routine operation pressure in the main chamber is $\sim 1 \times 10^{-9}$ Torr. All reported intensities are experimentally determined peak areas divided 
by the instrumental sensitivity factors. The acquired spectra were collected using multiple scans, and the data were averaged and analyzed using MultiPak v9 software. All the spectra registered were referred to signal C $1 \mathrm{~s} 284.8 \mathrm{eV}$ corresponding to adventitious carbon. All XPS peak assignments were acquired based on the NIST XPS database[30].

\subsubsection{Temperature-programmed Reduction Analysis of OCs}

Temperature-programmed reduction (TPR) analysis was carried out in Micromeritics Autochem 2900 instrument coupled with a thermal conductivity detector (TCD), at a heating rate

of $4{ }^{\circ} \mathrm{C} / \mathrm{min}$ up to $900{ }^{\circ} \mathrm{C}$, then holding at that temperature for $30 \mathrm{~min}$. Approximately $150 \mathrm{mg}$ of oxygen carriers sample was supported on a quartz wool plug inside the U-shaped quartz reactor and reduced with $5 \% \mathrm{H}_{2}$ (balanced with $95 \% \mathrm{He}$ ) as reducing agent $(25 \mathrm{~mL} / \mathrm{min})$. A K-type thermocouple was placed in quartz wool for accurate temperature measurement.

\subsubsection{Reaction Performance and OCs Decomposition Characterization}

Chemical looping reduction experiments of oxygen carriers were performed by using the Micromeritics Autochem 2900 instrument (fixed-bed reactor) coupled with a Pfeiffer Omnistar mass spectrometer in order to identify the gaseous products formed during the reduction. When the char presented as the solid fuel, $60 \mathrm{mg}$ char and $150 \mathrm{mg} \mathrm{CaO}-\mathrm{CuO}$ oxygen carriers were mixed prior to the tests. Then the mixture was heated from $50{ }^{\circ} \mathrm{C}$ to $900{ }^{\circ} \mathrm{C}$ at a heating rate of $4{ }^{\circ} \mathrm{C} / \mathrm{min}$ in helium at a flow rate of $25 \mathrm{~mL} / \mathrm{min}$ at atmospheric pressure. After that, the sample was maintained at $900{ }^{\circ} \mathrm{C}$ for $30 \mathrm{~min}$ in helium. Methane was also presented as a gaseous fuel. $150 \mathrm{mg}$ OC sample was loaded into quartz tube and heated to $900{ }^{\circ} \mathrm{C}$ at a heating rate of $4{ }^{\circ} \mathrm{C} / \mathrm{min}$ hold for $30 \mathrm{~min} 20 \% \mathrm{CH}_{4} / 80 \% \mathrm{Ar}$ stream at a flow rate of $25 \mathrm{~mL} / \mathrm{min}$. 
The decomposition (uncoupling) experiments were carried out in U.H.P He atmosphere to ensure an inert environment to promote the reaction. $150 \mathrm{mg} \mathrm{CaO}-\mathrm{CuO}$ sample was heated in flowing U.H.P He (flowing rate $=25 \mathrm{~mL} / \mathrm{min}$ ) from $50{ }^{\circ} \mathrm{C}$ to $900{ }^{\circ} \mathrm{C}$ (ramping rate $=4{ }^{\circ} \mathrm{C} / \mathrm{min}$ ) and holding there for an additional $30 \mathrm{~min}$.

\subsubsection{Raman Spectroscopy of OCs Decomposition}

The two oxygen carrier samples, pure $\mathrm{CuO}$ and $2 \mathrm{wt} \% \mathrm{CaO}-\mathrm{CuO}$, were decomposed in situ in a Raman catalytic reactor (Linkam CCR1000) before Raman spectral collection. The decomposition was done by heating the sample (ca. $15 \mathrm{mg}$ ) in flowing pure $\mathrm{He}(60 \mathrm{~mL} / \mathrm{min})$ from room temperature to $900{ }^{\circ} \mathrm{C}$ (ramping rate $20^{\circ} \mathrm{C} / \mathrm{min}$ ) and holding there for an additional $5 \mathrm{~min}$. Due to the decrease of Raman band intensities with increasing temperature,[31, 32] the spectra were collected at lower temperature to reduce this thermal effect. For example, after staying at each temperature $\left(400,500,600,700,800,900^{\circ} \mathrm{C}\right)$ for $5 \mathrm{~min}$, the sample was then cooled down to $300^{\circ} \mathrm{C}$ in $\mathrm{He}$, and Raman spectra were collected with laser excitation of 532nm. Since the experiments were conducted in the sealed Raman cell with purging pure He, no reversible reaction for the oxygen carriers will occur when the temperature is decreased to $300{ }^{\circ} \mathrm{C}$ for spectra collection. The Raman measurements were performed on a multiwavelength Raman system at Oak Ridge National Laboratory's Center for Nanophase Materials Sciences.[33] Raman scattering was collected via a customized ellipsoidal mirror and directed by a fiber optic bundle to the spectrograph stage of a triple Raman spectrometer (Princeton Instruments Acton Trivista 555). Edge filters (Semrock) were used in front of the UV-vis fiber optic bundle (Princeton Instruments) to block the laser irradiation. The $532 \mathrm{~nm}$ excitation ( $20 \mathrm{~mW}$ at sample) is emitted from a solidstate laser (Princeton Scientific, MSL 532-50). A UV-enhanced liquid $\mathrm{N}_{2}$-cooled CCD detector (Princeton Instrument) was employed for signal detection. The Raman reactor sits on an XY stage 
(Prior Scientific, OptiScan XY system) and translates in raster mode while collecting the spectrum. The fast translation has shown to be able to eliminate/minimize any laser damage of the samples.[33]

\subsection{Results and Discussion}

\subsubsection{Characterization of Oxygen Carriers}

The respective X-ray diffraction (XRD) patterns of calcined oxygen carriers are shown in Figure 1. Pure $\mathrm{CuO}$ and $\mathrm{CaO}$ XRD patterns are characterized as references. XRD patterns of the oxygen carriers is identical to the single-phase $\mathrm{CuO}$ with a monoclinic structure and the positions of the peaks are in good agreement with PDF-4+ 2016 card of $\mathrm{CuO}$ (Reference code: 01-0736234). XRD patterns exhibited strong diffraction peaks at $36^{\circ}, 39^{\circ}, 49^{\circ}, 58^{\circ}, 62^{\circ}, 72^{\circ}$ and $76^{\circ}$. The crystallographic parameters for this $\mathrm{CuO}$ unit cell are $\mathrm{a}=4.662 \AA, \mathrm{b}=3.417 \AA, \mathrm{c}=5.118 \AA, \alpha=\gamma=90^{\circ}$, $\beta=99.48^{\circ}$. No peaks of impurity are observed in the oxygen carriers and $\mathrm{CuO}$ reference sample XRD patterns. XRD patterns of $\mathrm{CaO}$ reference sample was also shown in Fig. 1. Obvious peaks appeared with $2 \theta$ values of $32^{\circ}, 37^{\circ}, 54^{\circ}, 64^{\circ}, 67^{\circ}$ and $80^{\circ}$, which were correspondent to a diffraction pattern of cubic calcium oxide with crystallographic parameters $\mathrm{a}=\mathrm{b}=\mathrm{c}=4.797 \AA$, $\alpha=\beta=\gamma=90^{\circ}$ (matched by reference code:00-001-1160). For the XRD patterns from oxygen carriers, no peaks could be attributed to $\mathrm{CaO}$ or other precursor compounds. $\mathrm{CuO}$ is the only crystalline phase that is clearly apparent. The presence of copper and absence of calcium implies there is no interaction between calcium and copper oxide in the bulk phase. 


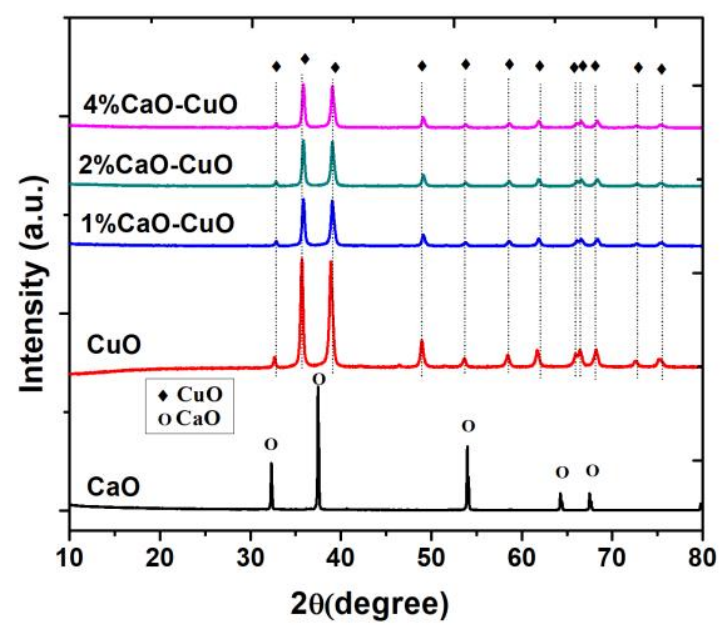

Figure 1. Powder XRD patterns of $\mathrm{CaO}-\mathrm{CuO}$ oxygen carriers calcined at $550{ }^{\circ} \mathrm{C}$

Even though bulk lattice oxygen is a crucial reactant, the reaction between oxygen carriers and solid fuels (i.e. coal, char and carbon black) was regarded to proceed at the solid-solid interface in some researches[24, 34, 35]. It is therefore important to investigate the surface properties of oxygen carriers in addition to their bulk structural properties. The near-surface elemental compositions of the as-prepared $\mathrm{CaO}-\mathrm{CuO}$ oxygen carriers as determined by XPS. From the survey scan, $\mathrm{Cu} 2 \mathrm{p}, \mathrm{Ca} 2 \mathrm{p}$ and $\mathrm{O} 1 \mathrm{~s}$ peaks are observed, which is understandable due to the OCs synthesis procedure. Apart from these, a significant amount of carbon is detected at the outer surface. This is due to carbonaceous contaminations, deposited on the sample during sample transfer under ambient conditions, which are frequently measured by XPS. On the other hand, this contamination may also result from the formation of small amounts of calcium carbonate, which is caused by the unavoidable absorption of $\mathrm{CO}_{2}$ in air by calcium oxide in $\mathrm{CaO}-\mathrm{CuO}$ sample.

Calcium-doped samples $\mathrm{O} 1 \mathrm{~s}$ and $\mathrm{Ca} 2 \mathrm{p}$ profiles are also examined and shown in Figure 2. Two major peaks are identified in the O1s profiles in Figure 2(a). The major peak located at 531.5 $\mathrm{eV}$ can be assigned to calcium oxide, and the other major peak at $529.5 \mathrm{eV}$ can be ascribed to lattice oxygen in copper (II) oxide. Comparing the relative intensities of $\mathrm{CaO}$ and $\mathrm{CuO}$ peaks, the 
increased intensities for $\mathrm{CaO}$ peaks on the surface of $1 \mathrm{wt} \%$, $2 \mathrm{wt} \%$ and $4 \mathrm{wt} \% \mathrm{CaO}-\mathrm{CuO}$ samples were corresponding with the increasing amount of calcium addition. The XPS Ca2p spectra of calcium-doped $\mathrm{CuO}$ are shown in Figure 2(b). The Ca2p (2p1/2 and 2p3/2) binding energy values of 351.1 and $347.3 \mathrm{eV}$ indicate that the oxidized $\mathrm{Ca}$ at the surface in the oxygen carriers can be assigned to calcium oxide as well. The increased Ca2p peak intensities are observed due to the increasing loading amount. The calcium enrichment on the oxygen carriers surface is proved by XPS atomic concentration analysis as well, which will be discussed later. The absence of calcium in the OC bulk phase presented by XRD analysis as well as the presence of calcium on the surface illustrated by XPS analysis prove that the calcium is doped only on the surface of copper oxide as desired.
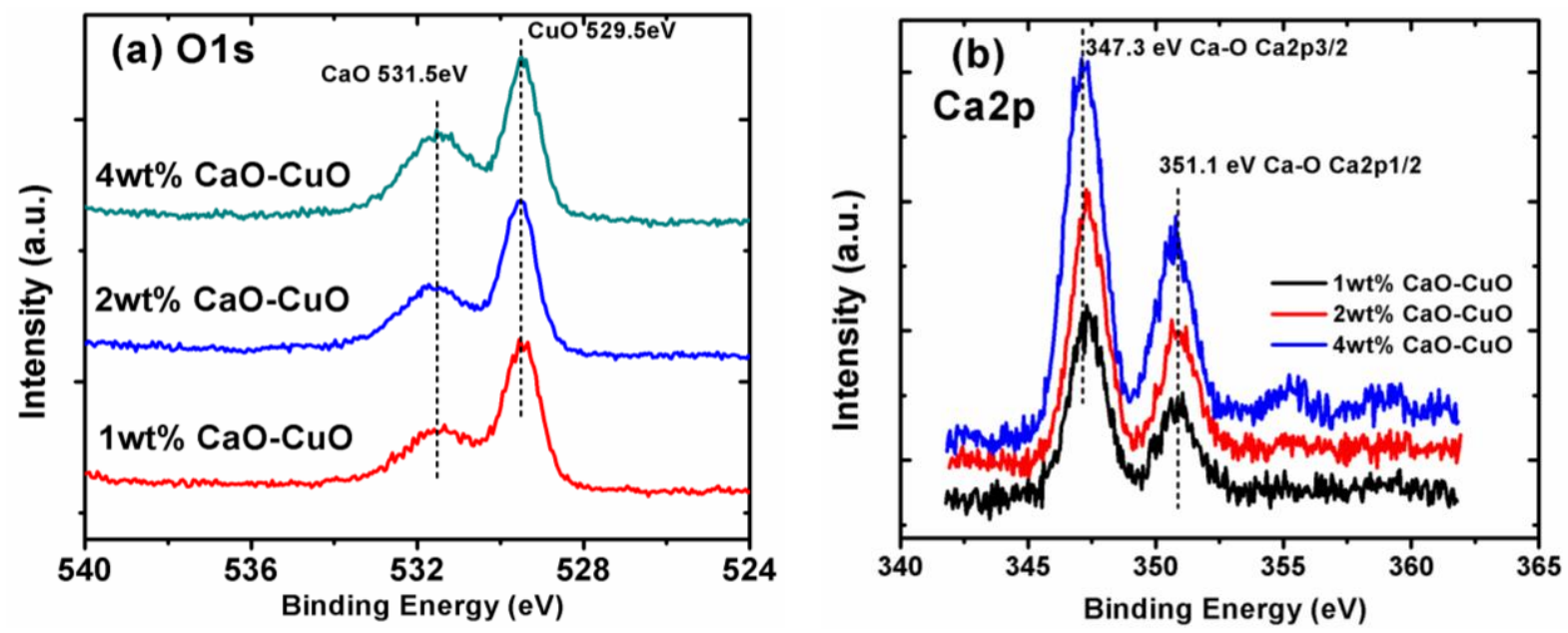

Figure. 2 Detailed O1s XPS scan for OC samples with different amount of doping calcium

The degree of Ca surface enrichment can also be quantified by calculating the near surface $\mathrm{Ca}$ concentration. The bulk theoretical calcium molar ratio can be estimated by assuming the oxygen carriers to be homogeneous mixture of $\mathrm{CaO}-\mathrm{CuO}$ samples with different $\mathrm{Ca}$-doping amounts. The calculated molar ratios of $\mathrm{Ca}$ and $\mathrm{Cu}$ of 1,2, 4wt $\% \mathrm{CaO}-\mathrm{CuO}$ samples are listed in Table 2. As it shown, a significant surface enrichment of calcium can be observed on all Ca-doped oxygen carriers. The near-surface $\mathrm{Ca}$ concentration becomes more pronounced with a higher 
amount of $\mathrm{Ca}$ addition, while $\mathrm{Cu}$ drops to $84.9 \%$. It is necessary to pay attention that the $\mathrm{Ca}$ concentration derived from XPS is much higher than theoretical ones in bulk. Thus it is concluded that the calcium is accumulated on the $\mathrm{CuO}$ surface and it is valuable to study the impact of this surface doping on CLC, which will be discussed in later sections.

Table 2. $\mathrm{Ca}$ and $\mathrm{Cu}$ Concentrations of $1,2,4 \mathrm{wt} \% \mathrm{CaO}-\mathrm{CuO}$ samples (Excluding oxygen) (\%)

\begin{tabular}{lccccc}
\hline Sample & \multicolumn{2}{c}{ Surface metals concentration from XPS } & & \multicolumn{2}{c}{ Theoretical metals concentration in bulk } \\
\cline { 2 - 3 } \cline { 5 - 6 } & $\mathrm{Ca} 2 \mathrm{p}$ & $\mathrm{Cu} 2 \mathrm{p}$ & & $\mathrm{Ca}$ & $\mathrm{Cu}$ \\
\hline $1 \mathrm{wt} \% \mathrm{CaO}-\mathrm{CuO}$ & 8.3 & 91.7 & & 1.8 & 98.2 \\
$2 \mathrm{wt} \% \mathrm{CaO}-\mathrm{CuO}$ & 12.0 & 88.0 & & 3.6 & 96.4 \\
$4 \mathrm{wt} \% \mathrm{CaO}-\mathrm{CuO}$ & 15.1 & 84.9 & 7.1 & 92.9 \\
\hline
\end{tabular}

\subsubsection{Temperature-Programmed Reduction Analysis}

To study the reducibility of the $\mathrm{CaO}-\mathrm{CuO}$ oxygen carriers, Temperature-Programmed Reduction (TPR) was performed on all prepared oxygen carrier samples in $5 \% \mathrm{H}_{2} / 95 \% \mathrm{He}$ atmosphere. Pure $\mathrm{CuO}$ was also examined as a reference. The normalized $\mathrm{H}_{2}$ TPR profile is presented and three peaks are obtained in Figure 3. The corresponding peak areas are summarized in Table 3. Figure 3(a) illustrated that all Ca-doped samples show three main peaks with a maximum at $277^{\circ} \mathrm{C}, 357^{\circ} \mathrm{C}, 532^{\circ} \mathrm{C}$, which are donated as $\alpha, \beta, \gamma$, respectively. In contrast, only $\alpha$ peak is obtained for pure $\mathrm{CuO}$ sample. The $\alpha$ peak is ascribed to the reduction of $\mathrm{CuO}$ to metallic copper. Besides, water is detected at the exit of the reactor with a mass spectrometer when $\mathrm{CuO}$ reduction occurred. A similar report was found in previous investigation on CuO TPR study[36]. After the $\mathrm{CuO}$ is reduced, $\beta$ and $\gamma$ peaks start to appear after $300{ }^{\circ} \mathrm{C}$, as shown in Figure 3(b). To identify these two following peaks, pure calcium oxide is subjected to $\mathrm{H}_{2}$-TPR and two noticeable peaks are observed at the same temperatures with those of $\beta$ and $\gamma$ peaks. Therefore, $\beta$ and $\gamma$ peaks are assigned to the reduction of doped calcium compounds on OC surface. Water is detected by 
the mass spectrometer as well when the temperature is $\sim 357^{\circ} \mathrm{C}(\beta$ peak). This water is produced by the reaction between oxygen in $\mathrm{CaO}$ and hydrogen, indicating that the $\beta$ peak stemmed from the reduction of $\mathrm{CaO}$ in the oxygen carriers. As for $\gamma$ peak, it is partially caused by the $\mathrm{Ca}-\mathrm{O}$ bond reduction in $\mathrm{H}_{2}$ as well, which is observed around $600^{\circ} \mathrm{C}$ in another report[37]. On the other hand, the $\gamma$ peak is caused by calcium carbonate decomposition, which is proved by the $\mathrm{CO}_{2}$ appearance in low concentration from mass spectrometer analysis. Thus, produced $\mathrm{CO}_{2}$ partially contributes to the signal intensity of $\gamma$ peak which was detected by TCD. The presence of $\mathrm{CaCO}_{3}$ is consistent with the detected impurity carbon atom described by XPS in Section 3.1. As summarized in Table 3 , the relative peak areas of $\alpha$ peak decrease slightly with calcium dopant amount in the order: pure $\mathrm{CuO}>1 \mathrm{wt} \% \mathrm{CaO}-\mathrm{CuO}>2 \mathrm{wt} \% \mathrm{CaO}-\mathrm{CuO}>4 \mathrm{wt} \% \mathrm{CaO}-\mathrm{CuO}$. This is because the introduction of inactive calcium sacrifices a small amount of oxygen transfer capacity of $\mathrm{CuO}$. The intensity and peak area of $\beta$ and $\gamma$ are increasing with $\mathrm{CaO}$ loading from $1 \mathrm{wt} \%$ to $4 \mathrm{wt} \%$. Furthermore, $\gamma$ peak positions shifts with increasing $\mathrm{CaO}$ loading from 525 to $550{ }^{\circ} \mathrm{C}$. It is believed that samples with finely dispersed $\mathrm{CaO}$ (lower calcium dopant) tend to be reduced at lower temperature.[38]
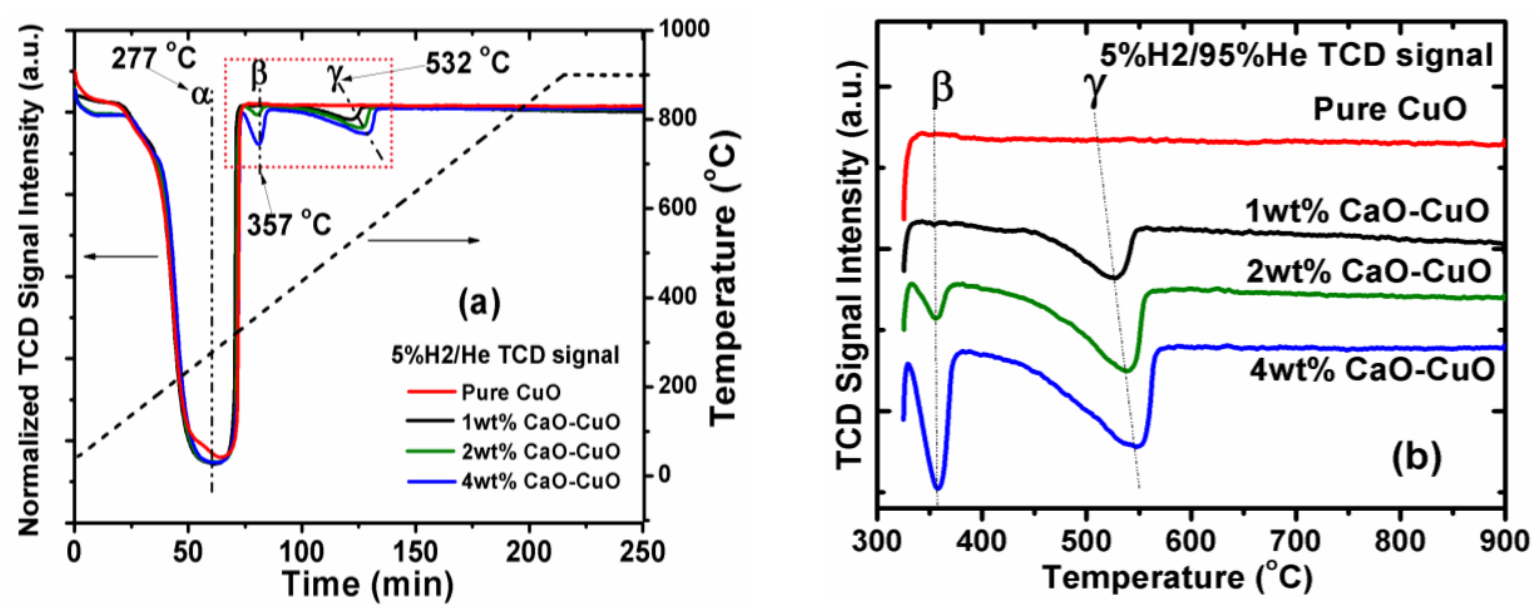

Figure. $3 \mathrm{H}_{2}$ temperature-programmed reduction profiles for three $\mathrm{CaO}-\mathrm{CuO}$ OCs and pure CuO. (a) plot of TCD signal/Temperature vs. Time during whole reduction process; (b) plot of TCD signal vs. Temperature in $300-900{ }^{\circ} \mathrm{C}$ range. 
Table 3. Peak areas for $\mathrm{H}_{2}$-TPR peaks.

\begin{tabular}{cccccccc}
\hline Sample & $\begin{array}{c}\text { Area for } \\
\alpha \text { peak } \\
\text { (a.u.) }\end{array}$ & $\begin{array}{c}\text { Area for } \\
\beta \text { peak } \\
\text { (a.u.) }\end{array}$ & $\begin{array}{c}\text { Area for } \\
\gamma \text { peak } \\
\text { (a.u.) }\end{array}$ & $\begin{array}{c}\text { Area for } \\
\alpha+\beta+\gamma \\
\text { peak (a.u.) }\end{array}$ & $\begin{array}{c}\text { CuO reduction } \\
\text { peak area }(\alpha \text { peak) } \\
\text { in percentage }(\%)\end{array}$ & $\begin{array}{c}\text { Total peak areas } \\
(\alpha+\beta+\gamma \text { peaks) in } \\
\text { percentage }(\%)\end{array}$ & $\begin{array}{c}\text { Theoretical } \\
\text { CuO amount } \\
(\text { wt\%) }\end{array}$ \\
\hline Pure $\mathrm{CuO}$ & 52.11 & 0 & 0 & 52.11 & 100 & 100 & 100 \\
$1 \mathrm{wt} \% \mathrm{CaO}-\mathrm{CuO}$ & 50.64 & 0 & 0.86 & 51.5 & 97.2 & 98.8 & 99.0 \\
$2 \mathrm{wt} \% \mathrm{CaO}-\mathrm{CuO}$ & 49.81 & 0.16 & 1.64 & 51.61 & 95.6 & 98.8 \\
$4 \mathrm{wt} \% \mathrm{CaO}-\mathrm{CuO}$ & 48.17 & 0.95 & 2.35 & 51.47 & 92.4 & 96 \\
\hline
\end{tabular}

\subsubsection{Effect of Calcium on CLOU}

In order to understand how the oxygen uncoupling reaction from the $\mathrm{CaO}-\mathrm{CuO}$ oxygen carrier is affected by $\mathrm{Ca}$-doping, decomposition of $\mathrm{CaO}-\mathrm{CuO}$ oxygen carriers with different $\mathrm{Ca}$ contents and pure $\mathrm{CuO}$ were conducted in helium. Oxygen concentration from the effluent gas stream was analyzed during the temperature ramp. The results are shown in Figure 4(a). Two peaks for released oxygen concentration are observed when pure $\mathrm{CuO}$ is decomposed in helium and this phenomenon is confirmed by repeated experiments. The first peak, centered at $880^{\circ} \mathrm{C}$, can be assigned to the reduction of $\mathrm{CuO}$ to $\mathrm{Cu}_{2} \mathrm{O}$. Meanwhile, the second small peak represented the further transition of copper oxide state from $\mathrm{Cu}_{2} \mathrm{O}$ to $\mathrm{Cu}$, to release oxygen. The similar phase changes were also obtained by Siriwardane et al.[24] by using in situ XRD and XPS. These studies clearly showed that during carbon/CuO combustion: $\mathrm{CuO}$ was first converted to $\mathrm{Cu}_{2} \mathrm{O}$ at relative low temperature, and then reaction proceeds until $\mathrm{Cu}_{2} \mathrm{O}$ is fully converted to $\mathrm{Cu}$ metal at higher temperature.

In contrast, the addition of calcium significantly accelerates the reduction process, which is shown by single peak of the oxygen release when Ca-doped oxygen carriers are employed. Calcium addition on the surface strongly promotes the reduction process of copper oxide so that the carrier releases all the available oxygen in a single range of temperature to directly achieve full 
conversion (from $\mathrm{CuO}$ to $\mathrm{Cu}$ ). The data indicate that the presence of $\mathrm{Ca}$ is favorable for the oxygen un-coupling process, which is consistent with the data reported previously[21]. Before reaching the maximum value $\left(215 \mathrm{~min}, \sim 880^{\circ} \mathrm{C}\right.$ ), the $\mathrm{O}_{2}$ releasing rate (which can be represented by the slope of the curves in Figure $4(\mathrm{a}))$, increased in the order: pure $\mathrm{CuO} \approx 1 \mathrm{wt} \% \mathrm{CaO}-\mathrm{CuO}<$ $4 \mathrm{wt} \% \mathrm{CaO}-\mathrm{CuO}<2 \mathrm{wt} \% \mathrm{CaO}-\mathrm{CuO}$. Figure 4 (b) displays the $\mathrm{O}_{2}$ production rate over temperature $\left[\mathrm{dC}\left(\mathrm{O}_{2}\right) / \mathrm{dT}\right]$ at the ramping stage, which is represented by the first derivative of the $\mathrm{O}_{2}$ concentration curve. The maximum $\mathrm{O}_{2}$ production rates are found at 882,863 and $879{ }^{\circ} \mathrm{C}$ for $1 \mathrm{wt} \% \mathrm{CaO}-\mathrm{CuO}, 2 \mathrm{wt} \% \mathrm{CaO}-\mathrm{CuO}, 4 \mathrm{wt} \% \mathrm{CaO}-\mathrm{CuO}$, respectively. Meanwhile the rate reaches maximum at higher temperature $885^{\circ} \mathrm{C}$ for pure $\mathrm{CuO}$ sample. Therefore, it is concluded that $\mathrm{Ca}$ can accelerate the oxygen release from $\mathrm{CuO}$. Moreover, it can be seen that $2 \mathrm{wt} \% \mathrm{CaO}-\mathrm{CuO}$ sample possesses both the maximum $\mathrm{O}_{2}$ concentration and lowest peak temperature of $\mathrm{O}_{2}$ production rate. This implies that when $2 \mathrm{wt} \% \mathrm{CaO}$ is doped and dispersed on $\mathrm{CuO}$ surface, monolayer coverage is formed to initiate and accelerate the decomposition reaction[39].
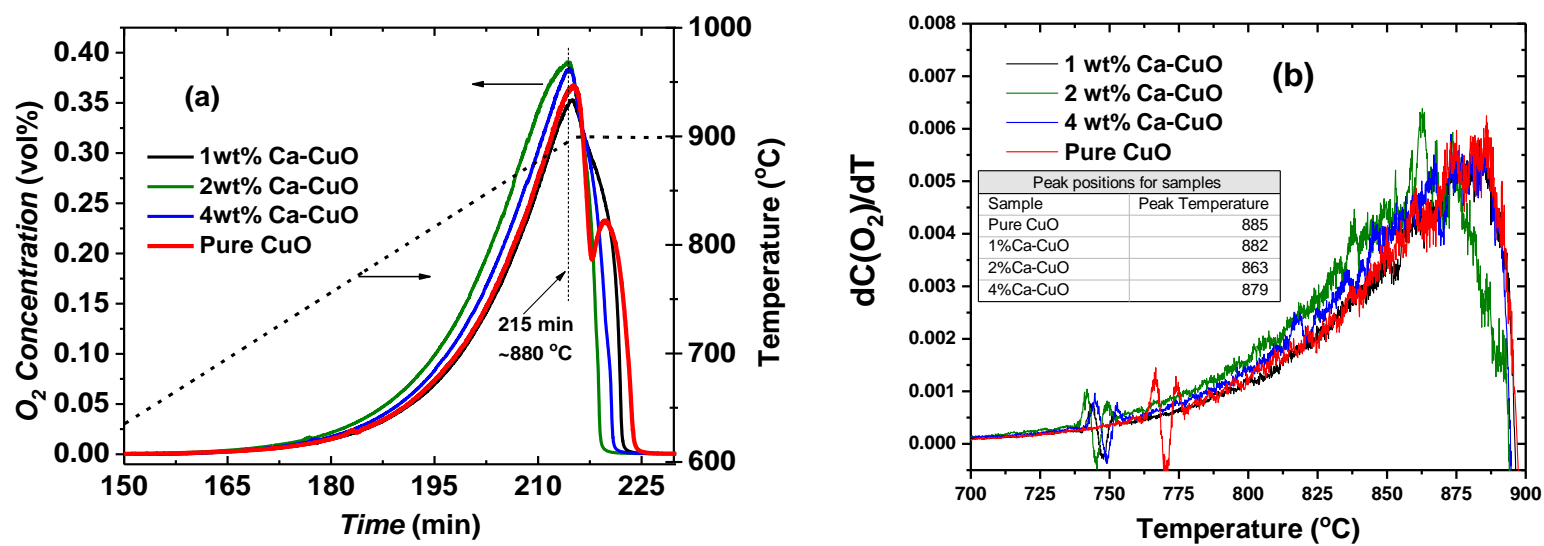

Figure. $4 \mathrm{O}_{2}$ concentration in product gas during the temperature ramp for decomposition of $\mathrm{CaO}-\mathrm{CuO}$ oxygen carries and pure $\mathrm{CuO}$. 


\subsubsection{Raman Spectra as Function of Temperature during OCs Decomposition}

The in situ Raman was employed to test the pathway of copper(II) oxide reduction process during decomposition of oxygen carriers. The decomposition property of pure $\mathrm{CuO}$ and $2 \mathrm{wt} \%$ $\mathrm{CaO}-\mathrm{CuO}$ was tested with temperature-programmed experiments coupled with in situ visible Raman spectroscopy. Figure 5(a) shows the 532nm excitation Raman spectra collected after different temperatures for pure $\mathrm{CuO}$ to correlate the observed change in reactivity (Section 2.3.3) with any structural changes to the lattice during the decomposition process. Since the Raman signal intensity is diminished with increased temperature, all Raman spectra were collected at $300^{\circ} \mathrm{C}$ after sample materials(both pure $\mathrm{CuO}$ and $2 \mathrm{wt} \%-\mathrm{CaO}-\mathrm{CuO}$ ) were heated up and kept for $5 \mathrm{~min}$ at the desired temperature, i.e. $400-900^{\circ}$ C.[32] Meanwhile, Raman spectra was collected at room temperature. In the Raman shift range of $100-600 \mathrm{~cm}^{-1}, \mathrm{CuO}$ peaks are assigned at 290 and 329 $\mathrm{cm}^{-1}$, while $\mathrm{Cu}_{2} \mathrm{O}$ peaks were assigned at 219 and $408 \mathrm{~cm}^{-1}$. The $\mathrm{CuO}$ and $\mathrm{Cu}_{2} \mathrm{O}$ spectra agree well with the literature[40]. The plasma peaks noted in Figure 5, which are derived from the laser source itself[41], are regarded as an internal standard making Raman spectra at different temperatures comparable. As can be seen, for the pure $\mathrm{CuO}$ sample, only the $\mathrm{CuO}$ peaks at 290 and $329 \mathrm{~cm}^{-1}$ are existing and no extra peak is found when the temperature is lower than $800^{\circ} \mathrm{C}$. When the temperature is raised to $900{ }^{\circ} \mathrm{C}, \mathrm{Cu}_{2} \mathrm{O}$ peaks at 219 and $408 \mathrm{~cm}^{-1}$ appear while $\mathrm{CuO}$ peaks diminish, even disappear. The appearance of $\mathrm{Cu}_{2} \mathrm{O}$ and disappearance of $\mathrm{CuO}$ peaks confirm that $\mathrm{CuO}$ decomposed to $\mathrm{Cu}_{2} \mathrm{O}$ when the temperature reached $900^{\circ} \mathrm{C}$. This result is consist with the $\mathrm{O}_{2}$ production from pure $\mathrm{CuO}$ sample decomposition in Section 2.3.3, the temperature for the first $\mathrm{O}_{2}$ concentration peak is $880^{\circ} \mathrm{C}$ where the $\mathrm{O}_{2}$ is generated from the transition from $\mathrm{CuO}$ to $\mathrm{Cu}_{2} \mathrm{O}$.

For the $2 \mathrm{wt} \%-\mathrm{CaO}-\mathrm{CuO}$ sample, similarly, there is no phase changes of $\mathrm{CuO}$ when the temperature is lower than $800^{\circ} \mathrm{C}$. However, when the temperature goes up to $900^{\circ} \mathrm{C}, \mathrm{CuO}$ is 
directly converted to metallic $\mathrm{Cu}$, without producing $\mathrm{Cu}_{2} \mathrm{O}$. The Raman spectra for $2 \mathrm{wt} \%-\mathrm{CaO}-$ $\mathrm{CuO}$ along with pure $\mathrm{CuO}$ sample are compared in Figure 5(b). For 2wt $\%$-CaO-CuO sample, it is obvious that $\mathrm{CuO}$ peaks diminish and still exist when the decomposition reaction occurs. $\mathrm{No}_{\mathrm{Cu}_{2} \mathrm{O}}$ peaks are detected from the Raman spectra. The absence of $\mathrm{Cu}_{2} \mathrm{O}$ and existence of $\mathrm{CuO}$ confirmed the one-step decomposition of $\mathrm{Ca}$-doped $\mathrm{CuO}(\mathrm{CuO} \rightarrow \mathrm{Cu})$. Different reduction pathways are revealed through in situ Raman spectra and $\mathrm{O}_{2}$ yield from oxygen carriers decomposition. The comparison of decomposition reactivity and in situ Raman spectra of doped and un-doped $\mathrm{CuO}$ suggested the change of reduction pathway from a sequential $\left(\mathrm{CuO} \rightarrow \mathrm{Cu}_{2} \mathrm{O} \rightarrow \mathrm{Cu}\right)$ to a direct transition $(\mathrm{CuO} \rightarrow \mathrm{Cu})$ during OCs decomposition. These different pathways can be illustrated in Figure 6. It can be explained that $\mathrm{CaO}$ potentially forms a surface structure with oxygen vacancies and electron gaps, which are regarded as the possible driving force to allow $\mathrm{O}_{2}$ to form the surface $\mathrm{O}^{2-}$ anions moving from the solid lattice structure[42]. The further study on the cause for the change of $\mathrm{CuO}$ transition pathway is undergoing.
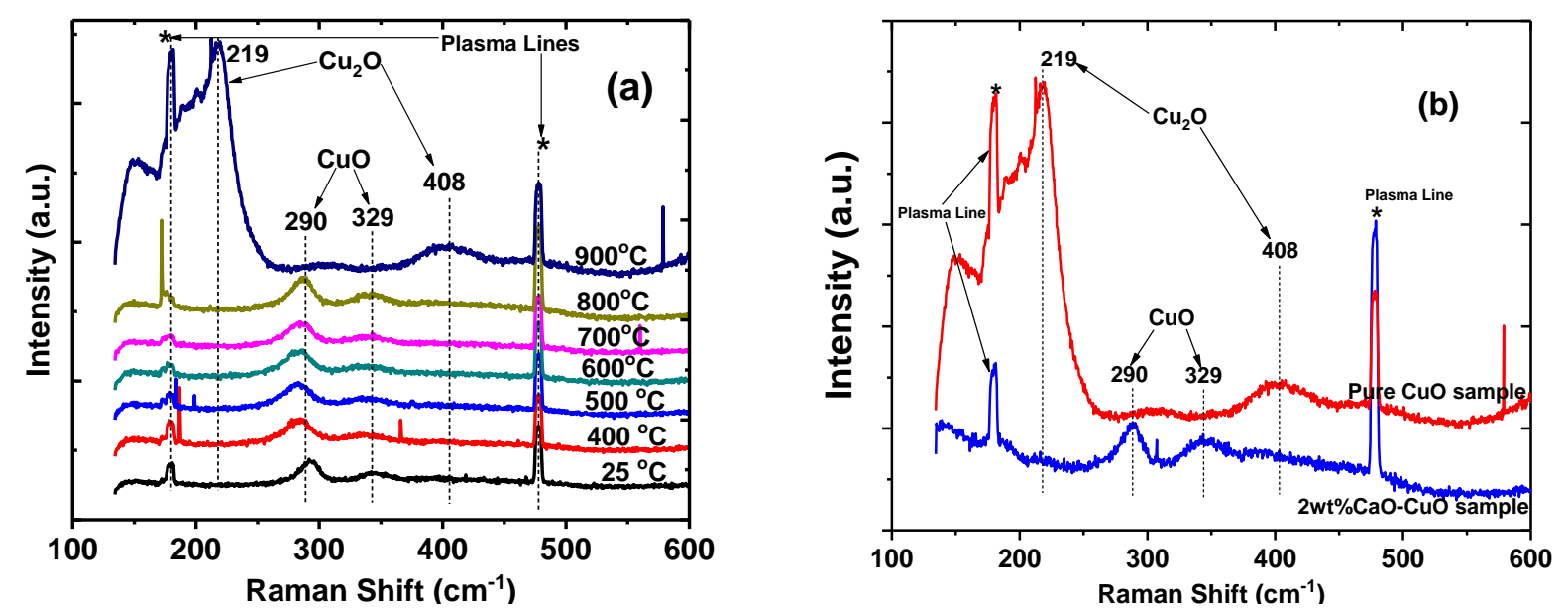

Figure. 5 Raman spectra $(532 \mathrm{~nm}$ ) of (a)pure $\mathrm{CuO}$ collected at different temperatures and (b)comparison between pure $\mathrm{CuO}$ and $\mathrm{CaO}-\mathrm{CuO}$ oxygen carries at $900^{\circ} \mathrm{C}$.

Note: * Peaks are denoted to plasma peaks, which are regarded as internal standard to make Raman peaks are comparable. 


\section{Sequential Transition of undoped $\mathrm{CuO}$}

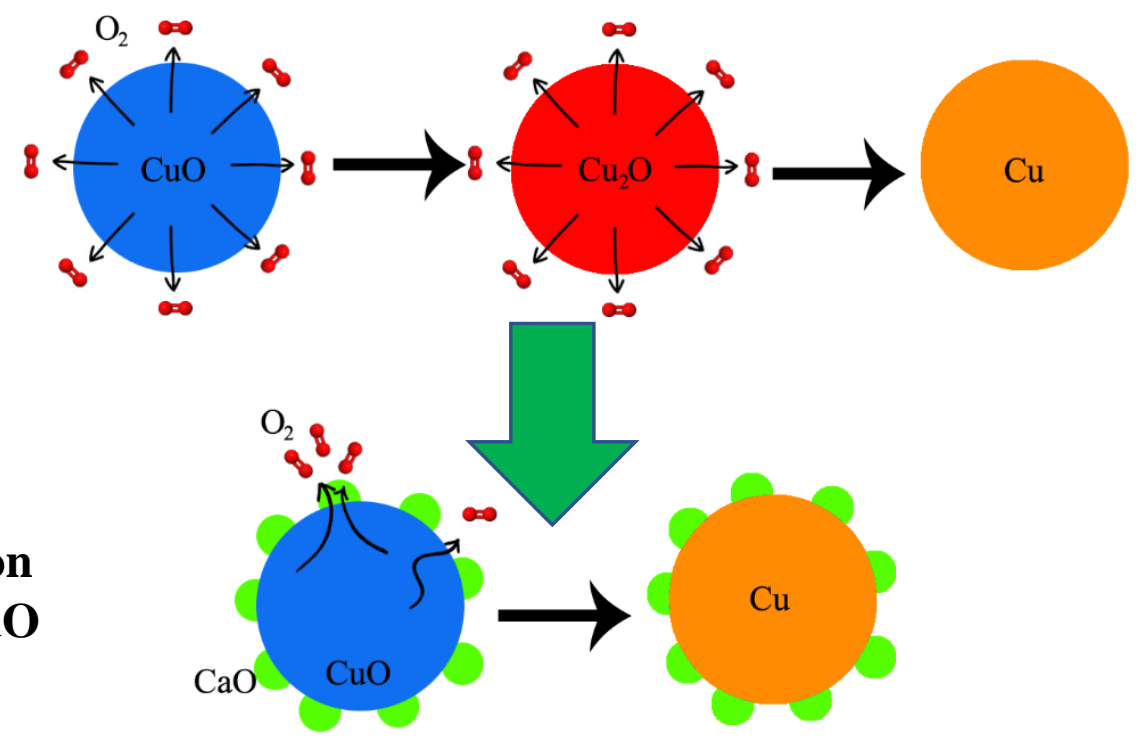

Figure. 6 Proposed reduction pathway scheme schematic for calcium-undoped/doped $\mathrm{CuO}$ based on decomposition reactivity and Raman spectra.

\subsubsection{Effect of Surface-doped Calcium on CuO on Char-CLC Performance}

To investigate the role of doped calcium on $\mathrm{CuO}$ surface on reaction performance of CLC, the mixtures of Wyodak Char and $\mathrm{CuO}$ oxygen carriers with various amount of $\mathrm{CaO}(1 \mathrm{wt} \%, 2 \mathrm{wt} \%$, $4 \mathrm{wt} \%$ ) were heated to $900^{\circ} \mathrm{C}$ and kept for $30 \mathrm{~min}$. The concentrations of $\mathrm{CO}_{2}$ and $\mathrm{CO}$ are presented as a function of time from reaction performance of char/OCs mixtures in Figure 7. When a mixture of char and $\mathrm{CaO}-\mathrm{CuO}$ oxygen carriers was heated in helium, a combustion reaction with a significant rate is observed around $550{ }^{\circ} \mathrm{C}$, which is consistent with previous studies[14, 24]. Since volatiles are not produced from char[43, 44], the rapid reaction of $\mathrm{CuO}$ and char cannot proceed via the coal volatiles. Therefore, this reaction can only be explained as solid-solid interaction between metal oxide and solid fuel. It has been claimed that solid-solid reactions can occur with coal and oxygen carriers when there are significant contacts between the oxygen carrier and coal. 
This kind of reaction mechanism is described as "fuel-induced oxygen release" from metal oxides and presented in the following equation[24, 45]:

$$
\mathrm{Me}_{x} \mathrm{O}_{y}+\frac{1}{2} \mathrm{C} \rightarrow x \mathrm{Me}+\frac{y}{2} \mathrm{CO}_{2}
$$

The concentration peak of $\mathrm{CO}_{2}$ with $\mathrm{CaO}$-doped $\mathrm{CuO}$ were higher than that with pure $\mathrm{CuO}$, indicating faster reaction rate with $\mathrm{CaO}-\mathrm{CuO}$. The relative amount of produced gases can be indicated by the areas of produced gas curve. In Figure 7(a), the areas of produced $\mathrm{CO}_{2}$ employing $\mathrm{CaO}-\mathrm{CuO}$ are clearly larger than that using pure $\mathrm{CuO}$, indicating that there is additional carbon dioxide formation due to the presence of calcium surface-decorated oxygen carrier. Namely, more oxygen is released/transferred from the $\mathrm{CuO}$ at faster rate from either surface or bulk with the help of the calcium doped on the surface. Furthermore, it can be seen a significant $\mathrm{CO}_{2}$ production from the $2 \mathrm{wt} \%-\mathrm{CaO}-\mathrm{CuO}$ sample with the maximum values ( $3.81 \%$ for $\mathrm{p} 1$ and $5.32 \%$ for $\mathrm{p} 2)$. These maximum values for $\mathrm{p} 1$ and $\mathrm{p} 2$ increased $47.1 \%$ and $26.7 \%$ compared to those for pure $\mathrm{CuO}$ sample (2.59\% for $\mathrm{p} 1$ and $4.20 \%$ for $\mathrm{p} 2)$. The reaction with $2 \mathrm{wt} \%-\mathrm{CaO}-\mathrm{CuO}$ also takes place at a lower temperature than that with other samples which also indicates the best reactivity to process the chemical looping combustion of Wyodak char. As noted earlier in Section 2.3.3, when calcium oxide loading reached $2 \mathrm{wt} \%$, a $\mathrm{CaO}$ monolayer on $\mathrm{CuO}$ surface would be generated and then promote the CLOU characteristics of CuO-based oxygen carriers. This Ca monolayer probably is also the main reason for the best reactivity performance of $2 \mathrm{wt} \% \mathrm{CaO}-\mathrm{CuO}$ sample to accelerate the OCs-char reaction to produce $\mathrm{CO}_{2}$.

It is necessary to note that there are no significant changes in the peak intensity and amount of $\mathrm{CO}$ produced, as shown in Figure 7(b). $\mathrm{CO}$ was considered as the intermediate during the solid- 
solid reaction between metal oxide and char. Saucedo et al.[46] also claimed that rapid oxidation of $\mathrm{CO}$ by the oxygen carrier (i.e. $\mathrm{Fe}_{2} \mathrm{O}_{3}$ ) to $\mathrm{CO}_{2}$ occurred within the mass transfer boundary layer surrounding the char particle.
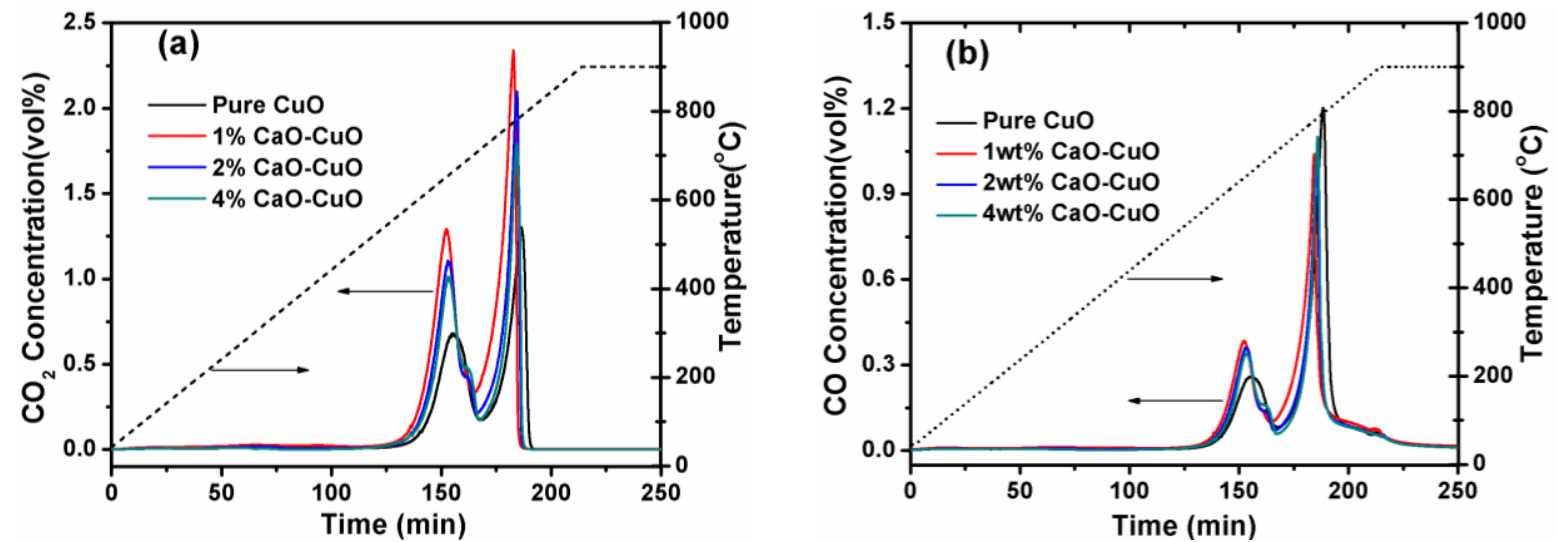

Figure. $7 \mathrm{CO}_{2}$ (a) and $\mathrm{CO}$ (b) concentration in product gas during the temperature ramp as a function of time from reaction performance of char/OCs mixtures.

\subsubsection{Effect of Surfaced-doped Calcium on $\mathrm{CuO}$ on $\mathrm{CH}_{4}$-CLC performance}

The reaction performance of $\mathrm{CaO}$-doped and pure $\mathrm{CuO}$ were conducted with $20 \mathrm{vol} \%$ $\mathrm{CH}_{4} / \mathrm{Ar}$ and results are shown in Figure 8. Different from solid fuel (char) CLC, there are three peaks in produced $\mathrm{CO}_{2}$ and $\mathrm{CO}$ concentrations plots, designated as $\mathrm{p} 1, \mathrm{p} 2$ and $\mathrm{p} 3$ for $\mathrm{CO}_{2}$ and $\mathrm{q} 1$, $\mathrm{q} 2$ and $\mathrm{q} 3$ for $\mathrm{CO}$, respectively. Similar data were reported elsewhere[24] explaining that $\mathrm{p} 1$ and p2 are attributed to two reaction steps during the CLC process: $\mathrm{CuO}$ is first reduced to $\mathrm{Cu}_{2} \mathrm{O}$ at relatively low temperature, and then fully reduced to metallic $\mathrm{Cu}$ at higher temperature. $\mathrm{CO}_{2} / \mathrm{CO}$ of $\mathrm{p} 1 / \mathrm{q} 1$ is produced by the reaction of $\mathrm{CH}_{4}$ with oxygen released from $\mathrm{CuO} \rightarrow \mathrm{Cu}_{2} \mathrm{O}$, while those of $\mathrm{p} 2 / \mathrm{q} 2$ is acquired from the reaction of $\mathrm{CH}_{4}$ with oxygen generated from $\mathrm{Cu}_{2} \mathrm{O} \rightarrow \mathrm{Cu}$. In Figure 8(a), the slight increase of $\mathrm{CO}_{2}$ production rate (maximum value) is observed for $\mathrm{CaO}-\mathrm{CuO}$ samples over the pure $\mathrm{CuO}$, is attributed to the favorable influence of the alkali addition. During the CLC process, calcium oxide absorbs the released $\mathrm{CO}_{2}$ so that the $\mathrm{CO}_{2} / \mathrm{CO}$ production is delayed 
for $\mathrm{CaO}-\mathrm{CuO}$ samples compared with the pure $\mathrm{CuO}$ experiment. The third peak $\mathrm{p} 3$ appears when the temperature is higher than $500-550{ }^{\circ} \mathrm{C} . \mathrm{CaCO}_{3}$ decomposes to be $\mathrm{CaO}$ and $\mathrm{CO}_{2}$, thus a small $\mathrm{CO}_{2}$ peak (p3) is found at the third stage. The generated $\mathrm{CO}_{2}$ would also react with $\mathrm{CH}_{4}$ at a relatively higher temperature and thus the methane reforming reaction is initiated to produce $\mathrm{CO}$ (q3). $\mathrm{CaO}-\mathrm{CO}_{2}$ adsorption and decomposition processes are also obtained and explained in the research about biomass catalytic pyrolysis with alkali-treated CaO/ZSM-5 by Sun et al.[47]. In addition, the methane reforming reaction is also promoted by the produced metallic $\mathrm{Cu}$ as catalyst[48]. Therefore, it is reasonable that the maximum value and peak area for both $\mathrm{p} 3$ and $\mathrm{q} 3$ peaks are pronouncedly increasing with the $\mathrm{CaO}$ doping amounts. $\mathrm{H}_{2}$ concentration in the product gas as a function of time during the temperature ramp of the reaction between oxygen carriers and methane is shown in Figure 9. The $\mathrm{H}_{2}$ concentration profile is deconvoluted into four peaks, designated as $\mathrm{r} 1, \mathrm{r} 2, \mathrm{r} 3$ and $\mathrm{r} 4$, respectively. A small amount of $\mathrm{H}_{2}$ was generated at $\mathrm{r} 1$ and $\mathrm{r} 2$, which are corresponding to the CLC decomposition of $\mathrm{CH}_{4}$ (simultaneously producing $\mathrm{p} 1 / \mathrm{q} 1$ and $\mathrm{p} 2 / \mathrm{q} 2$ peaks). $\mathrm{r} 3$ peak is generated by the above-mentioned dry $\left(\mathrm{CO}_{2}\right)$ reforming of methane. It is clear to see that $\mathrm{H}_{2}$ concentrations derived by calcium doped samples are much higher than that of pure $\mathrm{CuO}$ sample. Moreover, the maximum $\mathrm{H}_{2}$ concentration increases with the $\mathrm{Ca}$ loading amount, which is in line with the $\mathrm{CO}$ results. It is interesting to note that a set of peaks $\mathrm{r} 4$ shows up at higher temperature $\left(700-800{ }^{\circ} \mathrm{C}\right)$, where the catalytic decomposition of methane (CDM) is occurring[49-51]. When the temperature reaches $700{ }^{\circ} \mathrm{C}, \mathrm{CuO}$ has been reduced to metal $\mathrm{Cu}$, which is not active for methane decomposition[52]. Meanwhile, the doped $\mathrm{Ca}$ as a catalyst, promotes the $\mathrm{H}_{2}$ production[53], which is increasing with $\mathrm{Ca}$ dopant content. Many researches have reported that the calcium species, mainly $\mathrm{CaO}$ and calcium, could serve as promoters to improve the activity and lifetime of catalysts in methane decomposition[54-56]. The main reactions during the whole 
$\mathrm{CLC}$ using $\mathrm{CaO}$-doped $\mathrm{CuO}$ as oxygen carrier are summarized as shown below. The whole process could be expressed in Figure 10.
$\mathrm{CLC}$ of $\mathrm{CH}_{4}$ :
$\mathrm{CuO}+\frac{1}{4} \mathrm{CH}_{4} \rightarrow \mathrm{Cu}+\frac{1}{4} \mathrm{CO}_{2}+\frac{1}{2} \mathrm{H}_{2} \mathrm{O}$
$\mathrm{CaO}$ Adsorption:
$\mathrm{CaO}+\mathrm{CO}_{2} \rightarrow \mathrm{CaCO}_{3}$
$\mathrm{CaO}$ Decomposition:
$\mathrm{CaCO}_{3} \rightarrow \mathrm{CaO}+\mathrm{CO}_{2}$
Methane Reforming:
$\mathrm{CO}_{2}+\mathrm{CH}_{4} \rightarrow 2 \mathrm{CO}+2 \mathrm{H}_{2}$
Methane Decomposition:
$\mathrm{CH}_{4} \rightarrow \mathrm{C}+2 \mathrm{H}_{2}$
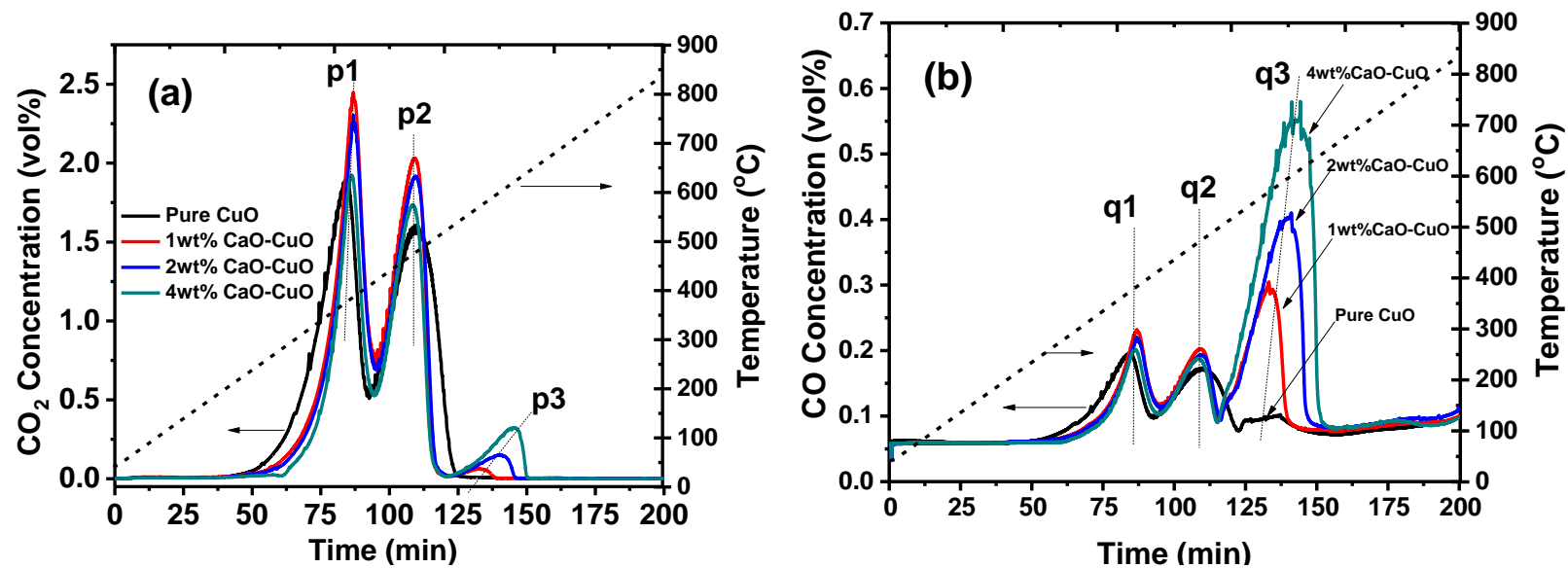

Figure. 8 (a) $\mathrm{CO}_{2}$ and (b) $\mathrm{CO}$ concentration in product gas during the temperature ramp as a function of time from reaction performance of oxygen carriers and methane.

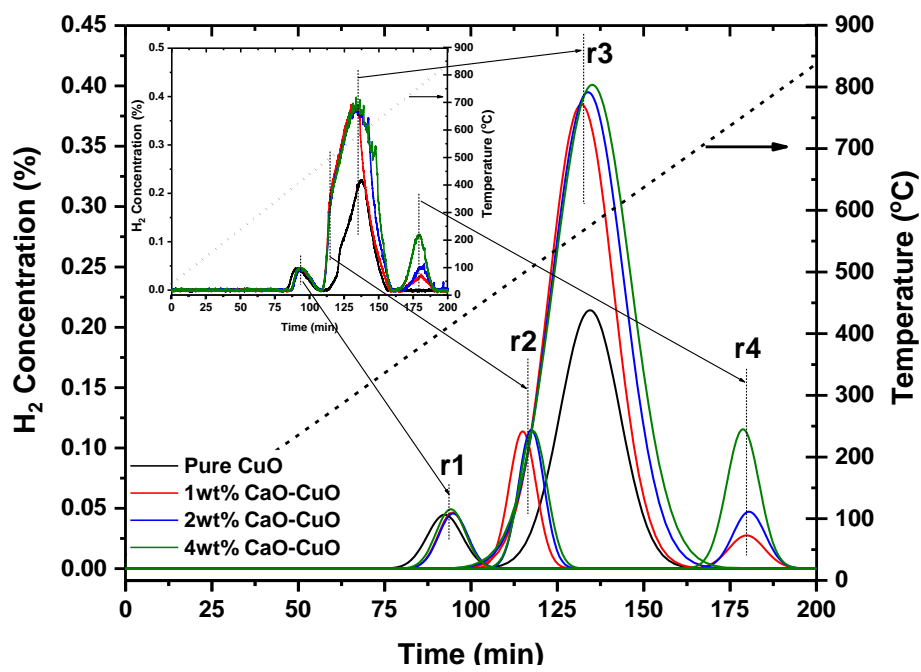

Figure $9 . \mathrm{H}_{2}$ concentration in product gas as a function of time during the temperature ramp of the reaction between oxygen carriers and methane. The curves in the small window represent 
the original curves for four oxygen carriers. Deconvolution peaks (r1, r2, r3, r4) of $\mathrm{H}_{2}$ concentration profiles are shown in the main window.

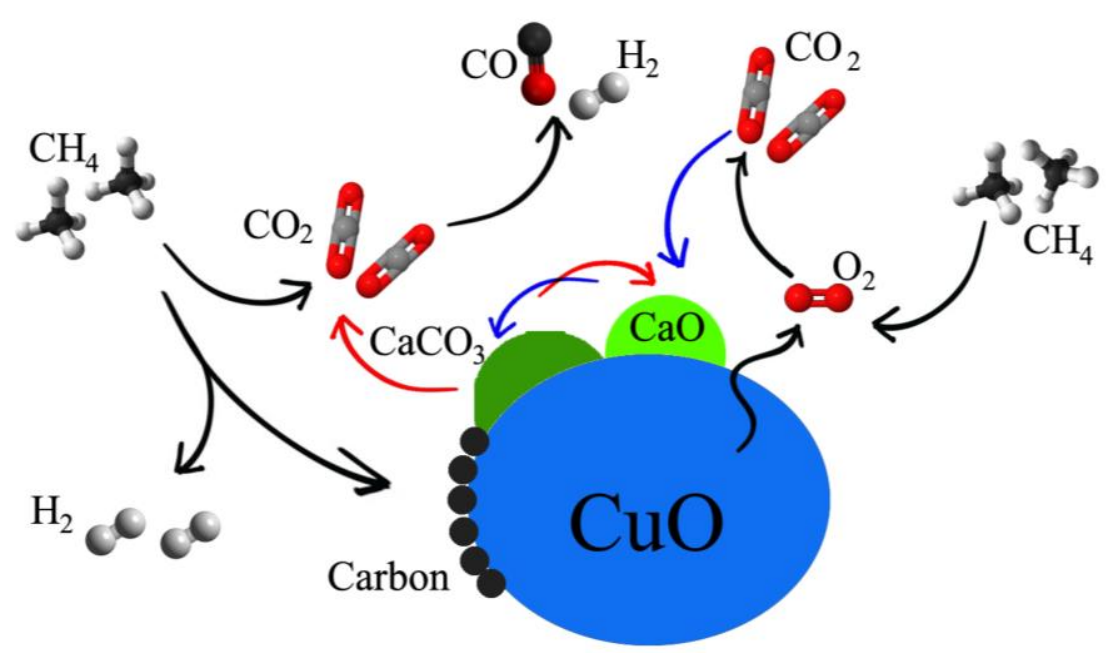

Figure. 10 Scheme schematic of the contributing reactions in the $\mathrm{CH}_{4} /$ oxygen carrier system

\subsection{Conclusions}

In this study, copper oxides were doped with calcium (1,2 or $4 \mathrm{wt} \%)$ to improve reactivity and enhance surface controlled reactions. Combined results from XRD and XPS illustrate that the $\mathrm{CaO}$ is dispersed on $\mathrm{CuO}$ surface. $\mathrm{CaO}-\mathrm{CuO}$ oxygen carriers present three reductive active sites corresponding to $\mathrm{CuO}$ reduction, $\mathrm{CaO}$ reduction and impurity $\mathrm{CaCO}_{3}$ decomposition in $5 \% \mathrm{H}_{2}$ TPR process. It was claimed that doping $\mathrm{Ca}$ improves the $\mathrm{CuO}$ oxygen uncoupling characteristics. Ca surface-doping increases the lattice oxygen transfer and surface $\mathrm{O}_{2}$ formation rate under CLOU conditions. Additionally, reduction pathway for $\mathrm{CuO}$ from a sequential $\left(\mathrm{CuO} \rightarrow \mathrm{Cu}_{2} \mathrm{O} \rightarrow \mathrm{Cu}\right)$ to a direct transition $(\mathrm{CuO} \rightarrow \mathrm{Cu})$ is verified through OCs decomposition and in situ Raman analysis. When char reacts as solid fuel in the CLC process, more $\mathrm{CO}_{2}$ is generated at a faster rate with 
CaO-doped $\mathrm{CuO}$ especially with $2 \mathrm{wt} \%$ loading content. In contrast, when methane was used as gaseous fuel in the CLC process, the calcium dopant not only accelerated the reaction rate, but also induced the methane reforming reaction by reacting with released $\mathrm{CO}_{2}$, that was initially bound in the form of $\mathrm{CaCO}_{3}$, to promote the formation of $\mathrm{CO}$ and $\mathrm{H}_{2}$. 


\section{Reference}

[1] X. Zhao, H. Zhou, V.S. Sikarwar, M. Zhao, A.-H.A. Park, P.S. Fennell, L. Shen, L.-S. Fan, Biomass-based chemical looping technologies: the good, the bad and the future, Energy \& Environmental Science, 10 (2017) 1885-1910.

[2] Q. Yi, W. Li, J. Feng, K. Xie, Carbon cycle in advanced coal chemical engineering, Chemical Society Reviews, 44 (2015) 5409-5445.

[3] A. Goeppert, M. Czaun, J.-P. Jones, G.K. Surya Prakash, G.A. Olah, Recycling of carbon dioxide to methanol and derived products - closing the loop, Chemical Society Reviews, 43 (2014) 7995-8048.

[4] R. Siriwardane, J. Riley, S. Bayham, D. Straub, H. Tian, J. Weber, G. Richards, 50-kWth methane/air chemical looping combustion tests with commercially prepared $\mathrm{CuO}-\mathrm{Fe}_{2} \mathrm{O}_{3}$-alumina oxygen carrier with two different techniques, Applied Energy, 213 (2018) 92-99.

[5] K. Wang, X. Tian, H. Zhao, Sulfur behavior in chemical-looping combustion using a copper ore oxygen carrier, Applied Energy, 166 (2016) 84-95.

[6] A. Lyngfelt, Chemical-looping combustion of solid fuels - Status of development, Applied Energy, 113 (2014) 1869-1873.

[7] M. Arjmand, H. Leion, T. Mattisson, A. Lyngfelt, Investigation of different manganese ores as oxygen carriers in chemical-looping combustion (CLC) for solid fuels, Applied Energy, 113 (2014) 1883-1894.

[8] L. Chen, J. Bao, L. Kong, M. Combs, H.S. Nikolic, Z. Fan, K. Liu, The direct solid-solid reaction between coal char and iron-based oxygen carrier and its contribution to solid-fueled chemical looping combustion, Applied Energy, 184 (2016) 9-18.

[9] L. Chen, J. Bao, L. Kong, M. Combs, H.S. Nikolic, Z. Fan, K. Liu, Activation of ilmenite as an oxygen carrier for solid-fueled chemical looping combustion, Applied Energy, 197 (2017) 4051.

[10] W. Yang, H. Zhao, J. Ma, D. Mei, C. Zheng, Copper-decorated hematite as an oxygen carrier for in situ gasification chemical looping combustion of coal, Energy \& Fuels, 28 (2014) 39703981.

[11] T. Song, T. Shen, L. Shen, J. Xiao, H. Gu, S. Zhang, Evaluation of hematite oxygen carrier in chemical-looping combustion of coal, Fuel, 104 (2013) 244-252.

[12] M.R. Quddus, M.M. Hossain, H.I. de Lasa, Ni based oxygen carrier over $\gamma-\mathrm{Al}_{2} \mathrm{O}_{3}$ for chemical looping combustion: Effect of preparation method on metal support interaction, Catalysis today, 210 (2013) 124-134.

[13] R. Siriwardane, H. Tian, G. Richards, T. Simonyi, J. Poston, Chemical-Looping Combustion of Coal with Metal Oxide Oxygen Carriers, Energy \& Fuels, 23 (2009) 3885-3892.

[14] Y. Cao, B. Casenas, W.-P. Pan, Investigation of chemical looping combustion by solid fuels. 2. Redox reaction kinetics and product characterization with coal, biomass, and solid waste as solid fuels and $\mathrm{CuO}$ as an oxygen carrier, Energy \& Fuels, 20 (2006) 1845-1854. 
[15] Y. Zhang, H. Zhao, L. Guo, C. Zheng, Decomposition mechanisms of Cu-based oxygen carriers for chemical looping with oxygen uncoupling based on density functional theory calculations, Combustion and Flame, 162 (2015) 1265-1274.

[16] L. Qin, Z. Cheng, M. Guo, M. Xu, J.A. Fan, L.-S. Fan, Impact of 1\% lanthanum dopant on carbonaceous fuel redox reactions with an iron-based oxygen carrier in chemical looping processes, ACS Energy Letters, 2 (2016) 70-74.

[17] V. Manovic, E.J. Anthony, Integration of calcium and chemical looping combustion using composite $\mathrm{CaO} / \mathrm{CuO}$-based materials, Environmental science \& technology, 45 (2011) 1075010756.

[18] Y. Zheng, K. Li, H. Wang, D. Tian, Y. Wang, X. Zhu, Y. Wei, M. Zheng, Y. Luo, Designed oxygen carriers from macroporous $\mathrm{LaFeO}_{3}$ supported $\mathrm{CeO}_{2}$ for chemical-looping reforming of methane, Applied Catalysis B: Environmental, 202 (2017) 51-63.

[19] N. Galinsky, A. Mishra, J. Zhang, F. Li, $\mathrm{Ca}_{1-x} \mathrm{~A}_{x} \mathrm{MnO}_{3}(\mathrm{~A}=\mathrm{Sr}$ and $\mathrm{Ba})$ perovskite based oxygen carriers for chemical looping with oxygen uncoupling (CLOU), Applied energy, 157 (2015) 358-367.

[20] X. Cheng, K. Li, Y. Wei, X. Zhu, D. Tian, Modification of $\mathrm{KNO}_{3}$ on the reducibility and reactivity of $\mathrm{Fe}_{2} \mathrm{O}_{3}$ - based oxygen carriers for chemical - looping combustion of methane, The Canadian Journal of Chemical Engineering, 95 (2017) 1569-1578.

[21] L. Duan, D. Godino, V. Manovic, F. Montagnaro, E.J. Anthony, Cyclic oxygen release characteristics of bifunctional copper oxide/calcium oxide composites, Energy Technology, 4 (2016) 1171-1178.

[22] T. Mattisson, A. Lyngfelt, H. Leion, Chemical-looping with oxygen uncoupling for combustion of solid fuels, International Journal of Greenhouse Gas Control, 3 (2009) 11-19.

[23] L. Shen, J. Wu, J. Xiao, Q. Song, R. Xiao, Chemical-Looping Combustion of Biomass in a 10 kWth Reactor with Iron Oxide As an Oxygen Carrier, Energy \& Fuels, 23 (2009) 2498-2505.

[24] R. Siriwardane, H. Tian, D. Miller, G. Richards, T. Simonyi, J. Poston, Evaluation of reaction mechanism of coal-metal oxide interactions in chemical-looping combustion, Combustion and flame, 157 (2010) 2198-2208.

[25] J. Adanez, A. Abad, F. Garcia-Labiano, P. Gayan, L.F. de Diego, Progress in ChemicalLooping Combustion and Reforming technologies, Progress in Energy and Combustion Science, 38 (2012) 215-282.

[26] A. Lyngfelt, C. Linderholm, Chemical-Looping Combustion of Solid Fuels - Status and Recent Progress, Energy Procedia, 114 (2017) 371-386.

[27] E.J. Anthony, Solid Looping Cycles: A New Technology for Coal Conversion, Industrial \& Engineering Chemistry Research, 47 (2008) 1747-1754.

[28] H. Gu, L. Shen, J. Xiao, S. Zhang, T. Song, Chemical Looping Combustion of Biomass/Coal with Natural Iron Ore as Oxygen Carrier in a Continuous Reactor, Energy \& Fuels, 25 (2011) 446455. 
[29] T. Mendiara, A. Abad, L.F. de Diego, F. García-Labiano, P. Gayán, J. Adánez, Biomass combustion in a CLC system using an iron ore as an oxygen carrier, International Journal of Greenhouse Gas Control, 19 (2013) 322-330.

[30] NIST X-ray Photoelectron Spectroscopy (XPS) Database, in, https://srdata.nist.gov/xps/, 2018.

[31] S. Xie, E. Iglesia, A.T. Bell, Effects of temperature on the Raman spectra and dispersed oxides, The Journal of Physical Chemistry B, 105 (2001) 5144-5152.

[32] Z. Wu, P.C. Stair, S. Rugmini, S.D. Jackson, Raman spectroscopic study of $\mathrm{V} / \theta-\mathrm{Al}_{2} \mathrm{O}_{3}$ catalysts: quantification of surface vanadia species and their structure reduced by hydrogen, The Journal of Physical Chemistry C, 111 (2007) 16460-16469.

[33] Z. Wu, M. Li, J. Howe, H.M. Meyer III, S.H. Overbury, Probing defect sites on $\mathrm{CeO}_{2}$ nanocrystals with well-defined surface planes by Raman spectroscopy and $\mathrm{O}_{2}$ adsorption, Langmuir, 26 (2010) 16595-16606.

[34] J. Riley, R. Siriwardane, H. Tian, W. Benincosa, J. Poston, Kinetic analysis of the interactions between calcium ferrite and coal char for chemical looping gasification applications: Identifying reduction routes and modes of oxygen transfer, Applied energy, 201 (2017) 94-110.

[35] R. Siriwardane, J. Riley, H. Tian, G. Richards, Chemical looping coal gasification with calcium ferrite and barium ferrite via solid-solid reactions, Applied energy, 165 (2016) 952-966.

[36] J.A. Rodriguez, J.Y. Kim, J.C. Hanson, M. Pérez, A.I. Frenkel, Reduction of $\mathrm{CuO}_{\text {in } \mathrm{H}_{2} \text { : in }}$ situ time-resolved XRD studies, Catalysis Letters, 85 (2003) 247-254.

[37] S. Sivasangar, M. Mastuli, A. Islam, Y. Taufiq-Yap, Screening of modified CaO-based catalysts with a series of dopants for the supercritical water gasification of empty palm fruit bunches to produce hydrogen, RSC Advances, 5 (2015) 36798-36808.

[38] M.-F. Luo, Y.-J. Zhong, X.-X. Yuan, X.-M. Zheng, TPR and TPD studies of $\mathrm{CuOCeO}_{2}$ catalysts for low temperature CO oxidation, Applied Catalysis A: General, 162 (1997) 121-131.

[39] T. Andrushkevich, V. Kaichev, Y.A. Chesalov, A. Saraev, V. Buktiyarov, Selective oxidation of ethanol over vanadia-based catalysts: The influence of support material and reaction mechanism, Catalysis Today, 279 (2017) 95-106.

[40] L. Debbichi, M. Marco de Lucas, J. Pierson, P. Kruger, Vibrational properties of CuO and $\mathrm{Cu}_{4} \mathrm{O}_{3}$ from first-principles calculations, and Raman and infrared spectroscopy, The Journal of Physical Chemistry C, 116 (2012) 10232-10237.

[41] Z. Wu, S. Dai, S.H. Overbury, Multiwavelength Raman spectroscopic study of silicasupported vanadium oxide catalysts, The Journal of Physical Chemistry C, 114 (2009) 412-422.

[42] Q. Imtiaz, P.M. Abdala, A.M. Kierzkowska, W. Van Beek, S. Schweiger, J.L. Rupp, C.R. Müller, $\mathrm{Na}^{+}$doping induced changes in the reduction and charge transport characteristics of $\mathrm{Al}_{2} \mathrm{O}_{3}-$ stabilized, $\mathrm{CuO}$-based materials for $\mathrm{CO}_{2}$ capture, Physical Chemistry Chemical Physics, 18 (2016) 12278-12288.

[43] B. Tian, Y. Qiao, L. Bai, W. Feng, Y. Jiang, Y. Tian, Pyrolysis behavior and kinetics of the trapped small molecular phase in a lignite, Energy Conversion and Management, 140 (2017) 109120. 
[44] X.-q. Xu, Y.-g. Wang, Z.-d. Chen, X.-j. Chen, H.-y. Zhang, L. Bai, S. Zhang, Variations in char structure and reactivity due to the pyrolysis and in-situ gasification using Shengli brown coal, Journal of Analytical and Applied Pyrolysis, 115 (2015) 233-241.

[45] R. Siriwardane, W. Benincosa, J. Riley, H. Tian, G. Richards, Investigation of reactions in a fluidized bed reactor during chemical looping combustion of coal/steam with copper oxide-iron oxide-alumina oxygen carrier, Applied energy, 183 (2016) 1550-1564.

[46] M.A. Saucedo, J.Y. Lim, J.S. Dennis, S.A. Scott, $\mathrm{CO}_{2}$-gasification of a lignite coal in the presence of an iron-based oxygen carrier for chemical-looping combustion, Fuel, 127 (2014) 186201.

[47] Z. Sun, B. Xu, A.H. Rony, S. Toan, S. Chen, K.A. Gasem, H. Adidharma, M. Fan, W. Xiang, Thermogravimetric and kinetics investigation of pine wood pyrolysis catalyzed with alkali-treated CaO/ZSM-5, Energy Conversion and Management, 146 (2017) 182-194.

[48] Z. Zhou, L. Han, O. Nordness, G.M. Bollas, Continuous regime of chemical-looping combustion (CLC) and chemical-looping with oxygen uncoupling (CLOU) reactivity of $\mathrm{CuO}$ oxygen carriers, Applied Catalysis B: Environmental, 166 (2015) 132-144.

[49] H. Wang, R.T.K. Baker, Decomposition of methane over a $\mathrm{Ni}-\mathrm{Cu}-\mathrm{MgO}$ catalyst to produce hydrogen and carbon nanofibers, The Journal of Physical Chemistry B, 108 (2004) 20273-20277.

[50] U. Ashik, W.W. Daud, H.F. Abbas, Production of greenhouse gas free hydrogen by thermocatalytic decomposition of methane-A review, Renewable and Sustainable Energy Reviews, 44 (2015) 221-256.

[51] H.F. Abbas, W.W. Daud, Hydrogen production by methane decomposition: a review, International journal of hydrogen energy, 35 (2010) 1160-1190.

[52] A. Cunha, J. Órfão, J. Figueiredo, Methane decomposition on Ni-Cu alloyed Raney-type catalysts, International Journal of hydrogen energy, 34 (2009) 4763-4772.

[53] M.M. Hossain, H.I. de Lasa, Chemical-looping combustion (CLC) for inherent $\mathrm{CO}_{2}$ separations - a review, Chemical Engineering Science, 63 (2008) 4433-4451.

[54] J. Wang, L. Jin, Y. Zhou, Y. Li, H. Hu, Effect of $\mathrm{Ca}\left(\mathrm{NO}_{3}\right)_{2}$ addition in coal on properties of activated carbon for methane decomposition to hydrogen, Fuel processing technology, 176 (2018) 85-90.

[55] Z. Alipour, M. Rezaei, F. Meshkani, Effect of alkaline earth promoters ( $\mathrm{MgO}, \mathrm{CaO}$, and $\mathrm{BaO})$ on the activity and coke formation of $\mathrm{Ni}$ catalysts supported on nanocrystalline $\mathrm{Al}_{2} \mathrm{O}_{3}$ in dry reforming of methane, Journal of Industrial and Engineering Chemistry, 20 (2014) 2858-2863.

[56] Z. Hou, O. Yokota, T. Tanaka, T. Yashima, Characterization of Ca-promoted Ni/ $\alpha-\mathrm{Al}_{2} \mathrm{O}_{3}$ catalyst for $\mathrm{CH}_{4}$ reforming with $\mathrm{CO}_{2}$, Applied Catalysis A: General, 253 (2003) 381-387. 


\title{
Chapter 3. Impact of Surface Composition of $\mathrm{SrTiO}_{3}$ Catalysts for Oxidative Coupling of Methane (OCM)
}

\begin{abstract}
Due to the increasing production of shale gas (mostly methane), various schemes for direct catalytic methane conversion have regained attention from the research community. One of the routes for upgrading methane is the oxidative coupling of methane (OCM) to $\mathrm{C}_{2}$ hydrocarbons $\left(\mathrm{C}_{2} \mathrm{H}_{6}\right.$ and $\left.\mathrm{C}_{2} \mathrm{H}_{4}\right)$. Perovskite-type oxide catalysts have shown promising activity and selectivity toward $\mathrm{C}_{2}$ hydrocarbons. The present work investigates the effect of surface reconstruction (which leads to different surface compositions) of perovskites on the OCM by using $\mathrm{SrTiO}_{3}$ (STO) as a model catalyst. Different surface densities of Sr, between 25 and $96 \%$ according to low energy ion scattering studies (LEIS), were attained via various treatments of STO. UV-Raman and LEIS analysis results are in good agreement on the surface and subsurface composition of the reconstructed STO samples. Temperature programmed desorption (TPD) of ammonia and carbon dioxide was conducted to measure the concentration of acid and base sites, respectively. From hydrogen temperature-programmed reduction (TPR) results, only surface $\mathrm{Ti}^{4+}$ reduction occurs and $\mathrm{H}_{2}$ consumption of the STO samples was found to be the same, which allows correlating their catalytic performances with surface acid-base properties. Steady-state catalytic tests were performed at $600-800{ }^{\circ} \mathrm{C}$, and it was found that the enrichment of surface $\mathrm{Sr}$ enhances $\mathrm{CH}_{4}$ conversion, $\mathrm{C}_{2}$ selectivity and the ratio $\mathrm{C}_{2} \mathrm{H}_{4} / \mathrm{C}_{2} \mathrm{H}_{6}$ up to a $\mathrm{Sr} /(\mathrm{Sr}+\mathrm{Ti})$ of 0.66 at the surface and then levels off. Compared to the surface concentration of $\mathrm{Sr}$, the relative concentration of basic sites, base/(base+acid) ratio, are observed as a better descriptor for the catalytic performance of the various STO samples. Extensive kinetic analysis for OCM was attempted with various rate
\end{abstract}


expressions reported in the literature. However, none of those expressions could accurately describe the performance of all the STO catalysts under this study and thus further study is necessary. This work shows the clear correlation between surface reconstruction, relative basicity/acidity of the surface and the catalytic performance for OCM over perovskite catalysts. The trends here are similar to those observed for methane combustion over the reconstructed STO in a recent work[1]. Overall, it is suggested that tuning surface reconstruction/composition of perovskites can be an effective approach for controlling methane activation and conversions.

\subsection{Introduction}

Due to the pronounced increase in shale gas (mostly methane) production in recent years, there has been a renewed interest in various schemes for catalytic methane conversion. These schemes can be classified as indirect and direct methods. Indirect conversion of methane to valuable chemicals, e.g. Fischer-Tropsch (FT) synthesis and methanol-to-olefins (MTO), include multiple stages, beginning with syngas production $\left(\mathrm{H}_{2} / \mathrm{CO}\right.$ mixture) from methane. The direct method is defined as those schemes that convert methane to hydrocarbons without undergoing the capital cost of the intermediate syngas step. Therefore, direct methods are expected to be more economical and environmentally friendly than indirect methods. One of the attractive routes for direct upgrading of methane is the oxidative coupling of methane (OCM) to $\mathrm{C}_{2}$ hydrocarbons $\left(\mathrm{C}_{2} \mathrm{H}_{6}\right.$ and $\left.\mathrm{C}_{2} \mathrm{H}_{4}\right)$, which are valuable intermediates for many chemical industries [2]. However, some difficulties for the commercialization of OCM have been recognized, such as (1) overcoming significant heat emission at high reaction temperature $\left(700-1000{ }^{\circ} \mathrm{C}\right)$; and (2) finding active catalysts with high selectivity to meet the requirement for $30 \% \mathrm{C}_{2}$ yield [3]. Thus, there is a crucial need for efficient catalysts with high $\mathrm{C}_{2}$ selectivity at significant levels of methane conversion, and long-term thermal stability. 
It is widely accepted that ethylene formation through the OCM follows three steps[4]: (1) homolytic cleavage of methane $\mathrm{C}-\mathrm{H}$ bond occurs on oxygen species of the catalyst surface to generate the methyl radicals; (2) two methyl radicals homogeneously couple in the gas phase to form ethane; (3) ethane is dehydrogenated to ethylene. The main function of the OCM catalyst is to generate methyl radicals [5] and simultaneously to circumvent the overoxidation of radicals at the surface [6]. As for the former function, the surface oxygen ion-radicals $\left(\mathrm{O}^{-}\right.$and $\left.\mathrm{O}_{2}{ }^{2-}\right)$ as the electron deficient species, are reported to be the active centers for methane activation to produce methyl radicals in the OCM reaction.[7-10] For example, the existence of peroxide-like ions has been observed in the perovskite $\mathrm{BaPbO}_{3}$ and $\mathrm{BaBiO}_{3}$ catalysts, [11] resulting in their good catalytic performance in the OCM reaction. These surface oxygen sites have been accepted as the basic centers.[12] Considering the latter function, the lattice oxygen $\mathrm{O}^{2-}$ is responsible for completed oxidation of methyl radicals to form $\mathrm{CO}$ and $\mathrm{CO}_{2}[7,8,13,14]$. The low mobility of lattice oxygen in the OCM catalyst is desired, aiming to avoid the overoxidation of $\mathrm{CH}_{3}$. Therefore, the low oxygen mobility and the presence of surface oxygen ion-radicals, which are acting as the active sites for the methyl radical generation, are essential properties for the OCM catalysts. Numerous efforts have been made to find a high-performance catalyst since the pioneering work by Keller and Bhasin in 1982 [15]. Simple basic oxides (e.g. $\mathrm{CaO}$ [16], $\mathrm{MgO}$ [17], SrO [18], etc.), and alkali and alkaline metals supported on basic oxides (e.g. $\mathrm{Li} / \mathrm{MgO}$ [19-21], $\mathrm{Na} / \mathrm{MgO}$ and $\mathrm{Na} / \mathrm{CaO}$ [22], etc.) have shown high activity in the OCM reaction. On the other hand, transition metal oxides combined with alkali metals, e.g. $\mathrm{Na}_{2} \mathrm{WO}_{4}-\mathrm{Mn} / \mathrm{SiO}_{2}$ system, are also considered as promising catalysts for the OCM reaching $\mathrm{C}_{2}$ yields as high as $25 \%[23-25]$.

The thermally and chemically stable perovskite-type oxide catalysts[26, 27] are attractive alternatives. Perovskites oxides have a general formula $\mathrm{ABO}_{3}(\mathrm{~A}$ represents a lanthanide, alkali or 
alkaline earth and B represents a transition metal). Numerous studies have found that the perovskite-type oxides are a promising OCM catalyst with high activity and selectivity toward $\mathrm{C}_{2}$ hydrocarbons[28-32]. For instance, Fakhroueian and co-workers[33] reported the $\mathrm{C}^{2+}$ selectivity and ethylene yield of a Na-doped $\mathrm{BaSrTiO}_{3}$ perovskite catalyst to be $51 \%$ and $24 \%$, respectively. The promising catalytic performance of perovskite catalysts is attributed not only to the segregation of oxygen ion-radicals at the surface, but also the creation of electronic defects and oxygen vacancies (achieved by doping cations in the A and B sublattice)[34]. Some studies have been conducted to investigate the effect of active alkali dopants on catalytic behavior of perovskite oxides under the OCM conditions. D.V. Ivanov[34] synthesized Mg- and Al-doped $\mathrm{SrTiO}_{3}$ and $\mathrm{Sr}_{2} \mathrm{TiO}_{4}$, obtaining $\mathrm{C}_{2}$ yields and selectivity up to $25 \%$ and $66 \%$, respectively, under optimal OCM reaction conditions. It was found that "layered" perovskite phases $\mathrm{Sr}_{2-\mathrm{x}} \mathrm{A}_{\mathrm{x}} \mathrm{TiO}_{4}$ or $\mathrm{Sr}_{3-\mathrm{x}} \mathrm{A}_{\mathrm{x}} \mathrm{Ti}_{2} \mathrm{O}_{7}$ $(\mathrm{A}=\mathrm{Mg}, \mathrm{Al})$ are destroyed and $\mathrm{SrO}$ segregated on the catalyst surface, promoting methane activation. However, fundamental understanding of the effects of perovskite surface reconstruction, independent of the dopant used, on catalytic reactivity/selectivity for OCM is yet to be fully attained.

In addition, the effect of surface reconstruction (which leads to different surface compositions) of perovskites has been recently considered to play an important role in various catalytic process, such as oxygen evolution[35-37], $\mathrm{NO}_{\mathrm{x}}$ storage and reduction (NSR)[38], ethanol dehydrogenation[39] etc. Previous work has demonstrated that surface reconstruction is capable of tuning catalytic acid/base properties[39, 40], which are reported to be related to active sites in the OCM reaction[41, 42]. In addition, the effect of surface reconstruction on the rate of methane combustion was investigated by employing a set of $\mathrm{SrTiO}_{3}$ (STO) samples with various surface compositions[1]. Surface Sr concentration is found to be proportional to the rate of 
methane combustion. However, the impact of surface reconstruction on the OCM catalysis has, to the best of our knowledge, not yet been reported.

The goal of the present work is to unveil the effect of the surface reconstruction of perovskites using STO as a model material on the OCM reaction. The composition of surface and subsurface layers of STO samples, which were tuned via post-synthesis-treatments (thermal treatment, chemical etching and incipient wetness impregnation), has been characterized via low energy ion scattering (LEIS) in previous work [1], and UV Raman spectroscopy (in the present work). The density and strength of acid/base sites on the STO samples have been characterized via $\mathrm{NH}_{3} / \mathrm{CO}_{2}$-temperature programmed desorption. Correlations between the surface termination of STO samples, the acid/base sites, and the catalytic performance for the OCM were drawn, providing insights into the structure-performance relationships.

\subsection{Experimental Section}

\subsubsection{Materials}

Strontium titanate (STO) and strontium oxide (SrO) were purchased from Sigma-Aldrich. Titanium oxide in the rutile phase was purchased from Alfa Aesar. Argon, Helium, $10 \% \mathrm{CH}_{4} / \mathrm{Ar}$, $5 \% \mathrm{O}_{2} / \mathrm{He}, 2 \% \mathrm{CO}_{2} / \mathrm{Ar}, 2 \% \mathrm{NH}_{3} / \mathrm{He}$ and $4 \% \mathrm{H}_{2} /$ Ar were all purchased from Airgas.

\subsubsection{Sample Preparation}

Five STO samples with different concentrations of $\mathrm{Sr}$ at the surface $\left(\mathrm{STO}\left(\mathrm{HNO}_{3}\right)\right.$, $\left.\mathrm{Sr} / \mathrm{STO}\left(\mathrm{HNO}_{3}\right)-1, \mathrm{Sr} / \mathrm{STO}\left(\mathrm{HNO}_{3}\right)-2, \mathrm{Sr} / \mathrm{STO}-1, \mathrm{Sr} / \mathrm{STO}-2\right)$ were prepared using chemical etching and incipient wetness impregnation (IWI), as reported in previous publications [1, 39, 40]. Figure 1 is a flowchart for the preparation of these STO samples with surface reconstruction. In brief, to promote the exposure of the Ti-terminated surface, $\mathrm{STO}\left(\mathrm{HNO}_{3}\right)$ was prepared by 
submerging the commercial STO in the $0.2 \mathrm{M}$ aqueous solution of $\mathrm{HNO}_{3}(20 \mathrm{~mL}$ of solution per gram of catalyst), the mixture was vigorously stirred for a few seconds and left still for 1 day at room temperature. The catalyst was then washed with deionized water and centrifuged at least four times at $12000 \mathrm{RPM}$ for $10 \mathrm{~min}$. The separated solid was dried at $60{ }^{\circ} \mathrm{C}$ overnight in a vacuum oven to obtain $\mathrm{STO}\left(\mathrm{HNO}_{3}\right)$. $\mathrm{Sr} / \mathrm{STO}\left(\mathrm{HNO}_{3}\right)-1$ and $\mathrm{Sr} / \mathrm{STO}\left(\mathrm{HNO}_{3}\right)-2$ were prepared from impregnating $\mathrm{Sr}$ on $\mathrm{STO}\left(\mathrm{HNO}_{3}\right)$, to alter the exposure of the Sr-terminated surface after reconstruction. A prescribed amount of $\mathrm{STO}\left(\mathrm{HNO}_{3}\right)$ was mixed with an aqueous solution of $\mathrm{Sr}\left(\mathrm{NO}_{3}\right)_{2}$ in a glass dish to ensure the solid was homogeneously wetted with the solution. The mixture was placed in the drying oven at $110^{\circ} \mathrm{C}$ for approximately $16 \mathrm{~h}$ at $110{ }^{\circ} \mathrm{C}$. To promote the exposure of the Sr-terminated surface after reconstruction, Sr/STO-1 and Sr/STO-2 were prepared with loading Sr at the surface of commercial STO by employing the same abovementioned IWI method. All samples were calcined at $750{ }^{\circ} \mathrm{C}$ for at least $5 \mathrm{~h}$ and then subjected to following analyses and catalytic performance tests.

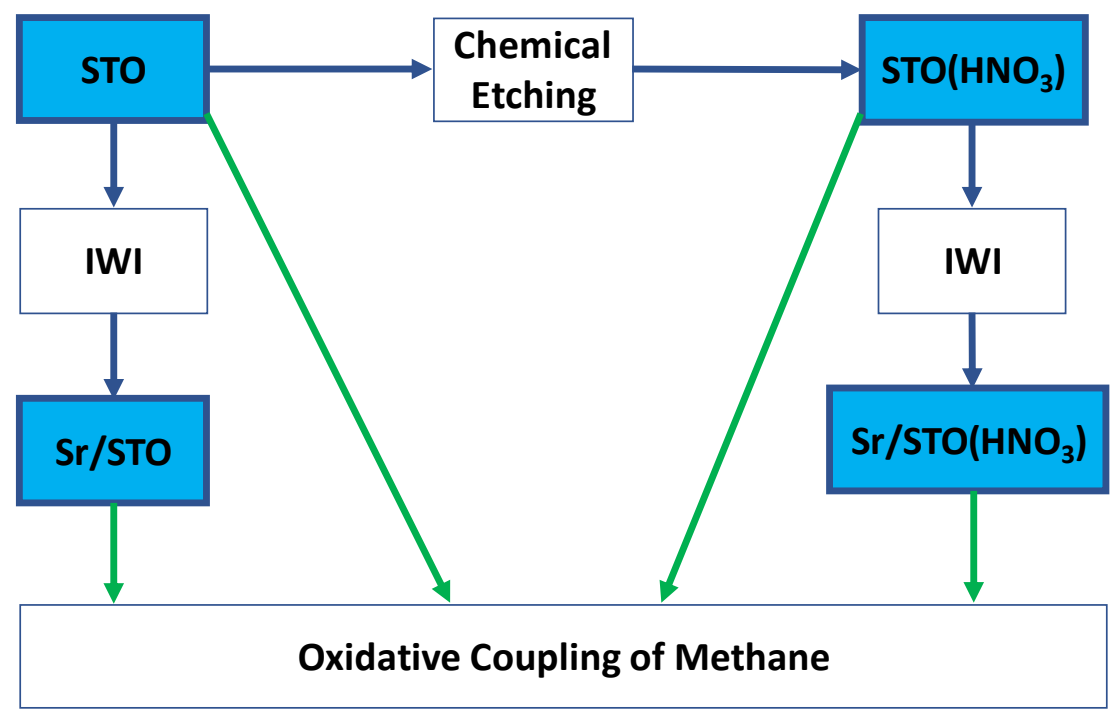

Figure 1. Process Sequences for the preparation of STO catalysts.

In previous study[1], it was found that all prepared samples have similar BrunauerEmmett-Teller (BET) surface area $\left(18.8-22.2 \mathrm{~m}^{2} / \mathrm{g}\right)$. In addition, all samples presented the same 
STO perovskite crystal structure without detectable additional phases via XRD. For the reference sample, the BET surface area for $\mathrm{SrO} / \mathrm{TiO}_{2}$ is $2.8 \mathrm{~m}^{2} / \mathrm{g}$, and the $\mathrm{SrO}$ content on this sample is 3.55 $\mathrm{mg} /\left(\mathrm{m}^{2}\right.$,catalyst $)$. The particle size for $\mathrm{Sr} / \mathrm{TiO}_{2}$ is c.a.40nm, calculated with XRD data using the Scherrer equation.

\subsubsection{Low Energy Ion Scattering (LEIS) Analysis}

LEIS measurements were performed at Lehigh University in an IONTOF Qtac100 spectrometer (ION-TOF GmbH, Münster, Germany) to determine the composition of the outmost atomic layer. Charge neutralization was invoked during spectra acquisition and sputtering. More details of LEIS measurement can be found in previous work[1]. Sr-composition, namely $\mathrm{Sr} /(\mathrm{Sr}+\mathrm{Ti})$, reported in this work is calculated by assuming that the $\mathrm{Sr}$-composition is $50 \%$ at 5 $\mathrm{nm}$ depth for a commercial STO sample without any pretreatment.

\subsubsection{Raman Spectroscopy}

Raman spectroscopy was performed on a multiwavelength Raman system[43] at subambient temperature $\left(-75^{\circ} \mathrm{C}\right)$ since the STO Raman signal intensity is enhanced at low temperature[44]. Raman spectral collection was performed with 325 and $442 \mathrm{~nm}$ laser excitations, which are ultraviolet- and visible-laser excitations, respectively. Raman scattering was collected via a customized ellipsoidal mirror and directed by a fiber optic bundle to the spectrograph stage of a triple Raman spectrometer (Princeton Instruments Acton Trivista 555). Edge filters (Semrock) were used in front of the UV-vis fiber optic bundle (Princeton Instruments) to block the laser irradiation. The 325 ( $<5 \mathrm{~mW}$ at sample) and $442 \mathrm{~nm}(<10 \mathrm{~mW}$ at sample) excitations are from a HeCd laser (Melles Griot). A UV-enhanced liquid $\mathrm{N}_{2}$-cooled CCD detector (Princeton Instruments) was employed for signal detection. The Raman reactor (Linkam THMS 600) sits on 
an XY stage (Prior Scientific, OptiScan XY system). Prior to Raman characterization, all STO samples were pretreated in air in the muffle oven at $850{ }^{\circ} \mathrm{C}$ for $5 \mathrm{~h}$. The samples were then transferred to the Raman reactor and cooled down to the measurement temperature under a constant Ar flow (30mL/min).

\subsubsection{Temperature Programmed Desorption of Ammonia ( $\left.\mathrm{NH}_{3}-\mathrm{TPD}\right)$ and Carbon Dioxide $\left(\mathrm{CO}_{2}-\mathrm{TPD}\right)$}

The temperature programmed desorption of ammonia ( $\left.\mathrm{NH}_{3}-\mathrm{TPD}\right)$ and carbon dioxide $\left(\mathrm{CO}_{2}-\mathrm{TPD}\right)$ was conducted to evaluate the comparative strength and quantify the concentration of surface acid and base sites of the samples under study. An Altamira Instruments system (AMI300) coupled with an on-line mass spectrometer (Omnistar GSD-301, Pfeiffer Vacuum) was used to perform the TPD measurements. Prior to a TPD measurement, $20 \mathrm{mg}$ of a STO sample was loaded into a U-tube quartz reactor and pretreated at $850{ }^{\circ} \mathrm{C}$ for $5 \mathrm{~h}$ under $50 \mathrm{~mL} / \mathrm{min}$ of $5 \% \mathrm{O}_{2} / \mathrm{He}$. The temperature was increased from 25 to $850{ }^{\circ} \mathrm{C}$ at a heating rate of $20{ }^{\circ} \mathrm{C} / \mathrm{min}$. After pretreatment, the sample was cooled to $150{ }^{\circ} \mathrm{C}$ (for ammonia adsorption) or $30{ }^{\circ} \mathrm{C}$ (for carbon dioxide adsorption) under helium. Prior to desorption, the catalyst was exposed to $30 \mathrm{~mL} / \mathrm{min}$ of $2 \% \mathrm{NH}_{3} / \mathrm{He}$ for $2 \mathrm{~h}$. Then, the sample was purged with $30 \mathrm{~mL} / \mathrm{min}$ of He for $2 \mathrm{~h}$ to remove physisorbed $\mathrm{NH}_{3}$. Afterwards, the temperature of the sample was ramped from 150 to $800{ }^{\circ} \mathrm{C}$ at a rate of $5{ }^{\circ} \mathrm{C} / \mathrm{min}$, and the $\mathrm{NH}_{3}$-TPD profile was recorded using the mass spectrometer. $\mathrm{CO}_{2}-\mathrm{TPD}$ profiles were collected using the same procedure as the $\mathrm{NH}_{3}$-TPD. $2 \% \mathrm{CO}_{2} / \mathrm{Ar}$ was employed to perform the $\mathrm{CO}_{2}$ adsorption/desorption cycle to evaluate the density of the basic sites for the STO catalysts. 


\subsubsection{Temperature Programmed Reduction with Hydrogen $\left(\mathrm{H}_{2}-\mathrm{TPR}\right)$}

The reducibility of the STO samples was evaluated via temperature-programmed reduction with hydrogen $\left(\mathrm{H}_{2}-\mathrm{TPR}\right)$. These measurements were done in an Altamira Instruments AMI-300 system, coupled with an online mass spectrometer (Omnistar GSD-301, Pfeiffer). Before the reduction, $20 \mathrm{mg}$ of the STO catalyst were treated at $850{ }^{\circ} \mathrm{C}$ for $5 \mathrm{~h}$ under $50 \mathrm{~mL} / \mathrm{min}$ of $5 \%$ $\mathrm{O}_{2} / \mathrm{He}$. Then, the catalyst temperature was cooled to $50{ }^{\circ} \mathrm{C}$ under He. Once the temperature of the catalyst bed reached $50{ }^{\circ} \mathrm{C}$, the flow through the bed was switched to $30 \mathrm{~mL} / \mathrm{min}$ of $4 \% \mathrm{H}_{2} / \mathrm{Ar}$. After exposure to $4 \% \mathrm{H}_{2} / \mathrm{Ar}$ for $2 \mathrm{~h}$, the temperature of the catalyst sample was ramped from 50 ${ }^{\circ} \mathrm{C}$ to $800{ }^{\circ} \mathrm{C}$ at a rate of $5{ }^{\circ} \mathrm{C} / \mathrm{min}$, and the $\mathrm{H}_{2}$-TPR profile was recorded using the online mass spectrometer.

\subsubsection{Steady-State Kinetic Measurement}

The OCM reaction was performed in the AMI-300 system. $5 \mathrm{mg}$ STO or SrO sample (particle sizes both are $177-250 \mu \mathrm{m}$ ) was diluted in quartz sand $(177-250 \mu \mathrm{m})$ to minimize channeling and local temperature differences. The quartz-to-catalyst mass ratio was approximately 60:1. The catalyst bed was placed inside a quartz u-tube $(10 \mathrm{~mm}$ inner diameter) and held in place by quartz wool at both ends of the bed. A K-type thermocouple was placed inside the reactor to monitor the temperature of the catalyst bed. Before kinetic measurements, each sample was pretreated under $50 \mathrm{~mL} / \mathrm{min}$ of $5 \% \mathrm{O}_{2} / \mathrm{He}$ at $850{ }^{\circ} \mathrm{C}$ for $5 \mathrm{~h}$. Steady-state conversions and selectivity do not change during at least $2 \mathrm{~h}$ time-on-stream, suggesting that the surface does not reconstruct further after the initial activation in $\mathrm{O}_{2}$ at high temperature. The feed used to perform the OCM reaction consisted of $25 \mathrm{~mL} / \mathrm{min}$ of $10 \% \mathrm{CH}_{4} / \mathrm{Ar}, 10 \mathrm{~mL} / \mathrm{min}$ of $5 \% \mathrm{O}_{2} / \mathrm{He}$, and 15 $\mathrm{mL} / \mathrm{min}$ of $\mathrm{He}$ as balance gas. Thus, the methane to oxygen ratio was 5 . Products were analyzed by an on-line gas chromatograph (Agilent Technologies, 6890N) with HayeSep-N and Molecular 
Sieve 13X columns using both thermal conductivity and flame ionization detectors. The GC response factor was calibrated for all compounds. All lines were heated to $120^{\circ} \mathrm{C}$ to avoid water condensation. All the kinetic data were measured under differential conditions (methane conversion less than $6 \%$ ) at temperatures of $650{ }^{\circ} \mathrm{C}$. A blank test using the same U-tube reactor without catalyst was carried out and showed negligible methane conversion and $\mathrm{C}_{2}$ yield $\left(\mathrm{CH}_{4}\right.$ conversion of $0.39 \%, 0.94 \%, 2.3 \%$, and $\mathrm{C}_{2}$ yield of $0 \%, 0 \%, 0.04 \%$ at $600,700,800{ }^{\circ} \mathrm{C}$, respectively). All data points are averaged values of 3 to 5 GC-runs after the reaction reached steady state. The error for each data point is less than 5\%, and the averaged values are presented below. The $\mathrm{CH}_{4}$ conversion (\%), $\mathrm{C}_{2}$ hydrocarbon selectivity (\%), $\mathrm{C}_{2}$ hydrocarbon yield (\%), $\mathrm{CO}_{\mathrm{x}}$ selectivity (\%), $\mathrm{CO}_{\mathrm{x}}$ yield $(\%)$ and ethylene/ethane ratio (mol/mol) were defined as follows:

$$
\begin{aligned}
& \text { Methane conversion }(\%)=\frac{\text { moles of methane reacted }}{\text { moles of methane in feed }} \times 100 \\
& C_{2} \text { selectivity }(\%)=\frac{2(\text { moles of ethane and ethlene formed })}{\text { moles of methane reacted }} \times 100 \\
& \mathrm{C}_{2} \text { yield }(\%)=\text { methane conversion }(\%) \times C_{2} \text { selectivity }(\%) \times \frac{1}{100} \\
& \mathrm{CO}_{x} \text { selectivity }(\%)=\frac{\text { moles of } \text { co or } \mathrm{CO}_{2} \text { formed }}{\text { moles of methane reacted }} \times 100 \\
& \mathrm{CO}_{x} \text { yield }(\%)=\text { methane conversion }(\%) \times C \mathrm{O}_{x} \text { selectivity }(\%) \times \frac{1}{100} \\
& \mathrm{C}_{2} \mathrm{H}_{4} / \mathrm{C}_{2} \mathrm{H}_{6}(\mathrm{~mol} / \mathrm{mol})=\frac{\text { moles of ethylene produced }}{\text { moles of ethane produced }}
\end{aligned}
$$

\subsection{Results and Discussion}

\subsubsection{Surface Composition}

LEIS was used to analyze the composition at the surface of the STO samples since it is considered as a particularly suitable technique to probe the top atomic monolayer of a material 
(escape depth of $\sim 0.3 \mathrm{~nm}$ ) with a sensitivity on the order of 0.1 at.\% [45-47]. Sr-compositions $(\mathrm{Sr} /(\mathrm{Sr}+\mathrm{Ti}))$ of the outermost surface layer of STO samples are presented in Figure 2. The $\mathrm{Sr} /(\mathrm{Sr}+\mathrm{Ti})$ value for the $\mathrm{STO}\left(\mathrm{HNO}_{3}\right)$ sample is 0.25 , indicating the $\mathrm{STO}\left(\mathrm{HNO}_{3}\right)$ surface is enriched with Ti cations. As reported previously, chemical etching with $\mathrm{HNO}_{3}$ exposed Ti cations at the surface (as single and double layers)[40]. Although Sr-doping increases the surface composition of $\mathrm{Sr}$ for $\mathrm{Sr} / \mathrm{STO}\left(\mathrm{HNO}_{3}\right)-1$ and $\mathrm{Sr} / \mathrm{STO}\left(\mathrm{HNO}_{3}\right)-2$ samples (whose $\mathrm{Sr} /(\mathrm{Sr}+\mathrm{Ti})$ values are larger than that of $\mathrm{STO}\left(\mathrm{HNO}_{3}\right)$ sample), surface Ti enrichment is also observed for $\mathrm{Sr} / \mathrm{STO}\left(\mathrm{HNO}_{3}\right)-1$ sample since its $\mathrm{Sr} /(\mathrm{Sr}+\mathrm{Ti})$ value is 0.28 , namely $72 \%$ of its surface is covered by Ti cations. For the commercial STO sample, $\mathrm{Sr} /(\mathrm{Sr}+\mathrm{Ti})$ at the surface is 0.66 , i.e. the $\mathrm{Sr} / \mathrm{Ti}$ ratio is about 2 . The impregnation of $\mathrm{Sr}$ significantly increases the $\mathrm{Sr}$ termination on the top layer of $\mathrm{Sr} / \mathrm{STO}-1$ and $\mathrm{Sr} / \mathrm{STO}-2$ samples, whose $\mathrm{Sr} /(\mathrm{Sr}+\mathrm{Ti})$ are 0.92 and 0.96 , respectively. To sum up, chemical etching and IWI methods effectively tuned the surface compositions of the STO perovskite. The concentration of surface $\mathrm{Sr}$ increases in the order: $\mathrm{STO}\left(\mathrm{HNO}_{3}\right)<\mathrm{Sr} / \mathrm{STO}\left(\mathrm{HNO}_{3}\right)-1<$ $\mathrm{Sr} / \mathrm{STO}\left(\mathrm{HNO}_{3}\right)-2<\mathrm{STO}<\mathrm{Sr} / \mathrm{STO}-1<\mathrm{Sr} / \mathrm{STO}-2$. The ratio of base/acid sites (quantified by $\mathrm{NH}_{3}-$ TPD and $\mathrm{CO}_{2}$-TPD to be shown in a later section) is also tuned by the surface compositions of the samples (see Figure 2). This base/acid ratio correlates with the surface $\mathrm{Sr}$ concentration, and the details about this relationship will be discussed in Section 3.3.3. 


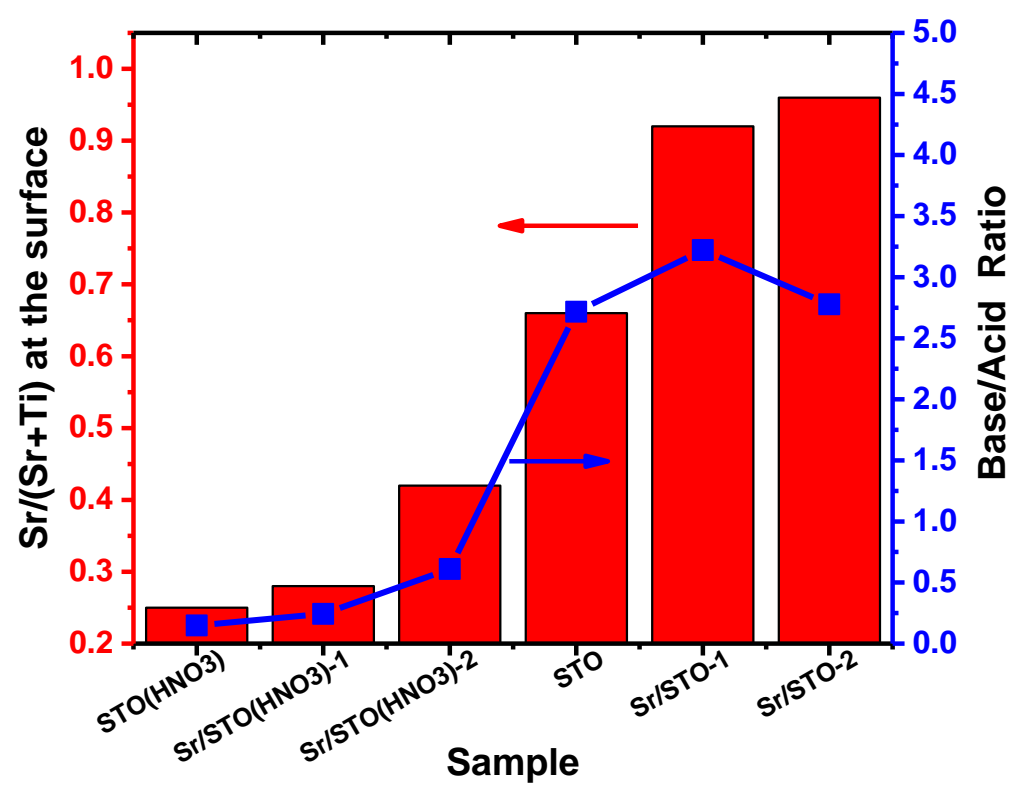

Figure 2. Sr-compositions $(\mathrm{Sr} /(\mathrm{Sr}+\mathrm{Ti}))$ of outermost surface layer and ratio of base/acid site of STO samples.

The evidence for surface reconstruction of the STO perovskites upon high temperature treatment was collected via LEIS. Significant differences in the segregation of cations at the surface were observed before and after the in situ $\mathrm{O}_{2}$ treatment (the treatment in the $\mathrm{O}_{2}$ atmosphere at high temperatures attempts to reproduce approximately the OCM reaction conditions, given the limitations of the technique). The compositions before and after reconstruction for commercial STO and $\mathrm{STO}\left(\mathrm{HNO}_{3}\right)$ samples are summarized in Table 1.

Table 1. Surface composition from LEIS analysis with in situ heat treatment in $\mathrm{O}_{2}$ atmosphere at $500^{\circ} \mathrm{C}$ for $30 \mathrm{~min}$.

\begin{tabular}{ccc}
\hline Catalyst & \multicolumn{2}{c}{$\mathbf{S r} / \mathbf{( S r}+\mathbf{T i})$ at the surface } \\
\cline { 2 - 3 } & \multicolumn{3}{c}{ Before Treatment } & After Treatment \\
\hline STO & 0.35 & 0.66 \\
$\mathrm{STO}\left(\mathrm{HNO}_{3}\right)$ & 0.20 & 0.25 \\
\hline
\end{tabular}

\subsubsection{Raman Spectra as Function of Laser Excitations and Surface Composition}

The commercial STO sample was selected for the comparison of the Raman spectra from UV- and visible- laser excitations. Figure 3(a) shows the Raman spectra of commercial STO 
excited at 325 (UV-Raman spectrum) and $442 \mathrm{~nm}$ (visible Raman spectrum). All the peaks assignments are listed in Table 2. Excitation by the two lasers at different wavelengths gives Raman spectra with similar peak positions but different relative intensity. The relative intensities of the peaks at $795,1038,1292$ and $1618 \mathrm{~cm}^{-1}$ to that of the peak at $308 \mathrm{~cm}^{-1}$ are greatly enhanced with the 325-nm excitation, due to the resonance enhancement effect [48, 49].
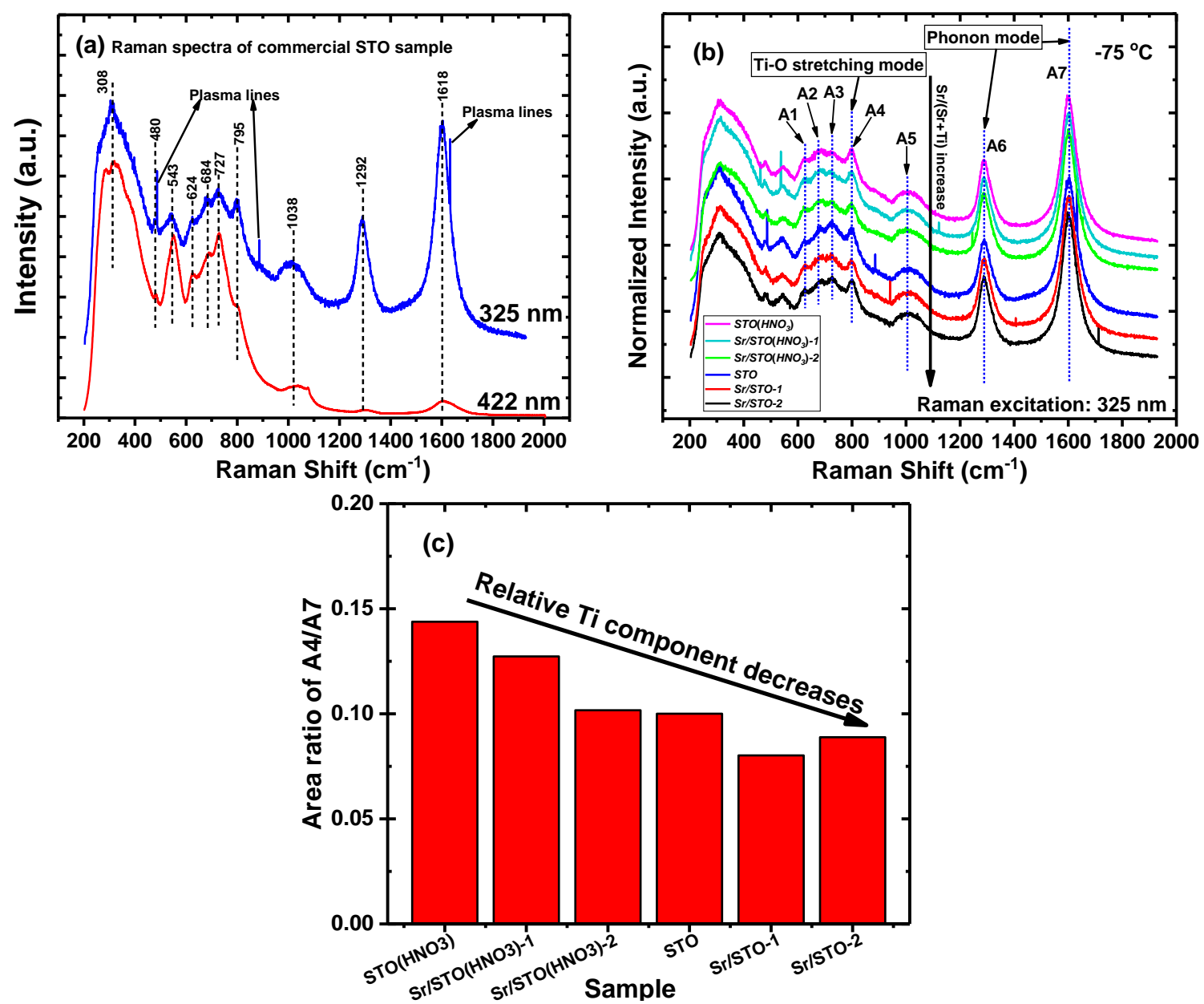

Figure 3. (a) Raman spectra of commercial STO excited at 325 and $442 \mathrm{~nm}$. (b) 325-nm excited Raman spectra of STO samples with surface reconstruction. (c) Ratio of $\mathrm{I}_{\mathrm{A} 4} / \mathrm{I}_{\mathrm{A} 7}$ values for different STO samples. 
Table 2. Raman peak assignments for STO samples.

\begin{tabular}{ccc}
\hline Peak Position $\left(\mathbf{c m}^{-1}\right)$ & Assignment & Reference \\
\hline 308 & $\mathrm{TO}_{2}+\mathrm{TA}, \mathrm{TO}_{2}+\mathrm{TO}_{1}, \mathrm{TO}_{4}-\mathrm{TO}_{2}$ & {$[50]$} \\
480 & $\mathrm{LO}_{3}$ & {$[51]$} \\
543 & $\mathrm{TO}_{4}$ & {$[51]$} \\
624 & $\mathrm{TO}_{4}+\mathrm{TA}_{4} \mathrm{TO}_{4}+\mathrm{TO}_{1}$ & {$[50]$} \\
684 & $2 \mathrm{TO}_{3}$ & {$[50]$} \\
727 & $\mathrm{TO}_{4}+\mathrm{TO}_{2}$ & {$[50]$} \\
795 & $\mathrm{LO}_{4}, \mathrm{Ti}_{-}-\mathrm{O}_{4}$ stretching mode & {$[52,53]$} \\
1038 & $2 \mathrm{LO}_{2}, 2 \mathrm{TO}_{4}$ & {$[50]$} \\
1292 & $\mathrm{LO}_{4}+\mathrm{LO}_{2}$ & {$[50]$} \\
1618 & $2 \mathrm{LO}_{4}$ & {$[50]$} \\
\hline
\end{tabular}

In its diffuse reflectance UV-vis spectrum in Figure 4, STO shows strong electronic absorption in the region below $400 \mathrm{~nm}$, whereas it exhibits little absorption in the visible region. As a result, compared to the conventional visible Raman spectroscopy, UV-excitation Raman has a shorter penetration depth, preventing light from entering the substrate or deep bulk[44, 49]. Therefore, the UV excitation at $325 \mathrm{~nm}$ was utilized for studying the composition in the surface sublayers in the STO samples. Indeed the $325 \mathrm{~nm}$ laser was found to have a penetration depth of $\sim 9 \mathrm{~nm}$ [54] of STO, a relatively small portion of the outside of the STO particles with an average particle size of $\sim 100 \mathrm{~nm}[39]$. 


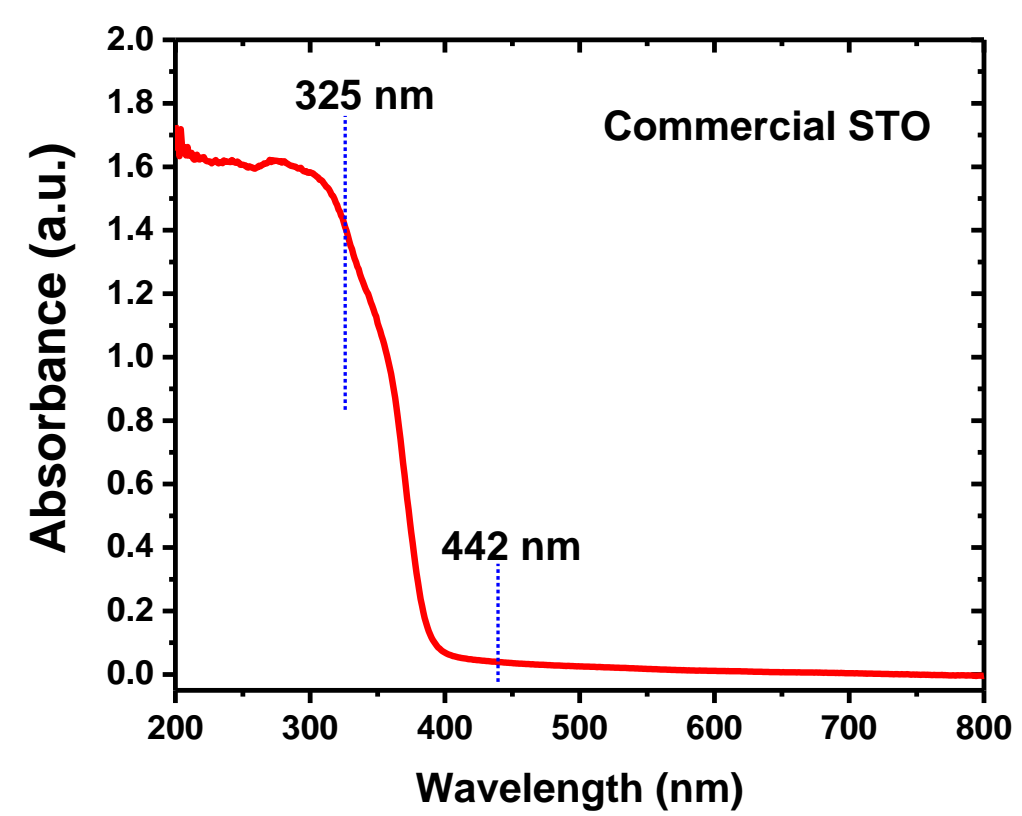

Figure 4. UV-vis diffuse reflectance spectrum of the commercial STO sample.

Figure 3(b) gives the $325 \mathrm{~nm}$ excited Raman spectra of various STO samples and the corresponding Raman spectra from $442 \mathrm{~nm}$ excitation are shown in Figure 5.

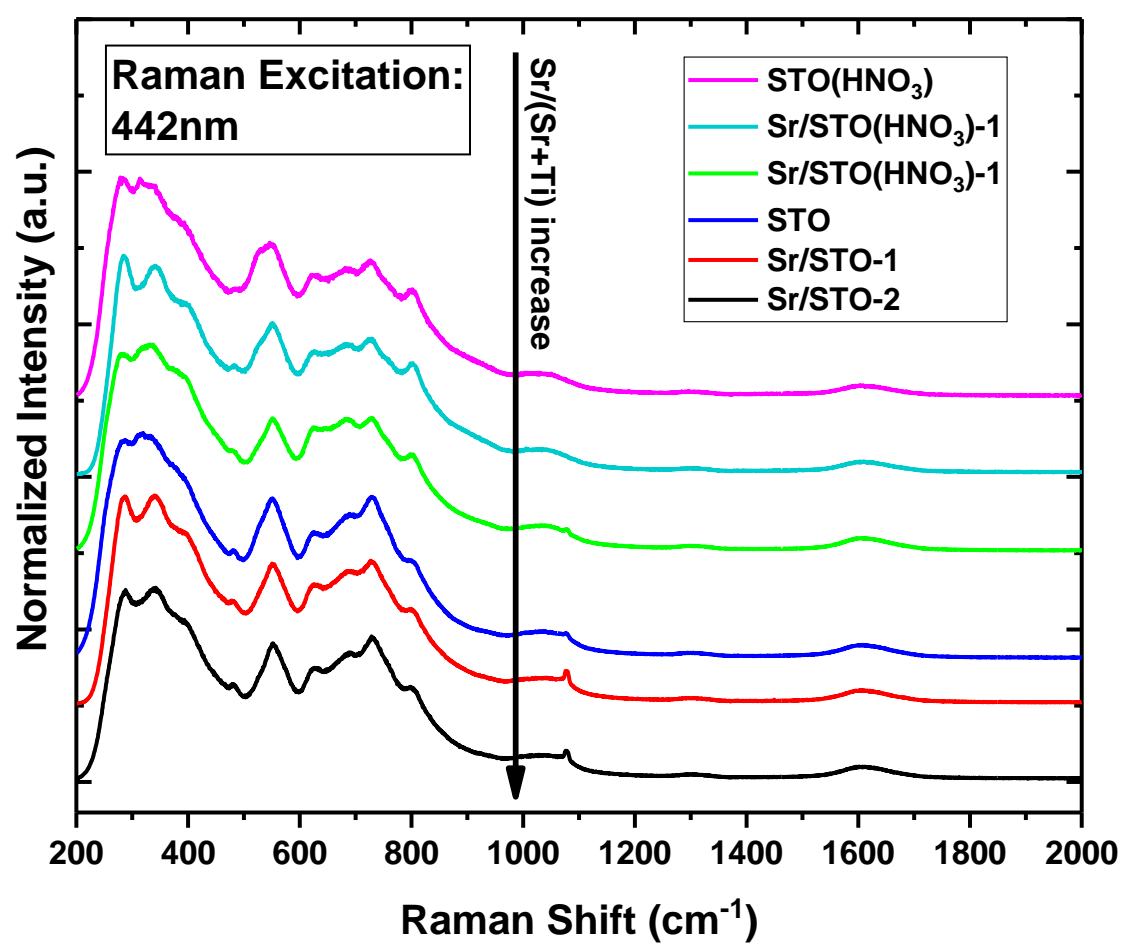

Figure 5. Raman spectra of all STO samples with excitation at $442 \mathrm{~nm}$. 
Since the three overtone bands at 1038, 1292 and $1618 \mathrm{~cm}^{-1}$ yield consistent values for the phonon energies of the $\mathrm{LO}_{4}$ and $\mathrm{LO}_{2}$ modes[50], their intensities remain constant for all the samples and normalization was conducted regarding the band at $1618 \mathrm{~cm}^{-1}$ as the reference. Each of the acquired spectra in the region between $600-1900 \mathrm{~cm}^{-1}$ were deconvoluted to 7 Gaussian bands A1-A7. A typical example of the spectral deconvolution of the Raman spectra of the commercial STO sample is shown in Figure 6. Coefficient of determination $\left(\mathrm{R}^{2}\right)$ of curve deconvolution is more than 0.98 for all samples $\left(0 \leq R^{2} \leq 1\right)$. All band assignments for A1-A7 can be found in Table 2. Especially, the A4 peak at $795 \mathrm{~cm}^{-1}$ is assigned to the Ti-O stretching mode [53] and A7 peak at $1618 \mathrm{~cm}^{-1}$ is assigned to the combination of $\mathrm{LO}_{4}+\mathrm{LO}_{2}$ mode. The relative amount of Ti in the sublayer of STO samples can be described by the area ratios of the A4 band to A7 band $\left(\mathrm{I}_{\mathrm{A} /} / \mathrm{I}_{\mathrm{A} 7}\right)$. Figure 3(c) exhibits the $\mathrm{I}_{\mathrm{A} 4} / \mathrm{I}_{\mathrm{A} 7}$ values for different STO samples. The $\mathrm{I}_{\mathrm{A} 4} / \mathrm{I}_{\mathrm{A} 7}$ ratio, namely, the relative amount of the Ti in the STO sublayer, decreases with the increase of $\mathrm{Sr} /(\mathrm{Sr}+\mathrm{Ti})$ detected from LEIS analysis. UV-Raman and LEIS analysis results are in good agreement on the surface and subsurface composition of reconstructed STO samples. 


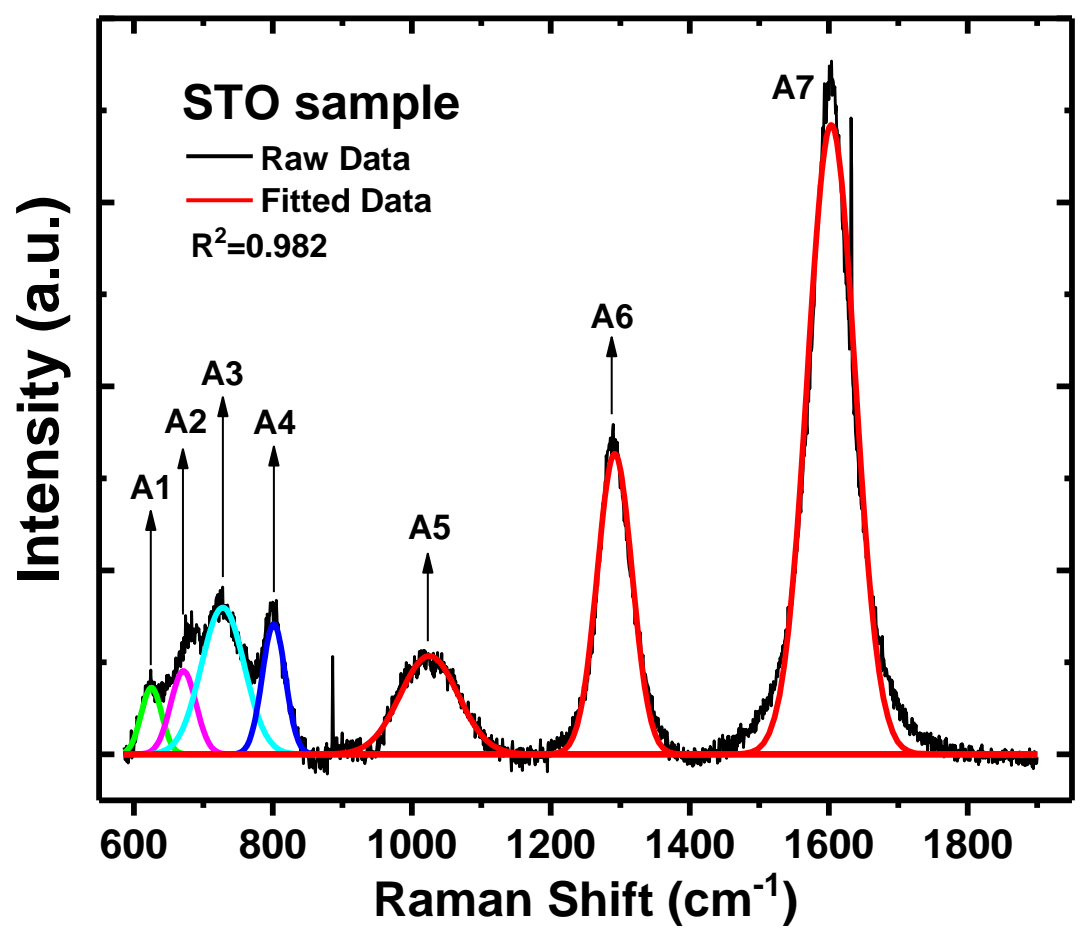

Figure 6. Spectral deconvolution of the Raman spectrum of the commercial STO sample.

In situ Raman was also attempted to probe any possible surface reconstruction of the STO samples during the OCM reaction. Unfortunately, some featured peaks (i.e. peaks at 684, 727, 795 $\mathrm{cm}^{-1}$ etc.) for STO samples become weak at such high temperature $\left(600-800{ }^{\circ} \mathrm{C}\right)$ due to thermal effects.[55] Also, the oxygen ion-radicals expected in the range of $800-1500 \mathrm{~cm}^{-1}$ are not found in the in situ Raman spectra after reaction at the high temperatures shown in the Figure 7. 


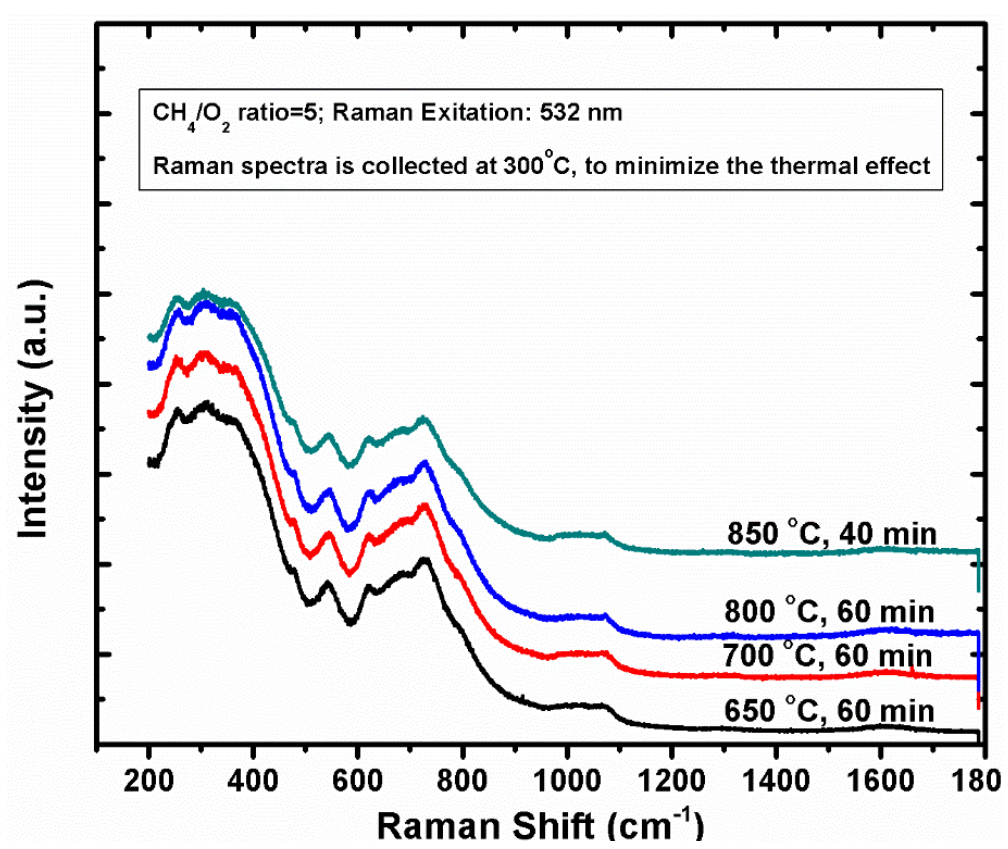

Figure 7. Raman spectra for commercial STO sample under OCM conditions at different temperatures and reaction time.

\subsubsection{Acid-base Properties Investigation}

It is widely accepted that the acid/base properties of the catalysts, especially the concentration of surface base sites, play an important role in the formation of $\mathrm{C}_{2}$ hydrocarbons in the OCM reaction. Florica et al.[41] claimed that the higher the catalyst basicity, the better the efficiency for selectively converting methane to $\mathrm{C}_{2}$ products. Acid/base catalytic properties of perovskites have been studied with multiple techniques and these studies were reviewed recently[12]. It is accepted that the acid/base catalytic performance can be influenced by some factors, such as density, strength and type of adsorption sites, the surface reconstruction (both surface concentration and surface structure) under reaction conditions and the facet exposed. In recent work [39], the acid-base properties were found to relate with the surface composition which can be tuned by surface reconstruction of shape-controlled STO nanocrystals. In this work, the $\mathrm{NH}_{3}$-TPD measurements were performed to analyze the acid-site strength distribution and concentration on the STO surface. As shown in Figure. 8(a), three desorption peaks Q1, Q2, Q3 
were obtained by conducting deconvolution at low temperature around 190 and $250{ }^{\circ} \mathrm{C}$ and high temperature around $500{ }^{\circ} \mathrm{C}$. The low temperature peaks (Q1 and Q2) correspond to weak acid sites, whereas the higher temperature peak Q3 is related to strong acid sites. It is observed that surface-Sr-rich samples $(\mathrm{Sr} /(\mathrm{Sr}+\mathrm{Ti})>0.5)$, i.e. $\mathrm{STO}, \mathrm{Sr} / \mathrm{STO}-1, \mathrm{Sr} / \mathrm{STO}-2$, only possess a weak Q2 peak at low temperature; in contrast, surface-Ti-rich samples (i.e. $\mathrm{STO}\left(\mathrm{HNO}_{3}\right)$, $\left.\mathrm{Sr} / \mathrm{STO}\left(\mathrm{HNO}_{3}\right)-1, \mathrm{Sr} / \mathrm{STO}\left(\mathrm{HNO}_{3}\right)-2\right)$ exhibit both Q1 and Q2 low temperature peaks. Moreover, the increase of $\mathrm{Ti}$ at the surface further increases the strength of acid sites by shifting the corresponding high temperature desorption peak Q3 from 450 to $550{ }^{\circ} \mathrm{C}$. The amount of $\mathrm{NH}_{3}$ adsorbed represents the surface acid site concentration of the catalysts and is summarized in Table 3. The acid site density increases in the order: Sr/STO-2 $<\mathrm{Sr} / \mathrm{STO}-1<\mathrm{STO}<\mathrm{STO}\left(\mathrm{HNO}_{3}\right)-2<$ $\mathrm{Sr} / \mathrm{STO}\left(\mathrm{HNO}_{3}\right)-1<\mathrm{STO}\left(\mathrm{HNO}_{3}\right)$.

Table 3. Acid and base site density of catalyst

\begin{tabular}{|c|c|c|c|c|}
\hline Catalyst ID & $\begin{array}{l}\text { Acid site } \\
(\mu \mathrm{mol} / \mathrm{g})\end{array}$ & $\begin{array}{l}\begin{array}{l}\text { Base site } \\
(\mu \mathrm{mol} / \mathrm{g})\end{array} \\
\end{array}$ & $\begin{array}{c}\text { Ratio of } \\
\text { base/acid }\end{array}$ & $\begin{array}{c}\text { Ratio of } \\
\text { base/(base+acid) }\end{array}$ \\
\hline $\mathrm{STO}\left(\mathrm{HNO}_{3}\right)$ & 71.32 & 10.58 & 0.15 & 0.13 \\
\hline $\mathrm{Sr} / \mathrm{STO}\left(\mathrm{HNO}_{3}\right)-1$ & 71.37 & 17.33 & 0.24 & 0.20 \\
\hline $\mathrm{Sr} / \mathrm{STO}\left(\mathrm{HNO}_{3}\right)-2$ & 62.00 & 37.53 & 0.61 & 0.38 \\
\hline STO & 54.05 & 146.82 & 2.72 & 0.73 \\
\hline $\mathrm{Sr} / \mathrm{STO}-1$ & 48.40 & 155.92 & 3.22 & 0.76 \\
\hline $\mathrm{Sr} / \mathrm{STO}-2$ & 52.36 & 145.46 & 2.78 & 0.74 \\
\hline $\mathrm{Sr} / \mathrm{TiO}_{2}$ & 51.77 & 1.13 & 0.02 & 0.02 \\
\hline
\end{tabular}

The basicity of STO catalysts was measured by $\mathrm{CO}_{2}$-TPD as shown in Figure $8(\mathrm{~b})$. There are three peaks in the $\mathrm{CO}_{2}$-TPD profile, labelled $\mathrm{P} 1, \mathrm{P} 2$ and $\mathrm{P} 3$. $\mathrm{P} 1$ and $\mathrm{P} 2$ were assigned to the weak and strong $\mathrm{CO}_{2}$ desorption at the temperature $<100$ and $300{ }^{\circ} \mathrm{C}$, respectively, which are due to the alkalinity of strontium[56]. P3 appears at $700{ }^{\circ} \mathrm{C}$ for the $\mathrm{Sr} / \mathrm{STO}$ samples, which is caused by the decomposition of surface carbonate $\left(\mathrm{SrCO}_{3} \rightarrow \mathrm{SrO}+\mathrm{CO}_{2}\right)[57,58]$. Surface-Sr-rich STO samples possess P1, P2 and P3 basic sites; whereas surface-Ti-rich samples only have the P1 
weakly basic sites, except that $\mathrm{STO}\left(\mathrm{HNO}_{3}\right)-2$ shows small amount of $\mathrm{P} 2$ strong basic sites. The amount of basic sites for the STO samples was also calculated and summarized in Table 3. The total amount of basic sites increases with the surface Sr concentration. The plot in Figure 9 suggests the correlation of base-site density with acid-site density on STO samples, where the base site concentration is inversely proportional to that of the acid sites.

The catalyst performance was evaluated over the temperature range of $600-800{ }^{\circ} \mathrm{C}$ and the product $\mathrm{CO}_{2}$ can form carbonate species on the STO surface. From the $\mathrm{CO}_{2}-\mathrm{TPD}$ profile, it is found that most basic sites (locating on P1 and P2 peaks) on the STO samples are available to reactants when the temperature is higher than $600{ }^{\circ} \mathrm{C}$. Furthermore, when reaction temperature is higher than $700{ }^{\circ} \mathrm{C}$, the basic sites corresponding to $\mathrm{P} 3$ are exposed and can contribute to the formation of $\mathrm{C}_{2}$. Reactivity trends are similar in the temperature range studied $\left(600-800{ }^{\circ} \mathrm{C}\right)$; and therefore, we conclude that the basic sites corresponding to $\mathrm{P} 3$ at reaction temperatures above 700 ${ }^{\circ} \mathrm{C}$ do not have significant impact on the OCM performances over the STO samples.

The surface ratio of base/acid sites and base/(base+acid) are listed in the Table 3. From Figure 2, the base/acid ratio trend in the STO samples is in good agreement with the LEIS results, indicating that the surface $\mathrm{Sr}$ enrichment of the catalysts is proportional to the density of basic sites. 

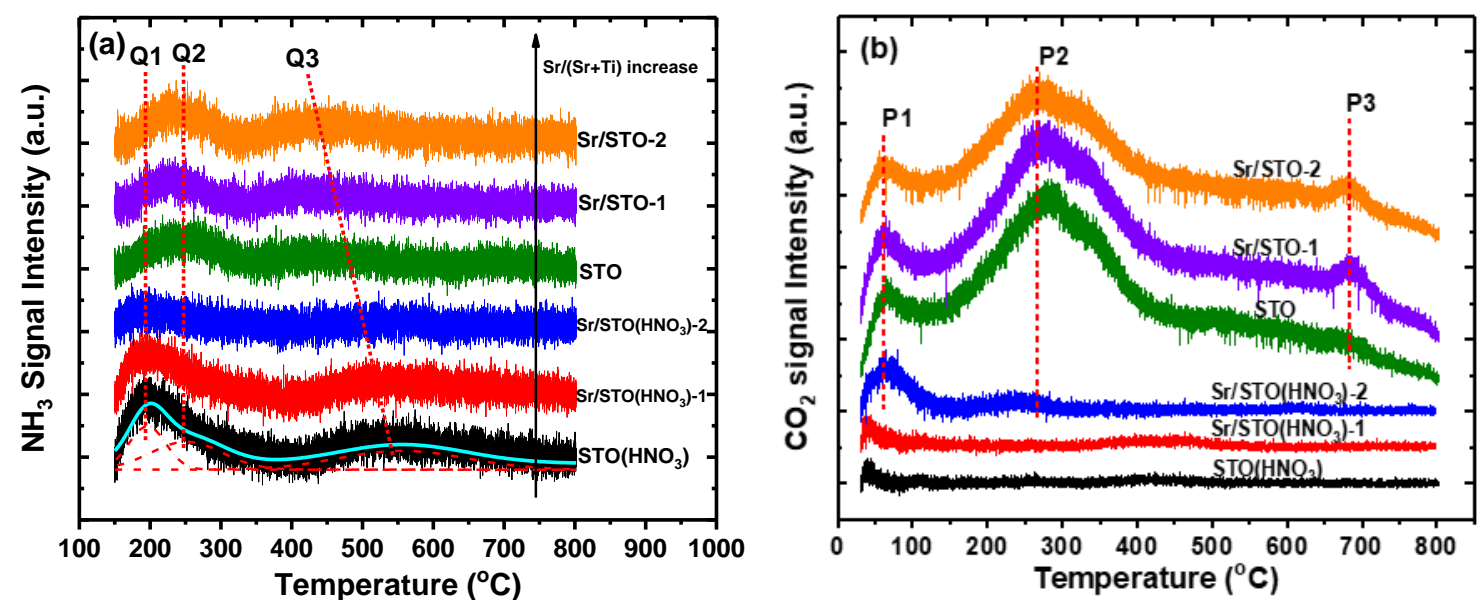

Figure 8. (a) $\mathrm{NH}_{3}-\mathrm{TPD}$ profiles and (b) $\mathrm{CO}_{2}$-TPD profiles of STO samples.

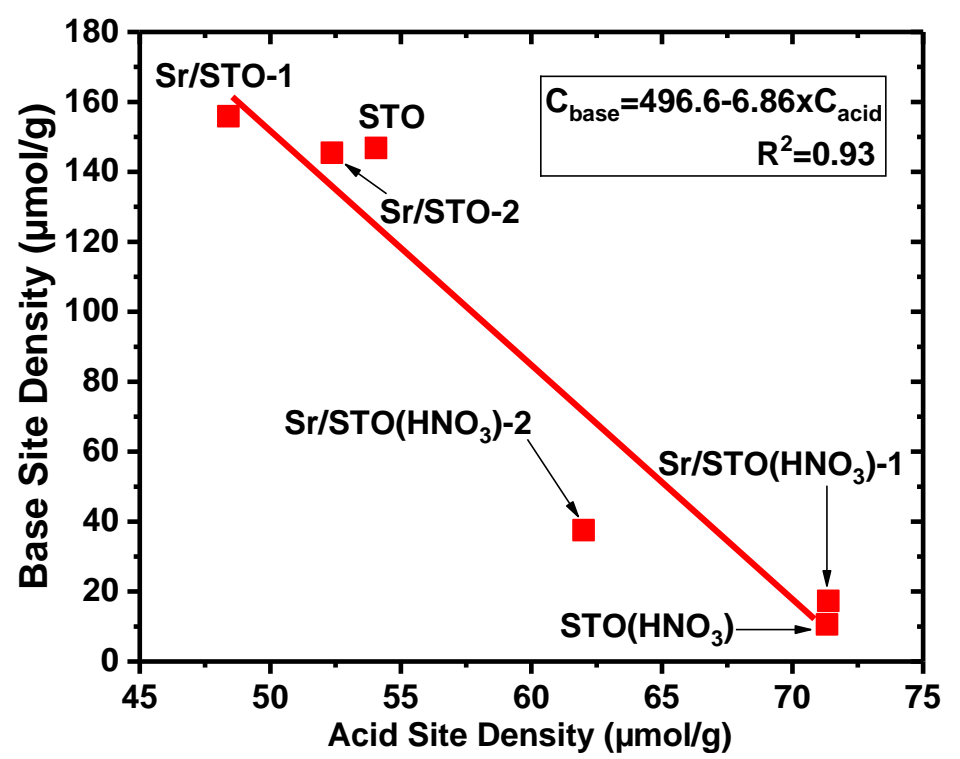

Figure 9. Correlation of base-site density with acid-site density on STO samples.

\subsection{4 $\mathrm{H}_{2}-\mathrm{TPR}$ Analysis}

To study the dependence of the reducibility of the STO samples with surface termination, TPR tests were performed in $30 \mathrm{~mL} / \mathrm{min} 4 \% \mathrm{H}_{2} / \mathrm{He}$ flow. The $\mathrm{H}_{2}$-TPR profiles are presented in Figure 10, illustrating that all STO samples show one main peak with a maximum at $500{ }^{\circ} \mathrm{C}$. This peak was assigned to the reduction of the $\mathrm{B}$-site $\mathrm{Ti}^{4+}$ to $\mathrm{Ti}^{3+}$ of perovskites [59]. The $\mathrm{H}_{2}$ uptake for 
all STO samples was calculated and summarized in Table 4. All samples showed similar $\mathrm{H}_{2}$ consumption $(584-595 \mu \mathrm{mol} / \mathrm{g})$; therefore, the surface composition has negligible effect on the reducibility of STO samples.

Table 4. $\mathrm{H}_{2}$ consumption of STO samples during $\mathrm{H}_{2}$-TPR

\begin{tabular}{cc}
\hline Catalyst ID & H2 consumption $(\boldsymbol{\mu m o l} / \mathbf{g})$ \\
\hline STO $\left(\mathrm{HNO}_{3}\right)$ & 595.9 \\
$\mathrm{Sr} / \mathrm{STO}\left(\mathrm{HNO}_{3}\right)-1$ & 592.9 \\
$\mathrm{Sr} / \mathrm{STO}\left(\mathrm{HNO}_{3}\right)-2$ & 581.6 \\
STO & 591.3 \\
$\mathrm{Sr} / \mathrm{STO}-1$ & 586.4 \\
$\mathrm{Sr} / \mathrm{STO}-2$ & 584.0 \\
\hline
\end{tabular}

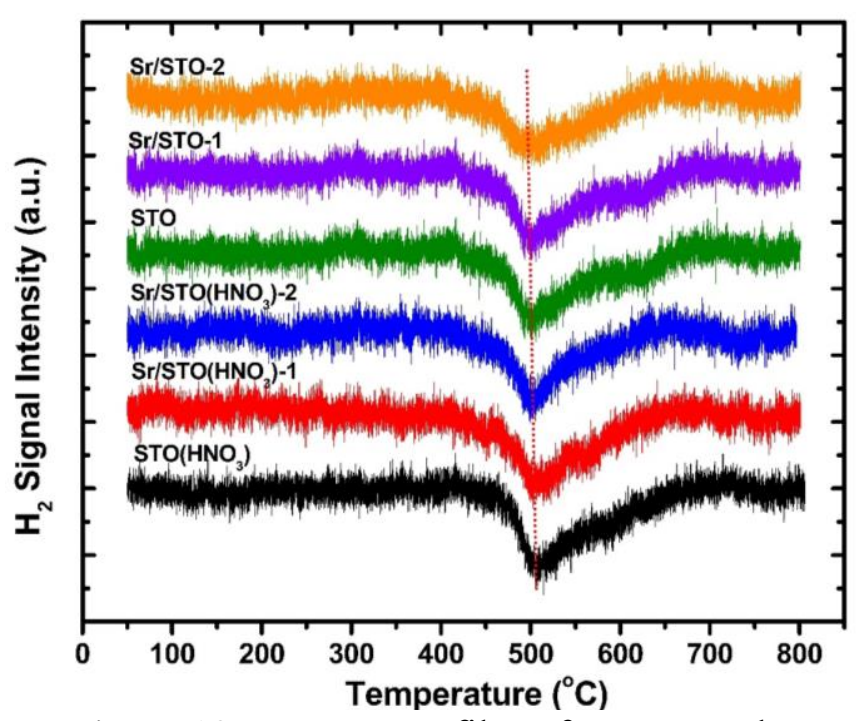

Figure 10. $\mathrm{H}_{2}$-TPR profiles of STO samples.

\subsubsection{Catalytic Performance}

When tested for the OCM reaction, the STO catalysts have shown promising activity and selectivity toward $\mathrm{C}_{2}$ hydrocarbons, i.e. $\mathrm{C}_{2}$ yield can reach $10.5 \%$ for $30 \mathrm{mg} \mathrm{STO}$ at $800 \sim 850{ }^{\circ} \mathrm{C}$ at $\mathrm{CH}_{4} / \mathrm{O}_{2}=5$ (See Figure 11). The yield, upon further catalyst optimization, has the potential to meet the industrial requirement, which is $30 \%$ for combined $\mathrm{C}_{2}$ yield $[10,60]$. For example, D. V. Ivanov and co-workers[34] reported the $\mathrm{C}_{2}$ yield in the OCM reaction for Mg-/Al-doped STO and 
$\mathrm{Sr}_{2} \mathrm{TiO}_{4}$ can achieve as high as $25 \%$ at $850-900{ }^{\circ} \mathrm{C}$, thus can be comparable to that found for thestate-of-the-art OCM catalysts, such as Na-doped $\mathrm{Ba}_{0.5} \mathrm{Sr}_{0.5} \mathrm{TiO}_{3}\left(24 \% \mathrm{C}_{2}\right.$ yield)[33], and $\mathrm{Na}-\mathrm{W}$ $\mathrm{Mn} / \mathrm{SiO}_{2}$ (29\% $\mathrm{C}_{2}$ yield)[55], among others. In addition, excellent regenerability of the STO catalysts was validated in the present work. The spent STO after the OCM reaction at $850{ }^{\circ} \mathrm{C}$ for $3 \mathrm{~h}$ was exposed to oxygen $\left(5 \% \mathrm{O}_{2} / \mathrm{He}, 850{ }^{\circ} \mathrm{C}, 5 \mathrm{~h}\right)$ for regeneration. The regenerated STO exhibited unchanged catalytic activity as shown in Figure 11.

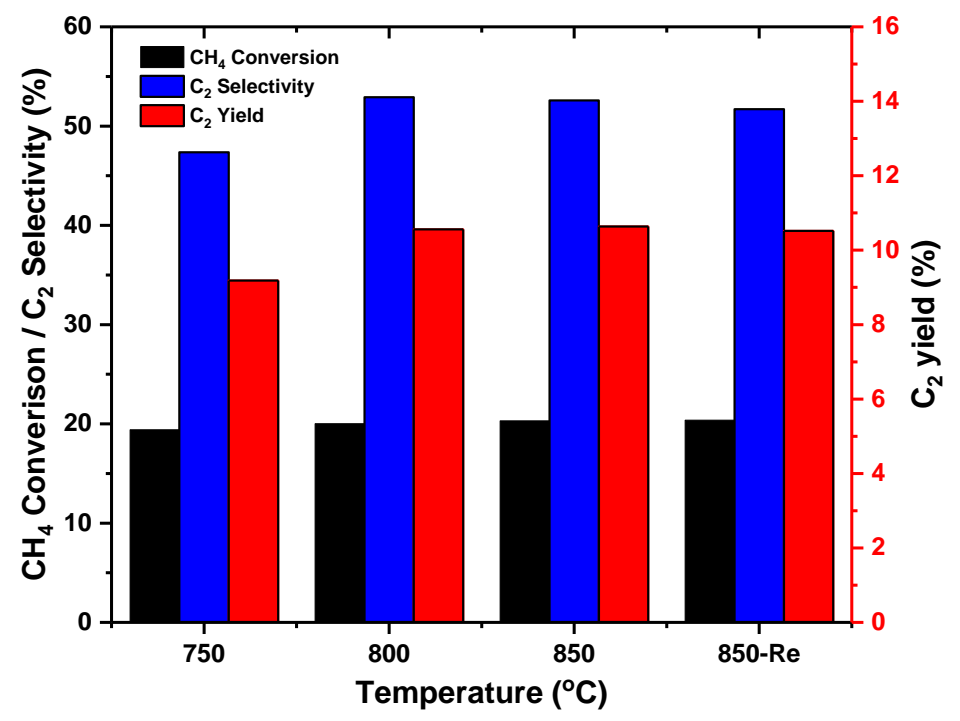

Figure 11. Regenerability test of commercial STO sample for OCM reaction.

Note: $\mathrm{CH}_{4}$ conversion, $\mathrm{C}_{2}$ selectivity and $\mathrm{C}_{2}$ yield for $30 \mathrm{mg}$ commercial STO with $\mathrm{CH}_{4} / \mathrm{O}_{2}$ feeding ratio 5 at different temperatures in OCM reaction. 850-Re represents that spent STO sample was regenerated (in 5\% $\mathrm{O}_{2} / \mathrm{He}$ for $5 \mathrm{~h}$ at $\left.850{ }^{\circ} \mathrm{C}\right)$ after $\mathrm{OCM}$ reaction $\left(850^{\circ} \mathrm{C}\right.$ for $\left.3 \mathrm{~h}\right)$, then employed to OCM reaction in the same condition at 850 ${ }^{\circ} \mathrm{C}$.

To study the OCM kinetics, the STO catalysts were tested for the OCM reaction with $\mathrm{CH}_{4} / \mathrm{O}_{2}=5$ over the $600-800{ }^{\circ} \mathrm{C}$ temperature range with $\mathrm{CH}_{4}$ conversion below $10 \%$. The variation of $\mathrm{CH}_{4}$ consumption rate and product $\left(\mathrm{CO}_{2}, \mathrm{CO}, \mathrm{C}_{2} \mathrm{H}_{4}\right.$ and $\left.\mathrm{C}_{2} \mathrm{H}_{6}\right)$ yields with respect to the composition of the top catalyst surface at different temperatures are presented in Figure 12(a)-(e). Although the maximum $\mathrm{C}_{2}\left(\mathrm{C}_{2} \mathrm{H}_{4}+\mathrm{C}_{2} \mathrm{H}_{6}\right)$ yield in present experimental condition is $5.3 \%$ (Figure 12 (d) and (e)), the fundamental understanding of the effects of perovskite surface composition can be investigated. The methane consumption rate and product yields are found proportional to 
the concentration of $\mathrm{Sr}$ at the surface for the range of temperature studied up to $\mathrm{Sr} /(\mathrm{Sr}+\mathrm{Ti})$ ratio of 0.66, beyond which the $\mathrm{CH}_{4}$ conversion and yields tend to level off. The trends are similar to the trend observed for methane combustion over these STO samples in recent work (See Figure 13), i.e., similar enhancement of $\mathrm{CH}_{4}$ conversion is present with surface $\mathrm{Sr}$ concentration of STO in both methane combustion and the OCM reaction. Apparently, the surface $\mathrm{Sr}$ concentration can be highlighted as a universal descriptor for methane activation, independent of the reaction (OCM or combustion). As a control test, the OCM reaction was conducted on a $\mathrm{Sr} / \mathrm{TiO}_{2}$ catalyst and no activity was observed $\left(\mathrm{CH}_{4}\right.$ conversion of $0.65 \%, 0.84 \%, 2.45 \%$ at $600,700,800{ }^{\circ} \mathrm{C}$, respectively, similar to the blank test results). From recent report[1], the $\mathrm{Sr} / \mathrm{TiO}_{2}$ sample was synthesized by impregnating $\mathrm{Sr}$ on the surface of rutile $\mathrm{TiO}_{2}$. XRD results indicated $\mathrm{Sr}$ does not diffuse into the $\mathrm{TiO}_{2}$ lattice and its theoretical surface $\mathrm{Sr} /(\mathrm{Sr}+\mathrm{Ti})$ value is 1 . This prominent reactivity difference between $\mathrm{Sr}$-doped $\mathrm{TiO}_{2}$ and impregnated STO indicates that the arrangement of cations in the bulk, related to the crystal structure, is critical for the OCM reaction. From Table 3, the acid-site density of $\mathrm{Sr} / \mathrm{TiO}_{2}$ is comparable to those of perovskite STO with surface reconstruction (48.40-71.37 $\mu \mathrm{mol} / \mathrm{g}$ ). In contrast, the base-site density of $\mathrm{Sr} / \mathrm{TiO}_{2}$ is only $1.13 \mu \mathrm{mol} / \mathrm{g}$, which is much less than those of perovskite STO samples $(10.58-155.92 \mu \mathrm{mol} / \mathrm{g})$, resulting in poor OCM activity. Therefore, it can be concluded that the $\mathrm{ABO}_{3}$ crystal structure is necessary for the existence and stabilization of basic sites on the catalyst surface. 

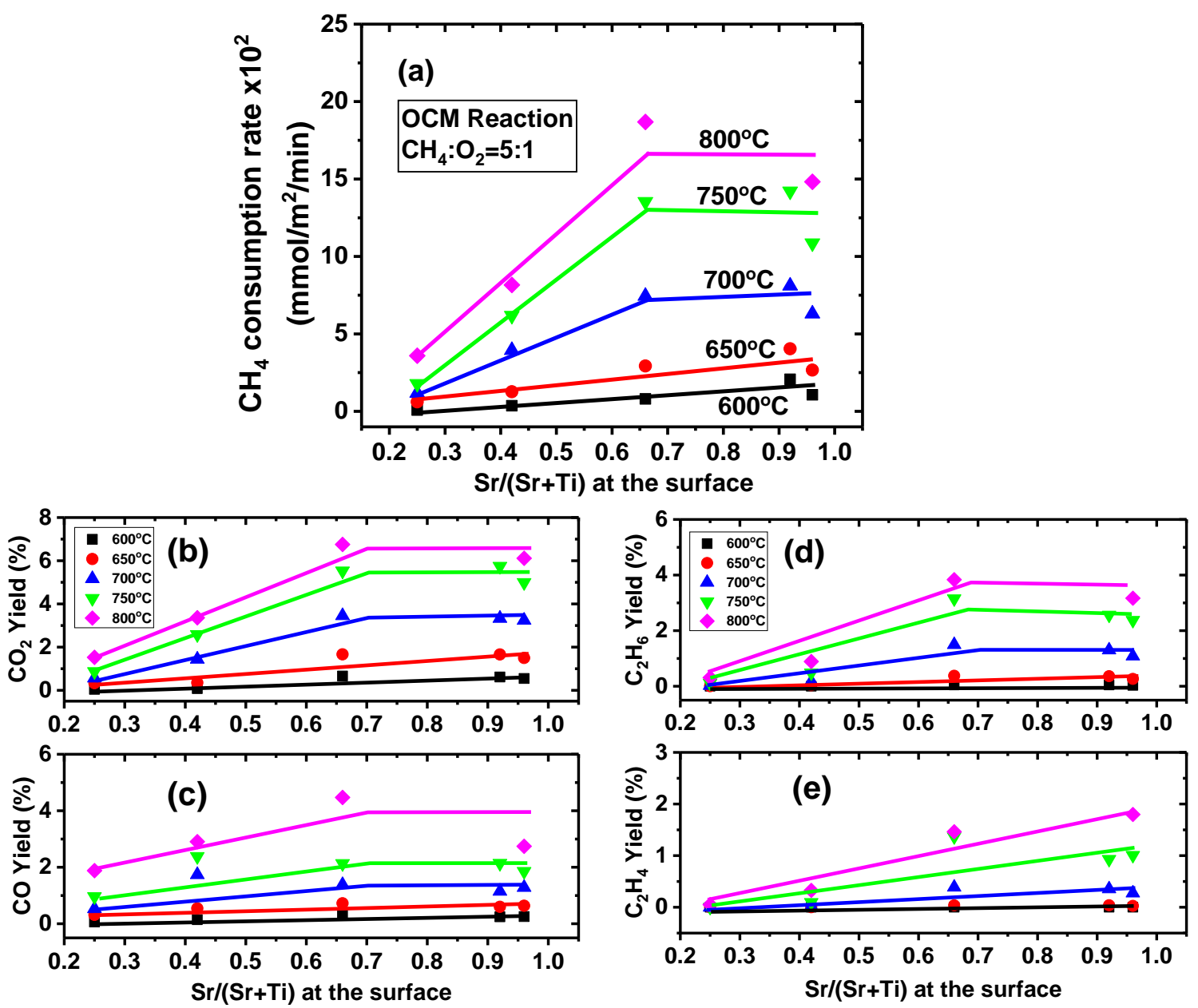

Figure 12. (a) $\mathrm{CH}_{4}$ conversion, (b) $\mathrm{CO}_{2}$ yield, (c) $\mathrm{CO}$ yield, (d) $\mathrm{C}_{2} \mathrm{H}_{6}$ yield and (e) $\mathrm{C}_{2} \mathrm{H}_{4}$ yield with respect to the composition of the top surface of various STO samples at different catalyst bed temperatures $\left(600,650,700,750,800^{\circ} \mathrm{C}\right)$ for OCM reaction with conditions in present work. 


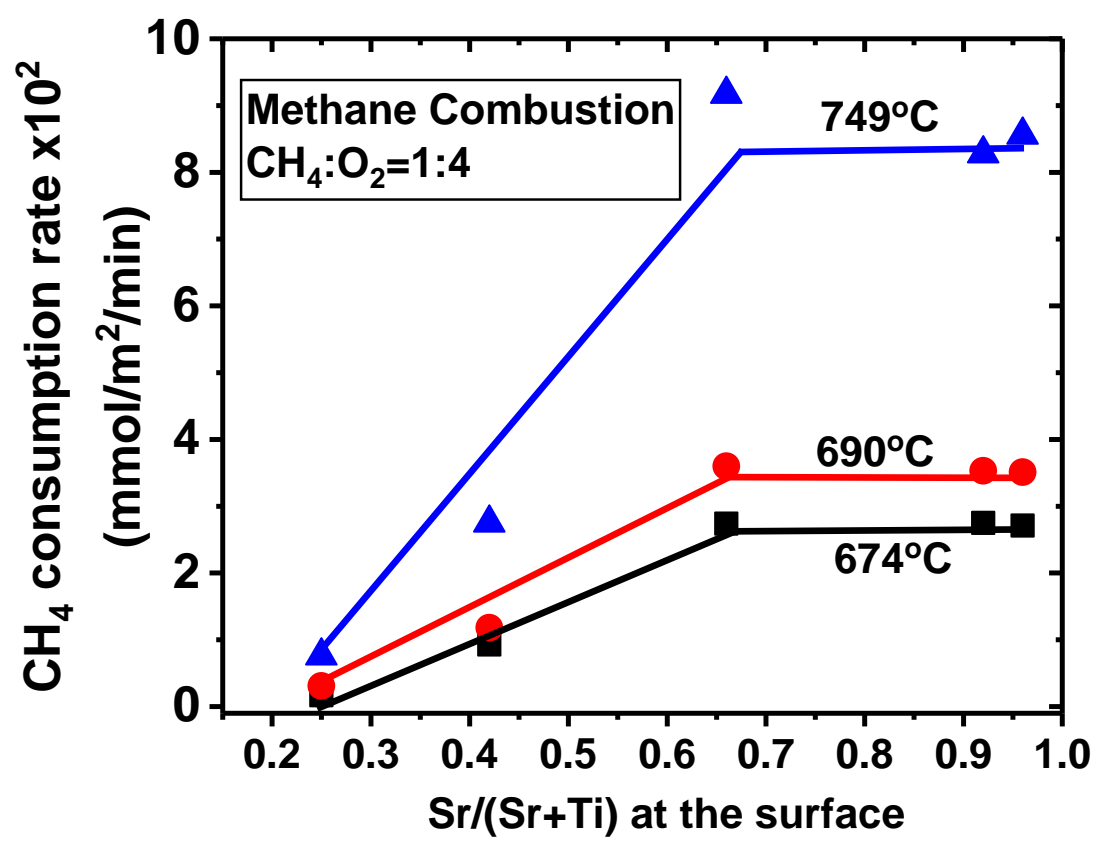

Figure 13. Rate of $\mathrm{CH}_{4}$ conversion versus composition of outermost atomic layer of various STO samples at different temperatures for methane combustion.

Note: Reaction conditions for methane combustion: $30 \mathrm{mg}$ of catalyst, $1.4 \mathrm{~atm}$, feed consists of $51 \mathrm{~mL} / \mathrm{min} 1.1 \%$ $\mathrm{CH}_{4}, 4.5 \% \mathrm{O}_{2}$, balance $\mathrm{Ar}+$ He. Reprinted with permission from (F. Polo-Garzon, V. Fung, X. Liu, Z.D. Hood, E.E. Bickel, L. Bai, H. Tian, G.S. Foo, M. Chi, D.-e. Jiang, Z. Wu, Understanding the Impact of Surface Reconstruction of Perovskite Catalysts on CH4 Activation and Combustion, ACS Catalysis, (2018)). Copyright (2018) American Chemical Society.

Figure 14(a) and (b) show the ratio of $\mathrm{C}_{2} / \mathrm{CO}_{\mathrm{x}}$ and ethylene/ethane yield, respectively, at different temperatures as a function of top surface composition. $\mathrm{C}_{2}$ selectivity along with ethylene/ethane ratio increased with both temperature and $\mathrm{Sr} /(\mathrm{Sr}+\mathrm{Ti})$ at the surface. The surface basic sites are reported to be responsible for the formation of $\mathrm{C}_{2}$.[41, 42]. From previous work [1], the homolytic dehydrogenation of methane, which would create free methyl radicals, presents the lowest activation energy $(0.32 \mathrm{eV})$ on the Sr-terminated step surface, compared with Ti-terminated step surface and other heterolytic C-H bond cleavage over STO surface. Subsequently, more $\mathrm{C}_{2} \mathrm{H}_{6}$ is formed via the combination of methyl radicals in the gas phase. Then, the dehydrogenation of concentrated $\mathrm{C}_{2} \mathrm{H}_{6}$ is promoted and finally more $\mathrm{C}_{2} \mathrm{H}_{4}$ is generated in the gas phase. In short, a clear connection between STO surface composition and the OCM catalytic performance is expressed, i.e., 
Sr concentration at the surface is shown to be an indicator for the activity and selectivity in the OCM reaction.
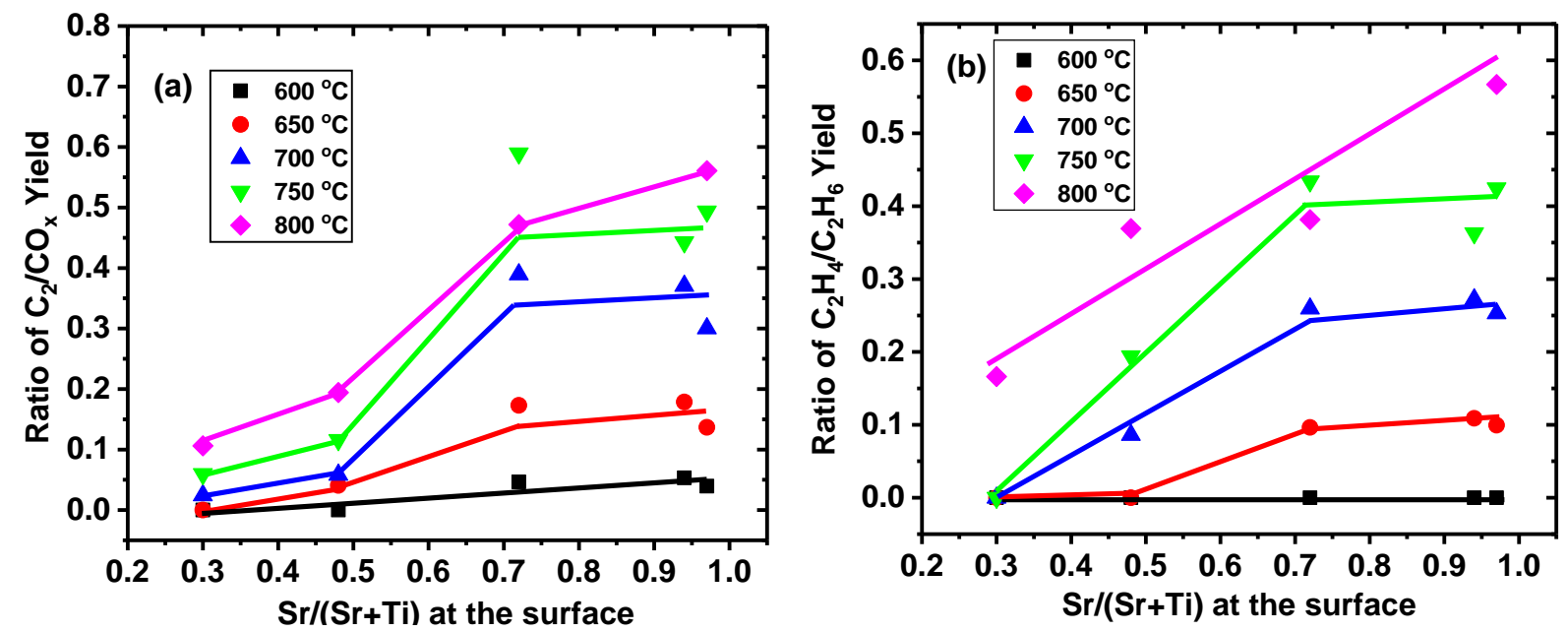

Figure 14. (a) Ratio of $\mathrm{C}_{2} / \mathrm{CO}_{\mathrm{x}}$ yield and (b) ratio of ethylene/ethane yield as function of top surface composition at different catalyst bed temperatures over various STO samples.

To calculate the apparent activation energies for different STO samples, the reaction rates under differential conditions $\left(\mathrm{CH}_{4}\right.$ conversion $\left.<10 \%\right)$ are fitted to power law model[61] with a simple rate expression:

$$
\text { rate }=k\left(P_{\mathrm{CH}_{4}}\right)^{a}\left(P_{\mathrm{O}_{2}}\right)^{b} \quad(\mathrm{Eq} 3.3-1)
$$

with $k=A^{\prime} \exp \left(-\frac{E_{a}}{R T}\right)$

Where the $A^{\prime}$ is the pre-exponential factor in the Arrhenius equation, Ea is the apparent activation energy, $\mathrm{R}$ is the gas constant with the value of $8.314 \times 10^{-3} \mathrm{~kJ} / \mathrm{K} / \mathrm{mol}$, $\mathrm{T}$ is the reaction temperature.

Thus, the Eq3.3-1 can be rewritten as: 


$$
\begin{aligned}
& \text { rate }=A^{\prime} \exp \left(-\frac{E_{a}}{R T}\right)\left(P_{C H_{4}}\right)^{a}\left(P_{O_{2}}\right)^{b} \quad(\mathrm{Eq} 3.3-2) \quad \text { or, } \\
& \text { rate }=A \cdot \exp \left(-B \cdot\left(\frac{1000}{T}\right)\right)
\end{aligned}
$$

Where, $\mathrm{A}=\mathrm{A}^{\prime}\left(\mathrm{P}_{\mathrm{CH}}\right)^{\mathrm{a}}\left(\mathrm{P}_{2}\right)^{\mathrm{b}}, \mathrm{B}=\mathrm{Ea} /(1000 \times \mathrm{R})$. By plotting the $\ln ($ rate $)$ against the $(1000 / \mathrm{T})$, A and B can be derived from the intercept and slope of the plots, respectively. Hence, the Ea can be solved from B values in (Eq-S3), which are shown in Table 5. The calculated Ea values are listed in the Table 6 in the following part.

\begin{tabular}{|c|c|c|c|c|}
\hline \multirow[t]{2}{*}{ Sample } & \multicolumn{4}{|c|}{ Fitted B values } \\
\hline & $\mathrm{CH}_{4}$ consumption & $\mathrm{CO}$ formation & $\mathrm{CO}_{2}$ formation & $\mathrm{C}_{2}$ formation \\
\hline $\mathrm{STO}\left(\mathrm{HNO}_{3}\right)$ & $16.388 \pm 2.666$ & $15.209 \pm 0.950$ & $14.952 \pm 1.374$ & $22.09 \pm 3.100$ \\
\hline $\mathrm{Sr} / \mathrm{STO}\left(\mathrm{HNO}_{3}\right)-2$ & $14.902 \pm 1.957$ & $14.274 \pm 0.407$ & $18.08 \pm 0.831$ & $23.745 \pm 3.176$ \\
\hline STO & $14.839 \pm 1.560$ & $12.04 \pm 1.842$ & $11.087 \pm 2.671$ & $22.746 \pm 0.394$ \\
\hline $\mathrm{Sr} / \mathrm{STO}-1$ & $14.171 \pm 1.672$ & $12.792 \pm 0.568$ & $13.251 \pm 1.176$ & $36.016 \pm 3.554$ \\
\hline Sr/STO-2 & $12.603 \pm 0.985$ & $11.045 \pm 2.405$ & $11.437 \pm 2.450$ & $23.899 \pm 1.989$ \\
\hline
\end{tabular}

Table 5. Fitted B values according to Eq3.3-3.

The Arrhenius plots for $\mathrm{CH}_{4}$ consumption with various catalysts are presented in Figure 15(a). The apparent activation energies (Ea) for $\mathrm{CH}_{4}$ consumption, $\mathrm{CO}, \mathrm{CO}_{2}$ and $\mathrm{C}_{2}$ formation are shown in Table 6. Moreover, Figure 16 shows the Arrhenius plots for $\mathrm{CO}, \mathrm{CO}_{2}$ and $\mathrm{C}_{2}$ formation rates with different catalysts. The relationship between apparent activation energies with surface Sr concentration is plotted in Figure. 15(b). The Ea values remained constant with varying surface Sr concentration for the STO samples, indicating the reaction pathway for the OCM reaction on STO is unchanged. It is reported in precious publication[1] that the rate-determining step (RDS) for the combustion of methane over STO is involved in the dehydrogenation of $\mathrm{CH}_{4}$ rather than the dissociation of $\mathrm{O}_{2}$, confirmed by kinetic isotopic experiments. Since the OCM rate trends are similar to that for methane combustion over these STO samples, it is reasonable to assume the 
RDS for OCM reaction is also related to the $\mathrm{C}-\mathrm{H}$ bond breaking of $\mathrm{CH}_{4}$. The difference in the rate of the OCM reaction (Figure 12(a)) can be attributed to the different surface density of active sites, which increases with either surface Sr or basic sites.
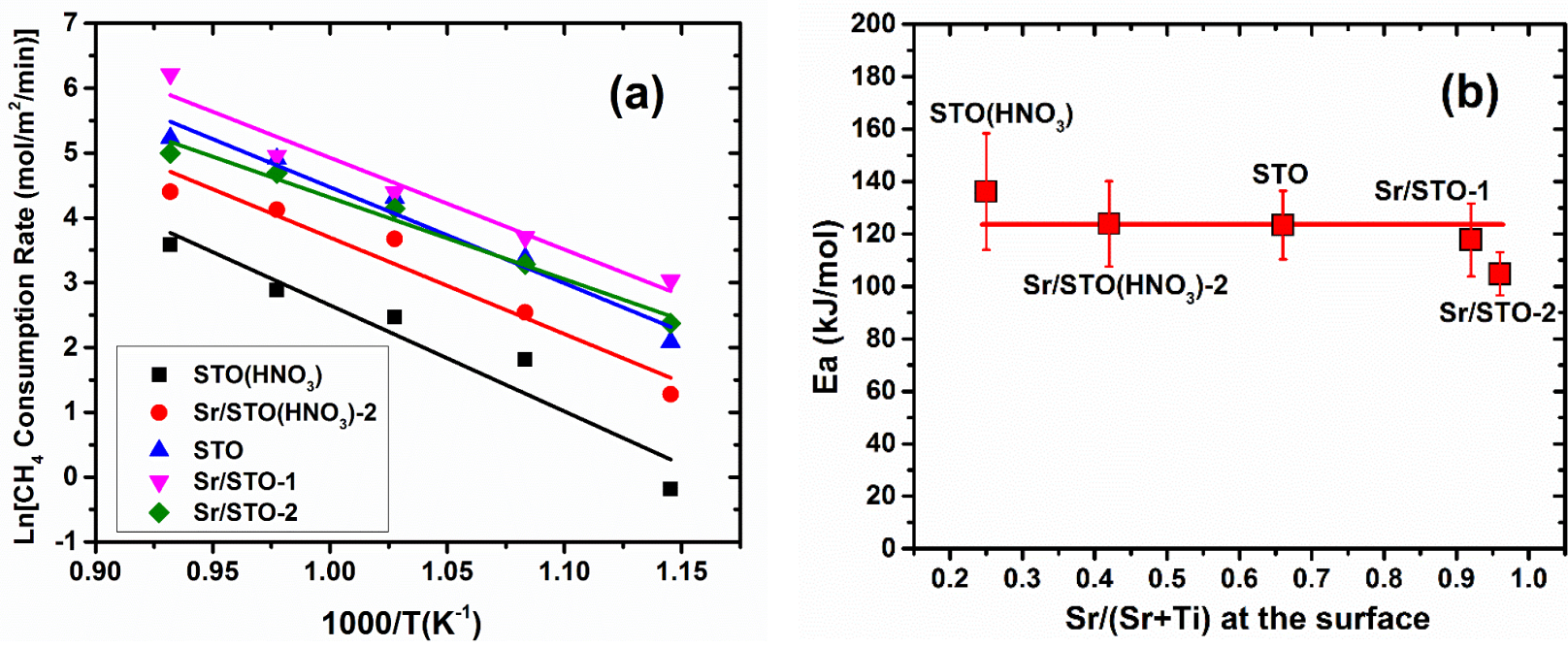

Figure 15. (a) Arrhenius plots for the $\mathrm{CH}_{4}$ consumption rate. (b) Apparent activation energies (Ea) measured under differential conditions, for $\mathrm{CH}_{4}$ consumption rate over STO catalysts under study with different surface $\mathrm{Sr}$ concentration. Experimental conditions: $5 \mathrm{mg}$ catalyst, $1.0 \mathrm{~atm}$, feed consists of $25 \mathrm{~mL} / \mathrm{min}$ of $10 \% \mathrm{CH}_{4} / \mathrm{Ar}, 10 \mathrm{~mL} / \mathrm{min}$ of $5 \% \mathrm{O}_{2} / \mathrm{He}$, and $15 \mathrm{~mL} / \mathrm{min}$ of $\mathrm{He}$ as balance gas.

Table 6. Apparent Activation Energies for $\mathrm{CH}_{4}$ consumption and $\mathrm{CO}, \mathrm{CO}_{2}, \mathrm{C}_{2}$ formation

\begin{tabular}{lcccc}
\hline Sample & \multicolumn{4}{c}{ Apparent Activation Energy (kJ/mol) } \\
\cline { 2 - 5 } & $\mathbf{C H}_{\mathbf{4}}$ consumption & $\mathbf{C O ~ f o r m a t i o n}$ & $\mathbf{C O}_{\mathbf{2}}$ formation & $\mathbf{C}_{\mathbf{2}}$ formation \\
\hline STO $\left(\mathrm{HNO}_{3}\right)$ & $136.2 \pm 22.2$ & $126.4 \pm 7.9$ & $124.3 \pm 11.4$ & $183.7 \pm 25.8$ \\
Sr/STO$\left(\mathrm{HNO}_{3}\right)-2$ & $123.9 \pm 16.3$ & $118.7 \pm 3.4$ & $150.3 \pm 6.9$ & $197.4 \pm 26.4$ \\
STO & $123.4 \pm 13.0$ & $100.1 \pm 15.3$ & $92.2 \pm 22.2$ & $189.1 \pm 3.3$ \\
Sr/STO-1 & $117.8 \pm 13.9$ & $106.4 \pm 4.7$ & $110.2 \pm 9.8$ & $299.4 \pm 29.6$ \\
Sr/STO-2 & $104.8 \pm 8.2$ & $91.8 \pm 20.0$ & $95.1 \pm 20.4$ & $198.7 \pm 16.5$ \\
\hline
\end{tabular}



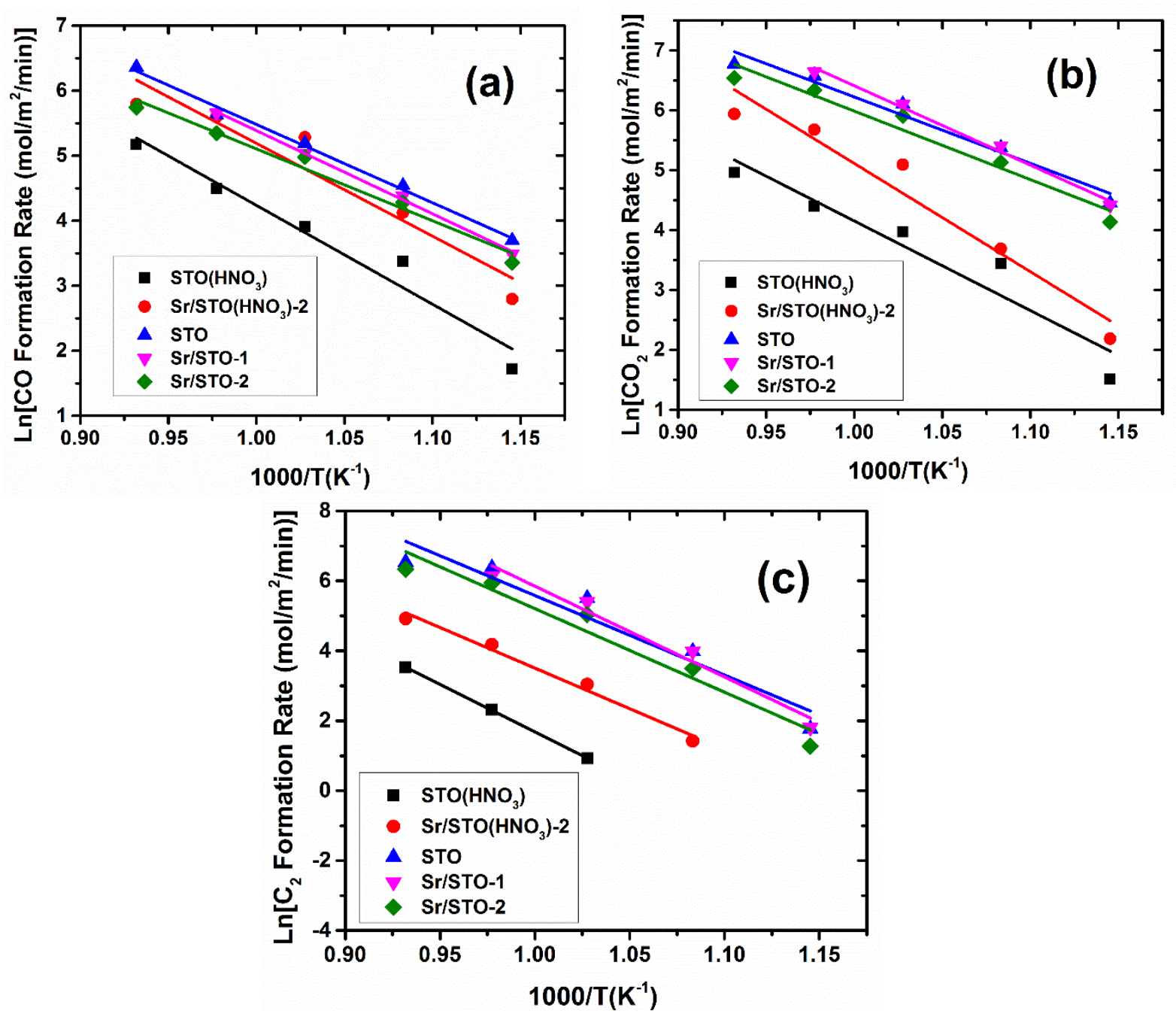

Figure 16. The Arrhenius plots for $\mathrm{CO}, \mathrm{CO}_{2}$ and $\mathrm{C}_{2}$ formation during $\mathrm{OCM}$ over various $\mathrm{STO}$ catalysts.

Note: Experimental conditions: $5 \mathrm{mg}$ catalyst, $1.0 \mathrm{~atm}$, feed consists of $25 \mathrm{~mL} / \mathrm{min}$ of $10 \% \mathrm{CH}_{4} / \mathrm{Ar}, 10 \mathrm{~mL} / \mathrm{min}$ of $5 \% \mathrm{O}_{2} / \mathrm{He}$, and $15 \mathrm{~mL} / \mathrm{min}$ of $\mathrm{He}$ as balance gas.

The acid-base properties of active sites on catalysts are reported to be responsible for the catalytic performance in the OCM reaction[41, 42]. Therefore, the relationship between $\mathrm{CH}_{4}$ conversion and acid or base site density is investigated and plotted in Figure 17. The $\mathrm{CH}_{4}$ conversion increases with increasing surface base site density (Figure 17(a)), while it decreases with increasing acid site density (Figure 17(b)). 

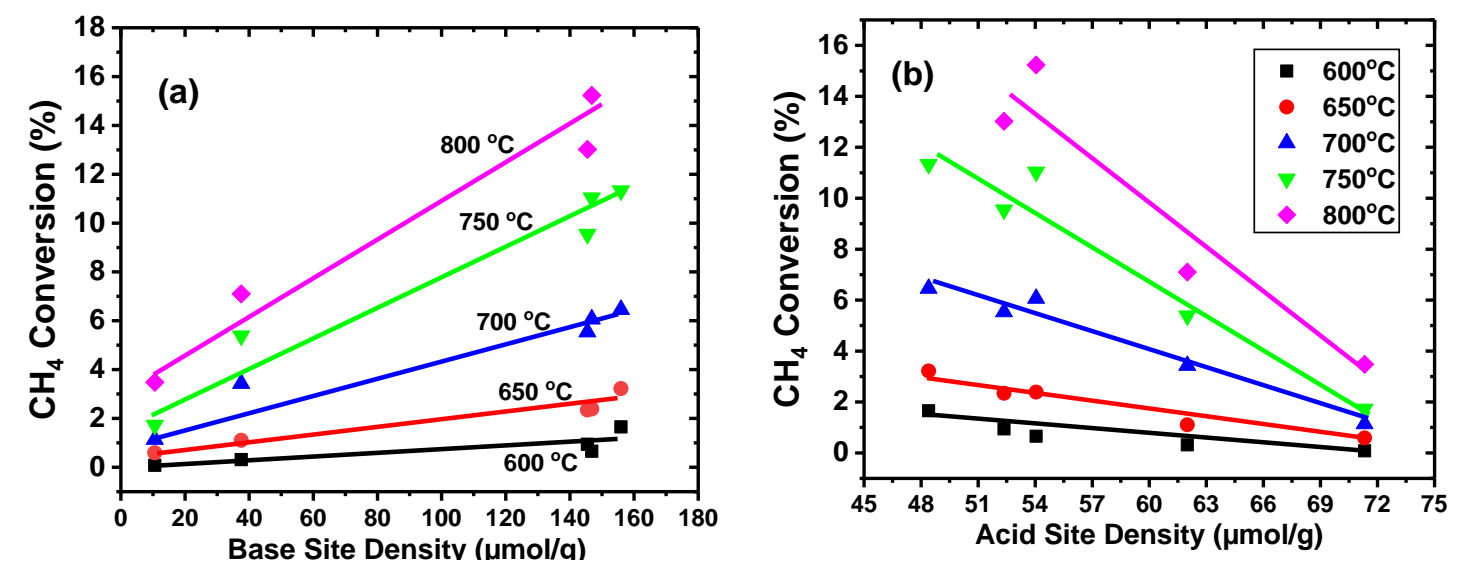

Figure 17. $\mathrm{CH}_{4}$ conversion as the function of the surface base site density and the acid site density for OCM reaction over various STO samples.

Moreover, Figure 18 indicates that the higher the relative concentration of base sites (i.e. base/(base+acid)), the higher the $\mathrm{CH}_{4}$ conversion. As mentioned before, $\mathrm{CH}_{4}$ conversions of STO samples remain steady when $\mathrm{Sr} /(\mathrm{Sr}+\mathrm{Ti})$ is greater than 0.66 . However, after $\mathrm{Sr} /(\mathrm{Sr}+\mathrm{Ti})>0.66$, the relative concentration of basic sites (base/(base+acid)) also remains constant. Furthermore, Figure 8(b) shows that the strength of the basic sites is the same for STO samples with $\mathrm{Sr} /(\mathrm{Sr}+\mathrm{Ti})$ ratio more than 0.66. Therefore, the $\mathrm{CH}_{4}$ conversion shows a linear increase with the ratio of base/(base+acid) over the whole range of surface compositions, suggesting that the relative base site concentration (i.e. base/(base+acid)) is a better descriptor for the catalytic activity. This relationship also suggested that the synergy between the basic sites and the acid sites over STO catalysts plays an important role in the oxidative coupling of methane. 


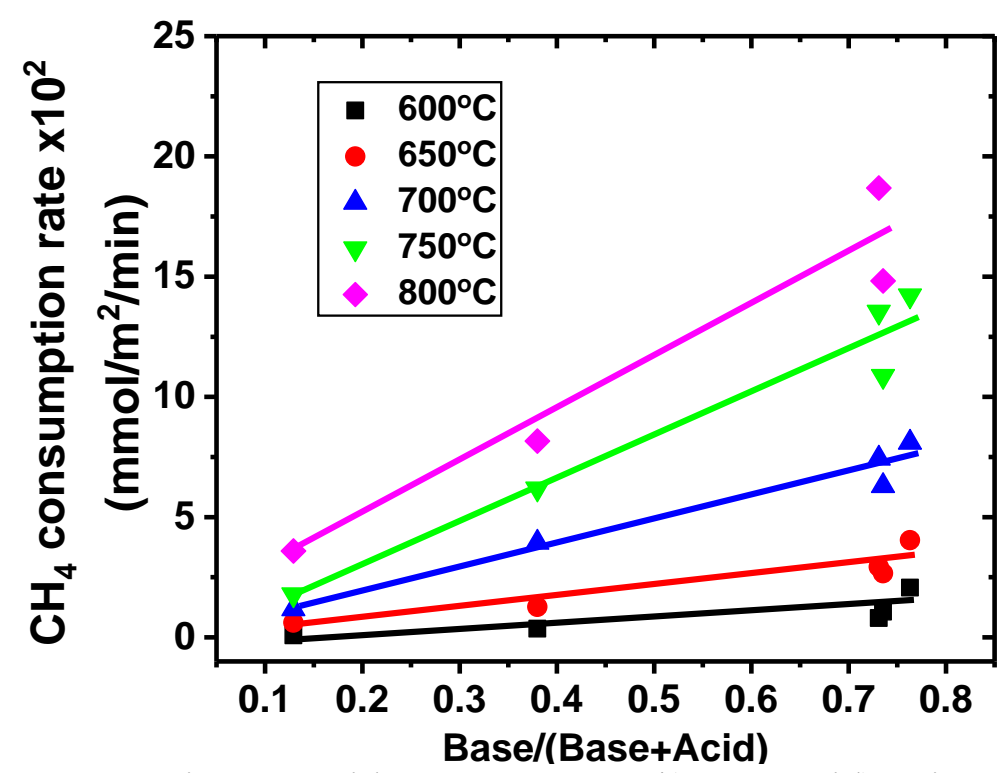

Figure 18. $\mathrm{CH}_{4}$ conversion rate with respect to Base/(Base+Acid) ratio at different temperatures over various STO samples.

In Figure 18, the enhancement effect of base sites on the $\mathrm{CH}_{4}$ conversion can be represented by the slopes of the trendlines at each temperature. The enhancement effect of base sites on the $\mathrm{CH}_{4}$ conversion increases with reaction temperature, since the slope values rise with temperatures (See Table 7). It is also observed from Figure 19, for each sample with a fixed Base/(Base+Acid) concentration, the $\mathrm{CH}_{4}$ consumption rate is exponentially enhanced with reaction temperature.

Table 7. Slopes of trendlines for Base/(Base+Acid)-CH4 consumption relationship.

\begin{tabular}{lccccc}
\hline Temperatures & 600 & 650 & 700 & 750 & 800 \\
\hline Slopes of Trendline & 2.2 & 4.5 & 9.9 & 18.2 & 22.1 \\
\hline
\end{tabular}




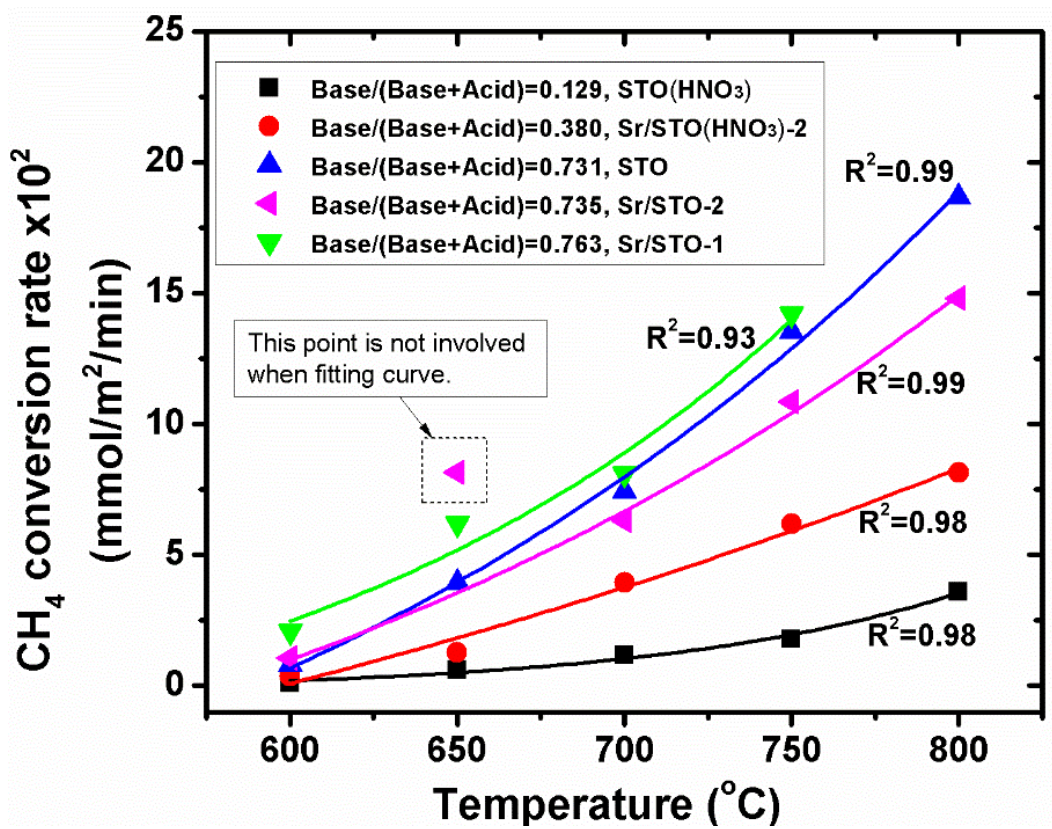

Figure 19. $\mathrm{CH}_{4}$ conversion rate with respect to temperatures over various STO samples (with different Base/(Base+Acid) ratios).

\subsubsection{Kinetics Analysis of STO Samples in OCM}

The kinetics of the OCM reaction has been intensively studied over different catalysts[6264]. In this work, four reported mechanisms, including the Power Law model[61, 65], the MarsVan Krevelen model[66], the double-site Langmuir-Hinshelwood model[67] and the Eley-Rideal model[68], were examined for the OCM reactions over the STO catalysts. All the reaction schemes proposed by each model and the corresponding rate equations for each mechanism are presented in the Section 3.3.7. To achieve the differential conditions, the OCM reaction was performed at $650^{\circ} \mathrm{C}$ to obtain low $\mathrm{CH}_{4}$ conversion $(<10 \%)$. It is noted that the $\mathrm{O}_{2}$-lean condition for kinetic tests $\left(\mathrm{CH}_{4} / \mathrm{O}_{2}\right.$ ratio in the range of 2-7) is in favor of both $\mathrm{OCM}$ and the partial oxidation reaction $[69,70]$. In some kinetic tests for $\mathrm{OCM}$, production of $\mathrm{CO}$ and $\mathrm{H}_{2}$ was detected, suggesting the coexistence of partial oxidation over a metastable state of the catalyst surface. The catalyst pretreatment in $\mathrm{O}_{2}$ was extended in some cases out to $15 \mathrm{~h}$ to achieve the thermodynamically stable 
surface that favors the OCM reaction. All results presented in this work are for cases where OCM dominates.

Figure 20 shows the methane consumption rate as a function of $\mathrm{P}\left(\mathrm{CH}_{4}\right)$ and $\mathrm{P}\left(\mathrm{O}_{2}\right)$ over different STO catalysts. In general, the rate of $\mathrm{CH}_{4}$ conversion exhibits a positive dependence on both $\mathrm{P}\left(\mathrm{CH}_{4}\right)$ and $\mathrm{P}\left(\mathrm{O}_{2}\right)$. Through a comparison across these STO catalysts, it can be observed that the commercial STO sample has the highest methane conversion rate (except that Sr/STO-1 shows higher conversion rate when $\mathrm{P}\left(\mathrm{CH}_{4}\right)>0.048$ atm), while the acid-treated $\mathrm{STO}\left(\mathrm{HNO}_{3}\right)$ sample shows the lowest methane conversion rate at the same $\mathrm{P}\left(\mathrm{CH}_{4}\right)$ or $\mathrm{P}\left(\mathrm{O}_{2}\right)$. We have attempted kinetic analyses of the OCM reaction by using the above-mentioned four models over this set of STO samples (Section 3.3.7). However, poor fitting of the measured methane consumption rates with any of the models suggests that the catalytic behavior of the STO samples cannot be simply described by these proposed four models. Accurate modelling of kinetics for OCM over the reconstructed perovskite catalysts remains contingent upon a detailed computational study of reaction elementary steps.
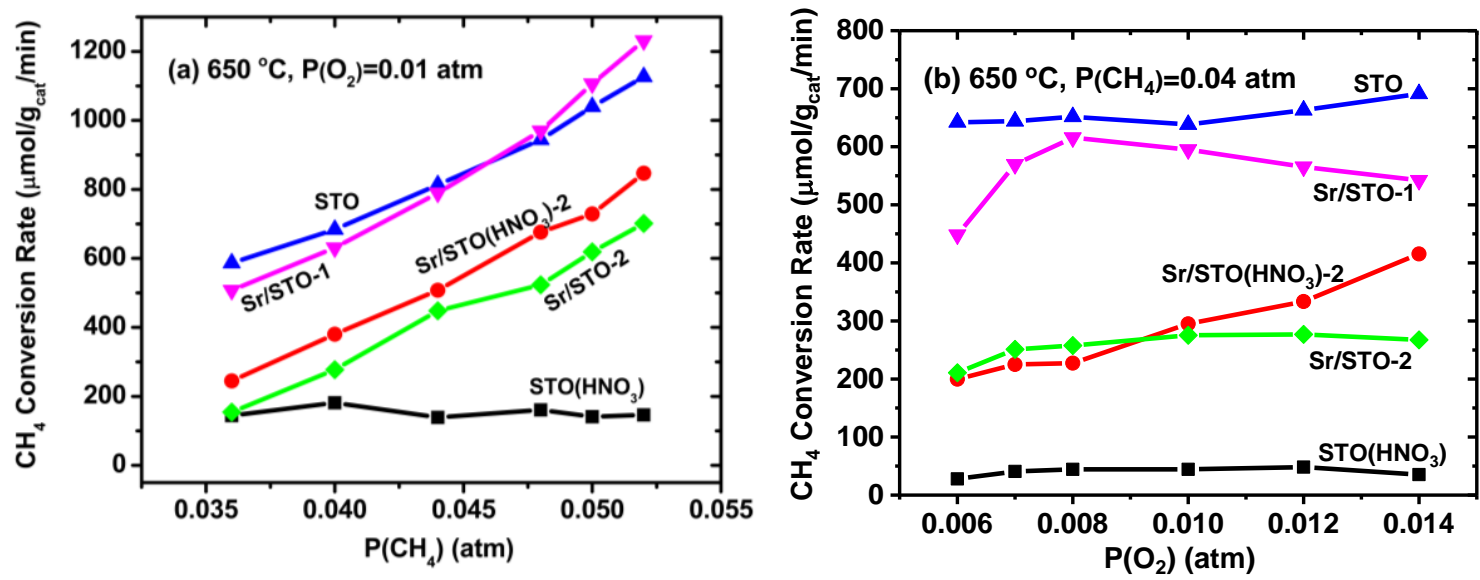

Figure 20. Methane consumption rate as a function of (a) $\mathrm{CH}_{4}$ pressure at $\mathrm{P}\left(\mathrm{O}_{2}\right)=0.01$ atm and of (b) $\mathrm{O}_{2}$ pressure at $\mathrm{P}\left(\mathrm{CH}_{4}\right)=0.04$ atm, respectively, over various STO samples. (Reaction conditions: $650{ }^{\circ} \mathrm{C}$ for bed temperature, total flow rate $=50 \mathrm{~mL} / \mathrm{min}, \mathrm{He}+\mathrm{Ar}$ as balance gas.) 


\subsubsection{Methane and Oxygen Consumption Rates over STO Catalysts Based on Different Mechanisms}

In present work, the methane consumption rates $\left(\mathrm{r}_{\mathrm{CH}}\right)$ were measured under various partial pressure of methane $\left(\mathrm{P}_{\mathrm{CH} 4}\right)$ or oxygen $\left(\mathrm{P}_{2}\right)$ to study the kinetics of OCM reactions. Four kinetic models are tested to analyze the OCM reaction over the STO catalysts with surface reconstruction. The applied models are Power Law model[61, 65], Mars-Van Krevelen model[71], Double site Langmuir-Hinshelwood model[67] and Eley-Rideal model[68].

\subsubsection{Power Law Model}

This model is proposed by Takanabe and Iglesia[65], with the assumption that the methane activation is the rate determine step and dissociative oxygen adsorption is weak at high temperature for OCM reaction. In this mechanism, the first step involves oxygen $\left(\mathrm{O}_{2}\right)$ dissociatively adsorbed on the active surface vacancies $(*)$ to form $\mathrm{O}^{*}$. In the second step, methane is activated by surface $\mathrm{O} *$ to form methyl radicals and $\mathrm{OH}^{*}$. Finally, two $\mathrm{OH}^{*}$ combine to from $\mathrm{H}_{2} \mathrm{O}$ and surface vacancies $\left(^{*}\right)$. The later steps for $\mathrm{C}_{2} \mathrm{H}_{6}$ and $\mathrm{CO}_{\mathrm{x}}$ formation and corresponding methane consumption rate expression are presented in the Table 8 . 
Table 8 . The OCM reaction scheme proposed by Takanabe and Iglesia[65].

$$
\begin{aligned}
& O_{2}+2(*) \stackrel{K_{1}}{\leftrightarrow} 2 O^{*} \\
& \mathrm{CH}_{4}+\mathrm{O}^{*} \stackrel{\mathrm{k}_{2}}{\rightarrow} \mathrm{CH}_{3} \cdot+\mathrm{OH}^{*} \\
& 2 \mathrm{OH}^{*} \stackrel{\mathrm{K}_{3}}{\leftrightarrow} \mathrm{H}_{2} \mathrm{O}+\mathrm{O}^{*}+(*) \\
& 2 \mathrm{CH}_{3} \bullet+M \stackrel{k_{4}}{\rightarrow} C_{2} \mathrm{H}_{6}+M \\
& \mathrm{CH}_{3} \cdot+\mathrm{O}_{2} \stackrel{k_{5}}{\rightarrow} \mathrm{CO} \\
& 2 \mathrm{CH}_{3} \bullet+\mathrm{O}^{*} \stackrel{k_{6}}{\rightarrow} \mathrm{C}_{2} \mathrm{H}_{6}+\mathrm{M}
\end{aligned}
$$

$\mathrm{CH}_{4}$ consumption rate expression: $r_{\mathrm{CH}_{4}}=k_{p} P_{\mathrm{CH}_{4}} \sqrt{P_{\mathrm{O}_{2}}}$

M: third body in the reaction.

Based on the above-mentioned mechanism, a power law expression for methane conversion is proposed and tested:

$$
r_{C_{4}}=k\left(P_{C H_{4}}\right)^{a}\left(P_{O_{2}}\right)^{b}
$$

The effect of partial pressure of $\mathrm{CH}_{4}$ and $\mathrm{O}_{2}$ on methane conversion rate are studied to calculate the reactant orders. Figure 21(a) presents the $\mathrm{CH}_{4}$ conversion rate as a function of $\mathrm{CH}_{4}$ partial pressure at a constant oxygen pressure, meanwhile 21(b) shows the $\mathrm{CH}_{4}$ conversion rate as a function of $\mathrm{O}_{2}$ partial pressure at fixed methane pressure on all investigated STO samples. Reactant order $a$ and one rate constant $k$ can be calculated from fitting the curves in Figure 21(a). Similarly, reactant order $b$ and one rate constant $k^{\prime}$ can be calculated from fitting the curves in Figure 21(b). If the present STO samples follow this OCM mechanism, the reactants orders should be $\mathrm{a}=1, \mathrm{~b}=0.5$, respectively. $k$ should be equal to $k$ '. However, from the fitting results listed in 
Table 9, it found that $a$ and $b$ are not equal to 1 and 0.5 , respectively. Moreover, most calculated $k$ and $k^{\prime}$ are different. Therefore, the proposed power law rate expression is not satisfactory to describe the OCM reaction of present STO samples.
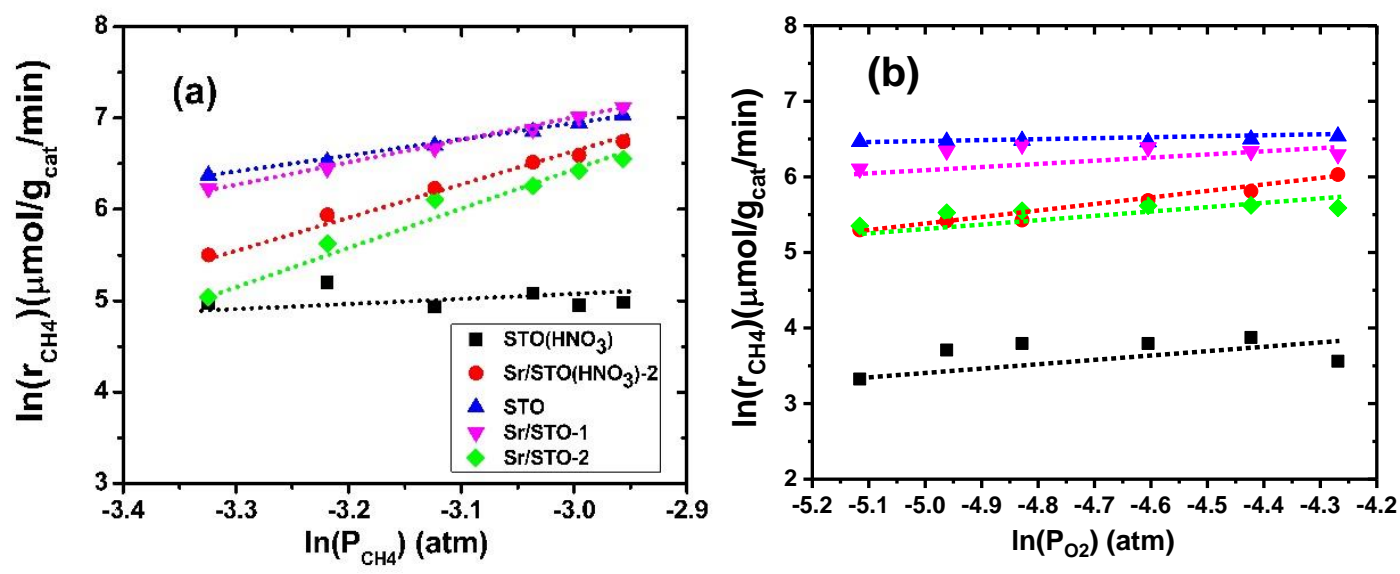

Figure 21. Effect of (a) $\mathrm{CH}_{4}$ partial pressure on $\mathrm{CH}_{4}$ conversion rate at $\mathrm{P}\left(\mathrm{O}_{2}\right)=0.01$ atm and (b) $\mathrm{O}_{2}$ partial pressure on $\mathrm{CH}_{4}$ conversion rate at $\mathrm{P}\left(\mathrm{CH}_{4}\right)=0.04$ atm at $650^{\circ} \mathrm{C}$.

Table 9. Results of reactant orders and rate constants for STO samples analyzed by power law model.

\begin{tabular}{|c|c|c|c|c|}
\hline Catalyst ID & $a$ & $b$ & \multicolumn{2}{|c|}{$\left(\mu \mathrm{mol} / \mathrm{g}_{\mathrm{cat}} / \mathrm{min} / \mathrm{atm}^{1.5}\right)$} \\
\hline $\mathrm{STO}\left(\mathrm{HNO}_{3}\right)$ & -0.178 & 0.263 & $2.92 \mathrm{E}+02$ & $7.67 \mathrm{E}+01$ \\
\hline $\mathrm{Sr} / \mathrm{STO}\left(\mathrm{HNO}_{3}\right)-2$ & 3.287 & 0.846 & $7.02 \mathrm{E}+08$ & $5.74 \mathrm{E}+08$ \\
\hline STO & 1.779 & 0.071 & $2.95 \mathrm{E}+05$ & $2.80 \mathrm{E}+05$ \\
\hline Sr/STO-1 & 2.408 & 0.133 & $2.73 \mathrm{E}+06$ & $2.39 \mathrm{E}+06$ \\
\hline Sr/STO-2 & 3.984 & 0.250 & $3.07 \mathrm{E}+08$ & $3.07 \mathrm{E}+08$ \\
\hline
\end{tabular}

\subsubsection{Mars-Van Krevelen Model}

The scheme in the Table 10 shows the elementary reaction steps in the proposed Mars-Van Krevelen mechanism[71]. First of all, the surface active site is oxidized to form the O.S. In the second step, the gaseous methane reacts with oxidized active site, which consequently reduced the 
active site to its original form. The methyl radical is also formed in this step. Then the methyl radicals partially react with oxygen to generate $\mathrm{CO}_{\mathrm{x}}$ (step S2-3), partially undergo coupling to form $\mathrm{C}_{2} \mathrm{H}_{6}$ (step S2-4). The corresponding methane consumption rate is also presented in the Table 10.

Table 10. The Mars-Van Krevelen mechanism for OCM reaction[71].

$$
\begin{aligned}
& \frac{1}{2} O_{2}+S \stackrel{\mathrm{k}_{1}}{\rightarrow} O \cdot S \\
& \mathrm{CH}_{4}+\mathrm{O} \cdot \mathrm{S} \stackrel{\mathrm{k}_{2}}{\rightarrow} \mathrm{CH}_{3} \bullet+\mathrm{OH} \bullet+\mathrm{S} \\
& \mathrm{CH}_{3} \bullet+\frac{x}{2} \mathrm{O}_{2} \stackrel{\mathrm{k}_{3}}{\rightarrow} \mathrm{CO}_{x} \\
& 2 \mathrm{CH}_{3} \bullet \stackrel{\mathrm{k}_{4}}{\rightarrow} \mathrm{C}_{2} \mathrm{H}_{6}
\end{aligned}
$$

$\mathrm{CH}_{4}$ consumption rate expression: $r_{\mathrm{CH}_{4}}=\frac{k_{1} k_{2} P_{O_{2}}^{0.5} P_{C H_{4}}}{k_{1} P_{O_{2}}^{0.5}+k_{2} P_{C H_{4}}}$

S: surface active site in reduced form; O·S: surface active site in oxidized form.

The equation (EqS2-1) can be rearranged to the following two expressions:

$$
\begin{aligned}
& \frac{P_{O_{2}}^{0.5}}{r_{C H_{4}}}=\frac{1}{k_{1}}+\frac{P_{O_{2}}^{0.5}}{k_{2} P_{C H_{4}}} \\
& \frac{P_{C H_{4}}}{r_{C H_{4}}}=\frac{1}{k_{2}}+\frac{P_{C H_{4}}}{k_{1} P_{O_{2}}^{0.5}}
\end{aligned}
$$

When the $P_{\mathrm{O}_{2}}$ is constant, plots of $\frac{P_{\mathrm{O}_{2}}^{0.5}}{r_{\mathrm{CH}_{4}}}$ against $\frac{1}{P_{\mathrm{CH}_{4}}}$ can be obtained. Similarly, when the $P_{C H_{4}}$ is fixed, plots of $\frac{P_{C H_{4}}}{r_{C_{4}}}$ against $\frac{1}{P_{O_{2}}^{0.5}}$ can also be drawn. These two plots are shown in Figure

22. Two sets of kinetic parameters $k_{1}, k_{2}$ and $k_{1}{ }^{\prime}, k_{2}{ }^{\prime}$ can be determined from the relationships of 
$\frac{P_{O_{2}}^{0.5}}{r_{C_{4}}} \sim \frac{1}{P_{C H_{4}}}$ and $\frac{P_{C H_{4}}}{r_{C_{4}}} \sim \frac{1}{P_{O_{2}}^{0.5}}$, respectively. Ideally, if the OCM reaction of STO samples follows the Mars-Van Krevelen model, identical $k_{1}$ and $k_{1}$ ' $\left(k_{2}\right.$ and $\left.k_{2}{ }^{\prime}\right)$ are supposed to be attained. The kinetic parameters, determined from the linear plots, are given in Table 11. Obviously, $k_{l}$ and $k_{l}$, ( $k_{2}$ and $k_{2}^{\prime}$ ) are significantly different. This model does not fit the kinetics for the OCM reactions over all the STO catalysts.
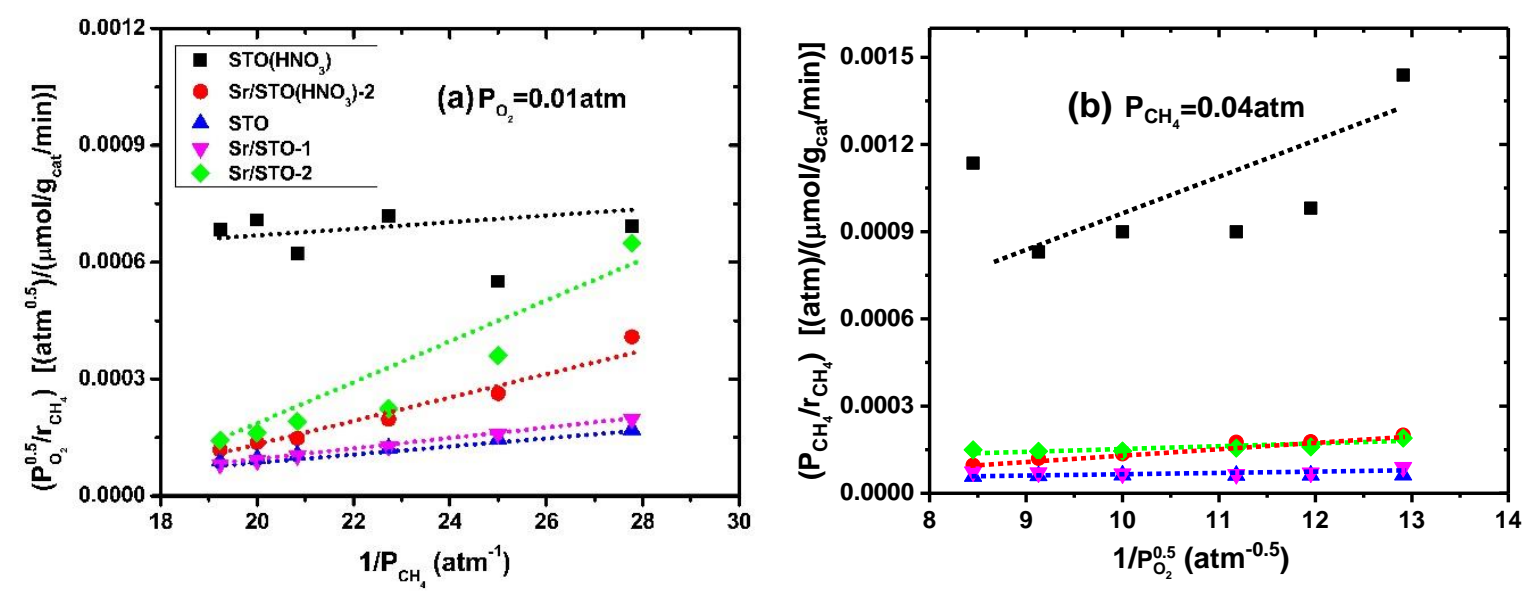

Figure 22. (a) Plots of $\frac{P_{O_{2}}^{0.5}}{r_{C_{4}}}$ against $\frac{1}{P_{C_{4}}}$ at $\mathrm{P}\left(\mathrm{O}_{2}\right)=0.01 \mathrm{~atm}$ and (b)plots of $\frac{P_{C_{4}}}{r_{C_{4}}}$ against $\frac{1}{P_{O_{2}}^{0.5}}$ at $\mathrm{P}\left(\mathrm{CH}_{4}\right)=0.04$ atm at $650^{\circ} \mathrm{C}$.

Table 11. Kinetic parameters for STO samples analyzed by Mars-Van Krevelen model.

\begin{tabular}{lcccc}
\hline $\begin{array}{l}\text { Catalyst ID } \\
(\text { Unit })\end{array}$ & $\begin{array}{c}k_{1} \\
\left(\mu \mathrm{mol} / \mathrm{g}_{\text {cat }} / \mathrm{min} / \mathrm{atm}^{0.5}\right)\end{array}$ & $\begin{array}{c}k_{2} \\
(\mu \mathrm{mol} / \mathrm{g} / \mathrm{min} / \mathrm{atm})\end{array}$ \\
\hline $\mathrm{STO}\left(\mathrm{HNO}_{3}\right)$ & $1.32 \mathrm{E}+03$ & $6.18 \mathrm{E}+02$ & $-2.32 \mathrm{E}+04$ & $2.90 \mathrm{E}+03$ \\
Sr/STO$\left(\mathrm{HNO}_{3}\right)-2$ & $-1.90 \mathrm{E}+03$ & $1.74 \mathrm{E}+03$ & $3.06 \mathrm{E}+03$ & $-1.07 \mathrm{E}+04$ \\
$\mathrm{STO}$ & $-1.05 \mathrm{E}+04$ & $5.13 \mathrm{E}+04$ & $1.04 \mathrm{E}+04$ & $1.89 \mathrm{E}+04$ \\
Sr/STO-1 & $-5.55 \mathrm{E}+03$ & $1.72 \mathrm{E}+04$ & $7.38 \mathrm{E}+03$ & $2.08 \mathrm{E}+04$ \\
Sr/STO-2 & $-1.02 \mathrm{E}+03$ & $4.91 \mathrm{E}+03$ & $1.78 \mathrm{E}+03$ & $1.41 \mathrm{E}+04$ \\
\hline
\end{tabular}




\subsubsection{Double Site Langmuir-Hinshelwood Model}

Table 12 shows the proposed reaction steps for OCM reactions following the Double site Langmuir-Hinshelwood mechanism. In this mechanism, oxygen and methane are adsorbed on two types of active sites $\left(\mathrm{S}^{1}\right.$ and $\left.\mathrm{S}^{2}\right)$ to form the $\mathrm{O}_{2} \cdot \mathrm{S}^{1}$ and $\mathrm{CH}_{4} \cdot \mathrm{S}^{2}$ species in steps $\mathrm{S} 3-1$ and $\mathrm{S} 3-2$, respectively. In next step (S3-3), the C-H bond is activated and methyl radicals are produced by the reaction between molecularly adsorbed methane and oxygen species. Then the methyl radicals partially react with either oxygen on the catalyst surface or gaseous oxygen to generate $\mathrm{CO}_{\mathrm{x}}(\mathrm{S} 3-$ 4). Simultaneously, methyl radicals undergo coupling to form $\mathrm{C}_{2} \mathrm{H}_{6}$ (S3-5). The corresponding methane consumption rate Eq S3-1 is presented in the Table 12.

When the $P_{\mathrm{O}_{2}}$ is fixed in the OCM reaction, Eq S3-1 can be rearranged to,

$$
\frac{P_{C_{4}}}{r_{C_{4}}}=\left(\frac{1+K_{O_{2}} P_{O_{2}}}{k K_{O_{2}} P_{O_{2}}}\right) P_{C H_{4}}+\frac{1+K_{O_{2}} P_{O_{2}}}{k K_{O_{2}} K_{C H_{4}} P_{O_{2}}}
$$

The plot of $\frac{P_{C_{4}}}{r_{C_{4}}}$ as a function of $P_{C_{4}}$ indicates that the slope of the plot is $\frac{1+K_{O_{2}} P_{O_{2}}}{k K_{O_{2}} P_{O_{2}}}$ and

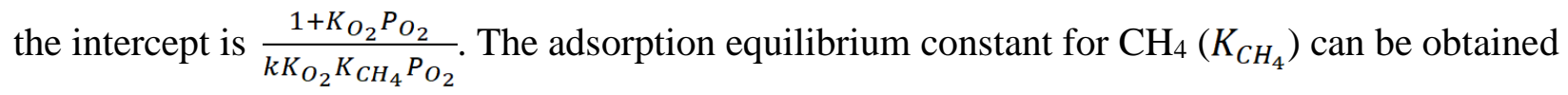

from the ratio of slope to intercept in Eq S3-2.

Similarly, when the $P_{\mathrm{CH}_{4}}$ is constant, Eq S3-1 can be rearranged to,

$$
\frac{P_{O_{2}}}{r_{C_{4}}}=\left(\frac{1+K_{C H_{4}} P_{C H_{4}}}{k K_{C H_{4}} P_{C H_{4}}}\right) P_{O_{2}}+\frac{1+K_{C H_{4}} P_{C H_{4}}}{k K_{O_{2}} K_{C_{4}} P_{C H_{4}}}
$$


The plot of $\frac{P_{O_{2}}}{r_{C_{4}}}$ as a function of $P_{O_{2}}$ indicates that the slope of the plot is $\frac{1+K_{C H_{4}} P_{C H_{4}}}{k K_{C H_{4}} P_{C H_{4}}}$ and the intercept is $\frac{1+K_{C_{4} P_{C H_{4}}}}{k K_{O_{2}} K_{C_{4}} P_{C_{4}}}$. The adsorption equilibrium constant for $\mathrm{O}_{2}\left(\mathrm{~K}_{\mathrm{O}_{2}}\right)$ can be obtained from the ratio of slope to intercept in Eq S3-3.

Plots of $\mathrm{P}_{\mathrm{CH}_{4}} / \mathrm{r}_{\mathrm{CH}_{4}}$ against $\mathrm{P}_{\mathrm{CH}_{4}}$ and plots of $\mathrm{P}_{2} / \mathrm{r}_{\mathrm{CH}_{4}}$ against $\mathrm{P}_{\mathrm{O}_{2}}$ are shown in Figure 23. Two methane activation rate constants ( $k$ and $k^{\prime}$ ) can be calculated by substituting the $K_{\mathrm{CH}_{4}}$ and $\mathrm{K}_{\mathrm{O}_{2}}$ into the Eq S3-2 and Eq S3-3, respectively. If the Double site Langmuir-Hinshelwood model fits the kinetics for the OCM reaction over STO samples, $k$ and $k$ ' with the same values will be solved. The determined kinetic parameters are listed in the Table 13. It is found from Figure 23 that the linear fitting for $\mathrm{Sr} / \mathrm{STO}\left(\mathrm{HNO}_{3}\right)-2, \mathrm{STO}, \mathrm{Sr} / \mathrm{STO}-1, \mathrm{Sr} / \mathrm{STO}-2$ samples exhibit negative intercepts. Also, all $K_{C_{4}}$ are with negative values, and $k$ does not match with $k$ ' value for each STO sample. These results are in contrary to the proposed model. Therefore, the Double site LangmuirHinshelwood model is not suitable to describe the OCM reaction over STO samples. 
Table 12. The Double site Langmuir-Hinshelwood mechanism for OCM reaction[67].

$$
\begin{aligned}
& \mathrm{O}_{2}+\mathrm{S}^{1} \stackrel{\mathrm{KOO}_{2}}{\leftrightarrow} \mathrm{O}_{2} \cdot \mathrm{S}^{1} \\
& \mathrm{CH}_{4}+\mathrm{S}^{2} \stackrel{\mathrm{K}_{\mathrm{CH}}}{\leftrightarrow} \mathrm{CH}_{4} \cdot \mathrm{S}^{2} \\
& \mathrm{CH}_{4} \cdot \mathrm{S}^{2}+\mathrm{O}_{2} \cdot \mathrm{S}^{1} \stackrel{k}{\rightarrow} \mathrm{CH}_{3} \bullet+\mathrm{HO}_{2} \cdot+\mathrm{S}^{1}+S^{2} \\
& \mathrm{CH}_{3} \bullet+\frac{x}{2} \mathrm{O}_{2} \stackrel{k_{1}}{\rightarrow} \mathrm{CO}_{x} \\
& 2 \mathrm{CH}_{3} \bullet \stackrel{k_{2}}{\rightarrow} \mathrm{C}_{2} \mathrm{H}_{6}
\end{aligned}
$$

$\mathrm{CH}_{4}$ consumption rate expression: $r_{\mathrm{CH}_{4}}=\frac{k K_{O_{2}} K_{C_{4}} P_{C H_{4}} P_{O_{2}}}{\left(1+K_{O_{2}} P_{O_{2}}\right)\left(1+K_{C_{4}} P_{C H_{4}}\right)}$
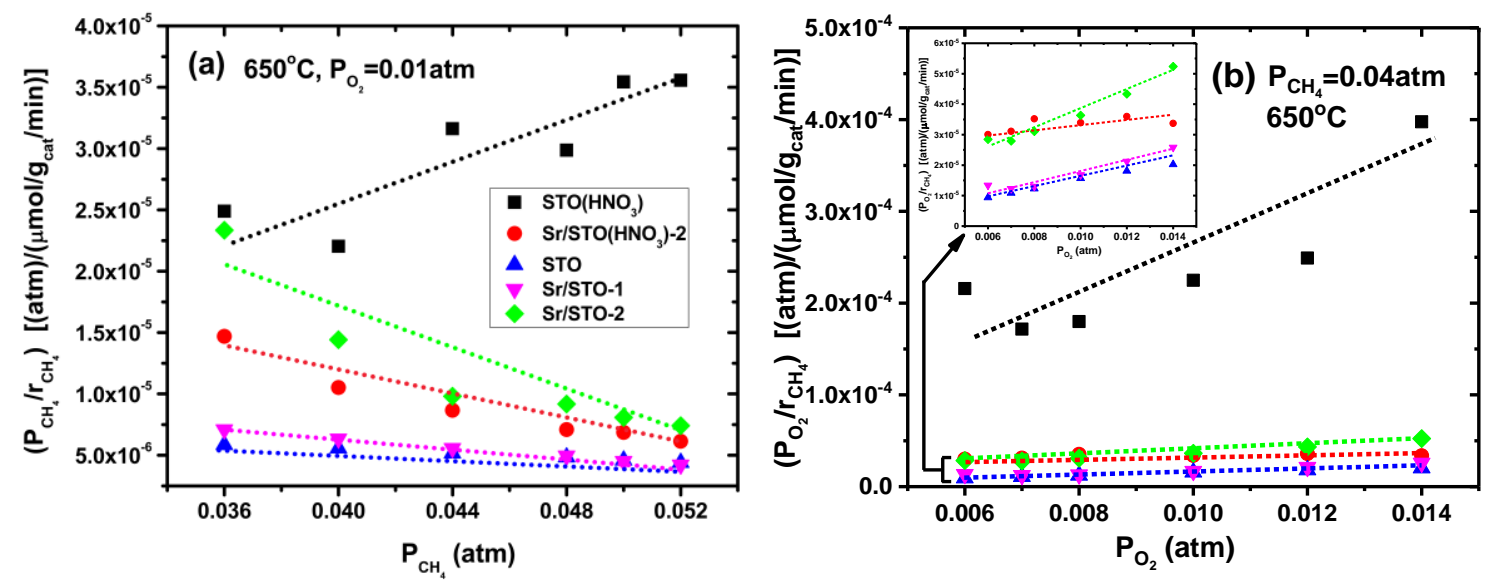

Figure 23. Linearized correlations of (a) $\frac{P_{C_{4}}}{r_{C_{4}}}$ versus $P_{C_{4}}$ and (b) $\frac{P_{O_{2}}}{r_{C_{4}}}$ versus $P_{O_{2}}$. The inset in (b) shows an enlarged image of $\mathrm{Sr} / \mathrm{STO}\left(\mathrm{HNO}_{3}\right)-2$, STO, Sr/STO-1, Sr/STO-2 samples. 
Table 13. Kinetic parameters for STO samples analyzed by Double site LangmuirHinshelwood model.

\begin{tabular}{lcccc}
\hline $\begin{array}{l}\text { Catalyst ID } \\
(\text { Unit })\end{array}$ & $\begin{array}{c}K_{\mathrm{CH}_{4}} \\
\left(\mathrm{~atm}^{-1}\right)\end{array}$ & $\begin{array}{c}K_{O_{2}} \\
\left(\mathrm{~atm}^{-1}\right)\end{array}$ & $\begin{array}{c}k \\
\left(\mu \mathrm{mol} / \mathrm{g}_{\mathrm{cat}} / \mathrm{min}\right)\end{array}$ & $\begin{array}{c}k^{\prime} \\
\left(\mu \mathrm{mol} / \mathrm{g}_{\mathrm{cat}} / \mathrm{min}\right)\end{array}$ \\
\hline $\mathrm{STO}\left(\mathrm{HNO}_{3}\right)$ & $-1.41 \mathrm{E}+02$ & $8.71 \mathrm{E}+02$ & $1.41 \mathrm{E}+02$ & $3.65 \mathrm{E}+01$ \\
Sr/STO$\left(\mathrm{HNO}_{3}\right)-2$ & $-1.59 \mathrm{E}+01$ & $1.67 \mathrm{E}+01$ & $-1.40 \mathrm{E}+03$ & $-1.20 \mathrm{E}+03$ \\
STO & $-9.98 \mathrm{E}+00$ & $1.10 \mathrm{E}+03$ & $-1.19 \mathrm{E}+03$ & $-1.09 \mathrm{E}+03$ \\
Sr/STO-1 & $-1.33 \mathrm{E}+01$ & $1.76 \mathrm{E}+03$ & $-5.89 \mathrm{E}+02$ & $-5.21 \mathrm{E}+02$ \\
Sr/STO-2 & $-1.72 \mathrm{E}+01$ & $4.20 \mathrm{E}+02$ & $-1.37 \mathrm{E}+02$ & $-1.49 \mathrm{E}+02$ \\
\hline
\end{tabular}

\subsubsection{Eley-Rideal Model}

The elementary steps in the Eley-Rideal mechanism are listed in Table 14. The oxygen is firstly adsorbed on the surface active site $\mathrm{S}$ and form the active species $\left(\mathrm{O}_{2}\right)_{\text {ads }}(\mathrm{S} 4-1)$. The gaseous methane reacts with $\left(\mathrm{O}_{2}\right)_{\text {ads }}$ to form the methyl radicals in step (S4-2). Similar with other mechanism, some generated methyl radicals are oxidized to $\mathrm{CO}_{\mathrm{x}}$ product (S4-3), and some undergo the coupling to form the ethane at the same time(S4-4). The rate law for $\mathrm{CH}_{4}$ consumption is listed in Table 14 as well.

Table 14. The Eley-Rideal mechanism for OCM reaction[68].

$\mathrm{O}_{2}+\mathrm{S} \stackrel{\mathrm{K}_{\text {ads }}}{\leftrightarrow}\left(\mathrm{O}_{2}\right)_{\text {ads }}$
$\mathrm{CH}_{4}+\left(\mathrm{O}_{2}\right)_{\text {ads }} \stackrel{\mathrm{k}}{\rightarrow} \mathrm{CH}_{3} \bullet+\mathrm{HO}_{2} \bullet+\mathrm{S}$
$\mathrm{CH}_{3} \bullet+\frac{x}{2} \mathrm{O}_{2} \stackrel{\mathrm{k}_{1}}{\rightarrow} \mathrm{CO}_{x}$
$2 \mathrm{CH}_{3} \bullet \stackrel{\mathrm{k}_{2}}{\rightarrow} \mathrm{C}_{2} \mathrm{H}_{6}$
$\mathrm{CH}_{4}$ consumption rate expression: $r_{\mathrm{CH}_{4}}=\frac{\text { PP }_{C H_{4}} K_{a d s} P_{O_{2}}}{\left(1+K_{a d s} P_{O_{2}}\right)}$

When the partial pressure of $\mathrm{CH}_{4}$ is fixed, the rate expression (Eq S4-1) can be rearranged to, 


$$
\frac{P_{C H_{4}}}{r_{C H_{4}}}=\left(\frac{1}{k K_{a d s}}\right) \frac{1}{P_{O_{2}}}+\frac{1}{k}
$$

The methane activation rate constant $\mathrm{k}$ and adsorption equilibrium constant for oxygen ( $\left.\mathrm{K}_{\mathrm{ads}}\right)$ can be determined from the intercept $\frac{1}{k}$ and slope $\frac{1}{k K_{a d s}}$.

When the partial pressure of $\mathrm{O}_{2}$ is fixed, the rate expression (Eq S4-1) can be written as,

$$
\frac{P_{O_{2}}}{r_{C H_{4}}}=\left(\frac{1+K_{a d s} P_{O_{2}}}{k K_{a d s}}\right) \frac{1}{P_{C H_{4}}}
$$

The linear correlation of $\frac{P_{\mathrm{O}_{2}}}{r_{\mathrm{CH}_{4}}}$ versus $\frac{1}{P_{\mathrm{CH}_{4}}}$ in (Eq S4-3), whose slope is $\frac{1+K_{a d s} P_{O_{2}}}{k K_{a d s}}$ and the intercept is 0 , can be used for validating the proposed model. The plots of $\frac{P_{C_{4}}}{r_{C_{4}}} \sim \frac{1}{P_{O_{2}}}$ and $\frac{P_{O_{2}}}{r_{C_{4}}} \sim$ $\frac{1}{P_{\mathrm{CH}_{4}}}$ are drawn in Figure 24.
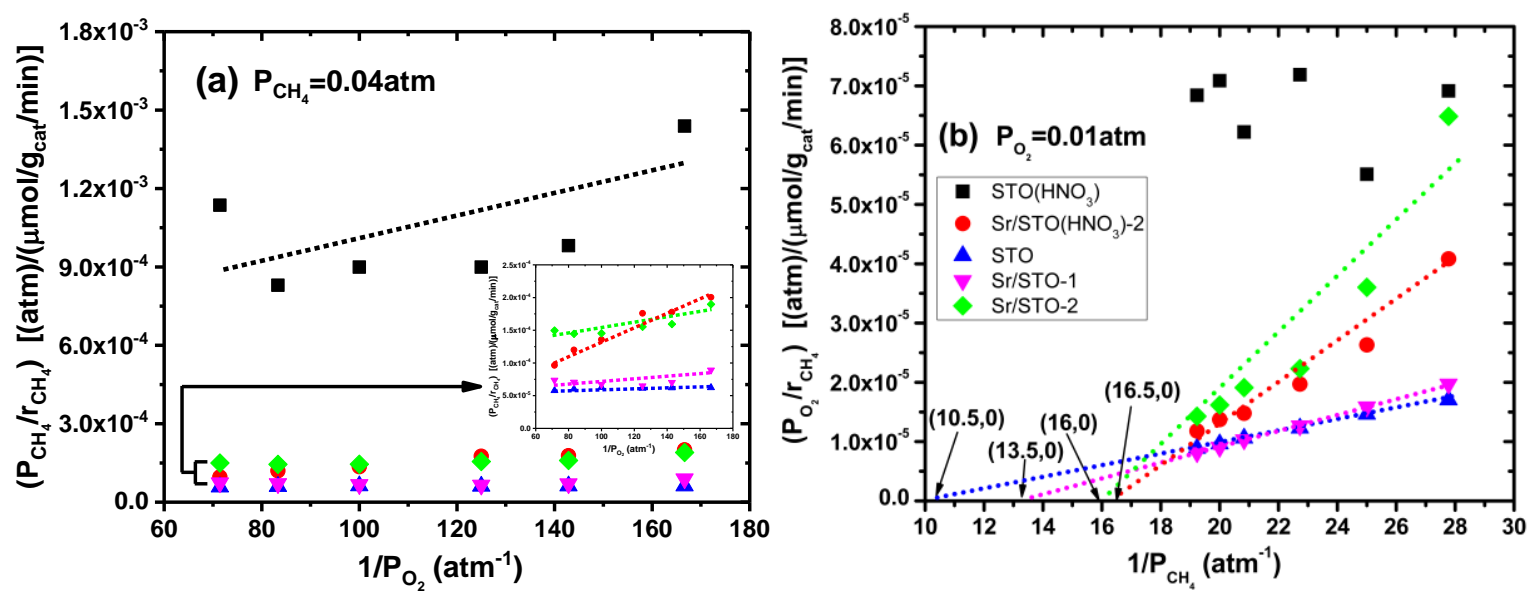

Figure 24. Linearized correlations of (a) $\frac{P_{C_{4}}}{r_{C_{4}}}$ versus $\frac{1}{P_{O_{2}}}$, and (b) $\frac{P_{O_{2}}}{r_{C_{4}}}$ versus $\frac{1}{P_{C H_{4}}}$. The inset in (a) shows an enlarged image of $\mathrm{Sr} / \mathrm{STO}\left(\mathrm{HNO}_{3}\right)-2$, STO, Sr/STO-1, Sr/STO-2 samples. 
Table 15. Kinetic parameters for STO samples analyzed by Eley-Rideal model.

\begin{tabular}{lcccc}
\hline $\begin{array}{l}\text { Catalyst ID } \\
(\text { Unit })\end{array}$ & $\begin{array}{c}k \\
\left(\mu \mathrm{mol} / \mathrm{g}_{\text {cat }} / \mathrm{min} / \mathrm{atm}\right)\end{array}$ & $\begin{array}{c}K_{\text {ads }} \\
\left(\mathrm{atm}^{-1}\right)\end{array}$ & Slope-1 & Slope-2 \\
\hline $\mathrm{STO}\left(\mathrm{HNO}_{3}\right)$ & $1.54 \mathrm{E}+03$ & $1.96 \mathrm{E}+02$ & $9.82 \mathrm{E}-06$ & $-4.30 \mathrm{E}-07$ \\
$\mathrm{Sr} / \mathrm{STO}\left(\mathrm{HNO}_{3}\right)-2$ & $3.58 \mathrm{E}+04$ & $2.61 \mathrm{E}+01$ & $1.35 \mathrm{E}-06$ & $3.27 \mathrm{E}-06$ \\
STO & $1.75 \mathrm{E}+04$ & $1.43 \mathrm{E}+03$ & $6.11 \mathrm{E}-07$ & $9.60 \mathrm{E}-07$ \\
Sr/STO-1 & $1.70 \mathrm{E}+04$ & $4.91 \mathrm{E}+02$ & $7.09 \mathrm{E}-07$ & $1.36 \mathrm{E}-06$ \\
Sr/STO-2 & $8.94 \mathrm{E}+03$ & $2.80 \mathrm{E}+02$ & $1.52 \mathrm{E}-06$ & $5.61 \mathrm{E}-06$ \\
\hline
\end{tabular}

Note: Slope-1: slope of Eq4-3, calculated based on the $\mathrm{k}$ and $\mathrm{K}_{\mathrm{ads}}$ values from Eq4-2 and Figure S14(a). Slope2: slope of Eq4-3, obtained from data fitting from Figure S14(b).

The determined kinetic parameters $k$ and $K_{a d s}$ are presented in the Table 15. However, the

curves of $\frac{P_{\mathrm{O}_{2}}}{r_{\mathrm{CH}_{4}}} \sim \frac{1}{P_{\mathrm{CH}_{4}}}$ plotted in Figure 24(b) show that x-intercepts for $\mathrm{Sr} / \mathrm{STO}\left(\mathrm{HNO}_{3}\right)-2, \mathrm{STO}$,

Sr/STO-1, Sr/STO-2 lines are $(16.5,0),(10.5,0),(13.5,0),(16,0)$, respectively. Also, the crosscheck of Eq S4-3 slope in Table 15 indicates the different values of slope-1 and slope-2. Thus, these results are in contrary to the proposed model. Eley-Rideal model cannot be used for fitting the OCM reaction over STO catalysts.

\subsection{Conclusions}

In this work, surface reconstructed $\mathrm{SrTiO}_{3}$ samples, with different surface composition of Sr, were obtained through incipient wetness impregnation and chemical etching with $\mathrm{HNO}_{3}$. UVRaman and low energy ion scattering (LEIS) analysis results are in good agreement on the surface and subsurface composition of reconstructed STO samples. The redox capability of STO samples was found to be the same, thus their different catalytic performance can be related to the surface acid-base properties rather than lattice reducibility. The OCM reaction at steady state was performed at $600-800{ }^{\circ} \mathrm{C}$ and it was found that the $\mathrm{Sr}$ enrichment (resulting from surface- 
reconstruction) enhances the $\mathrm{CH}_{4}$ conversion, $\mathrm{C}_{2}$ selectivity as well as the ratio of $\mathrm{C}_{2} \mathrm{H}_{4} / \mathrm{C}_{2} \mathrm{H}_{6}$ up to certain surface Sr concentration, similar to the promoting effect of the surface $\mathrm{Sr}$ concentration on methane combustion. Furthermore, it is shown that the catalytic activity $\left(\mathrm{CH}_{4}\right.$ conversion) increases linearly with the relative concentration of basic sites (base/(base+acid)) over the STO catalysts at the full range of surface $\mathrm{Sr}$ concentrations, rendering the relative concentration of basic sites as a tentative descriptor for the activity of STO samples in the OCM reaction. These results for the model STO samples with controlled surface compositions and with the same bulk structure provide valuable insights into designing more efficient perovskite-based catalysts for methane activation and conversion via surface reconstructions. 


\section{Reference}

[1] F. Polo Garzon, V. Fung, X. Liu, Z.D. Hood, E.E. Bickel, L. Bai, H. Tian, G.S. Foo, M. Chi, D.-e. Jiang, Z. Wu, Understanding the Impact of Surface Reconstruction of Perovskite Catalysts on CH4 Activation and Combustion, ACS Catalysis, 8 (2018) 10306-10315.

[2] C. Mesters, A Selection of Recent Advances in C1 Chemistry, Annu Rev Chem Biomol Eng, 7 (2016) 223-238.

[3] U. Zavyalova, M. Holena, R. Schlögl, M. Baerns, Statistical Analysis of Past Catalytic Data on Oxidative Methane Coupling for New Insights into the Composition of High-Performance Catalysts, ChemCatChem, 3 (2011) 1935-1947.

[4] P. Schwach, X. Pan, X. Bao, Direct Conversion of Methane to Value-Added Chemicals over Heterogeneous Catalysts: Challenges and Prospects, Chem Rev, 117 (2017) 8497-8520.

[5] D.J. Driscoll, W. Martir, J.X. Wang, J.H. Lunsford, Formation of gas-phase methyl radicals over magnesium oxide, Journal of the American Chemical Society, 107 (1985) 58-63.

[6] S.C. Reyes, C. Kelkar, E. Iglesia, Kinetic-transport models and the design of catalysts and reactors for the oxidative coupling of methane, Catalysis letters, 19 (1993) 167-180.

[7] J. Song, Y. Sun, R. Ba, S. Huang, Y. Zhao, J. Zhang, Y. Sun, Y. Zhu, Monodisperse Sr- $\mathrm{La}_{2} \mathrm{O}_{3}$ hybrid nanofibers for oxidative coupling of methane to synthesize $\mathrm{C}_{2}$ hydrocarbons, Nanoscale, 7 (2015) 2260-2264.

[8] P. Huang, Y. Zhao, J. Zhang, Y. Zhu, Y. Sun, Exploiting shape effects of $\mathrm{La}_{2} \mathrm{O}_{3}$ nanocatalysts for oxidative coupling of methane reaction, Nanoscale, 5 (2013) 10844-10848.

[9] T. Levan, M. Che, J.M. Tatibouet, M. Kermarec, Infrared Study of the Formation and Stability of $\mathrm{La}_{2} \mathrm{O}_{2} \mathrm{CO}_{3}$ During the Oxidative Coupling of Methane on $\mathrm{La}_{2} \mathrm{O}_{3}$, Journal of Catalysis, 142 (1993) 18-26.

[10] J.H. Lunsford, The Catalytic Oxidative Coupling of Methane, Angewandte Chemie International Edition in English, 34 (1995) 970-980.

[11] D. Dissanayake, K.C.C. Kharas, J.H. Lunsford, M.P. Rosynek, Catalytic Partial Oxidation of Methane over Ba-Pb, Ba-Bi, and Ba-Sn Perovskites, Journal of Catalysis, 139 (1993) 652-663.

[12] F. Polo-Garzon, Z. Wu, Acid-base catalysis over perovskites: a review, Journal of Materials Chemistry A, (2018).

[13] W. Ding, Y. Chen, X. Fu, Oxidative coupling of methane over $\mathrm{Ce}^{4+}$-doped $\mathrm{Ba}_{3} \mathrm{WO}_{6}$ catalysts: investigation on oxygen species responsible for catalytic performance, Catalysis Letters, 23 (1994) 69-78.

[14] W. Ding, Y. Chen, X. Fu, Influence of surface composition of perovskite-type complex oxides on methane oxidative coupling, Applied Catalysis A: General, 104 (1993) 61-75.

[15] G.E. Keller, M.M. Bhasin, Synthesis of ethylene via oxidative coupling of methane:I. Determination of active catalysts, Journal of Catalysis, 73 (1982) 9-19. 
[16] R.V. Siriwardane*, A. Shamsi, Oxidative coupling of methane over calcium manganate and gadolinium manganate perovskites promoted with sodium pyrophosphate, Applied Catalysis, 60 (1990) 119-136.

[17] R. Ghose, H.T. Hwang, A. Varma, Oxidative coupling of methane using catalysts synthesized by solution combustion method, Applied Catalysis A: General, 452 (2013) 147-154.

[18] K.-I. Aika, K. Aono, Oxidative coupling of methane over $\mathrm{SrCO}_{3}$ and $\mathrm{SrO}$, Journal of the Chemical Society, Faraday Transactions, 87 (1991).

[19] S. Arndt, G. Laugel, S. Levchenko, R. Horn, M. Baerns, M. Scheffler, R. Schlögl, R. Schomäcker, A Critical Assessment of Li/MgO-Based Catalysts for the Oxidative Coupling of Methane, Catalysis Reviews, 53 (2011) 424-514.

[20] L. Luo, Y. Jin, H. Pan, X. Zheng, L. Wu, R. You, W. Huang, Distribution and role of Li in Li-doped MgO catalysts for oxidative coupling of methane, Journal of Catalysis, 346 (2017) 5761.

[21] U. Zavyalova, M. Geske, R. Horn, G. Weinberg, W. Frandsen, M. Schuster, R. Schlögl, Morphology and Microstructure of $\mathrm{Li} / \mathrm{MgO}$ Catalysts for the Oxidative Coupling of Methane, ChemCatChem, 3 (2011) 949-959.

[22] N. Maksimov, G. Selyutin, A. Anshits, E. Kondratenko, V. Roguleva, The influence of defect nature on catalytic performance of $\mathrm{Li}, \mathrm{Na}$-doped $\mathrm{MgO}, \mathrm{CaO}$ and $\mathrm{SrO}$ in the oxidative coupling of methane, Catalysis today, 42 (1998) 279-281.

[23] S. Arndt, T. Otremba, U. Simon, M. Yildiz, H. Schubert, R. Schomäcker, Mn-Na $\mathrm{WO}_{4} / \mathrm{SiO}_{2}$ as catalyst for the oxidative coupling of methane. What is really known?, Applied Catalysis A: General, 425-426 (2012) 53-61.

[24] P. Wang, G. Zhao, Y. Wang, Y. Lu, $\mathrm{MnTiO}_{3}$-driven low-temperature oxidative coupling of methane over $\mathrm{TiO}_{2}$-doped $\mathrm{Mn}_{2} \mathrm{O}_{3}-\mathrm{Na}_{2} \mathrm{WO}_{4} / \mathrm{SiO}_{2}$ catalyst, Sci Adv, 3 (2017) e1603180.

[25] D.J. Wang, M.P. Rosynek, J.H. Lunsford, Oxidative Coupling of Methane over OxideSupported Sodium-Manganese Catalysts, Journal of Catalysis, 155 (1995) 390-402.

[26] Z. Taheri, N. Seyed-Matin, A.A. Safekordi, K. Nazari, S.Z. Pashne, A comparative kinetic study on the oxidative coupling of methane over LSCF perovskite-type catalyst, Applied Catalysis A: General, 354 (2009) 143-152.

[27] R. Spinicci, P. Marini, S. De Rossi, M. Faticanti, P. Porta, Oxidative coupling of methane on $\mathrm{LaAlO}_{3}$ perovskites partially substituted with alkali or alkali-earth ions, Journal of Molecular Catalysis A: Chemical, 176 (2001) 253-265.

[28] D. Dissanayake, K. Kharas, J.H. Lunsford, M. Rosynek, Catalytic partial oxidation of methane over Ba-Pb, Ba-Bi, and Ba-Sn perovskites, Journal of Catalysis, 139 (1993) 652-663.

[29] H. Liu, Y. Wei, J. Caro, H. Wang, Oxidative Coupling of Methane with High $\mathrm{C}_{2}$ Yield by using Chlorinated Perovskite $\mathrm{Ba}_{0.5} \mathrm{Sr}_{0.5} \mathrm{Fe}_{0.2} \mathrm{Co}_{0.8} \mathrm{O}_{3-\delta}$ as Catalyst and $\mathrm{N}_{2} \mathrm{O}$ as Oxidant, ChemCatChem, 2 (2010) 1539-1542.

[30] J. Xu, L. Peng, X. Fang, Z. Fu, W. Liu, X. Xu, H. Peng, R. Zheng, X. Wang, Developing reactive catalysts for low temperature oxidative coupling of methane: On the factors deciding the 
reaction performance of $\mathrm{Ln}_{2} \mathrm{Ce}_{2} \mathrm{O}_{7}$ with different rare earth A sites, Applied Catalysis A: General, 552 (2018) 117-128.

[31] Y. Ivanova, E. Sutormina, N. Rudina, A. Nartova, L. Isupova, Effect of preparation route on $\mathrm{Sr}_{2} \mathrm{TiO}_{4}$ catalyst for the oxidative coupling of methane, Catalysis Communications, (2018).

[32] H. Imai, T. Tagawa, N. Kamide, Oxidative coupling of methane over amorphous lanthanum aluminum oxides, Journal of Catalysis, 106 (1987) 394-400.

[33] Z. Fakhroueian, F. Farzaneh, N. Afrookhteh, Oxidative coupling of methane catalyzed by Li, $\mathrm{Na}$ and $\mathrm{Mg}$ doped $\mathrm{BaSrTiO}_{3}$, Fuel, 87 (2008) 2512-2516.

[34] D.V. Ivanov, L.A. Isupova, E.Y. Gerasimov, L.S. Dovlitova, T.S. Glazneva, I.P. Prosvirin, Oxidative methane coupling over $\mathrm{Mg}, \mathrm{Al}, \mathrm{Ca}, \mathrm{Ba}, \mathrm{Pb}$-promoted $\mathrm{SrTiO}_{3}$ and $\mathrm{Sr}_{2} \mathrm{TiO}_{4}$ : Influence of surface composition and microstructure, Applied Catalysis A: General, 485 (2014) 10-19.

[35] L.C. Seitz, C.F. Dickens, K. Nishio, Y. Hikita, J. Montoya, A. Doyle, C. Kirk, A. Vojvodic, H.Y. Hwang, J.K. Norskov, T.F. Jaramillo, A highly active and stable $\mathrm{IrOx} / \mathrm{SrIrO}_{3}$ catalyst for the oxygen evolution reaction, Science, 353 (2016) 1011-1014.

[36] J.M.P. Martirez, S. Kim, E.H. Morales, B.T. Diroll, M. Cargnello, T.R. Gordon, C.B. Murray, D.A. Bonnell, A.M. Rappe, Synergistic Oxygen Evolving Activity of a $\mathrm{TiO}_{2}$-Rich Reconstructed $\mathrm{SrTiO}_{3}(001)$ Surface, Journal of the American Chemical Society, 137 (2015) 2939-2947.

[37] E. Fabbri, M. Nachtegaal, T. Binninger, X. Cheng, B.-J. Kim, J. Durst, F. Bozza, T. Graule, R. Schäublin, L. Wiles, M. Pertoso, N. Danilovic, K.E. Ayers, T.J. Schmidt, Dynamic surface selfreconstruction is the key of highly active perovskite nano-electrocatalysts for water splitting, Nature Materials, 16 (2017) 925.

[38] Y. Peng, W. Si, J. Luo, W. Su, H. Chang, J. Li, J. Hao, J. Crittenden, Surface Tuning of $\mathrm{La}_{0.5} \mathrm{Sr}_{0.5} \mathrm{CoO}_{3}$ Perovskite Catalysts by Acetic Acid for $\mathrm{NO}_{\mathrm{x}}$ Storage and Reduction, Environmental Science \& Technology, 50 (2016) 6442-6448.

[39] G.S. Foo, Z.D. Hood, Z. Wu, Shape Effect Undermined by Surface Reconstruction: Ethanol Dehydrogenation over Shape-Controlled $\mathrm{SrTiO}_{3}$ Nanocrystals, ACS Catalysis, 8 (2018) 555-565.

[40] F. Polo-Garzon, S.Z. Yang, V. Fung, G.S. Foo, E.E. Bickel, M.F. Chisholm, D.E. Jiang, Z. $\mathrm{Wu}$, Controlling Reaction Selectivity through the Surface Termination of Perovskite Catalysts, Angew Chem Int Ed Engl, 56 (2017) 9820-9824.

[41] F. Papa, D. Gingasu, L. Patron, A. Miyazaki, I. Balint, On the nature of active sites and catalytic activity for OCM reaction of alkaline-earth oxides-neodymia catalytic systems, Applied Catalysis A: General, 375 (2010) 172-178.

[42] F. Papa, P. Luminita, P. Osiceanu, R. Birjega, M. Akane, I. Balint, Acid-base properties of the active sites responsible for $\mathrm{C}_{2}{ }^{+}$and $\mathrm{CO}_{2}$ formation over $\mathrm{MO}-\mathrm{Sm}_{2} \mathrm{O}_{3}(\mathrm{M}=\mathrm{Zn}, \mathrm{Mg}, \mathrm{Ca}$ and $\mathrm{Sr}$ ) mixed oxides in OCM reaction, Journal of Molecular Catalysis A: Chemical, 346 (2011) 46-54.

[43] Z. Wu, S. Dai, S.H. Overbury, Multiwavelength Raman Spectroscopic Study of SilicaSupported Vanadium Oxide Catalysts, The Journal of Physical Chemistry C, 114 (2010) 412-422.

[44] D.A. Tenne, A. Bruchhausen, N.D. Lanzillotti-Kimura, A. Fainstein, R.S. Katiyar, A. Cantarero, A. Soukiassian, V. Vaithyanathan, J.H. Haeni, W. Tian, D.G. Schlom, K.J. Choi, D.M. Kim, C.B. Eom, H.P. Sun, X.Q. Pan, Y.L. Li, L.Q. Chen, Q.X. Jia, S.M. Nakhmanson, K.M. Rabe, 
X.X. Xi, Probing nanoscale ferroelectricity by ultraviolet Raman spectroscopy, Science, 313 (2006) 1614-1616.

[45] I.E. Wachs, K. Routray, Catalysis Science of Bulk Mixed Oxides, ACS Catalysis, 2 (2012) 1235-1246.

[46] S.P. Phivilay, A.A. Puretzky, K. Domen, I.E. Wachs, Nature of Catalytic Active Sites Present on the Surface of Advanced Bulk Tantalum Mixed Oxide Photocatalysts, ACS Catalysis, 3 (2013) 2920-2929.

[47] M. Li, U. Tumuluri, Z. Wu, S. Dai, Effect of Dopants on the Adsorption of Carbon Dioxide on Ceria Surfaces, ChemSusChem, 8 (2015) 3651-3660.

[48] Y.T. Chua, P.C. Stair, I.E. Wachs, A Comparison of Ultraviolet and Visible Raman Spectra of Supported Metal Oxide Catalysts, The Journal of Physical Chemistry B, 105 (2001) 8600-8606.

[49] H. Tian, I.E. Wachs, L.E. Briand, Comparison of UV and visible Raman spectroscopy of bulk metal molybdate and metal vanadate catalysts, J Phys Chem B, 109 (2005) 23491-23499.

[50] W.G. Nilsen, J.G. Skinner, Raman Spectrum of Strontium Titanate, The Journal of Chemical Physics, 48 (1968) 2240-2248.

[51] D.A. Tenne, A.K. Farrar, C.M. Brooks, T. Heeg, J. Schubert, H.W. Jang, C.W. Bark, C.M. Folkman, C.B. Eom, D.G. Schlom, Ferroelectricity in nonstoichiometric $\mathrm{SrTiO}_{3}$ films studied by ultraviolet Raman spectroscopy, Applied Physics Letters, 97 (2010).

[52] L.F. da Silva, W. Avansi, J. Andres, C. Ribeiro, M.L. Moreira, E. Longo, V.R. Mastelaro, Long-range and short-range structures of cube-like shape $\mathrm{SrTiO}_{3}$ powders: microwave-assisted hydrothermal synthesis and photocatalytic activity, Phys Chem Chem Phys, 15 (2013) 1238612393.

[53] M.L. Moreira, V.M. Longo, W. Avansi, M.M. Ferrer, J. Andrés, V.R. Mastelaro, J.A. Varela,

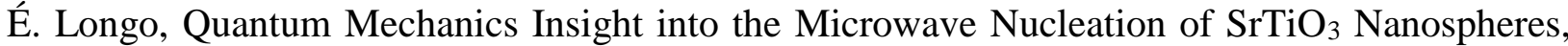
The Journal of Physical Chemistry C, 116 (2012) 24792-24808.

[54] C. Himcinschi, I. Radu, R. Singh, W. Erfurth, A.P. Milenin, M. Reiche, S.H. Christiansen, U. Gösele, Relaxation of strain in patterned strained silicon investigated by UV Raman spectroscopy, Materials Science and Engineering: B, 135 (2006) 184-187.

[55] Y.T. Chua, A.R. Mohamed, S. Bhatia, Oxidative coupling of methane for the production of ethylene over sodium-tungsten-manganese-supported-silica catalyst (Na-W-Mn/ $\left.\mathrm{SiO}_{2}\right)$, Applied Catalysis A: General, 343 (2008) 142-148.

[56] J. Shan, F. Raziq, M. Humayun, W. Zhou, Y. Qu, G. Wang, Y. Li, Improved charge separation and surface activation via boron-doped layered polyhedron $\mathrm{SrTiO}_{3}$ for co-catalyst free photocatalytic $\mathrm{CO}_{2}$ conversion, Applied Catalysis B: Environmental, 219 (2017) 10-17.

[57] Y. Xu, L. Yu, C. Cai, J. Huang, X. Guo, A study of the oxidative coupling of methane over SrO- $\mathrm{La}_{2} \mathrm{O}_{3} / \mathrm{CaO}$ catalysts by using $\mathrm{CO}_{2}$ as a probe, Catalysis Letters, 35 (1995) 215-231.

[58] Y. Cai, L. Chou, S. Li, B. Zhang, J. Zhao, Selective Conversion of Methane to $\mathrm{C}_{2}$ Hydrocarbons Using Carbon Dioxide over $\mathrm{Mn}-\mathrm{SrCO}_{3}$ Catalysts, Catalysis Letters, 86 (2003) 191195. 
[59] X. Liang, C. Wu, X. Yu, W. Huang, H. Yin, $\mathrm{Pd}$ Doped $\mathrm{La}_{0.1} \mathrm{Sr}_{0.9} \mathrm{TiO}_{3}$ as High-Temperature Water-Gas Shift Catalysts: In-Situ Formation of Active Pd Phase, Catalysis Letters, (2018).

[60] C. Hammond, S. Conrad, I. Hermans, Oxidative methane upgrading, ChemSusChem, 5 (2012) 1668-1686.

[61] R. Ghose, H.T. Hwang, A. Varma, Oxidative coupling of methane using catalysts synthesized by solution combustion method: Catalyst optimization and kinetic studies, Applied Catalysis A: General, 472 (2014) 39-46.

[62] D. Wolf, M. Slinko, E. Kurkina, Baerns, Kinetic simulations of surface processes of the oxidative coupling of methane over a basic oxide catalyst, Applied Catalysis A: General, 166 (1998) 47-54.

[63] E. Iwamatsu, Kinetic analysis of the oxidative coupling of methane over $\mathrm{Na}^{+}$-doped $\mathrm{MgO}$, Journal of Catalysis, 117 (1989) 416-431.

[64] S.C. Oh, Y. Lei, H. Chen, D. Liu, Catalytic consequences of cation and anion substitutions on rate and mechanism of oxidative coupling of methane over hydroxyapatite catalysts, Fuel, 191 (2017) 472-485.

[65] K. Takanabe, E. Iglesia, Mechanistic Aspects and Reaction Pathways for Oxidative Coupling of Methane on $\mathrm{Mn} / \mathrm{Na}_{2} \mathrm{WO}_{4} / \mathrm{SiO}_{2}$ Catalysts, The Journal of Physical Chemistry C, 113 (2009) 10131-10145.

[66] M. Sohrabi, B. Dabir, A. Eskandari, R.D. Golpasha, Some aspects of kinetics and mechanism of the oxidative coupling of methane, Journal of Chemical Technology \& Biotechnology: International Research in Process, Environmental AND Clean Technology, 67 (1996) 15-20.

[67] N.R. Farooji, A. Vatani, S. Mokhtari, Kinetic simulation of oxidative coupling of methane over perovskite catalyst by genetic algorithm: Mechanistic aspects, Journal of Natural Gas Chemistry, 19 (2010) 385-392.

[68] E.E. Miro, J.M. Santamaria, E.E. Wolf, Oxidative coupling of methane on alkali metalpromoted nickel titanate: II. Kinetic studies, Journal of Catalysis, 124 (1990) 465-476.

[69] B. Christian Enger, R. Lødeng, A. Holmen, A review of catalytic partial oxidation of methane to synthesis gas with emphasis on reaction mechanisms over transition metal catalysts, Applied Catalysis A: General, 346 (2008) 1-27.

[70] T. Hayakawa, A.G. Andersen, M. Shimizu, K. Suzuki, K. Takehira, Partial oxidation of methane to synthesis gas over some titanates based perovskite oxides, Catalysis Letters, 22 (1993) 307-317.

[71] M. Sohrabi, B. Dabir, A. Eskandari, R.D. Golpasha, Some Aspects of Kinetics and Mechanism of the Oxidative Coupling of Methane, Journal of Chemical Technology \& Biotechnology, 67 (1996) 15-20. 


\title{
Chapter 4. Fabrication of Pillared ZSM-5 Framework for Shape Selectivity of Ethane Dehydroaromatization
}

\begin{abstract}
Ethane, the second major component of shale gas, is a prospective raw feedstock to valuable chemicals and fuels. Innovative pillared ZSM-5 with various lamellar thicknesses and $\mathrm{Si} / \mathrm{Al}$ ratios were successfully synthesized with the dual-template method. $1 \%$ molybdenum species were dispersed over these lamellar ZSM-5, and evaluated for ethane dehydroaromatization. The influence of zeolite morphology and texture property for the reduction/acidity nature of $\mathrm{MoO}_{\mathrm{x}}$ species were investigated by XRD, SEM, nitrogen $\left(\mathrm{N}_{2}\right)$ sorption, $\mathrm{H}_{2}-\mathrm{TPR} / \mathrm{TPO}$ and $\mathrm{NH}_{3}-\mathrm{TPD}$. Strong acidity not only increases ethane conversion and aromatic selectivity, but intensely induces surface coking. Therefore, moderate $\mathrm{Si} / \mathrm{Al}$ ratio maintains a favorable option to balance catalytic reactivity and stability. Thicker zeolite layers with a long diffusion path exhibited fair ethane conversion, but high aromatization yield. It is of significant importance that Mo/MFI-50(T8) catalyst ( $\mathrm{Si} / \mathrm{Al}=50,210 \mathrm{~nm}$ layer thickness) demonstrated excellent regenerability during multicycle reaction/oxidation operation, which could be a promising system for industrial optimization and process deployment.
\end{abstract}




\subsection{Introduction}

With the global shale gas revolution, there are on-growing academia/industrial interests for utilizing $\mathrm{C}_{1}-\mathrm{C}_{4}$ compounds as the emerging resources for energy and chemical demands. Ethane, the second-concentrated component in natural gas and shale gas, is considered as an environmentally-benign resource for catalytic combustion or conversion. The price of ethane is extraordinary cheap because ethane is a by-product and waste from pipeline compression. In contrast, benzene, toluene and xylene (BTX) are the "building-block" chemicals in many applications, such as the polymer, medical or fragrance industries. The conventional scheme in which BTX is derived from naphtha reforming or oil thermal cracking could hardly meet the fastgrowing market demand in recent years. Consequently, non-oxidative dehydro-aromatization of ethane, instead of methane, provides an economically-viable and technical-feasible option for BTX and $\mathrm{H}_{2}$ production.

Zeolite-supported transition metals have been intensively investigated for the dehydroaromatization reaction. Particularly, HZSM-5 zeolite has been used for many decades in catalytic dehydroaromatization (DHA) of methane due to its acidic and shape selective properties $[1,2]$. However, methane DHA requires high reaction temperature and sometimes requires other pretreatment such as nonthermal plasma activation, to achieve higher aromatic yield[3, 4]. Consequently, with the difficulty in direct methane DHA, there is emerging research focusing on ethane DHA. Krogh et al.[5] used Re/HZSM-5 to achieve 65\% aromatic selectivity to BTX (benzene, toluene, xylene) under $550{ }^{\circ} \mathrm{C}$. Chetina et al.[6] discovered that platinum and gallium doped HZSM-5 catalyst can achieve $64 \%$ aromatic selectivity under $550{ }^{\circ} \mathrm{C} . \mathrm{ZnO}$ supported over HZSM-5 generally demonstrated $>60 \%$ ethane conversion with $>50 \%$ BTX selectivity[7, 8]. Mo species over ZSM-5 zeolite are still being considered as a potential catalyst 
for ethane DHA, even though they have smaller reactivity compared to $\mathrm{Ga}, \mathrm{Zn}$ and Pt catalysts. In academia, Mo/HZSM-5 has been extensively studied for methane-DHA[4, 9-13]. However, the fast deactivation of this catalyst system due to surface coke deposition and the migration of active sites under high-temperature conditions make it very difficult to scale-up for industrial deployment[14-22].

The catalytic mechanism of the ethane DHA reaction over Mo-based catalyst has been hypothesized as a sequential pathways [23-27]: (1) $\mathrm{C}-\mathrm{H}$ breakage and dehydrogenation of ethane molecules occurred over MoCx or oxycarbide structures anchored on acid sites located in the micro-channels of ZSM-5; (2) the produced ethylene oligomerized via cyclization to benzene or other aromatics over acidic sites. The bifunctional zeolite acidic sites, namely, anchoring the Mo structure and serving as catalytic active sites in oligomerization of ethylene, are both important for the aromatics formation. In addition, ethylene intermediates could re-adsorb over metallic sites for further aromatization[8, 28]. Therefore, catalytic performance of ethane dehydro-aromatization can be fundamentally affected by the distribution/location of Mo species, surface acidity and pore structures.

Compared to conventional microporous zeolites, micro- or mesoporous zeolites with lamellar structures allow the integration of high catalytic activities and fast molecular diffusion[29]. In previous reports, dual-functional templates and diquaternary ammonium-type surfactants have been successfully applied for preparing ZSM-5 zeolites with lamellar structures[30, 31]. A typical dual-functional template is composed of hydrophilic head (quaternary nitrogen atoms) and hydrophobic tails (long alkyl chains). Pentasil structures form in the presence of quaternary nitrogen atoms, and the growth of crystals along b-axis was limited by the long alkyl 
chains in the zeolitization process. The micro-mesopore ratio of lamellar ZSM-5 zeolites could be controlled by applying the similar template employing the second structure directing agent (SDA), such as Tetrapropylammonium Hydroxide (TPAOH), or Cetyltrimethylammonium Bromide (CTAB) $[32,33]$. Consequently, two-dimensional ZSM-5 nanosheet structures can be fabricated by the presence of two functional groups, which act as a "pillar" after calcination. In addition to surface-active structure, micro/mesopores structures of zeolite framework restrict mass diffusion rates of reactive molecules and surface intermediates, which play a key role for controlling reactivity and selectivity. For a given zeolite framework, the design strategies are generally associated with the change of crystal size, unit-cell volume, morphology[34-36]. In ethane-DHA, the desorption of ethylene intermediates can be accelerated from the catalytic surface and then diffuse from mesoporous structure of zeolite particles, skipping further dehydrogenation and oligomerization to produce aromatics[37, 38]. Furthermore, ZSM-5 particles at the nanoscale possesses high mesopores ratio and short diffusion paths. Big molecules like 1-hexene and aromatics could diffuse between the reaction gas flow and inside the zeolite. Consequently, nanosized zeolite particles and the meso/macropores framework enable effective mass diffusion, which can notably increase BTX yields during methane aromatization. Pillared ZSM-5, with hierarchical pores, could amplify the mass/heat transfer, which has successfully been demonstrated in the application of ethanol dehydration, monomolecular conversion of propane and isobutene and alkylation of benzyl alcohol with mesitylene reactions[39-41]. This enhanced mass/heat transfer capacity is supposed to be applicable to the DHA reaction. However, very few studies have been reported to directly associate the thickness of lamellar layers with reactant diffusion, $\mathrm{Si} / \mathrm{Al}$ ratios, surface acidities, as well as catalytic reactivity of ethane-DHA reaction. 
During the aromatization reaction, carbon deposition as polyaromatic or graphite species rapidly accumulates over the external surface, blocking the mass transfer in the porous channel, or covering the active Mo species active sites and Brønsted acidic sites, resulting in continuous catalytic deactivation[42, 43]. In the last decades, significant efforts have been attempted to address this issue, such as the recent breakthrough of $\mathrm{Fe} @ \mathrm{SiO}_{2}$ used at very high temperature during methane-DHA reaction[44]. However, to the best of our knowledge, the formation of carbonaceous deposit is still inevitable, even at laboratory-scale performance testing.

In this study, a regenerable $\mathrm{MoO}_{\mathrm{x}} /$ lamellar ZSM-5 is explored based on the strategy of optimizing micro/mesopores structure of zeolite framework, targeting high ethane conversion and aromatic selectivity by optimizing the $\mathrm{Si} / \mathrm{Al}$ ratio, surface acidity and diffusion path. A series of lamellar ZSM-5 zeolites with controllable thicknesses will be synthesized, the influence of Si/Al ratio of lamellar ZSM-5 zeolite on catalytic performance will be evaluated for the ethane-DHA reaction. Mass diffusion in lamellar zeolites will be optimized by adjusting the hierarchical micromesoporous structure, consequently mitigating catalytic deactivation. Different from conventional strategies to minimize catalytic deactivation, easy regeneration of spent catalyst would be more applicable for realistic industrial practices. Therefore, detailed examination of catalytic regenerability/stability will be evaluated during cyclic ethane-DHA/oxidation regeneration operations. 


\subsection{Experimental Section}

\subsubsection{Catalyst Preparation}

\subsubsection{Surfactant Synthesis}

The surfactants used for zeolite synthesis were prepared by following a previous report[30, 41]: $12.45 \mathrm{~g}$ 1-Bromodocosane (98\%, TCI) was dissolved in $150 \mathrm{~mL}$ toluene (99.5\%, Fisher) and $52.22 \mathrm{~g} \mathrm{~N}, \mathrm{~N}, \mathrm{~N}^{\prime}, \mathrm{N}^{\prime}$-tetramethyl-1,6-diaminohexane (98.5\%, ACROS Organics) was dissolved in $150 \mathrm{~mL}$ acetonitrile (99.9\% Fisher). These solutions were evenly mixed and stirred for $1 \mathrm{~h}$, and then refluxed at $353 \mathrm{~K}$ for $10 \mathrm{~h}$. After cooling to room temperature, the precipitate was filtered, washed with diethyl ether and dried overnight. The product has been identified as $\left[\mathrm{C}_{22} \mathrm{H}_{45^{-}}\right.$ $\left.\mathrm{N}^{+}\left(\mathrm{CH}_{3}\right)_{2}-\mathrm{C}_{6} \mathrm{H}_{12}-\mathrm{N}\left(\mathrm{CH}_{3}\right)_{2}\right] \mathrm{Br} .11 .22 \mathrm{~g}$ of $\left[\mathrm{C}_{22} \mathrm{H}_{45}-\mathrm{N}^{+}\left(\mathrm{CH}_{3}\right)_{2}-\mathrm{C}_{6} \mathrm{H}_{12}-\mathrm{N}\left(\mathrm{CH}_{3}\right)_{2}\right] \mathrm{Br}$ and $6.73 \mathrm{~g}$ of 1bromohexane (99\%, ACROS Organics) were added into acetonitrile $(100 \mathrm{~mL})$, stirred for $1 \mathrm{~h}$ and refluxed at $353 \mathrm{~K}$ for $10 \mathrm{~h}$. After cooling to room temperature, the precipitated products were filtered, washed with diethyl ether and dried in a vacuum oven at $373 \mathrm{~K}$ overnight. The final surfactant has been analyzed as $\left[\mathrm{C}_{22} \mathrm{H}_{45}-\mathrm{N}^{+}\left(\mathrm{CH}_{3}\right)_{2}-\mathrm{C}_{6} \mathrm{H}_{12}-\mathrm{N}^{+}\left(\mathrm{CH}_{3}\right)_{2}-\mathrm{C}_{6} \mathrm{H}_{13}\right] \mathrm{Br}_{2}\left(\mathrm{C}_{22-6-6} \mathrm{Br}_{2}\right)$.

\subsubsection{Dual Template Synthesis of Lamellar MFI (ZSM-5) with Different TPAOH Amounts}

The zeolites were synthesized with the chemical formula as: $30 \mathrm{Na}_{2} \mathrm{O}: 1 \mathrm{Al}_{2} \mathrm{O}_{3}: 100 \mathrm{SiO}_{2}: 10 \mathrm{C}_{22}-$ 6-6 $\mathrm{Br}_{2}: \mathrm{xTPAOH}: 4000 \mathrm{H}_{2} \mathrm{O}$, where $\mathrm{x}$ equaled to 0,2 , and 8 , respectively. Taking ZSM-5, where $\mathrm{x}$ equaled to 8 , as an example, the detailed procedure is presented as follows: $0.70 \mathrm{~g}$ sodium hydroxide (97\%, Fisher) was dissolved in $2.09 \mathrm{~g} \mathrm{C}_{22-6-6} \mathrm{Br}_{2}$ and $15 \mathrm{~g}$ DI water mixture. $1.17 \mathrm{~g}$ TPAOH $(40 \%, \mathrm{TCI})$ was dropwise added to the prepared solution followed by adding $0.19 \mathrm{~g}$ aluminum sulfate hydrate $\left(\mathrm{Al}_{2} \mathrm{~S}_{3} \mathrm{O}_{12} \cdot 18 \mathrm{H}_{2} \mathrm{O}, 98 \%\right.$, Fisher) and $3.58 \mathrm{~g}$ sulfuric acid (60\%, Fisher) and $3.06 \mathrm{~g}$ DI water with vigorous stirring. Subsequently the mixture was heated at $343 \mathrm{~K}$ to obtain 
a clear solution. At room temperature, $6.12 \mathrm{~g}$ TEOS (98\%, ACROS Organics) was dropwise added into the solution and stirred for $20 \mathrm{~h}$ at room temperature. The resulted gel was transferred into a Teflon-lined stainless-steel autoclave and crystallized for 5 days at $423 \mathrm{~K}$. The product was filtered and washed with DI water and then dried at $373 \mathrm{~K}$ overnight. The samples were calcined at $823 \mathrm{~K}$ for 6 hours in air with 10K/min heating rate. The as-synthesized zeolites were named as MFI50(T0), MFI-50(T2) and MFI-50(T8), whereas 0, 2 and 8 equaled to the TPAOH addition in the synthesis formulation and 50 was corresponding to $\mathrm{Si} / \mathrm{Al}$ ratios of 50. In comparison, commercial MFI zeolites with the same Si/Al ratio were obtained from Zeolyst Company.

\subsubsection{Dual Template Synthesis of Lamellar MFI of Different Si/Al Ratios}

To prepare lamellar MFI zeolites with different $\mathrm{Si} / \mathrm{Al}$ ratios, the formula was adjusted as follows: $30 \mathrm{Na}_{2} \mathrm{O}: \mathrm{xAlO}_{2}: 100 \mathrm{SiO}_{2}: 10 \mathrm{C}_{22-6-6} \mathrm{Br}_{2}: 8 \mathrm{TPAOH}: 4000 \mathrm{H}_{2} \mathrm{O}$, in which $\mathrm{x}$ equaled to 0.5 , 1 and 2, and corresponding to different $\mathrm{Si} / \mathrm{Al}$ ratios of 100, 50 and 25 respectively. The $\mathrm{Si} / \mathrm{Al}$ ratios of zeolite samples were adjusted by adding various amount of aluminum sulfate hydrate. The assynthesized zeolites were identified as MFI-25(T8), MFI-50(T8) and MFI-100(T8), whereas the numbers $25,50,100$ represented $\mathrm{Si} / \mathrm{Al}$ ratio of zeolites. The $\mathrm{Si} / \mathrm{Al}$ ratios of all the zeolites are analyzed and presented in Table 1.

\subsubsection{Synthesis of Supported Mo/MFI Zeolites}

The as-calcined MFI samples were firstly ion-exchanged with $1 \mathrm{M}$ aqueous $\mathrm{NH}_{4} \mathrm{NO}_{3}(99 \%$, ACROS Organics) at $353 \mathrm{~K}$ for $8 \mathrm{~h}$, subsequently washed with DI water, and dried at $343 \mathrm{~K}$ overnight. Commercial MFI zeolites were received as $\mathrm{NH}_{4}{ }^{+}$form.

$1 \mathrm{wt} . \%$ of $\mathrm{MoO}_{3} / \mathrm{MFI}$ catalysts were prepared by incipient wetness impregnation of aqueous ammonia molybdate tetrahydrate solution as precursor (99\%, ACROS Organics). After 
impregnation, the catalysts were dried in ambient conditions overnight, and then calcined in air at $773 \mathrm{~K}$ for $2 \mathrm{~h}$. The Mo/MFI zeolites with different Si/Al ratios were identified as Mo/MFI-25(T8), Mo/MFI-50(T8), Mo/MFI-100(T8), while the catalysts that were prepared by adding different amounts of TPAOH in the synthesis recipe were named as Mo/MFI-50(T0), Mo/MFI-50(T2), and Mo/MFI-50(T8).

\subsubsection{Catalyst Evaluation}

\subsubsection{Ethane Aromatization Reaction:}

Catalytic performance of Mo/MFI for ethane dehydro-aromatization was studied at $923 \mathrm{~K}$, atmospheric pressure with a space velocity of $1920 \mathrm{~mL} /\left(\mathrm{g}_{\mathrm{cat}} \cdot \mathrm{h}\right) .500 \mathrm{mg}$ of catalyst was loosely loaded in a fixed bed reactor (9 mm ID.) and purged in $\mathrm{N}_{2}(10 \mathrm{~mL} / \mathrm{min}$, UHP, Air gas) at $923 \mathrm{~K}$ for $1 \mathrm{~h}$. After pretreatment, $80 \% \mathrm{C}_{2} \mathrm{H}_{6} / \mathrm{He}$ was introduced into the catalyst at $20 \mathrm{~mL} / \mathrm{min}$. Since the produced aromatics cannot be detected by on-line GC at experimental condition, the outlet of the fixed bed reactor was connected with a replaceable bubbler containing hexadecane to absorb/condense aromatic products. The exit gas after the bubbler was analyzed by an on-line GC. The $\mathrm{C}_{2} \mathrm{H}_{6}$ conversion (\%), aromatics selectivity (\%), aromatics yield (\%)were defined as follows:

Ethane conversion $(\%)=\frac{\text { moles of ethane reacted }}{\text { moles of ethane in feed }} \times 100$

Aromatics selectivity $(\%)=$

$\frac{3(\text { moles of benzene } \text { formed })+3.5(\text { moles of toluene } \text { formed })+4(\text { moles of xylene fromed })}{\text { moles of ethane reacted }} \times 100$

Aromatics yield $(\%)=$ ethane conversion $(\%) \times$ aromatic selectivity $(\%) \times \frac{1}{100}(3)$ 


\subsubsection{Cyclic Ethane Dehydro-aromatization Reaction-oxidative Regeneration:}

The ethane dehydro-aromatization-oxidative regeneration cycles over Mo/MFI-50(T8) and Mo/Commercial MFI were carried out in Micromeritics Autochem 2950 analyzer. $50 \mathrm{mg}$ of catalyst were loosely loaded into a U-tube $(9.5 \mathrm{~mm} \mathrm{ID}$.) and pretreated at $923 \mathrm{~K}$ for $90 \mathrm{~min}$ in $\mathrm{He}$ (UHP, $50 \mathrm{~mL} / \mathrm{min})$. For a typical reaction-regeneration cycle, $20 \% \mathrm{C}_{2} \mathrm{H}_{6} / \mathrm{He}(50 \mathrm{~mL} / \mathrm{min})$ was introduced with on-line mass spectrometer for product analysis. After reacting for 15 minutes, the feedstock changed to pure $\mathrm{He}$ at the flow rate of $50 \mathrm{~mL} / \mathrm{min}$ and held for $10 \mathrm{~min}$ to flush out residue gas. The catalyst regeneration was conducted in $2 \% \mathrm{O}_{2}$ in $\mathrm{He}(50 \mathrm{~mL} / \mathrm{min})$ at $773 \mathrm{~K}$ for $20 \mathrm{~min}$. Each catalyst was tested for four reaction/regeneration cycles.

\subsubsection{Catalytic Characterization}

Powder X-ray diffraction (XRD) was performed to identify the product structure and calculate the zeolite crystallinity of each catalyst. XRD patterns were obtained using a PANalytical X'Pert Pro XRD system equipped with Ni filtered $\mathrm{Cu}$ target Ka radiation (operation at $45 \mathrm{kV}, 40$ $\mathrm{mA}$, wavelength $\lambda=0.15418 \mathrm{~nm}$ ). The morphologies and the crystal sizes of the synthesized samples were examined by scanning electron microscopy (SEM). Nitrogen $\left(\mathrm{N}_{2}\right)$ sorption analysis was performed using a Micromeritics Tristar 3000 at $77 \mathrm{~K}$, to characterize the porosity, pore sizes, and surface areas of the catalysts. Prior to measurement, samples were degassed under flowing nitrogen at $350{ }^{\circ} \mathrm{C}$ for at least $6 \mathrm{~h}$. The specific surface area was calculated using the BrunauerEmmett-Teller (BET) equation utilizing the adsorption branch.

The $\mathrm{H}_{2}$-TPR experiment was conducted in a Micromeritics Autochem 2950 analyzer equipped with a TCD detector to study the reducibility and dispersion of Mo phases anchored over the zeolite frameworks. $5 \mathrm{vol} \% \mathrm{H}_{2} / \mathrm{Ar}(20 \mathrm{~mL} / \mathrm{min})$ was introduced to the catalyst bed $(0.1 \mathrm{~g})$ at 
$373 \mathrm{~K}$ until stable TCD signals were obtained. The reactor was heated at $5 \mathrm{~K} / \mathrm{min}$ up to $1123 \mathrm{~K}$. Temperature-programmed oxidation (TPO) measurements were carried out after the fourth dehydro-aromatization/ regeneration cycle. The spent catalyst was heated from room temperature to $1073 \mathrm{~K}$ in a stream of $2 \mathrm{vol} \% \mathrm{O}_{2} / \mathrm{He}(20 \mathrm{~mL} / \mathrm{min})$ at the rate of $10 \mathrm{~K} / \mathrm{min}$.

$\mathrm{NH}_{3}$-TPD used the same micro-reactor system as the $\mathrm{H}_{2}$-TPR. $\mathrm{NH}_{3}$ adsorption/desorption cycles were performed to evaluate the effect of $\mathrm{Si} / \mathrm{Al}$ ratios and acidic structure of the synthesized MFI. These studies were performed in four steps: (i) pretreatment, (ii) $\mathrm{NH}_{3}$ adsorption, (iii) $\mathrm{Ar}$ purge, and (iv) temperature-programmed desorption (TPD). During sample pretreatment, the catalysts were dehydrated at $723 \mathrm{~K}$ in the mixture of $10 \mathrm{~cm}^{3} / \mathrm{min} 5 \% \mathrm{O}_{2} / \mathrm{He}$ anmd $20 \mathrm{~cm}^{3} / \mathrm{min} \mathrm{Ar}$ for $30 \mathrm{~min}$, and then the gas was switched to pure Ar flow for another $30 \mathrm{~min} . \mathrm{NH}_{3}$ adsorption was performed by exposing the catalyst to $1 \% \mathrm{NH}_{3} / \mathrm{He}\left(30 \mathrm{~cm}^{3} / \mathrm{min}\right)$ for $15 \mathrm{~min}$ at $423 \mathrm{~K}$ until $\mathrm{NH}_{3}$ adsorption was saturated. The residual gas in the reactor was completely purged by UHP Ar. TPD was conducted by heating the catalyst to $723 \mathrm{~K}$ at the rate of $10 \mathrm{~K} / \mathrm{min}$ with on-line MS detection (Omnistar GSD-301, Pfeiffer).

\subsection{Results and Discussion}

\subsubsection{Bulk Structures and Morphology of the Zeolites}

XRD patterns of lamellar MFI and commercial MFI zeolites are shown in Fig. 1. The highangle region of XRD patterns of lamellar MFI-50(T0), MFI-50(T2), MFI-50(T8), MFI-25(T8), MFI-100(T8) zeolites are identical to commercial MFI zeolite, indicating the pentasil-type zeolites are successfully prepared with MFI topology[30, 40]. Table 1 summarized the key parameters of the synthesized zeolites. The crystallinity of MFI-50(T0), MFI-50(T2), MFI-50(T8), MFI-25(T8), MFI-100(T8) zeolites respectively equaled to $56 \%, 75 \%, 83 \%, 105 \%$ and $82 \%$ as referred to 
commercial MFI with $100 \%$ crystallinity as standard. This type of pillared ZSM-5 is of numerically poor crystallinity compared to the conventional ZSM-5, partly due to the formation of small crystals (eg. (421) Miller index at $13.8^{\circ}$ and (133) Miller index at $24.3^{\circ}$ are weak) [29, 30, 32].

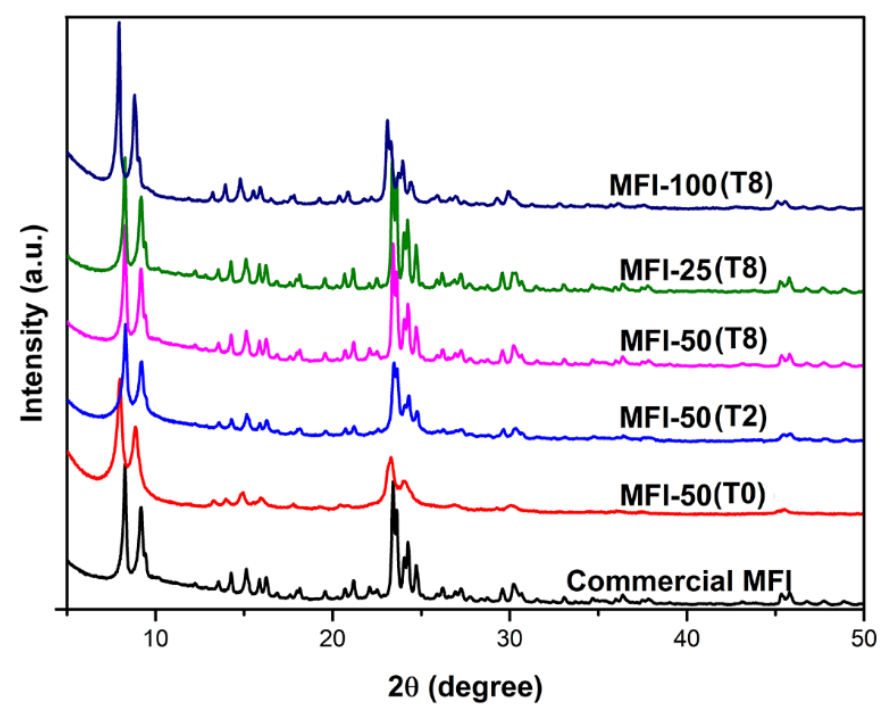

Figure 1. XRD patterns of lamellar MFI-50(T0), MFI-50(T2), MFI-50(T8), MFI-25(T8), MFI-100(T8) and commercial MFI.

Table 1 Key crystalline parameters of various zeolites from XRD result.

\begin{tabular}{cccc}
\hline Zeolite & Si/Al Ratio & Crystallinity (\%) & Layer thickness (nm) \\
\hline Commercial MFI & 50 & $100^{*}$ & - \\
MFI-50(T0) & 50 & 56 & 35 \\
MFI-50(T2) & 50 & 75 & 60 \\
MFI-50(T8) & 50 & 88 & 210 \\
MFI-25(T8) & 25 & 105 & - \\
MFI-100(T8) & 100 & 75 & - \\
\hline
\end{tabular}

*referenced crystallinity of the zeolites 
SEM images of the crystal morphologies of the lamellar zeolites are shown in Fig. 2. All zeolite samples consisted of random-oriented nanosheets with different thicknesses, which function as pillars to support a microporous structure. As shown in Fig. 2 (a-c), the thickness of nanosheets increases from ca. $35 \mathrm{~nm}$ on MFI-50(T0) to ca. $210 \mathrm{~nm}$ on MFI-50(T8). Due to the framework growth of ZSM-5 zeolites, the crystallinity of zeolites in the XRD pattern increases with the increasing of TPAOH/ $\mathrm{C}_{22-6-6} \mathrm{Br}_{2}$ ratio[32, 33]. The b-axis dimension of a single MFI unit cell is $1.9738 \mathrm{~nm}$ [30]. The zeolite was synthesized as multilamellar stacking of MFI nanosheets that were three-dimensionally intergrown. As mentioned, the overall thickness of the lamellar stacking was 35, 60 and $210 \mathrm{~nm}$, for MFI-50(T0), MFI-50(T2), MFI-50(T8), respectively. The stackings were proposed to composed of numerous 2.0-nm-thick MFI zeolite framework according to the reports from Ryong Ryoo and colleagues[30, 45]. Compared to MFI-50(T0), the other two zeolites (MFI-50(T2) and MFI-50(T8)) exhibit thicker nanosheets with extra addition of TPAOH, indicating that the formation of crystalline ZSM-5 was not only influenced by the addition of $\mathrm{C}_{22}$ 6-6 $\mathrm{Br}_{2}$, but also the amount of TPAOH. There are random nanosheets aligned with ZSM-5 framework which create hierarchical channels during the hydrotreating[46, 47]. Thicker nanosheets suggested longer diffusion paths, which could directly change the overall catalytic reactivity and selectivity[30]. Moreover, the $\mathrm{Si} / \mathrm{Al}$ ratios have noticeable impact on the morphologies as shown in Fig. 2c to 2e. A fraction of a nanosheet has converted to coffin-shape particles among the MFI-25(T8) zeolite sample, while MFI-100(T8) exhibits flower-like morphology with various thicknesses of nanosheet. For comparison, commercial ZSM-5 zeolite demonstrates spherical structure, which is totally different from nanosheet structure of lamellar MFI (Fig 2e). 

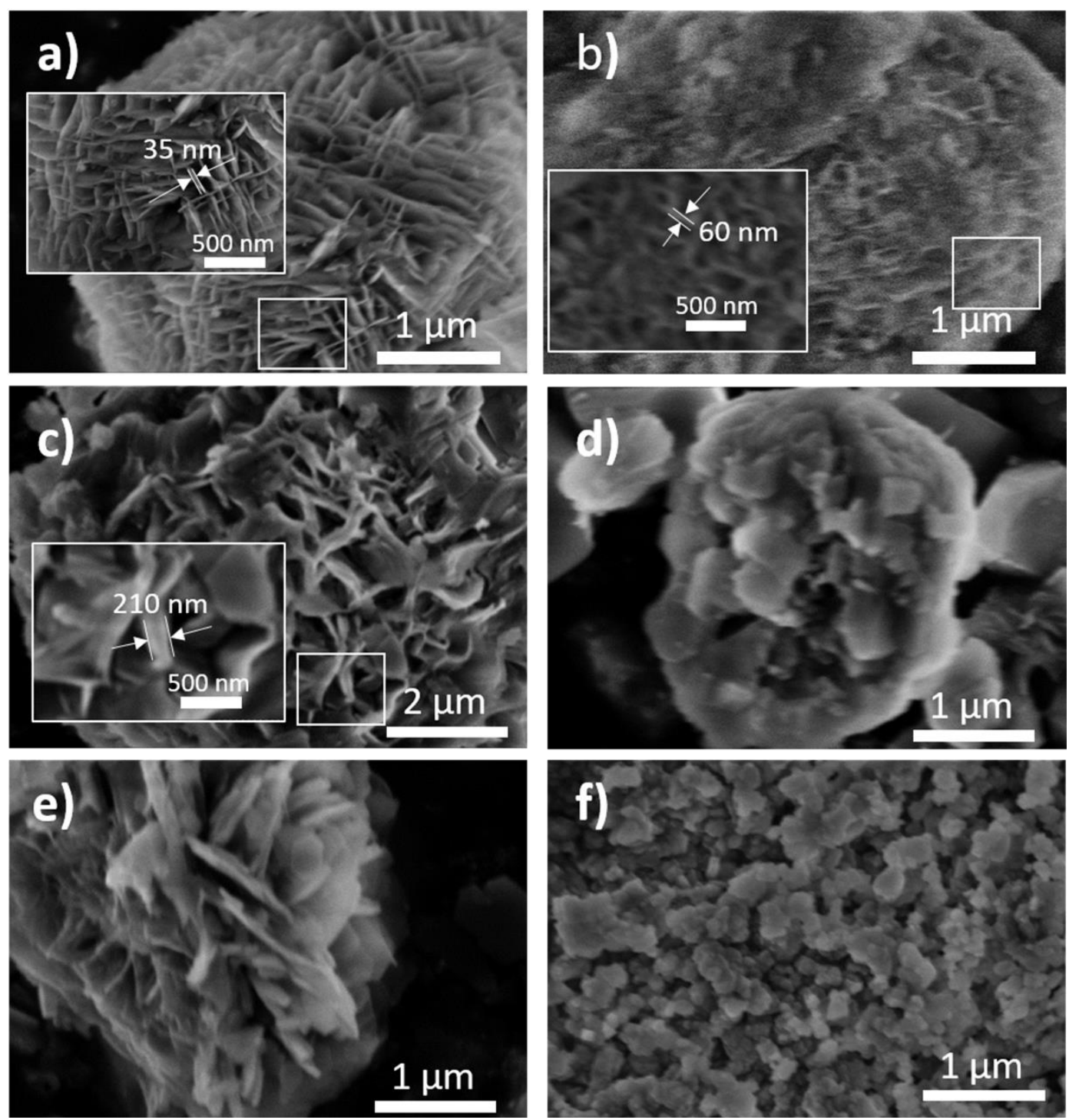

Figure 2. SEM images of a) MFI-50(T0); b) MFI-50(T2); c) MFI-50(T8); d) MFI-25(T8); e) MFI-100(T8); f) commercial MFI

$\mathrm{N}_{2}$ adsorption-desorption isotherms were carried out to reveal the porosity features of zeolites. All the samples exhibit type-IV $\mathrm{N}_{2}$ isotherms with a hysteresis loop, corresponding to capillary condensation in mesopores[48], as depicted in Fig. 3a. For MFI-50(T0), MFI-50(T2) and MFI-50(T8), the decrease in adsorption volume at the low pressure region $\left(P / P_{0}<0.45\right)$ indicates that the thicker layer expose less micropores (Table 2). Moreover, Fig. $3 b$ reveals that the mesopores at the range of 3-7 nm disappear with a high quantity of TPAOH added to the synthesis 
recipe, while those at the range $<3 \mathrm{~nm}$ increase slightly. This pore structure tendency is consistent with previous findings[32, 40]. For MFI-25(T8) and MFI-100(T8), morphologies and Si/Al ratio have a vital influence on porosities. As $\mathrm{Si} / \mathrm{Al}$ ratio increases, the increase of mesopore volume and the decrease of micropore volume can be observed (Table 2). The total pore volumes of most synthesized MFI are larger than those of commercial MFI. Therefore, most of the synthesized zeolites are more capable to accommodate coke than the commercial zeolites. The hierarchy factor, defined as the product of the relative micropore volume and the relative mesopore surface area, $\left(\mathrm{V}_{\text {micro }} / \mathrm{V}_{\text {total }}\right) \times\left(\mathrm{S}_{\text {meso }} / \mathrm{S}_{\mathrm{BET}}\right)$, is used to describe the interplay between the catalytic function located in the micropores and the accessibility function provided by the mesopores in the hierarchical zeolites[49]. The order of hierarchy factor of synthesized zeolites with various TPAOH adding amounts is: MFI-50(T0) < MFI-50(T2) < MFI-50(T8). For MFI samples with different Si/Al ratios, the order of hierarchy factor order is MFI-25(T8) $<$ MFI-50(T8) $<$ MFI-100(T8), since the relative increase of meso-porosity is higher than the relative decrease of micro-porosity in these zeolites. Both tailoring of the TPAOH concentration and $\mathrm{Si} / \mathrm{Al}$ ratio in the MFI synthesis process results in tunable meso-microporosity in lamellar MFI catalysts. 

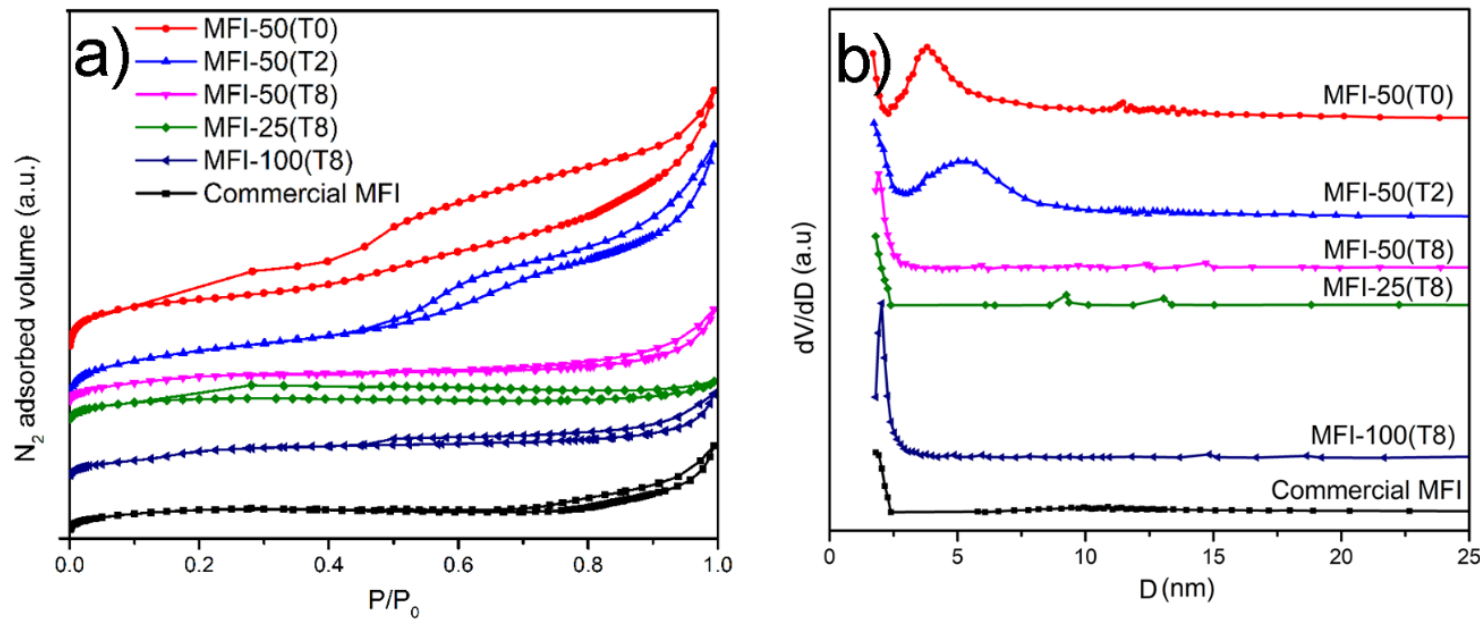

Figure 3. a) $\mathrm{N}_{2}$ adsorption-desorption isotherms and b) pore size distributions as derived from $\mathrm{N}_{2}$ sorption of the zeolites. The pore size distribution were calculated by using Barrett-JoynerHalenda (BJH) algorithm from the adsorption branch.

Table 2 Textural property of zeolites measured by $\mathrm{N}_{2}$ Adsorption-Desorption

\begin{tabular}{cccccccc}
\hline Catalyst & $\begin{array}{c}\mathrm{S}_{\mathrm{BET}}{ }^{a} \\
\left(\mathrm{~m}^{2} \mathrm{~g}^{-1}\right)\end{array}$ & $\begin{array}{c}\mathrm{S}_{\text {micro }}{ }^{b} \\
\left(\mathrm{~m}^{2} \mathrm{~g}^{-1}\right)\end{array}$ & $\begin{array}{c}\mathrm{S}_{\text {meso }}{ }^{b} \\
\left(\mathrm{~m}^{2} \mathrm{~g}^{-1}\right)\end{array}$ & $\begin{array}{c}\mathrm{V}_{\text {total }}{ }^{c} \\
\left(\mathrm{~cm}^{3} \mathrm{~g}^{-1}\right)\end{array}$ & $\begin{array}{c}\mathrm{V}_{\text {micro }}{ }^{b} \\
\left(\mathrm{~cm}^{3} \mathrm{~g}^{-1}\right)\end{array}$ & $\begin{array}{c}\mathrm{V}_{\text {meso }}{ }^{d} \\
\left(\mathrm{~cm}^{3} \mathrm{~g}^{-1}\right)\end{array}$ & $\begin{array}{c}\text { Hierarchy } \\
\text { factore }\end{array}$ \\
\hline $\begin{array}{c}\text { Commercial } \\
\text { MFI }\end{array}$ & 263.8 & 206.7 & 57.1 & 0.228 & 0.108 & 0.120 & 0.10 \\
MFI-50(T0) & 424.9 & 280.6 & 144.3 & 0.515 & 0.145 & 0.370 & 0.10 \\
MFI-50(T2) & 422.7 & 226.0 & 196.7 & 0.506 & 0.118 & 0.388 & 0.11 \\
MFI-50(T8) & 319.5 & 214.9 & 104.6 & 0.257 & 0.112 & 0.145 & 0.14 \\
MFI-25(T8) & 320.2 & 270.6 & 49.6 & 0.191 & 0.143 & 0.048 & 0.12 \\
MFI-100(T8) & 314.2 & 150.0 & 164.2 & 0.238 & 0.080 & 0.158 & 0.18 \\
\hline
\end{tabular}

$a$ : Determined from multipoint BET method. $b$ : Determined from t-method. $c$ : Determined from adsorbed volume at $\mathrm{P} / \mathrm{P}_{0}=0.99 . d$ : $\mathrm{V}_{\text {meso }}=\mathrm{V}_{\text {total }}-\mathrm{V}_{\text {micro }} e$ : Described as the product $\left(\mathrm{V}_{\text {micro }} / \mathrm{V}_{\text {total }}\right) \times\left(\mathrm{S}_{\text {meso }} / \mathrm{S}_{\mathrm{BET}}\right)$.

\subsubsection{Temperature-Programmed Reduction Analysis}

The reducibility of $\mathrm{MoO}_{x} / \mathrm{ZSM}-5$ species was studied by $\mathrm{H}_{2}$-TPR. Previous MAS NMR spectra suggested that surface $\mathrm{MoO}_{\mathrm{x}}$ could migrate into the structural channels during calcination, and anchor over conventional ZSM-5 frameworks as active sites[50, 51]. Moreover, DFT calculation and UV-Raman study also demonstrated that Mo oxide species preferentially anchor 
on framework $\mathrm{Al}$ sites[52, 53]. In this study, TPR profiles are deconvoluted into four peaks (as shown in Fig. 4), and the corresponding hydrogen consumptions are summarized in Table 3. Peak I at the lowest reduction temperature $(\sim 530 \mathrm{~K})$ is assigned to partial reduction of amorphous polymolybdates $\left(\mathrm{Mo}^{6+}\right)$, peak II at $\sim 640 \mathrm{~K}$ and peak III at $\sim 790 \mathrm{~K}$ are corresponding to the reduction of octahedrally-coordinated $\mathrm{Mo}^{6+}$ in $\mathrm{MoO}_{3}$ to $\mathrm{Mo}^{4+}$. Peak IV with the highest reducing temperature $(\sim 940 \mathrm{~K})$ is assigned to the sequential reduction of $\mathrm{Mo}^{4+}$ to metallic $\mathrm{Mo}(0)[54-56]$. The reduction of amorphous polymolybdates (peak I) are not pronounced in all Mo/MFI samples, which confirmed the successful preparation of highly-dispersed of Mo species over the synthetic zeolites. The reduction of $\mathrm{Mo}^{4+}$ to metal Mo (0) dominates the TPR profile, and only a small fraction of $\mathrm{Mo}^{4+}$ was reduced to metal Mo (0) over Mo/MFI-50(T0) catalyst. Mo/MFI-50(T8) catalyst indicates more than 3 -fold increase of hydrogen consumption of peak IV than that of Mo/MFI-50(T0). Therefore, thicker layers introduced by TPAOH addition contributed to the reducibility from $\mathrm{Mo}^{4+}$ to metal Mo. As summarized in Table 3, the relative concentration of reducible $\mathrm{Mo}^{4+}$ in various catalysts decreases with layer thickness in the order: MFI-50(T8) > MFI50(T2) > MFI-50(T0), while that of the catalysts with different $\mathrm{Si} / \mathrm{Al}$ ratios decreases in the order: Mo/MFI-25(T8) >Mo/MFI-100(T8) > Mo/MFI-50(T8). 


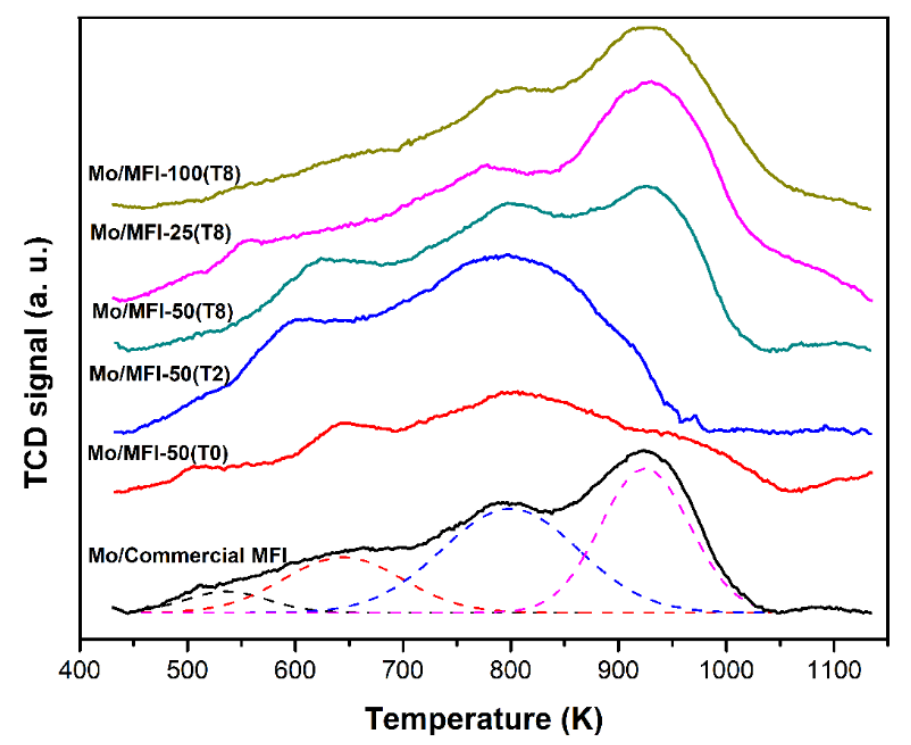

Figure 4. $\mathrm{H}_{2}$-TPR profiles for fresh Mo/MFI-50(T0), Mo/MFI-50(T2), Mo/MFI-50(T8), Mo/MFI-25(T8), Mo/MFI-100(T8) catalysts

Table 3 Numerical results of TPR experiments on Mo loaded catalysts

\begin{tabular}{cccccc}
\hline Catalyst & & Peak I & Peak II & Peak III & Peak IV \\
\hline \multirow{2}{*}{ Mo/Commercial MFI } & Temperature $(\mathrm{K})$ & 536 & 644 & 799 & 924 \\
& H2 consumption $(\boldsymbol{\mu m o l} / \mathbf{g})$ & $\mathbf{1 3}$ & $\mathbf{4 9}$ & $\mathbf{1 0 6}$ & $\mathbf{9 6}$ \\
Mo/MFI-50(T0) & Temperature $(\mathrm{K})$ & 541 & 646 & 808 & 964 \\
& H2 consumption $(\boldsymbol{\mu m o l} / \mathbf{g})$ & $\mathbf{1 4}$ & $\mathbf{2 3}$ & $\mathbf{1 4 2}$ & $\mathbf{1 5}$ \\
Mo/MFI-50(T2) & Temperature $(\mathrm{K})$ & 535 & 633 & 785 & 879 \\
& H2 consumption $(\boldsymbol{\mu m o l} / \mathbf{g})$ & $\mathbf{8}$ & $\mathbf{1 0 0}$ & $\mathbf{1 6 8}$ & $\mathbf{4 2}$ \\
Mo/MFI-50(T8) & Temperature $(\mathrm{K})$ & 519 & 633 & 807 & 932 \\
& H2 consumption $(\boldsymbol{\mu m o l} / \mathbf{g})$ & $\mathbf{3}$ & $\mathbf{5 9}$ & $\mathbf{1 7 4}$ & $\mathbf{7 0}$ \\
Mo/MFI-25(T8) & Temperature $(\mathrm{K})$ & 560 & 634 & 778 & 925 \\
& $\mathbf{H}$ c consumption $(\boldsymbol{\mu m o l} / \mathbf{g})$ & $\mathbf{2}$ & $\mathbf{8 5}$ & $\mathbf{8 7}$ & $\mathbf{2 0 3}$ \\
Mo/MFI-100(T8) & Temperature $(\mathrm{K})$ & 569 & 680 & 795 & 924 \\
& H2 consumption $(\boldsymbol{\mu m o l} / \mathbf{g})$ & $\mathbf{8}$ & $\mathbf{4 8}$ & $\mathbf{6 8}$ & $\mathbf{1 6 3}$ \\
\hline
\end{tabular}




\subsection{3 $\mathrm{NH}_{3}-\mathrm{TPD}$ Analysis}

The $\mathrm{NH}_{3}$-TPD measurements were performed to analyze the acid distribution and concentrations on the zeolite surface. As shown in Figure 5, two desorption peaks were obtained by conducting deconvolution at low temperature around $530 \mathrm{~K}$ and high temperature around 700 $\mathrm{K}$, which is consistent with reported data[57, 58]. These two peaks correspond to weak-acid sites and strong-acid sites on the zeolite surface, respectively. It is widely accepted that the $\mathrm{Al}$ in the zeolitic framework causes strong-acid sites, whereas framework terminal Si mainly brings weak acidity[59, 60]. The results indicated the concentration of strong-acid sites associated with $\mathrm{Al}$ are dominant among every zeolite.

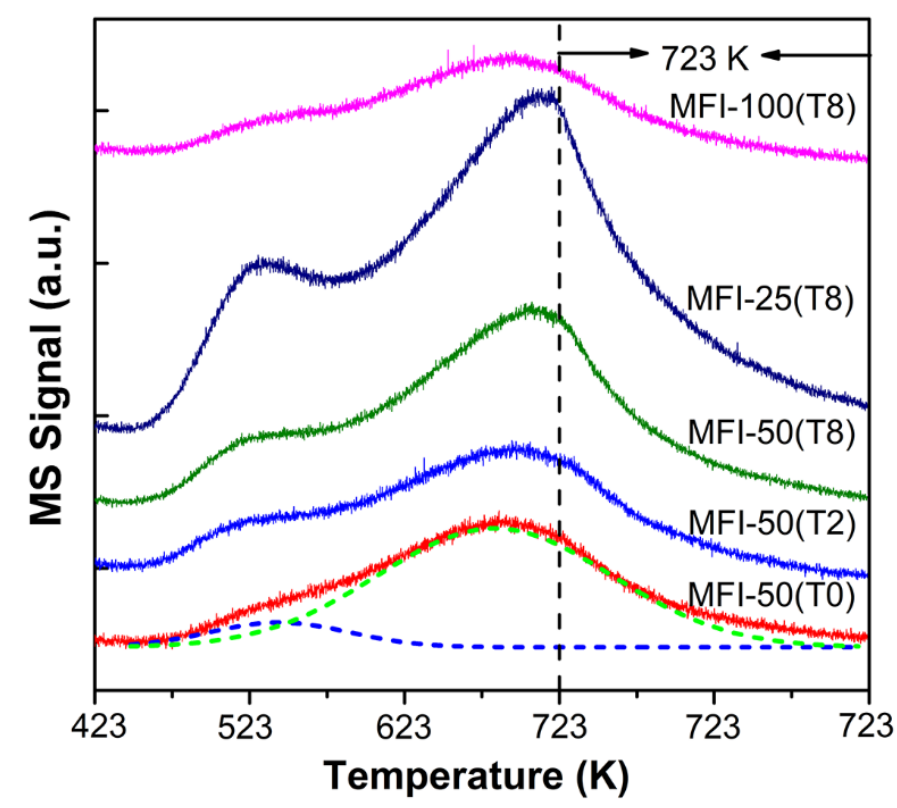

Figure 5. $\mathrm{NH}_{3}$-TPD profiles of MFI-50(T0), MFI-50(T2), MFI-50(T8), MFI-25(T8) and MFI100(T8). 
Table $4 \mathrm{NH}_{3}$-TPD data of synthesized ZSM-5

\begin{tabular}{|c|c|c|c|}
\hline \multirow{2}{*}{ Catalyst } & \multicolumn{3}{|c|}{ Distribution and concentration of acid sites $(\mu \mathrm{mol} \mathrm{NH} / \mathrm{g})$} \\
\hline & Region Weak & Region Strong & Total \\
\hline MFI-25(T8) & 118 & 443 & 561 \\
\hline MFI-100(T8) & 12 & 132 & 144 \\
\hline MFI-50(T8) & 60 & 280 & 340 \\
\hline MFI-50(T2) & 27 & 154 & 181 \\
\hline MFI-50(T0) & 19 & 150 & 169 \\
\hline
\end{tabular}

The acidities of the synthesized ZSM-5 are summarized in Table 4. The MFI-25(T8), MFI50(T8) and MFI-100(T8) clearly exhibited different scales of acid sites, suggesting that the change of the $\mathrm{Si} / \mathrm{Al}$ ratio is an effective approach to modify surface acidity. Moreover, the MFI-50(T8) possessed a larger amount of acidic sites than MFI-50(T2) and MFI-50(T0), though they were in the same Si/Al ratio of 50. Consequently, the extra addition of TPAOH in MFI-50(T2) and MFI50(T8) promoted the $\mathrm{Al}$ embedding into the framework.

\subsubsection{Ethane Dehydro-aromatization on Mo/MFI Catalysts with Different Layer} Thickness

All synthetic/commercial zeolites demonstrated negligible aromatic productivity. The reaction profiles of ethane conversion with time-on-stream (TOS) over Mo/MFI-50(T0), Mo/MFI50(T2), Mo/MFI-50(T8) and Mo/commercial MFI with the same Si/Al ratio (Si/Al=50), but different layer thickness are presented in Figure 6a. Among various catalysts, Mo/MFI-50(T0) with the thinnest nanosheets exhibits the best performance in ethane conversion, while Mo/MFI-50(T8) with the thickest nanosheets shows fair performance. During the initial period of dehydroaromatization reaction, gaseous ethane must diffuse through the channels of zeolite framework, and then contact the reduced Mo species[61-63]. Thus, the thicker the nanosheet, the longer 
diffusion path is necessary for the reactant to pass through. Once the intermediates and the products were mixed with ethane, the TOF (turn-over-frequency) of ethane on Mo active sites was negatively affected by longer channels, and results in lower ethane conversion. Moreover, from $\mathrm{NH}_{3}$-TPD results, the concentration of acid sites on MFI-50(T2) $(181 \mu \mathrm{mol} \mathrm{NH} / \mathrm{g})$ is comparable to that of MFI-50(T0) (169 $\mu$ mol $\mathrm{NH}_{3} / \mathrm{g}$ ), however Mo/MFI-50(T2) shows lower ethane conversion but higher aromatic selectivity. From Fig. $6 \mathrm{c}$ and d, it is found that the synthesized pillared MFI samples presented the higher produced ethylene flow rate but lower aromatic yields than those of commercial MFI, which is attributed to the less shape selectivity of the lamellar zeolite samples. 

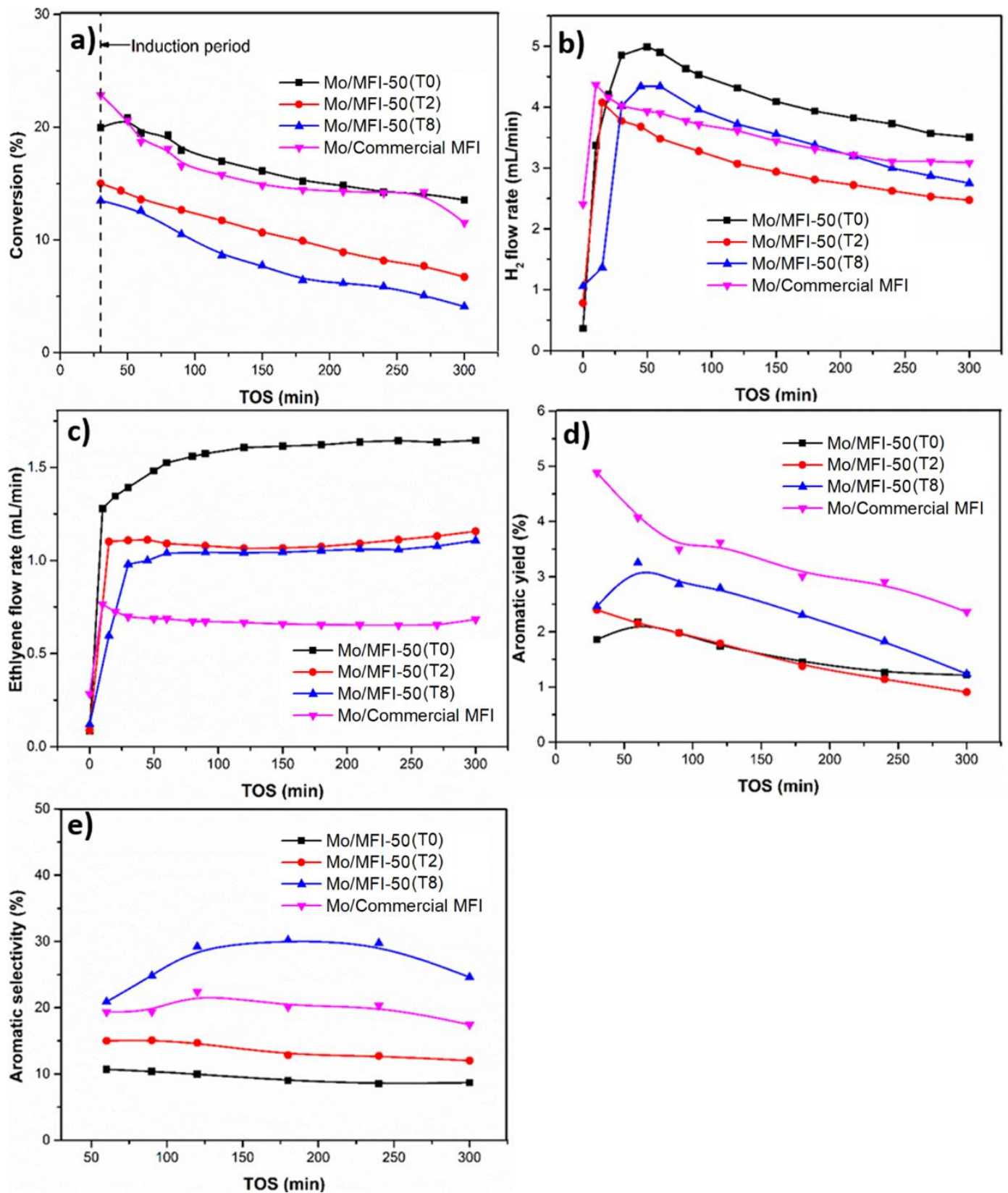

Figure 6. Mo/MFI-50(T0), Mo/MFI-50(T2), Mo/MFI-50(T8) and Mo/Commercial MFI catalysts in ethane aromatization reaction with the TOS of a) ethane conversion, b) $\mathrm{H}_{2}$ flow rate, c) $\mathrm{C}_{2} \mathrm{H}_{4}$ flow rate, d) aromatic yield, e) aromatic selectivity. 
Figure $6 b$, $c$, and d depict the productivities of $\mathrm{H}_{2}, \mathrm{C}_{2} \mathrm{H}_{4}$ and the aromatic yield (containing benzene and toluene). The ratio of benzene to toluene in the product of Mo/MFI-50(T8) catalyst reached 1.85, which is greater than that of Mo/MFI-50(T0) and Mo/MFI-50(T2) catalyst, whose ratio equaled 1.35 and 1.53 , respectively. Interestingly, Mo/MFI-50(T0) exhibited the highest $\mathrm{C}_{2} \mathrm{H}_{6}$ conversion and $\mathrm{H}_{2} / \mathrm{C}_{2} \mathrm{H}_{4}$ productivity, but the yield of aromatic was the lowest. Mo/MFI50(T8) exhibited higher aromatic yield compared to Mo/MFI-50(T0) and Mo/MFI-50(T2) despite lower ethane conversion, suggesting that the thicker zeolite layer is beneficial for aromatic yields. Based on the carbon balance, it is remarkable that the Mo/MFI-50(T8) catalyst showed the highest aromatic selectivity, even compared to the referential Mo/commercial ZSM-5 with spherical structure from SEM observation. Compared with Mo/MFI-50 (T0), both Mo/MFI-50(T2) and Mo/MFI-50(T8) catalysts with thicker layers demonstrated lower ethane conversion but higher aromatic yield. Therefore, it is conclusive that the pillar layers with long diffusion path plays a critical role in improving the formation of aromatics.

\subsubsection{Ethane Dehydro-aromatization on Mo/MFI Catalysts with Different Si/Al Ratios}

It is widely accepted that alumina defects provide nucleation sites during the formation of the ZSM-5 structure and Brønsted acidity[52, 64]. In this study, the influence of Si/Al ratio and Al/Mo for the reactivity of ethane dehydro-aromatization was studied with Mo/MFI-25(T8), Mo/MFI-50(T8) and Mo/MFI-100(T8), in which the numbers $(25,50,100)$ represents various $\mathrm{Si} / \mathrm{Al}$ ratios. Because this study focuses on the zeolite structure, the same Mo loading (1\%) was applied. Therefore, $\mathrm{Si} / \mathrm{Al}$ ratio is inversely with $\mathrm{Al} / \mathrm{Mo}$ ratios, which can serve as an indicator of the amount of acid sites taken by Mo for aromatization. As shown in Figure 7, the ethane conversion on the Mo/MFI-25(T8) catalyst with lowest $\mathrm{Si} / \mathrm{Al}$ (25) dropped dramatically after the initial period, while Mo/MFI-50(T8) ( $\mathrm{Si} / \mathrm{Al}=50, \mathrm{Al} / \mathrm{Mo}=3.14)$ and $\mathrm{Mo} / \mathrm{MFI}-100(\mathrm{~T} 8)(\mathrm{Si} / \mathrm{Al}=100$, 
$\mathrm{Al} / \mathrm{Mo}=1.57)$ decreased steadily. It should be noted that simultaneous downtrend of $\mathrm{H}_{2}$ and aromatic yields can be observed in Figure $7 \mathrm{~b}$ and $\mathrm{d}$. Stable ethylene yield was obtained over all catalysts after 30 mins reaction. Mo/MFI-25(T8) catalyst exhibited the highest initial activity, while Mo/MFI-100(T8) catalyst indicated the lowest aromatic yield. On the other hand, $\mathrm{NH}_{3}-\mathrm{TPD}$ profiles demonstrated that $\mathrm{Si} / \mathrm{Al}$ ratio of zeolite directly correlated with the surface acidity of Mo/MFI catalyst. As shown in Table 4, Mo/MFI-25(T8) represents the highest surface acidity among various synthesized zeolites. Considering negligible reactivity of pure zeolites, it is Mo species neighboring Brønsted acid sites that synergistically convert ethane into aromatics, and the $\mathrm{Si} / \mathrm{Al}$ ratios greatly affect initial reaction performance[52].

Despite the trace amount polymolybdates identified by $\mathrm{H}_{2}-\mathrm{TPR}$, Mo is mainly highlydispersed in all catalysts. There are three types of $\mathrm{MoO}_{\mathrm{x}}$ allocated in the zeolite framework: anchoring at double $\mathrm{Al}$ sites, single $\mathrm{Al}$ sites and surface $\mathrm{Si}$ sites. It is accepted that the $\mathrm{C}-\mathrm{H}$ bond activation energy over the Mo nanostructures anchored are increasing in the order: double Al acid sites > single Al acid sites > external Si sites[52, 53, 65]. In MFI-25(T8) and MFI-50(T8), the Al/Mo ratio are 6.28 and 3.14, respectively (Table 5). Therefore, Mo species are likely to anchor at double/single Al sites, which may contribute to the higher initial aromatic yield of MFI-25 (T8).

Table 5. The $\mathrm{Si} / \mathrm{Al}$ and $\mathrm{Al} / \mathrm{Mo}$ ratio for samples

\begin{tabular}{lll}
\hline Sample & Si/Al Ratio & Al/Mo Ratio \\
\hline MFI-25(T8) & 25 & 6.28 \\
MFI-50(T0)/(T2)/(T8) & 50 & 3.14 \\
MFI-100 (T8) & 100 & 1.57 \\
\hline
\end{tabular}



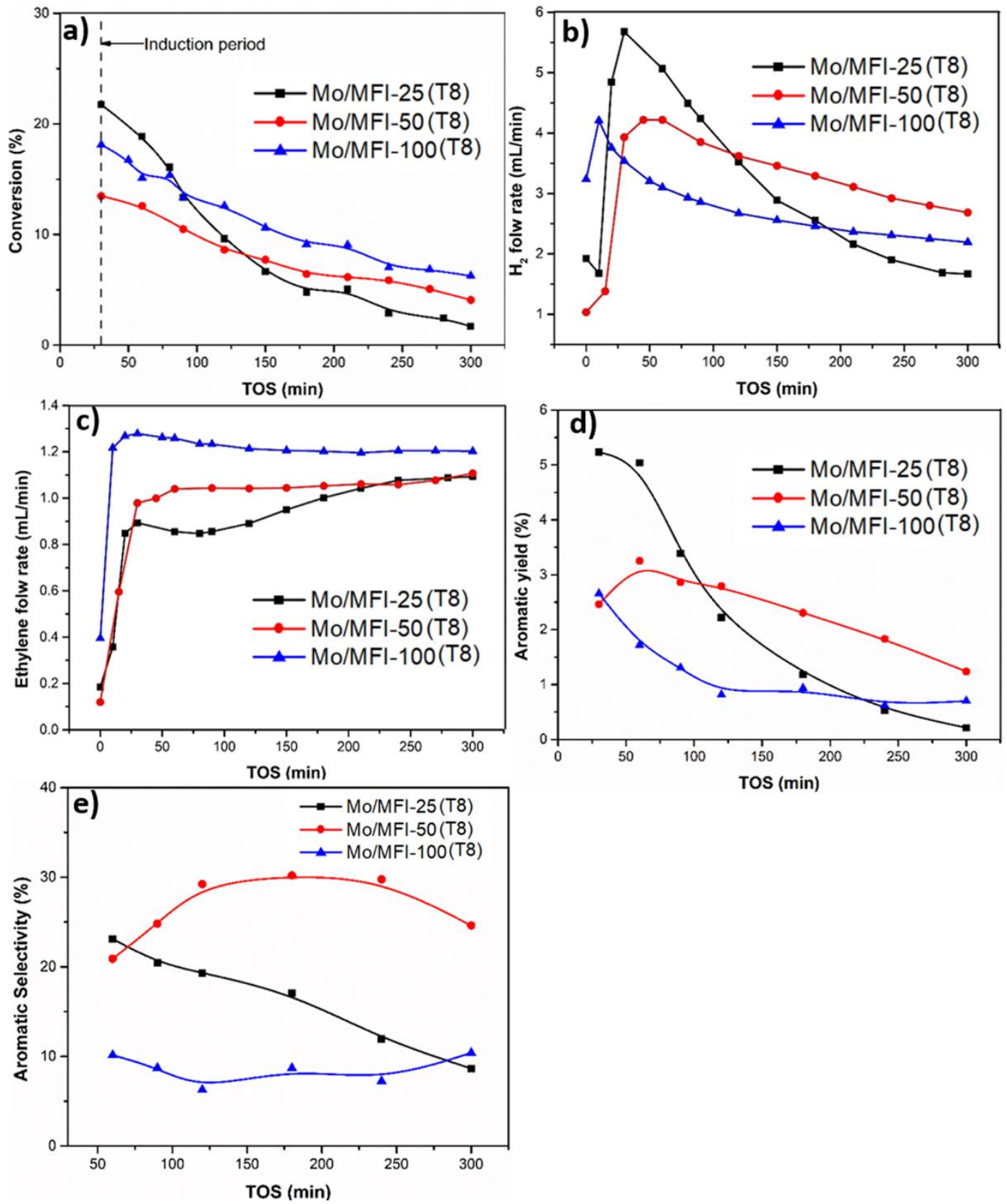

Figure 7. Mo/MFI-25(T8), Mo/MFI-50(T8), Mo/MFI-100(T8) catalysts in ethane aromatization reaction with the TOS of a) ethane conversion, b) $\mathrm{H}_{2}$ flow rate, c) $\mathrm{C}_{2} \mathrm{H}_{4}$ flow rate, d) aromatic yield, e) aromatic selectivity.

The prepared Mo/MFI catalysts indicated different deactivation behavior: the Mo/MFI25(T8) catalyst with the lowest $\mathrm{Si} / \mathrm{Al}$ ratio remarkably increases ethane conversion and aromatic 
selectivity, though fast deactivation was observed as well. For Mo/MFI-100(T8), Mo sites over the lowest acidity results in the lowest ethane conversion, lowest ethane/ $\mathrm{H}_{2} /$ aromatics productivity and least aromatic selectivity. Instead, Mo/MFI-50(T8) catalyst indicated highest $\mathrm{H}_{2}$ and aromatic productivity during 250 min reaction. Thus, lamellar zeolites with moderate $\mathrm{Si} / \mathrm{Al}$ ratio maintains a favorable balance between catalytic activity, high selectivity to aromatics and catalyst stability in ethane aromatization.

\subsubsection{Coke Analysis}

Coke formed during aromatization reaction is a complicated mixture of polyaromatics and graphitic species which blocks Brønsted acidic sites, zeolite micropores and Mo active centers, thus leading to the inevitable decline of catalytic performance[42, 43, 66]. Fig. 8 presents TPO profiles of spent catalysts after continuous aromatization testing at $923 \mathrm{~K}$ for $300 \mathrm{~min}$, and the relative areas of each peak were summarized in Table 6.

The amount of the coke deposit content is: Mo/MFI-25(T8) > Mo/MFI-50(T0) > Mo/MFI$50(\mathrm{~T} 2)>\mathrm{Mo} / \mathrm{MFI}-100(\mathrm{~T} 8)>\mathrm{Mo} / \mathrm{MFI}-50(\mathrm{~T} 8) \approx$ commercial MFI. $\mathrm{CO}_{2}$ profiles could be deconvoluted into three peaks at $\sim 705,750$ and $830 \mathrm{~K}[42,67,68]$ as shown in Figure 8. Carbon deposits burned out at $705 \mathrm{~K}$ were located at the external surface of the catalytic particles, the peak at $750 \mathrm{~K}$ corresponds to the coke associated with the Mo species in the zeolite, whereas the carbon species burning at high temperatures $(>800 \mathrm{~K})$ were mainly from coking anchored over the Brфnsted acid sites. 


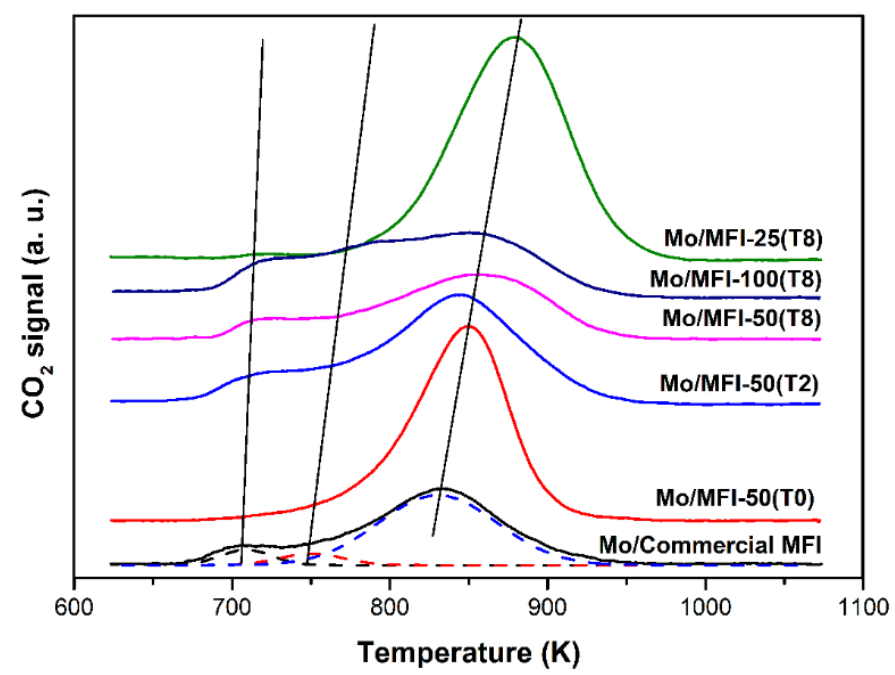

Figure 8. TPO profiles for spent Mo/MFI-50(T0), Mo/MFI-50(T2), Mo/MFI-50(T8), Mo/MFI25(T8), Mo/MFI-100(T8) catalysts after ethane dehydro-aromatization reactions

Trace carbon deposits over external surface of Mo species are observed at $705 \mathrm{~K}$, which demonstrated that the coking over external surface are negligible for prepared Mo/lamellar zeolites catalyst. On the spent $\mathrm{Mo} / \mathrm{MFI}-25(\mathrm{~T} 8)(\mathrm{Si} / \mathrm{Al}=25, \mathrm{Al} / \mathrm{Mo}=6.28)$, the largest amount of coke appeared on the Brønsted acid sites with very few carbon deposits associated with Mo species. In contrary, over the spent Mo/MFI-100(T8) catalyst with less Brønsted acidity, carbon deposits mainly associated with Mo species, instead of Brønsted sites.

Regarding the spent samples of Mo/MFI-50(T0), Mo/MFI-50(T2), Mo/MFI-50(T8) catalysts with same $\mathrm{Si} / \mathrm{Al}$ ratio, TPO profiles showed that the nature and amount of deposited coke are associated with zeolite thicknesses. With the thinner nanosheet, carbon deposits were preferable to be formed over Brønsted acid sites. Combined with performance data in Figure 7, it is concluded that that the large amount of coke in Mo/MFI-50(T0) catalyst with thinner layer could be induced by high ethane conversion and lower aromatic selectivity, whereas Mo/MFI-50(T8) 
catalyst exhibited higher aromatic selectivity as well as less amount of coke deposited on the Brønsted acid sites.

Table 6 Numerical results of TPO experiments on used Mo/MFI-T0, Mo/MFI-T2, Mo/MFIT8(Mo/MFI-50), Mo/MFI-25, Mo/MFI-100 catalysts.

\begin{tabular}{ccccc}
\hline \multirow{2}{*}{ Catalyst } & \multicolumn{3}{c}{ Peak relative area } & Total carbon amount \\
\cline { 2 - 5 } & Peak I & Peak II & Peak III & 106 \\
\hline Mo/MFI-25(T8) & 1 & 5 & $100^{*}$ & 59 \\
Mo/MFI-100(T8) & 2 & 42 & 15 & 47 \\
Mo/MFI-50(T8) & 3 & 10 & 34 & 69 \\
Mo/MFI-50(T2) & 3 & 10 & 56 & 80 \\
Mo/MFI-50(T0) & 2 & 11 & 67 & 45 \\
Commercial MFI & 4 & 3 & 38 & \\
\hline
\end{tabular}

*reference value of peak area

Overall, it is believed that the complicated coking over Mo/lamellar zeolites follows two mechanisms: (1) in the case of lamellar zeolites with high $\mathrm{Si} / \mathrm{Al}$ ratio, coke mainly covered Mo active sites, whereas only a small fraction of coke associated with Brønsted acid sites blocked the channel, ensuring the stability of aromatic selectivity while the ethane conversion dropped; (2) in the case of lamellar zeolites with lower $\mathrm{Si} / \mathrm{Al}$ ratio, a large amount of coke mainly covered Brønsted acid sites and clogged the channels, which would further decrease the ethane conversion. Consequently, a moderate $\mathrm{Si} / \mathrm{Al}$ ratio of a lamellar zeolite sustained the ethane conversion and aromatic selectivity, which benefited from the balance between hydrocarbons activation over Mo carbide species and modest channel coking over Brønsted acid sites.

\subsubsection{Oxidative Regenerations and Ethane Aromatization Reaction}

Considering surface coking and catalytic deactivation are unavoidable, it is proposed to study aromatization-regeneration cycle for realistic application of ethane aromatization. As 
discussed above, it is identified that surface coking is mainly associated with MoCx nanoparticles and strong acidic sites. Therefore, the preservation of the overall framework and the decoking degree should be considered during oxidative regeneration $[1,69,70]$. From the TPO data as shown in Figure 8, oxidative calcination at $823 \mathrm{~K}$ can greatly preserve the zeolite structure and avoid catalytic deactivation caused by Mo content[70]. Therefore, all cyclic reaction-regeneration experiments were performed at isothermal $823 \mathrm{~K}$ in this study.
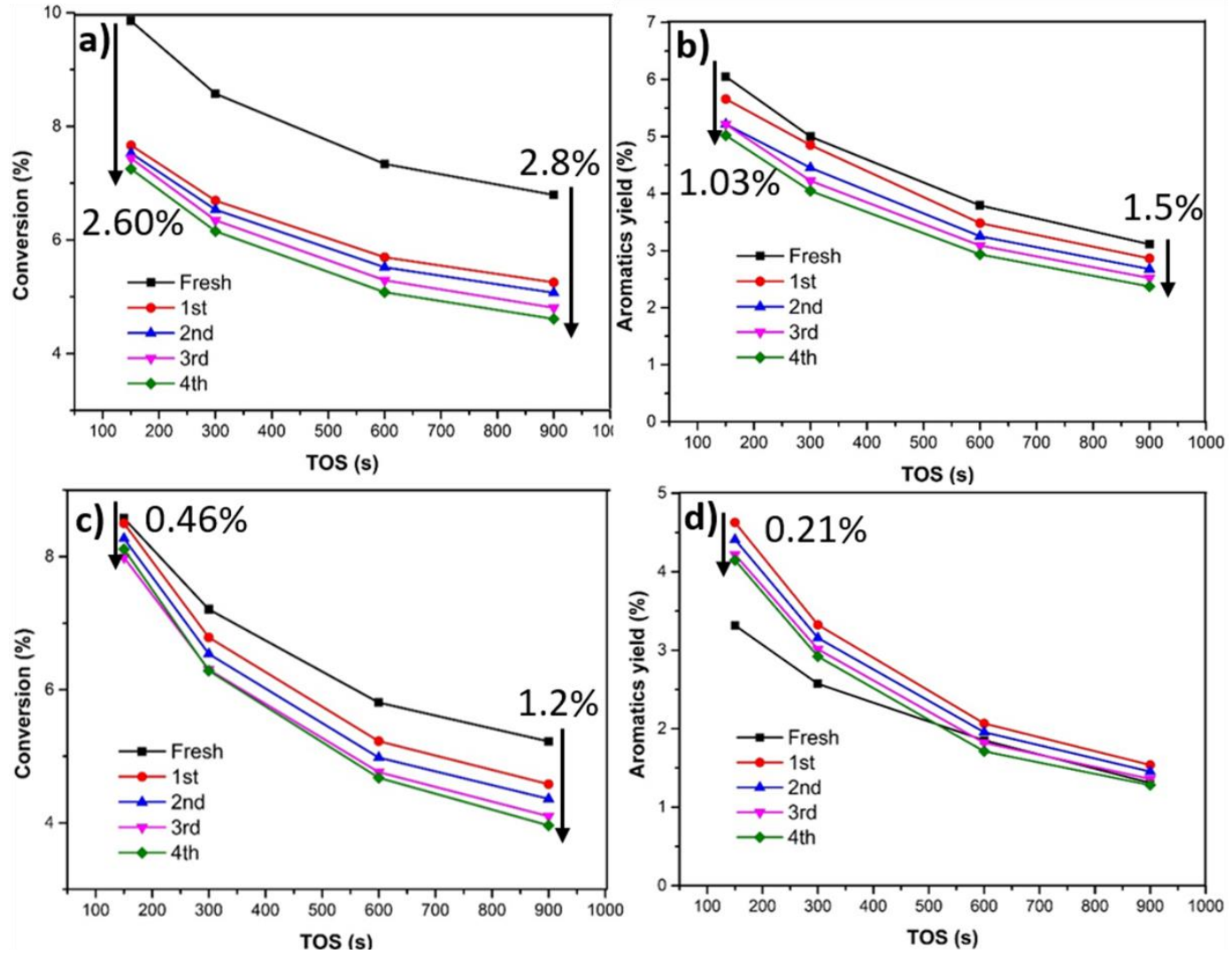

Figure 9. Ethane dehydro-aromatization reaction-regeneration cyclic operation. a), b) plots of ethane conversion and aromatic yield achieved on Mo/Commercial MFI catalyst in each reaction cycle; c), d) plots of ethane conversion and aromatic yield achieved on Mo/MFI-50(T8) in each reaction cycle.

Multi-cycle reaction-regeneration testing of Mo/Commercial-MFI and Mo/MFI-50(T8) were compared because they have the same $\mathrm{Si} / \mathrm{Al}$ ratio (as shown in Figure 9). At initial reaction (TOS=150s), ethane conversion notably dropped in the first cycle, and then continuously declined in the next three cycles over Mo/Commercial-MFI. The conversion for Mo/Commercial-MFI 
(Figure 9a) gave total $2.60 \%$ reactivity recession in four-cycle testing. In contrary, only $0.46 \%$ decrease of initial reactivity was observed over Mo/MFI-50(T8) under the same cyclic testing (Figure 9c). Regarding aromatic yield (Figure 9b and 9d), Mo/Commercial MFI showed continuous decrease with the increasing of cyclic testing, and totally $1.03 \%$ decrease of aromatic yields was observed. Surprisingly, the aromatic yields greatly improved from 3.1\% to $~ 5.0 \%$ after first regeneration for Mo/MFI-50(T8), and then minor decrease of aromatic yields in subsequent cycles. Therefore, the innovative Mo/MFI-50(T8) sample remains constant or even slightly improved aromatic productivity during multiple cyclic reactions.

Similar scenarios have been observed at ending stage of aromatization reaction (TOS=900s): ethane conversion and aromatic yield was significantly decreased at $2.8 \%$ and $1.5 \%$ for Mo/Commercial-MFI. In comparison, only $1.2 \%$ conversion was observed for Mo/MFI-50(T8) catalyst, while aromatic yields remains constant during four-cycle testing.

Excellent stability of Mo/MFI-50(T8) can also be validated by direct performance comparison of cycled catalyst with fresh sample. As shown in Table 7, catalytic performance (ethane conversion and aromatic yields) of spent catalyst after four cycle testing relatively mitigate $>30 \%$ reactivity compared to fresh sample. The Mo/MFI-50(T8), instead, lost less than 5\% of initial activity, and generate higher aromatic yield during cyclic testing. In conclusion, it is reasonable to predict that the industrial reaction/regeneration process will be operate quietly smoothly with Mo/MFI-50(T8) as a promising catalyst for ethane aromatization.

TPO profiles of the spent catalysts after the fourth aromatization reaction are shown in Figure 10. The spent Mo/Commercial ZSM-5 possess a considerably higher amount (by $21 \%$ compared to the Mo/MFI-50(T8)) of coke deposition than that of Mo/MFI-50(T8), which required 
longer period for decoking under oxidative condition. The size of HZSM-5 channels is identical to the diameters of benzene and naphthalene molecules so that the coke species, polyaromatics on the Brønsted acid sites spatially clogged the channel[43, 66]. The hierarchical cross of ZSM-5 nanosheet, micro-mesopores structure was fabricated to afford better mass transfer for regeneration of coking combustion as well as heat diffusion. Therefore, the hierarchical structure of Mo/MFI-50(T8) had an advantage of easy regeneration for continuous operations. In summary, our study confirmed that Mo/MFI-50(T8) is a promising catalyst support for ethane aromatization under cyclic operation. We are currently optimizing regeneration temperature and other parameters, and the results will be reported soon.

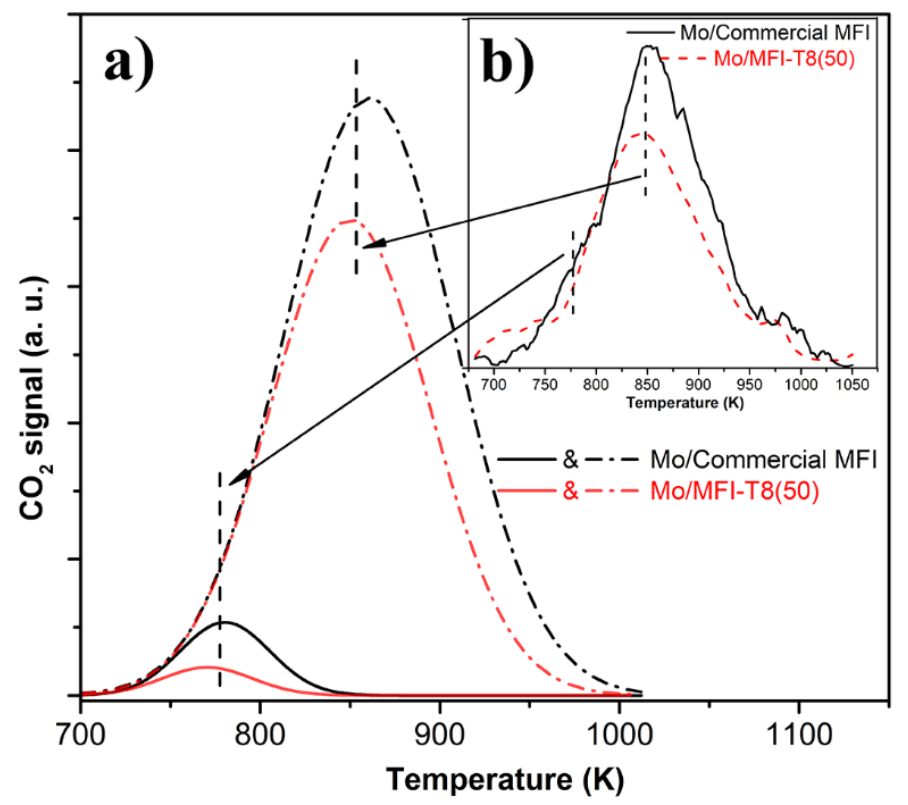

Figure 10. TPO profiles for fresh Mo/Commercial MFI and Mo/MFI-50(T8) catalyst after the fourth dehydro-aromatization reactions-regeneration cycles. The curves in the small window represent the original curves between two used catalysts. Deconvolution peaks of TPO profiles in the main window: a) back solid line and red solid line stand for carbide associated with Mo species over Mo/Commercial MFI and Mo/MFI-50(T8), respectively; b) black and red dashdot-dash lines are assigned to coke combined with Brønsted acid sites over Mo/Commercial MFI and Mo/MFI-50(T8), respectively. 


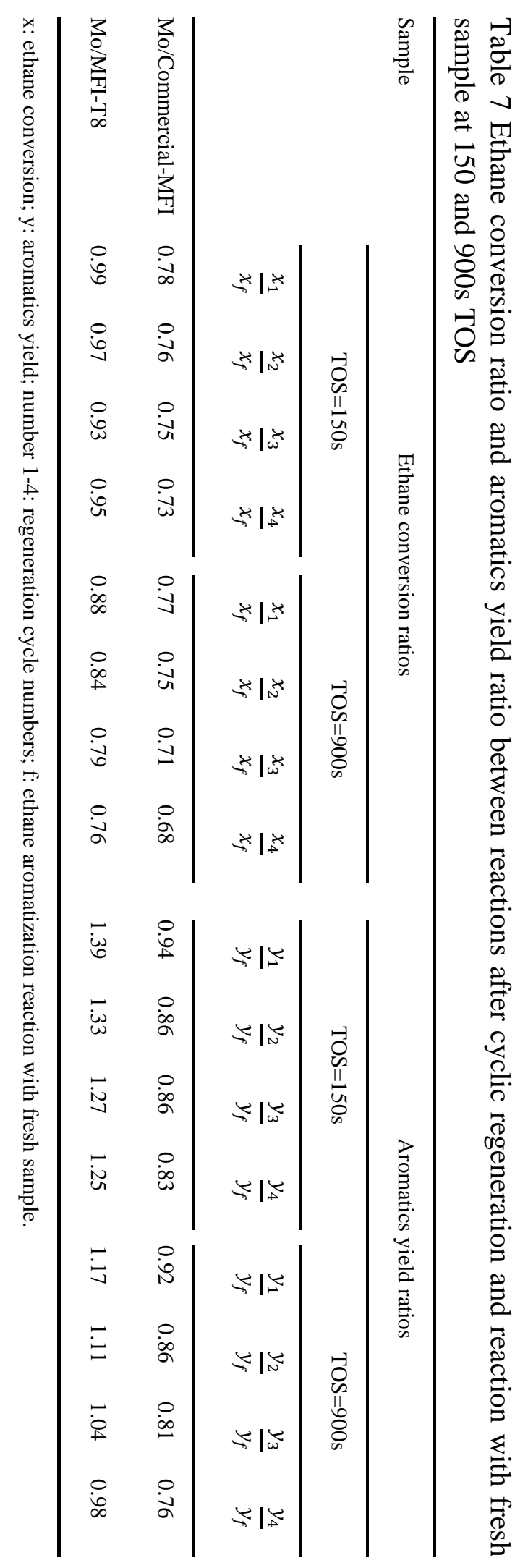




\subsection{Conclusions}

Lamellar $\mathrm{MoO}_{3} / \mathrm{ZSM}-5$ catalysts with various thicknesses were fabricated for ethane dehydro-aromatization by adding TPAOH in the synthesis recipe. The thicker layers with longer diffusion paths of zeolite lengthen the reaction path for the reactant and thus help the shape selectivity of aromatics, despite the lower ethane conversion. The ZSM-5 support with low Si/Al ratio helps to promote the ethane conversion as well as aromatic selectivity, but it sacrifices the stability of catalytic performance. Suitable $\mathrm{Si} / \mathrm{Al}$ ratios can balance high aromatic selectivity and catalytic stability. The longer diffusion pathway in ZSM-5 nanosheet can enhance the aromatic selectivity and lower the coke formation over thicker catalyst. Coke unevenly accumulated on Brønsted acid sites associated with Mo species, suggesting that $\mathrm{Si} / \mathrm{Al}$ ratio plays a crucial role in the reaction of ethane dehydro-aromatization. During the cyclic reaction-regeneration progress, lamellar zeolites with hierarchical structure among the layers allow better mass transfer for better reproducibility, which significantly improves catalyst regenerability over the conventional Mo/ZSM-5 catalyst. Overall, Mo-based catalysts supported over novel lamellar zeolites, such as Mo/MFI-50(T8) catalyst, indicated stable reactivity during multiple-cycle reaction-regeneration operation, and could be a promising system for industrial optimization and process deployment. 


\section{Reference}

[1] X. Bai, A. Samanta, B. Robinson, L. Li, J. Hu, Deactivation Mechanism and Regeneration Study of Ga-Pt Promoted HZSM-5 Catalyst in Ethane Dehydroaromatization, Industrial \& Engineering Chemistry Research, 57 (2018) 4505-4513.

[2] M. Guisnet, P. Magnoux, C. Canaff, Formation and nature of coke deposits on zeolites HY and HZSM-5, in: Studies in Surface Science and Catalysis, Elsevier, 1986, pp. 701-707.

[3] X.S. Li, C. Shi, Y. Xu, X.L. Zhang, K.J. Wang, A.M. Zhu, Pulsed Streamer Discharge Plasma over Ni/HZSM-5 Catalysts for Methane Conversion to Aromatics at Atmospheric Pressure, Plasma Processes and Polymers, 4 (2007) 15-18.

[4] L. Wang, L. Tao, M. Xie, G. Xu, J. Huang, Y. Xu, Dehydrogenation and aromatization of methane under non-oxidizing conditions, Catalysis Letters, 21 (1993) 35-41.

[5] A. Krogh, A. Hagen, T.W. Hansen, C.H. Christensen, I. Schmidt, Re/HZSM-5: a new catalyst for ethane aromatization with improved stability, Catalysis Communications, 4 (2003) 627-630.

[6] O. Chetina, T. Vasina, V. Lunin, Aromatization of ethane over Pt, Ga/HZSM-5 catalyst and the effect of intermetallic hydrogen acceptor on the reaction, Applied Catalysis A: General, 131 (1995) 7-14.

[7] Y. Xiang, H. Wang, J. Cheng, J. Matsubu, Progress and prospects in catalytic ethane aromatization, Catalysis Science \& Technology, 8 (2018) 1500-1516.

[8] A. Mehdad, R.F. Lobo, Ethane and ethylene aromatization on zinc-containing zeolites, Catalysis Science \& Technology, 7 (2017) 3562-3572.

[9] K. Skutil, M. Taniewski, Indirect methane aromatization via oxidative coupling, products separation and aromatization steps, Fuel processing technology, 88 (2007) 877-882.

[10] S. Majhi, P. Mohanty, H. Wang, K. Pant, Direct conversion of natural gas to higher hydrocarbons: A review, Journal of Energy Chemistry, 22 (2013) 543-554.

[11] M. Guisnet, N.S. Gnep, F. Alario, Aromatization of short chain alkanes on zeolite catalysts, Applied Catalysis A: General, 89 (1992) 1-30.

[12] L. Bai, Karnowo, S. Kudo, K. Norinaga, Y.-g. Wang, J.-i. Hayashi, Kinetics and Mechanism of Steam Gasification of Char from Hydrothermally Treated Woody Biomass, Energy \& Fuels, 28 (2014) 7133-7139.

[13] K. Sun, W. Gong, K. Gasem, H. Adidharma, M. Fan, R. Chen, Catalytic Methane Dehydroaromatization with Stable Nano Fe Doped on Mo/HZSM-5 Synthesized with a Simple and Environmentally Friendly Method and Clarification of a Perplexing Catalysis Mechanism Dilemma in This Field for a Period of Time, Industrial \& Engineering Chemistry Research, 56 (2017) 11398-11412.

[14] Y. Shu, D. Ma, L. Xu, Y. Xu, X. Bao, Methane dehydro - aromatization over Mo/MCM - 22 catalysts: a highly selective catalyst for the formation of benzene, Catalysis Letters, 70 (2000) 6773. 
[15] Y. Xu, L. Lin, Recent advances in methane dehydro-aromatization over transition metal ionmodified zeolite catalysts under non-oxidative conditions, Applied Catalysis A: General, 188 (1999) 53-67.

[16] Y. Wang, J. Zhou, L. Bai, Y. Chen, S. Zhang, X. Lin, Impacts of Inherent O-Containing Functional Groups on the Surface Properties of Shengli Lignite, Energy \& Fuels, 28 (2014) 862867.

[17] D.Y. Wang, Q.B. Kan, N. Xu, P. Wu, T.H. Wu, Study on methane aromatization over MoO3/HMCM-49 catalyst, Catalysis Today, 93-95 (2004) 75-80.

[18] B. Tian, Y. Qiao, L. Bai, W. Feng, Y. Jiang, Y. Tian, Pyrolysis behavior and kinetics of the trapped small molecular phase in a lignite, Energy Conversion and Management, 140 (2017) 109120.

[19] Z.R. Ismagilov, E.V. Matus, L.T. Tsikoza, Direct conversion of methane on Mo/ZSM-5 catalysts to produce benzene and hydrogen: achievements and perspectives, Energy \& Environmental Science, 1 (2008) 526-541.

[20] A. Samanta, X. Bai, B. Robinson, H. Chen, J. Hu, Conversion of Light Alkane to ValueAdded Chemicals over ZSM-5/Metal Promoted Catalysts, Industrial \& Engineering Chemistry Research, 56 (2017) 11006-11012.

[21] B. Robinson, X. Bai, A. Samanta, V. Abdelsayed, D. Shekhawat, J. Hu, Stability of Fe- and Zn-Promoted Mo/ZSM-5 Catalysts for Ethane Dehydroaromatization in Cyclic Operation Mode, Energy \& Fuels, 32 (2018) 7810-7819.

[22] R. Chu, C. Song, W. Hou, X. Meng, Z. Miao, X. Li, G. Wu, Y. Wan, L. Bai, Improved stability of Pd/HZSM-5 bifunctional catalysts by the addition of promoters $\left(\mathrm{CeO}_{2}, \mathrm{CaO}\right)$ for the One-step synthesis of dimethyl ether from Sulfur-containing $\mathrm{CO}_{2}$ hydrogenation, Journal of the Taiwan Institute of Chemical Engineers, 80 (2017) 1041-1047.

[23] C. Karakaya, H. Zhu, R.J. Kee, Kinetic modeling of methane dehydroaromatization chemistry on Mo/Zeolite catalysts in packed-bed reactors, Chemical Engineering Science, 123 (2015) 474486.

[24] M.C. Iliuta, I. Iliuta, B.P.A. Grandjean, F. Larachi, Kinetics of Methane Nonoxidative Aromatization over Ru-Mo/HZSM-5 Catalyst, Industrial \& Engineering Chemistry Research, 42 (2003) 3203-3209.

[25] K.S. Wong, J.W. Thybaut, E. Tangstad, M.W. Stöcker, G.B. Marin, Methane aromatisation based upon elementary steps: Kinetic and catalyst descriptors, Microporous and Mesoporous Materials, 164 (2012) 302-312.

[26] S.S. Arzumanov, A.A. Gabrienko, D. Freude, A.G. Stepanov, In situ high temperature MAS NMR study of the mechanisms of catalysis. Ethane aromatization on Zn-modified zeolite BEA, Solid State Nuclear Magnetic Resonance, 35 (2009) 113-119.

[27] J. Gao, Y. Zheng, Y. Tang, J.-M. Jehng, R. Grybos, J. Handzlik, I.E. Wachs, S.G. Podkolzin, Spectroscopic and Computational Study of Cr Oxide Structures and Their Anchoring Sites on ZSM-5 Zeolites, ACS Catalysis, 5 (2015) 3078-3092. 
[28] V.R. Choudhary, P. Devadas, S. Banerjee, A.K. Kinage, Aromatization of dilute ethylene over Ga-modified ZSM-5 type zeolite catalysts, Microporous and Mesoporous Materials, 47 (2001) 253-267.

[29] R. Srivastava, M. Choi, R. Ryoo, Mesoporous materials with zeolite framework: remarkable effect of the hierarchical structure for retardation of catalyst deactivation, Chemical Communications, (2006) 4489-4491.

[30] M. Choi, K. Na, J. Kim, Y. Sakamoto, O. Terasaki, R. Ryoo, Stable single-unit-cell nanosheets of zeolite MFI as active and long-lived catalysts, Nature, 461 (2009) 246.

[31] B. Liu, C. Li, Y. Ren, Y. Tan, H. Xi, Y. Qian, Direct synthesis of mesoporous ZSM-5 zeolite by a dual-functional surfactant approach, Chemical Engineering Journal, 210 (2012) 96-102.

[32] R. Barakov, N. Shcherban, P. Yaremov, I. Bezverkhyy, A. Baranchikov, V. Trachevskii, V. Tsyrina, V. Ilyin, Synthesis of micro-mesoporous aluminosilicates on the basis of ZSM-5 zeolite using dual-functional templates at presence of micellar and molecular templates, Microporous and Mesoporous Materials, 237 (2017) 90-107.

[33] Y. Wu, L. Emdadi, S.C. Oh, M. Sakbodin, D. Liu, Spatial distribution and catalytic performance of metal-acid sites in Mo/MFI catalysts with tunable meso-/microporous lamellar zeolite structures, Journal of Catalysis, 323 (2015) 100-111.

[34] J. Pérez-Ramírez, C.H. Christensen, K. Egeblad, C.H. Christensen, J.C. Groen, Hierarchical zeolites: enhanced utilisation of microporous crystals in catalysis by advances in materials design, Chemical Society Reviews, 37 (2008) 2530-2542.

[35] Y. Tao, H. Kanoh, L. Abrams, K. Kaneko, Mesopore-Modified Zeolites: Preparation, Characterization, and Applications, Chemical Reviews, 106 (2006) 896-910.

[36] J. Liu, L. Yu, Z. Zhao, Y. Chen, P. Zhu, C. Wang, Y. Luo, C. Xu, A. Duan, G. Jiang, Potassium-modified molybdenum-containing SBA-15 catalysts for highly efficient production of acetaldehyde and ethylene by the selective oxidation of ethane, Journal of Catalysis, 285 (2012) 134-144.

[37] K. Sun, D.M. Ginosar, T. He, Y. Zhang, M. Fan, R. Chen, Progress in Nonoxidative Dehydroaromatization of Methane in the Last 6 Years, Industrial \& Engineering Chemistry Research, 57 (2018) 1768-1789.

[38] Y. Wu, L. Emdadi, Z. Wang, W. Fan, D. Liu, Textural and catalytic properties of Mo loaded hierarchical meso-/microporous lamellar MFI and MWW zeolites for direct methane conversion, Applied Catalysis A: General, 470 (2014) 344-354.

[39] D. Liu, A. Bhan, M. Tsapatsis, S. Al Hashimi, Catalytic Behavior of Brønsted Acid Sites in MWW and MFI Zeolites with Dual Meso- and Microporosity, ACS Catalysis, 1 (2011) 7-17.

[40] L. Emdadi, Y. Wu, G. Zhu, C.-C. Chang, W. Fan, T. Pham, R.F. Lobo, D. Liu, Dual Template Synthesis of Meso- and Microporous MFI Zeolite Nanosheet Assemblies with Tailored Activity in Catalytic Reactions, Chemistry of Materials, 26 (2014) 1345-1355.

[41] Y. Wu, Z. Lu, L. Emdadi, S.C. Oh, J. Wang, Y. Lei, H. Chen, D.T. Tran, I.C. Lee, D. Liu, Tuning external surface of unit-cell thick pillared MFI and MWW zeolites by atomic layer deposition and its consequences on acid-catalyzed reactions, Journal of Catalysis, 337 (2016) 177187. 
[42] D. Ma, D. Wang, L. Su, Y. Shu, Y. Xu, X. Bao, Carbonaceous Deposition on Mo/HMCM-22 Catalysts for Methane Aromatization: A TP Technique Investigation, Journal of Catalysis, 208 (2002) 260-269.

[43] Y. Song, Y. Xu, Y. Suzuki, H. Nakagome, Z.-G. Zhang, A clue to exploration of the pathway of coke formation on Mo/HZSM-5 catalyst in the non-oxidative methane dehydroaromatization at 1073K, Applied Catalysis A: General, 482 (2014) 387-396.

[44] X. Guo, G. Fang, G. Li, H. Ma, H. Fan, L. Yu, C. Ma, X. Wu, D. Deng, M. Wei, D. Tan, R. Si, S. Zhang, J. Li, L. Sun, Z. Tang, X. Pan, X. Bao, Direct, Nonoxidative Conversion of Methane to Ethylene, Aromatics, and Hydrogen, Science, 344 (2014) 616-619.

[45] K. Na, M. Choi, W. Park, Y. Sakamoto, O. Terasaki, R. Ryoo, Pillared MFI Zeolite Nanosheets of a Single-Unit-Cell Thickness, Journal of the American Chemical Society, 132 (2010) 4169-4177.

[46] C.E.A. Kirschhock, R. Ravishankar, F. Verspeurt, P.J. Grobet, P.A. Jacobs, J.A. Martens, Identification of Precursor Species in the Formation of MFI Zeolite in the TPAOH-TEOS- ${ }_{2} \mathrm{O}$ System, The Journal of Physical Chemistry B, 103 (1999) 4965-4971.

[47] D.D. Kragten, J.M. Fedeyko, K.R. Sawant, J.D. Rimer, D.G. Vlachos, R.F. Lobo, M. Tsapatsis, Structure of the Silica Phase Extracted from Silica/(TPA)OH Solutions Containing Nanoparticles, The Journal of Physical Chemistry B, 107 (2003) 10006-10016.

[48] K.S.W. Sing, Reporting physisorption data for gas/solid systems with special reference to the determination of surface area and porosity (Recommendations 1984), in: Pure and Applied Chemistry, 1985, pp. 603.

[49] X. Zhang, D. Liu, D. Xu, S. Asahina, K.A. Cychosz, K.V. Agrawal, Y. Al Wahedi, A. Bhan, S. Al Hashimi, O. Terasaki, M. Thommes, M. Tsapatsis, Synthesis of Self-Pillared Zeolite Nanosheets by Repetitive Branching, Science, 336 (2012) 1684-1687.

[50] H. Zheng, D. Ma, X. Bao, J.Z. Hu, J.H. Kwak, Y. Wang, C.H.F. Peden, Direct Observation of the Active Center for Methane Dehydroaromatization Using an Ultrahigh Field 95Mo NMR Spectroscopy, Journal of the American Chemical Society, 130 (2008) 3722-3723.

[51] D. Ma, W. Zhang, Y. Shu, X. Liu, Y. Xu, X. Bao, MAS NMR, ESR and TPD studies of Mo/HZSM - 5 catalysts: evidence for the migration of molybdenum species into the zeolitic channels, Catalysis Letters, 66 (2000) 155-160.

[52] J. Gao, Y. Zheng, J.-M. Jehng, Y. Tang, I.E. Wachs, S.G. Podkolzin, Identification of molybdenum oxide nanostructures on zeolites for natural gas conversion, Science, 348 (2015) 686690.

[53] J. Gao, Y. Zheng, G.B. Fitzgerald, J. de Joannis, Y. Tang, I.E. Wachs, S.G. Podkolzin, Structure of $\mathrm{Mo}_{2} \mathrm{C}_{\mathrm{x}}$ and $\mathrm{Mo}_{4} \mathrm{C}_{\mathrm{x}}$ Molybdenum Carbide Nanoparticles and Their Anchoring Sites on ZSM-5 Zeolites, The Journal of Physical Chemistry C, 118 (2014) 4670-4679.

[54] P. Arnoldy, J.C.M. De Jonge, J.A. Moulijn, Temperature-programed reduction of molybdenum(VI) oxide and molybdenum(IV) oxide, The Journal of Physical Chemistry, 89 (1985) 4517-4526. 
[55] S. Rajagopal, H.J. Marini, J.A. Marzari, R. Miranda, Silica-Alumina-Supported Acidic Molybdenum Catalysts - TPR and XRD Characterization, Journal of Catalysis, 147 (1994) 417428.

[56] K. Chen, S. Xie, A.T. Bell, E. Iglesia, Structure and Properties of Oxidative Dehydrogenation Catalysts Based on $\mathrm{MoO}_{3} / \mathrm{Al}_{2} \mathrm{O}_{3}$, Journal of Catalysis, 198 (2001) 232-242.

[57] G.V.A. Martins, G. Berlier, C. Bisio, S. Coluccia, H.O. Pastore, L. Marchese, Quantification of Brønsted Acid Sites in Microporous Catalysts by a Combined FTIR and $\mathrm{NH}_{3}$-TPD Study, The Journal of Physical Chemistry C, 112 (2008) 7193-7200.

[58] Y. Xu, Y. Shu, S. Liu, J. Huang, X. Guo, Interaction between ammonium heptamolybdate and NH4ZSM-5 zeolite: the location of Mo species and the acidity of Mo/HZSM-5, Catalysis Letters, 35 (1995) 233-243.

[59] R. Kawase, A. Iida, Y. Kubota, K. Komura, Y. Sugi, K. Oyama, H. Itoh, Hydrothermal Synthesis of Calcium and Boron Containing MFI-Type Zeolites by Using Organic Amine as Structure Directing Agent, Industrial \& Engineering Chemistry Research, 46 (2007) 1091-1098.

[60] F. Yaripour, Z. Shariatinia, S. Sahebdelfar, A. Irandoukht, Effect of boron incorporation on the structure, products selectivities and lifetime of H-ZSM-5 nanocatalyst designed for application in methanol-to-olefins (MTO) reaction, Microporous and Mesoporous Materials, 203 (2015) 4153.

[61] I. Lezcano-González, R. Oord, M. Rovezzi, P. Glatzel, S.W. Botchway, B.M. Weckhuysen, A.M. Beale, Molybdenum Speciation and its Impact on Catalytic Activity during Methane Dehydroaromatization in Zeolite ZSM-5 as Revealed by Operando X-Ray Methods, Angewandte Chemie International Edition, 55 (2016) 5215-5219.

[62] A. Smiešková, P. Hudec, N. Kumar, T. Salmi, D.Y. Murzin, V. Jorík, Aromatization of methane on Mo modified zeolites: Influence of the surface and structural properties of the carriers, Applied Catalysis A: General, 377 (2010) 83-91.

[63] W. Ding, S. Li, G. D Meitzner, E. Iglesia, Methane Conversion to Aromatics on Mo/HZSM5: Structure of Molybdenum Species in Working Catalysts, The Journal of Physical Chemistry B, 105 (2001) 506-513.

[64] B. Hunger, M. Heuchel, L.A. Clark, R.Q. Snurr, Characterization of Acidic OH Groups in Zeolites of Different Types: An Interpretation of $\mathrm{NH}_{3}$-TPD Results in the Light of Confinement Effects, The Journal of Physical Chemistry B, 106 (2002) 3882-3889.

[65] N. Kosinov, A.S.G. Wijpkema, E. Uslamin, R. Rohling, F.J.A.G. Coumans, B. Mezari, A. Parastaev, A.S. Poryvaev, M.V. Fedin, E.A. Pidko, E.J.M. Hensen, Confined Carbon Mediating Dehydroaromatization of Methane over Mo/ZSM-5, Angewandte Chemie International Edition, 57 (2018) 1016-1020.

[66] Y.-H. Kim, R.W. Borry, E. Iglesia, Genesis of methane activation sites in Mo-exchanged HZSM-5 catalysts, Microporous and Mesoporous Materials, 35-36 (2000) 495-509.

[67] H. Liu, X. Bao, Y. Xu, Methane dehydroaromatization under nonoxidative conditions over Mo/HZSM-5 catalysts: Identification and preparation of the Mo active species, Journal of Catalysis, 239 (2006) 441-450. 
[68] H. Jiang, L. Wang, W. Cui, Y. Xu, Study on the induction period of methane aromatization over Mo/HZSM-5: partial reduction of Mo species and formation of carbonaceous deposit, Catalysis Letters, 57 (1999) 95-102.

[69] E.V. Matus, I.Z. Ismagilov, O.B. Sukhova, V.I. Zaikovskii, L.T. Tsikoza, Z.R. Ismagilov, J.A. Moulijn, Study of Methane Dehydroaromatization on Impregnated Mo/ZSM-5 Catalysts and Characterization of Nanostructured Molybdenum Phases and Carbonaceous Deposits, Industrial \& Engineering Chemistry Research, 46 (2007) 4063-4074.

[70] N. Kosinov, F.J.A.G. Coumans, G. Li, E. Uslamin, B. Mezari, A.S.G. Wijpkema, E.A. Pidko, E.J.M. Hensen, Stable Mo/HZSM-5 methane dehydroaromatization catalysts optimized for hightemperature calcination-regeneration, Journal of Catalysis, 346 (2017) 125-133. 


\section{Chapter 5. Conclusions}

The research efforts conducted for this work represent a contribution to the field of shale gas combustion and utilization via multiple promising schemes at various $\mathrm{O}_{2}$ partial pressure conditions. In this research, chemical looping combustion (CLC) of methane with inherent $\mathrm{CO}_{2}$ capture, oxidative coupling of methane (OCM) and dehydro-aromatization (DHA) of ethane are systematically studied as promising alternatives at $\mathrm{O}_{2}$-rich, $\mathrm{O}_{2}$-lean and nonoxidative conditions, respectively. The work offers several economically-viable and technically-feasible solutions for shale gas utilization to value-added products. The present research provided fundamental insights of surface structure performance relationships of model catalysts for catalytic methane/ethane conversion. Briefly:

The study of chemical looping combustion (CLC) of methane with inherent $\mathrm{CO}_{2}$ capture study (Chapter 2) reveals the oxygen transfer mechanisms in CLC by using the surface calciumdoped (1, 2 and 4 wt $\%)$ copper oxide-based OC. In this chapter, the Ca is well-dispersed on the $\mathrm{CuO}$ surface without deep penetration to the bulk, confirmed by the combination of XPS and XRD characterizations. $\mathrm{CaO}-\mathrm{CuO}$ oxygen carriers present three reductive active sites corresponding to $\mathrm{CuO}$ reduction, $\mathrm{CaO}$ reduction and impurity $\mathrm{CaCO}_{3}$ decomposition in $\mathrm{H}_{2}-\mathrm{TPR}$. The surface modification with the alkaline earth metal $\mathrm{Ca}$ promotes $\mathrm{CuO}$ oxygen uncoupling characteristics, since $\mathrm{Ca}$ surface-doping increases the lattice oxygen transfer and surface $\mathrm{O}_{2}$ formation rate under CLOU conditions. The reduction pathway for $\mathrm{CuO}$ from a sequential $\left(\mathrm{CuO} \rightarrow \mathrm{Cu}_{2} \mathrm{O} \rightarrow \mathrm{Cu}\right)$ to a direct transition $(\mathrm{CuO} \rightarrow \mathrm{Cu})$ during is verified through the decomposition of oxygen carriers and in situ Raman analysis. When methane was used as gaseous fuel in the CLC process, the calcium dopant not only accelerates the reaction rate, but also induces methane reforming reaction by 
reacting with released $\mathrm{CO}_{2}$, which was initially bound in the form of $\mathrm{CaCO}_{3}$, to promote the formation of $\mathrm{CO}$ and $\mathrm{H}_{2}$. (Publication: Lei Bai, Jarret Riley, Hanjing Tian, Zili Wu, Si Luo, He Qi, Haiyang Li, Xingbo Liu. Mechanism Study of Char/Methane Chemical Looping Reduction Process Over Calcium-doped Copper Oxide as Oxygen Carrier. Submitted to Applied Energy.)

Extending the CLC work in $\mathrm{O}_{2}$-rich conditions from Chapter 2 into Chapter 3 allowed the investigation of the effect of surface compositions of perovskites on the OCM by using $\mathrm{SrTiO}_{3}$ as a model catalyst in $\mathrm{O}_{2}$-lean conditions. Specifically, in this chapter, a set of $\mathrm{SrTiO}_{3}$ samples was synthesized with different surface densities of $\operatorname{Sr}$ (25-96\%, verified by Low Energy Ion Scattering (LEIS)), through incipient wetness impregnation, chemical etching with $\mathrm{HNO}_{3}$, and thermal treatment. The redox capability for STO samples was found to be the same due to the same bulk structure. Therefore, their different catalytic performance was studied and related to the surface acid-base properties rather than reducibility properties. The surface basicity and composition have been studied via $\mathrm{NH}_{3}-/ \mathrm{CO}_{2}-\mathrm{TPD}$, UV-Raman, LEIS, etc. The OCM reaction at steady state was performed at $600-800^{\circ} \mathrm{C}$ and it was found that the $\mathrm{Sr}$ enrichment enhances the $\mathrm{CH}_{4}$ conversion, $\mathrm{C}_{2}$ selectivity as well as the ratio of $\mathrm{C}_{2} \mathrm{H}_{4} / \mathrm{C}_{2} \mathrm{H}_{6}$ up to a certain surface $\mathrm{Sr}$ concentration. Furthermore, it was found that the catalytic activity $\left(\mathrm{CH}_{4}\right.$ conversion) increases linearly with the relative concentration of basic sites (base/(base+acid)) over the STO catalysts at the full range of surface Sr concentrations, rendering the relative concentration of basic sites as a tentative descriptor for the activity of STO samples in the OCM reaction. This work shows the clear correlation between surface compositions, relative basicity/acidity and OCM catalytic performance over perovskite catalysts. Overall, it is suggested that tuning the surface reconstruction/composition of perovskites can be an effective approach to control $\mathrm{CH}_{4}$ activation and conversions.(Publication: Lei Bai, Felipe Polo-Garzon, Zhenghong Bao, Si Luo, Hanjing Tian*, Zili Wu*. Effect of Surface 
Composition of $\mathrm{SrTiO}_{3}$ on Oxidative Coupling of Methane (OCM). Just Accepted. DOI:10.1002/cctc.201900159. ChemCatChem. 2019.)

Lastly, in Chapter 4, we designed a regenerable $\mathrm{MoO}_{\mathrm{x}} /$ lamellar ZSM-5 was designed with the strategy of optimizing the micro/mesopores structure of the zeolite framework. The pillar ZSM-5 is applied in the non-oxidative ethane dehydroaromatization reaction, and high ethane conversion and aromatic selectivity were obtained by optimizing Si/Al ratio, surface acidity and diffusion path. The thicker layers with longer diffusion paths of zeolite lengthen the reaction path for the reactant and thus help the shape selectivity of aromatics, despite the lower ethane conversion. ZSM-5 support with low $\mathrm{Si} / \mathrm{Al}$ ratio helps to promote the ethane conversion as well as aromatic selectivity, but it sacrifices the stability of catalytic performance. Suitable $\mathrm{Si} / \mathrm{Al}$ ratios can balance high aromatic selectivity and catalytic stability. The cyclic reaction-regeneration strategy was utilized to remove the produced coke, lamellar zeolites with hierarchical structure among the layers allows better mass transfer for better reproducibility, which significantly improve catalyst regeneratability than conventional Mo/ZSM-5 catalyst. Overall, Mo-based catalysts supported over novel lamellar zeolites, such as Mo/MFI-50(T8) catalyst, indicated stable reactivity during multiple-cycle reaction-regeneration operation, and could be a promising system for industrial optimization and process deployment. (Publication: Jiahui Ye" Lei Bai ${ }^{\#}$, Baoyu Liu, Hanjing Tian*, Jianli Hu, Felipe Polo-Garzon, Richard T. Mayes, Zili Wu, Yanxiong Fang*. Fabrication of ZSM-5 Framework for Shape Selectivity of Ethane Dehydroaromatization. (\# for equal contribution, Just Accepted. DOI: 10.1021/acs.iecr.8b04965. Industry \& Engineering Chemistry Research. 2019.) 